\title{
Task 8 - Design and Test of Critical Components
}

\author{
Topical Report \\ November 1996
}

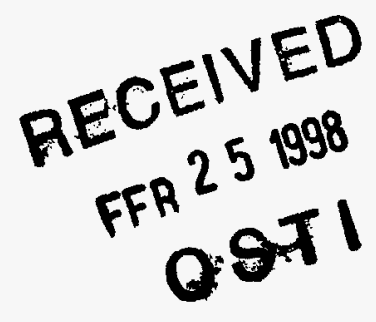

\author{
By \\ Thomas F. Chance
}

Work Performed Under Contract No.: DE-AC21-93MC30244

For

U.S. Department of Energy

Office of Fossil Energy

Federal Energy Technology Center

Morgantown Site

P.O. Box 880

Morgantown, West Virginia 26507-0880

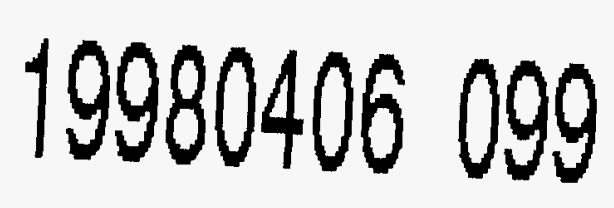

By

GE Power Systems

1 River Road

Schenectady, New York 12345

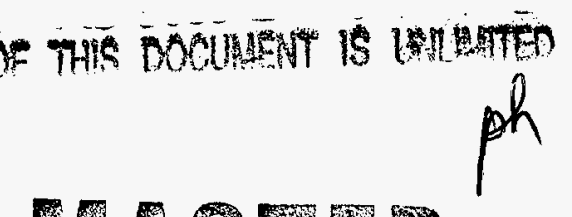




\section{Disclaimer}

This report was prepared as an account of work sponsored by an agency of the United States Government. Neither the United States Government nor any agency thereof, nor any of their employees, makes any warranty, express or implied, or assumes any legal liability or responsibility for the accuracy, completeness, or usefulness of any information, apparatus, product, or process disclosed, or represents that its use would not infringe privately owned rights. Reference herein to any specific commercial product, process, or service by trade name, trademark, manufacturer, or otherwise does not necessarily constitute or imply its endorsement, recommendation, or favoring by the United States Government or any agency thereof. The views and opinions of authors expressed herein do not necessarily state or reflect those of the United States Government or any agency thereof. 


\section{TASK 8 - DESIGN AND TEST OF CRITICAL COMPONENTS}

\section{OBJECTIVE}

Perform technical evaluations on selected components to enable implementation of advances in critical areas of the ATS design

\section{BACKGROUND}

It was acknowledged at the inception of the ATS program that major advances in gas turbine technology would be required in order to meet the ATS efficiency, cost, and emissions goals. A prioritized list of component technology tasks was determined and proposed for inclusion in the DOE/METC program. Figure 8.0-1 shows a schematic cross-section of the ATS engine, with technology areas labeled to show where these advancements would be utilized.

The ATS Phase 2 contract was expanded twice, with the contract value and duration more than doubling. The Scope of Work changes were all in Task 8, with many extensions and additions of subtasks. Table 8.0-1 (a reprint of Table 2-2) shows the subtask breakdown, and the Task 8 reporting follows this order. 


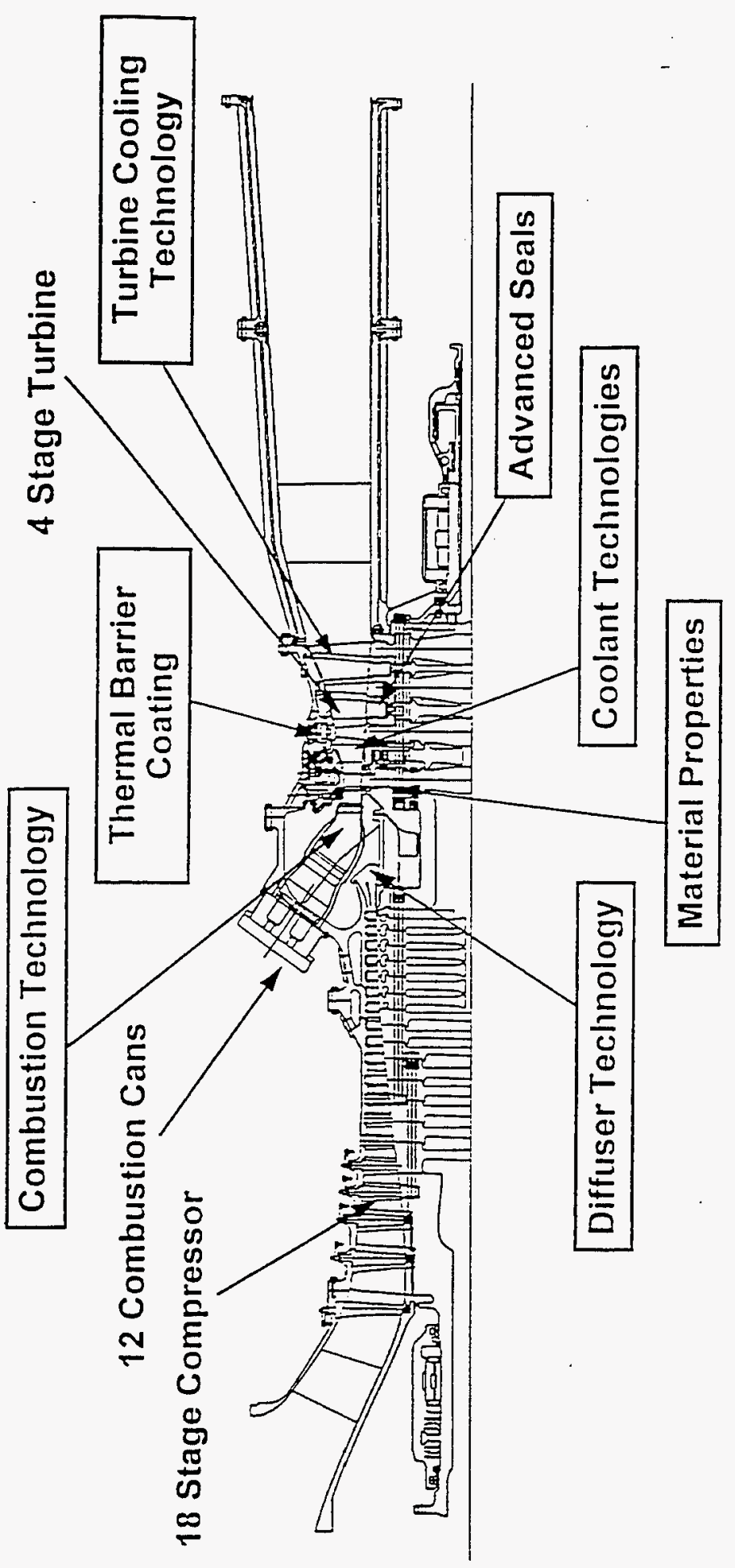

Figure 8.0-1. Technology applications advanced in Task 8. 
Table 8.0-1

Task 8 Subtasks Included in ATS Phase 2 Contract

ATS Program Final Report: Phase 2 DOE Contract Number DE-AC21-93MC30244

\begin{tabular}{|c|c|c|}
\hline Task & Task Title & \\
\hline 8.1 & Particulate Flow Deposition & \\
\hline 8.1 .1 & Coolant Purity & \\
\hline 8.2 & Particle Centrifugal Sedimentation & \\
\hline 8.2 .1 & Materials Coolant Compatibility & \\
\hline 8.2 .2 & Rotor Materials Coolant Compatibility & \\
\hline 8.3 & $\begin{array}{l}\text { Determination of Driving Forces for Thermal Barrier } \\
\text { Coating Failure }\end{array}$ & \\
\hline 8.3 .1 & TBC Testing and Analysis & \\
\hline 8.3 .2 & LCF Life and Crack Propagation & \\
\hline 8.3 .3 & Bond Coats for Improved TBC TCL & \\
\hline 8.3 .4 & Critical TBC Properties - Thermal Conductivity & \\
\hline 8.4 & Advanced Seal Technology & Reported in Task 8.4.1 \\
\hline 8.4 .1 & Advanced Seals & \\
\hline 8.5 & Enhanced Impingement Heat Transfer & GE Aircraft Engine Task \\
\hline 8.6 & Rotational Heat Transfer & Reported in Task 8.6.1. \\
\hline 8.6 .1 & Rotating Heat Transfer - Bucket Cooling & \\
\hline 8.6 .2 & RHT - Wheelspace Cooling & \\
\hline 8.7 & Turbine Inlet Nozzle Heat Transfer & \\
\hline 8.7 .1 & Turbine Inlet Nozzle Heat Transfer & Reported in Task 8.7.3 \\
\hline 8.7 .2 & Turbulent Heat Transfer & Reported in Task 8.7.9 \\
\hline 8.7 .3 & Nozzle End Wall Impingement & \\
\hline 8.7 .4 & Nozzle Airfoil Impingement & Reported in Task 8.7.9 \\
\hline 8.7 .5 & 1st Stage Bucket & \\
\hline 8.7 .6 & Combustion Instability & \\
\hline 8.7 .7 & Effect of Hot Fuel on Combustion Dynamics & \\
\hline 8.7 .8 & Turbulence Intensity Probes & \\
\hline $\begin{array}{l}8.7 .9 \\
\text { a,b,c }\end{array}$ & $\begin{array}{l}\text { Turbulent Heat Transfer Static Components: (a) Surface } \\
\text { Enhance HT; (b) Nozzle Airfoil Impingement; (c) Trailing } \\
\text { Edge Film Cooling }\end{array}$ & \\
\hline 8.7 .10 & Transition Piece Design Tools & \\
\hline 8.7.11 & Increased Mach No. Diffuser Design & \\
\hline 8.7 .12 & $\begin{array}{l}\text { Nozzle Cascade Preliminary Test and Facility } \\
\text { Qualification }\end{array}$ & \\
\hline
\end{tabular}




\section{TASK 8.1/8.1.1/8.2 - STEAM PURITY ASSURANCE FOR ADVANCED STEAM-COOLED TURBINES}

\section{OBJECTIVES}

The primary objective of Task 8.1, Particulates Flow Deposition, is to characterize the particulate generated in an operating gas turbine combined cycle (GTCC) power plant whose configuration approximates that proposed for an ATS power plant. In addition, the task is to evaluate the use of full-flow filtering to reduce the steam particulate loads. Before the start of this task, GE had already negotiated an agreement with the candidate power plant, piping and a filter unit had already been installed at the power plant site, and major elements of the data acquisition system had been purchased, all with GE funds. The remaining work involves completing assembly and checkout of the system, and then conducting measurements to meet the stated objectives. Using coolant extracted from an existing plant that most closely simulates projected ATS conditions, we will determine filtration- and operating-performances for a candidate full-flow metal filter system operating at ATS entry conditions and characterize the coolant particulates into and out of the metal filter.

The objective of Task 8.1.1, Coolant Purity, is to expose typical ATS gas turbine airfoil cooling channel geometries to real steam flow to determine whether there are any unexpected deposit formations. The task is a static analog of the centrifugal deposition rig trials of Task 8.2, in which a bucket channel return bend is exposed to steam flow. Two cooling channel geometries are of primary interest in this static exposure.

The static specimens will be mounted in a coded pressure vessel (already available at the power plant from previous GE work) that would serve both to offer personnel protection because the specimens do not have standard ASME closure designs and to enable preheating of the specimens by flooding the vessel with steam as a heating medium before steam flow initiation.

The primary objective of Task 8.2 , Particle Centrifugal Sedimentation, is to determine the settling characteristics of particles in a cooling stream from an operating gas turbine combined cycle (GTCC) power plant when that stream is ducted through a passage experiencing the G-loads expected in a simulated bucket channel specimen representative of designs proposed for an ATS gas turbine. GE has identified a target power plant at which to site the experiment. Prior to the start of this task, GE had completed a proprietary computational code that was proposed to be useful in predicting particle trajectories. A motor-driven centrifugal deposition rig that accepts coolant at ATS conditions accelerates it at conditions expected in specimens built to simulate ATS bucket coolant channels. Coolant flow conditioning and control will be provided by the filtration and control system already used for the Task 8.1 work effort. Deposits collected in the specimen tip channels will be compared to predictions and to desired times between outages for the ATS when the channels could be cleaned.

\section{INTRODUCTION AND BACKGROUND}

The new Advanced Gas Turbine (AGT) being developed collaboratively by GE and DOE on this Advanced Turbine Systems (ATS) program uses closed-cycle steam cooling. Major advances in gas turbine performance over the last three decades have been largely due to the sophisticated use 
of open-cycle air cooling. The advantage of using steam cooling instead of air cooling is the increase in overall power plant efficiency from values of approximately $54 \%$ (on lower heating value basis) to just over $60 \%$ for land-based, gas turbine combined cycle (GTCC) power plants. This advantage results primarily from delivering the heat acquired in cooling the gas turbine to the combined steam turbine cycle instead of discharging the coolant from the nozzles and buckets into the gas turbine hot working fluid, which cools it.

The cooling of hot gas path parts in advanced gas turbine (Brayton) cycles has commonly been accomplished by extracting compressor discharge air and directing it to both static and rotating parts immersed in the hot combustor discharge gas. Rotating parts have been cooled in an open cycle in which the air convectively cools the bucket interior or a trailing edge and is discharged into the working fluid, or film cools external airfoil structures as it is discharged through arrays of small holes providing a cool gas barrier. It is expected that AGT systems will seek to use closedcycle cooling to avoid degrading the Brayton cycle performance with large pressure drops and working fluid cooling, which are often associated with open-cycle cooling. Air, steam, inert gases, and other fluids have been proposed as closed cooling cycle coolants.

One major concern in cooling components subjected to a high centrifugal field is the possibility of sedimentation of coolant particulates in critical regions, that would give rise to problems of erosion, plugging, and insulation, as well as secondary problems of sediment release and reentrainment. The centrifugal field acts as an enhanced particulate settler and could lead to a buildup of deposits in the cooling channels of rotating components. Open-cycle air-cooled gas turbine bucket cooling passages are usually provided with bleed holes sufficiently large that accumulated particulates in the channels can be blown out of the buckets. Minimum allowable bleed hole sizes are specified for these exit holes (usually 30-40 mils) so that the exiting particulates do not gradually blind and ultimately plug the exit aperture. Such bleed holes could also be specified for closed-cycle cooling systems in which a small fraction of the coolant would be "blown down" at each bucket tip, preventing a long-term buildup of particulates, in the same way that steam boiler solids are often controlled by blowdown. However, for coolant gases where the loss of the blowdown coolant is a major replacement cost item or where the coolant pressure is so high, relative to the local working fluid pressure, that too much coolant would be lost through a minimum-sized, non-blinding hole, the use of blowdown is prohibited in practice. Nevertheless, successfully achieving closed-cycle cooling would provide major ATS efficiency advantages.

Using the heat extracted from the hot gas path parts requires that the steam be ducted both on-board and off-board the gas turbine rotor and stator. Moreover, the heat pickup must be accomplished within smaller flow channels than those typically found in steam turbine applications. However, the most important technical issue is that the steam is exposed to a high centrifugal field on the rotor system, particularly at the bucket tips, where it must begin flowing back to the rotor centerline. Because of the centrifugal force and small flow channels, a higher level of steam purity is required than commonly specified for steam turbines. The particulate loadings of the steam must be very low so that they do not cause erosion and deposition that will compromise AGT efficiency, reliability, or availability.

Particulates in the steam are the contaminants of special interest because the AGT subsystem of the ATS power plant accepts superheated steam as the incoming coolant and then superheats it before returning it to the steam turbine for work recovery. Therefore the usual problems associated with boiler 
water chemistry (e.g., dissolved solids, condensation on expansion) are taken care of elsewhere in the power system. The gas turbine cooling system sees only superheated steam that is not saturated or wet while in the gas turbine. There may be secondary concerns about any organic vapors that might come over from the boiler.

\section{STEAM PURITY SYSTEM ISSUES}

Particulates can cause erosion and deposition. Erosion of cooling passages can change flow distributions and weaken thinner gas path wall sections sufficiently to cause them to lose integrity. However, the analysis below, which is based on literature data, shows that erosion is not a problem as long as entrained particulates are smaller than approximately 3 microns at the steam velocities predicted in the AGT cooling system. Deposition, on the other hand, could cause problems with both flow distribution changes and insulation of critical wall regions where metal temperatures must be held sufficiently below gas temperatures to assure AGT reliability.

\section{SEDIMENTATION PREDICTIONS}

The well-established Stokes Law theory for the settling of particles in liquids and gases is applicable here. For very small particles, the Reynolds Number for settling tends to be very low, well under 0.1 where the discharge coefficient is proportional only to the inverse of the Reynolds Number. However, the acceleration term for the gas turbine rotor and bucket application is a large multiple of the normal gravity field used to calculate particle settling in a normal, quiescent fluid. In gas turbines, these G-forces sometimes exceed 15000 times sea level gravity, due to the large diameters of new machines running at from 3000 to $3600 \mathrm{rpm}$.

\section{PARTICLE TRAJECTORIES FROM CFD MODEL CALCULATIONS}

A more accurate estimate, however, can be developed for specific geometries using 3D computational fluid dynamic (CFD) codes which predict the gas velocities acting on the particles. The code utilized in this work was CONCERT-3D, a fully elliptic, 3D, body-fitted code based on pressure correction techniques In this approach, a 3D gas flow solution is generated in the channel geometry of interest. Onto these solutions are "injected" individual particles of specific diameter at specific positions at the flow entry point. The particle motion is assumed to be dictated by local velocities, but the flows are assumed to be unaffected by the presence of the particles. In the current application, the particle concentration is so low that this is a reasonable assumption. The trajectories of the particles are then followed stochastically to determine the number of collisions made with the wall and, in the case of a return bend at a large radius, the number of injected particles that ultimately make it through the turn and back into the returning coolant flow where the G-fields are lower. For this study, rebound characteristics of the particles have been taken from the literature.

Figure 8.1/8.2-1 shows a flow solution for a simple return bend, and Figure 8.1/8.2-2 shows a similar solution for a more realistic turn which demonstrates the capability of the CFD code. 


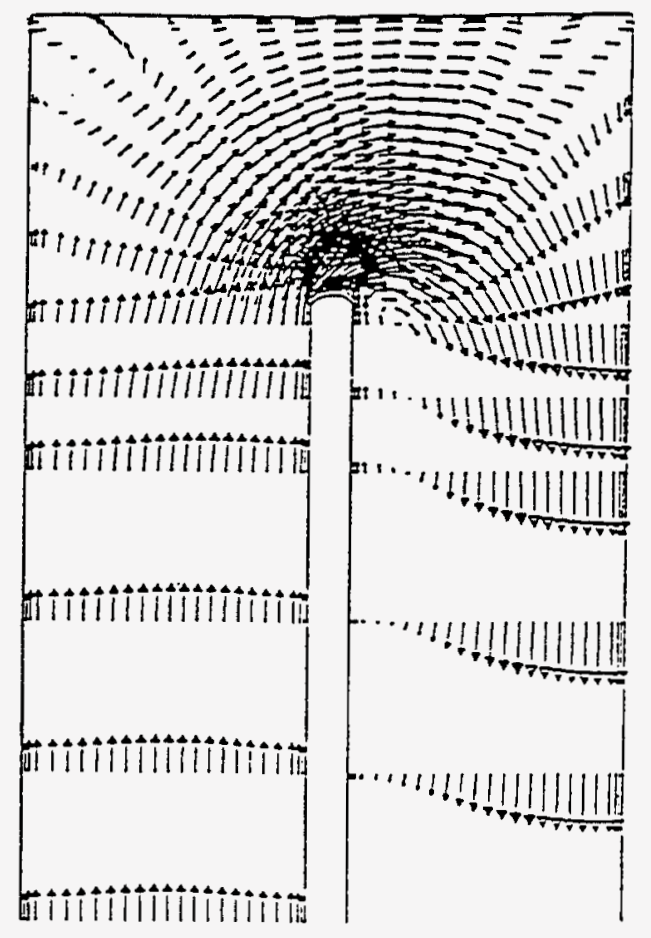

Figure 8.1/8.2-1. Flow Solution for a Square Return Bend

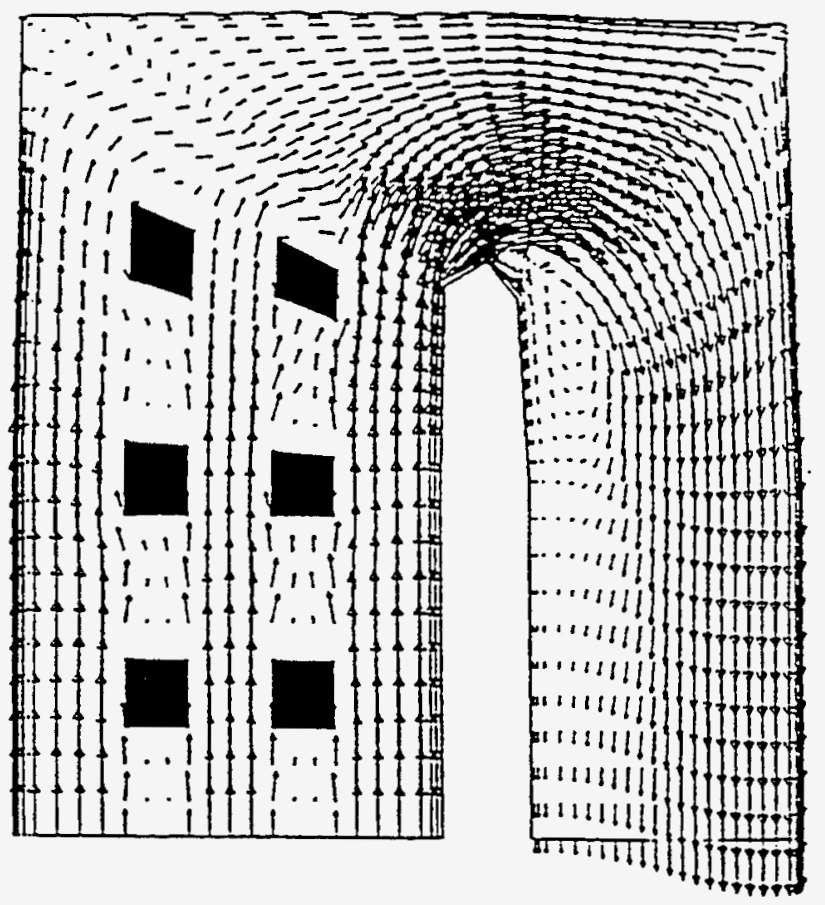

Figure 8.1/8.2-2. Flow Solution for a Bucket Tip Turn 


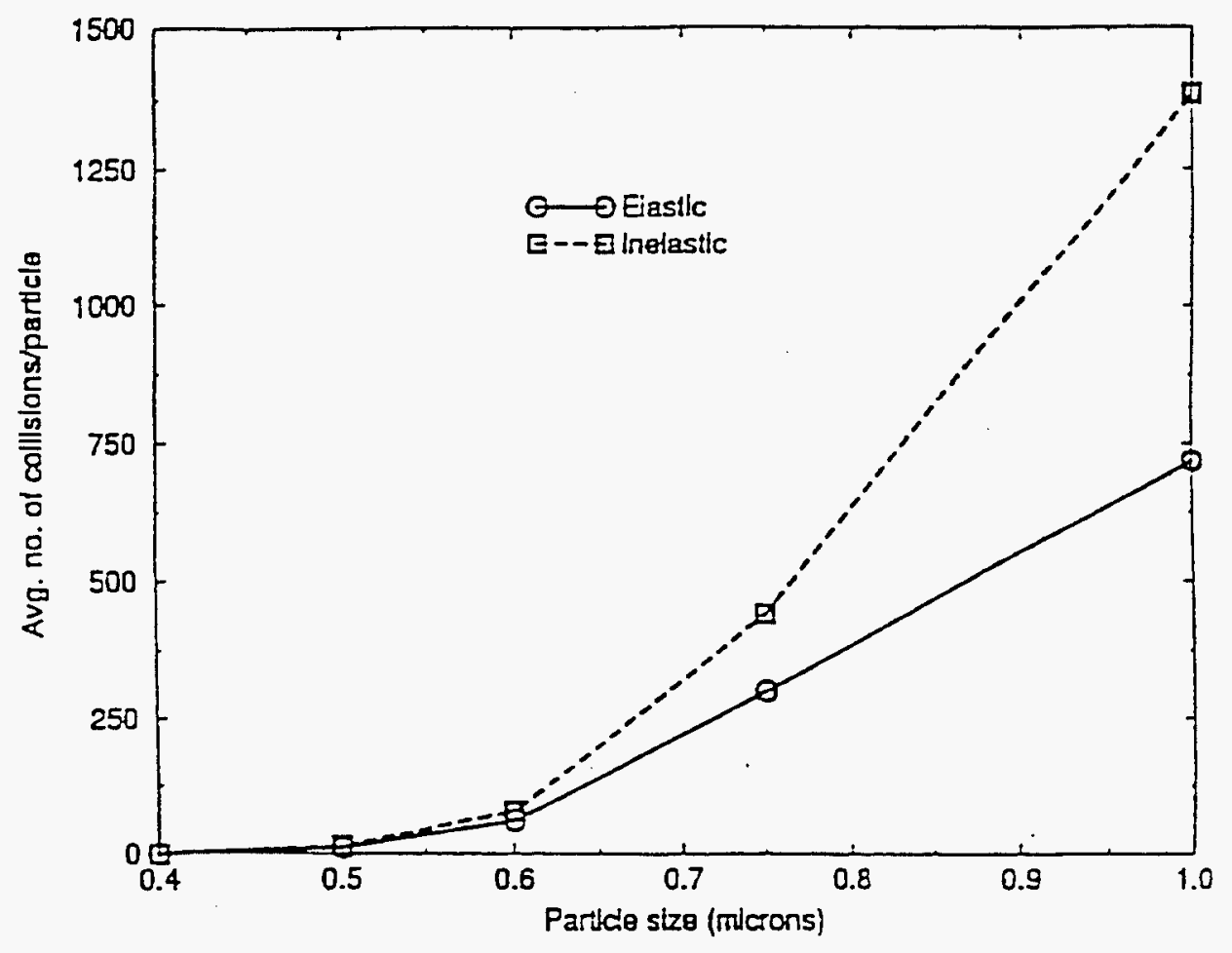

Figure 8.1/8.2-3. Average Number of Wall Collisions 


\section{DISCUSSION OF SEDIMENTATION PREDICTIONS}

The results of the sedimentation calculations by the simple Stokes Law approximation for settling across a laminar flow gap generally agreed with the more accurate 3D-CFD calculations, which built up statistics based on a stochastic particle tracking procedure. Both sets of calculations indicate that most iron oxide particles smaller than approximately 0.5 micron should pass through the tip turns of the bucket coolant channels on the AGT. For a monotonic particle dispersion in this size range, the particle entrapment will depend upon where the particles are in the flow field cross section when they enter the turn. In part this position sensitivity appears to be a result of the way the Coriolis forces might drive particles toward a bounding wall and lead to deceleration and ultimate entrapment at the tip.

However, it is also clear that larger particles will progressively become a concern for deposition. Large particles found in earlier studies in iron-based coolant systems will clearly necessitate providing pre-filtration or pre-sedimentation systems in the coolant to assure that cooling channels would neither plug nor build up insulating layers quickly. While these large particulates may represent a very small fraction of the number of particles and even total particle mass flow, it is clear that their presence could not be tolerated since they would be one-third the size of the smallest apertures in high intensity stator cooling regions and create potential plugging as well as insulating problems at the bucket tips.

The coolant system must also be protected from the influx of any organic vapors carried in the gas phase that might serve as a binder for the corrosion product deposits. Such binders could come from organics carried overhead in steam systems, compressor lubricants in highpressure-air and inert-gas-systems, and even natural pollens and other organic matter from air systems. Particular care must be taken to reduce the impact of leaking heat exchangers that could unintentionally contaminate the coolant gases and load a binder onto the internal cooled surfaces in a short period of time. In some cases a full-flow polishing system as well as a

redundant continuous monitoring system may be required to enable operator actions in the event of such a leak.

\section{MEANS OF REMOVING PARTICULATES FROM COOLANTS}

There are a number of techniques for removing particulates from fluids. Among these are filtration, magnetic separation, electrostatic attraction, and sedimentation. Absolute filtration would be desirable because no large particulates can be allowed in the cooling passages of advanced gas turbines, but the pressure drop through such systems might compromise overall plant performance. Nevertheless, hot gas filtration through ceramic filter bags, sintered ceramics, and sintered metals has been done. For example, steam and air used in food or pharmaceutical applications have been filtered through sintered metal filters to assure cleanliness, where the volumes are usually small so that a large associated pressure drop is not a significant product cost.

While the other options cannot be entirely ruled out for possible future use, they do have disadvantages. Work done on high gradient magnetic separation showed that large fields and 
distributed collection media (steel wool) could effectively remove ferromagnetic materials. While metal corrosion products are indeed often ferromagnetic, there is a concern that other materials like $\mathrm{SiO}_{2}$ would not be captured in such filters. Also, the filtration is not absolute and any momentary failure of the magnet would release contaminant into the engine and necessitate an emergency shutdown. Similarly, electrostatic precipitation might pick up many contaminants, but the operation of charged media at high pressures has been found to be difficult in practice. Clearly the systems engineer needs to select from a series of options, each one of which has disadvantages.

After evaluating all these options, it was decided to test the hypothesis that a modern absolute steam filter built to capture particles from the steam but also to have a low pressure drop would be suitable to protect the AGT cooling circuits. Details of the filter selected for the test will be described below.

\section{MEANS OF REMOVING DEPOSITS FROM SURFACES}

Ash deposits in boilers are commonly removed while the plant is on-line. A similar system for cleaning the internal gas turbine cooling passages would be desirable, but it could not be implemented so easily. Nevertheless, several other options may be available for such deposit removal. They include on-line deposit removal by pulsing coolant flows or erodants (as in gas turbine compressor "ricing") and off-line cleaning procedures that do not require engine disassembly, which could include chemical cleaning as is done in boilers. However, the gas turbine coolant passages are much smaller than boiler passages, and it is likely that the assembly of the rotor cooling circuit will include mechanical, rather than welded, joints. Such mechanical joints offer opportunities for chemicals to diffuse into the mechanical joints and be extremely difficult to rinse out. Chemical cleaning would likely be a last resort used only on turbine disassembly.

A final caution must be discussed in connection with internal, closed-circuit, AGT cooling systems. Even if the system operates successfully to a coolant particulate loading specification to limit the buildup of deposits in both stator and rotor passages, any subsequent release of previously deposited material is a major system hazard if not handled well in the system design. Deposit release can allow particle agglomerate re-entrainment into the flowing coolant. This would usually happen on system transients like shutdown and startup. Therefore, the cooling circuit may also need to be equipped with (1) internal traps ahead of critical cooling regions and (2) small apertures that would hold any re-entrained agglomerates that would tend to plug or insulate.

\section{EXPERIMENT}

\section{STEAM PLANT SELECTION}

The purity of the steam delivered to the AGT must be the highest practically possible to assure high reliability and availability. Therefore, a relatively new GTCC power plant (built in 1989) was selected as the test site for these steam purity experiments [Ref. 9]. The plant consists of two identical equipment installation phases, each rated at approximately $250 \mathrm{MWe}$. Each phase consists of two General Electric Frame 7EA gas turbines, each of which provides 
sensible exhaust heat into heat recovery steam generators (HRSGs) that drive an 85 MWe steam turbine.

\section{GTCC PLANT SITE STEAM CHEMISTRY}

The boilers for this three-pressure (9.3, 0.52, $0.007 \mathrm{MPa}[1350,75,3 \mathrm{psig}])$ steam system are provided with mixed bed deionized feedwater protected by a congruent phosphate treatment. In addition, the high-pressure (HP) steam is de-misted by a modern set of cyclonic separators and dried through baffle separators before proceeding to the superheater.

The superheaters are made of a T22 alloy $(2.25 \mathrm{Cr}, 1 \mathrm{Mo}$, balance $\mathrm{Fe}$ ) commonly used in modern boiler systems. The superheater metallurgy is important to the particulate loading of the steam because the particulates are almost exclusively corrosion products from the superheater.

A final-site characteristic of the experiment is the method of heat rejection. The plant is landlocked and uses evaporative cooling towers to condense expanded steam. It also has operated without any liquid emissions by using the cooling towers for the discharge of boiler water and then processing the subsequent cooling tower blowdown to solids which are then discarded. This use of the cooling towers leads to a higher contaminant loading in the cooling water sent to the steam condensers than many power plants using once-through cooling water systems.

\section{APPARATUS}

Figure 8.1/8.2-4 shows theprocess and instrumentation diagram (P\&ID) of the apparatus constructed (in several stages) for this study.

Figure 8.1/8.2-5 shows the filtration system as assembled in the basement of the power plant site adjacent to the Phase 2 condenser. 


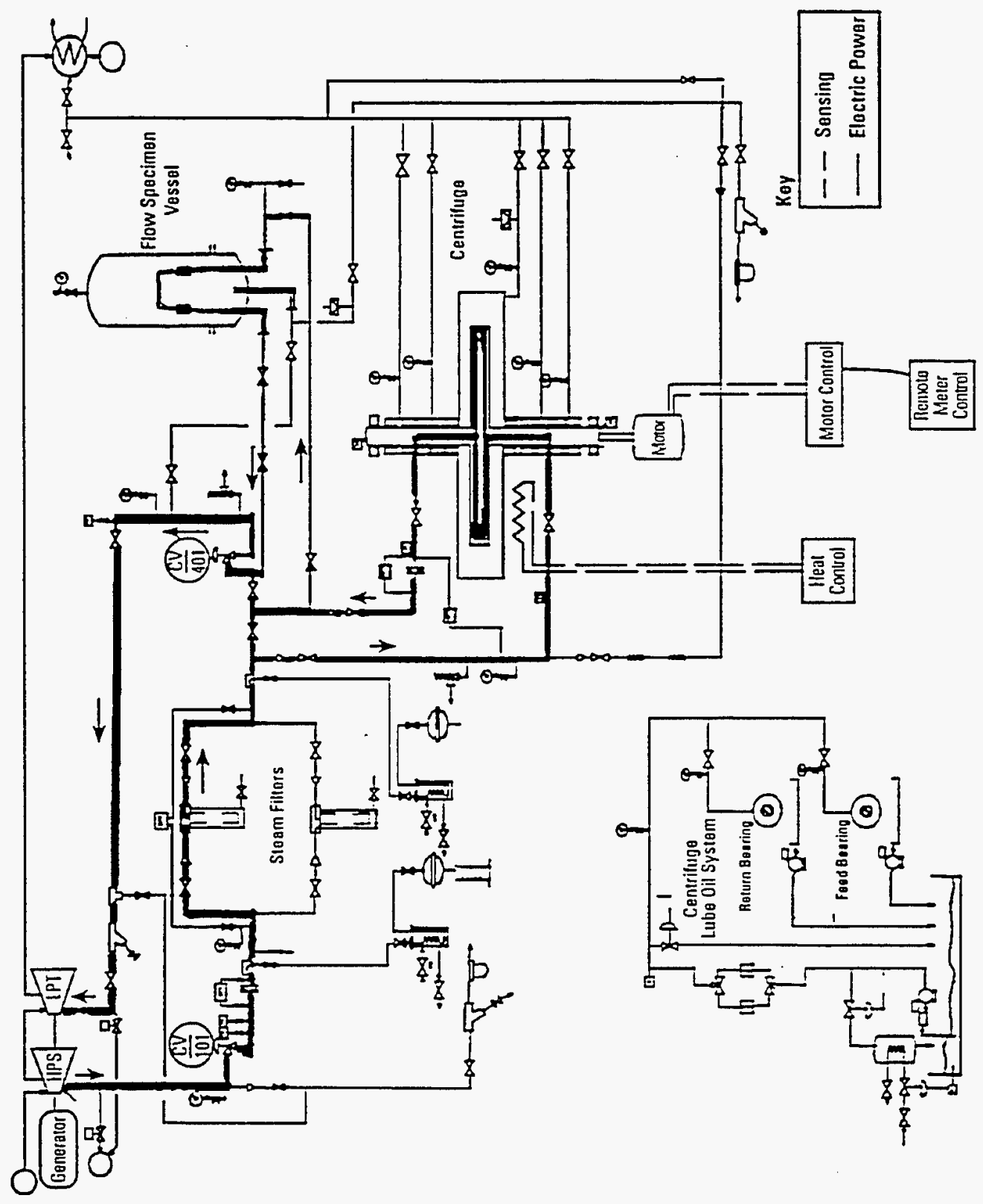

Figure 8.1/8.2-4. Overall Process Flow System 


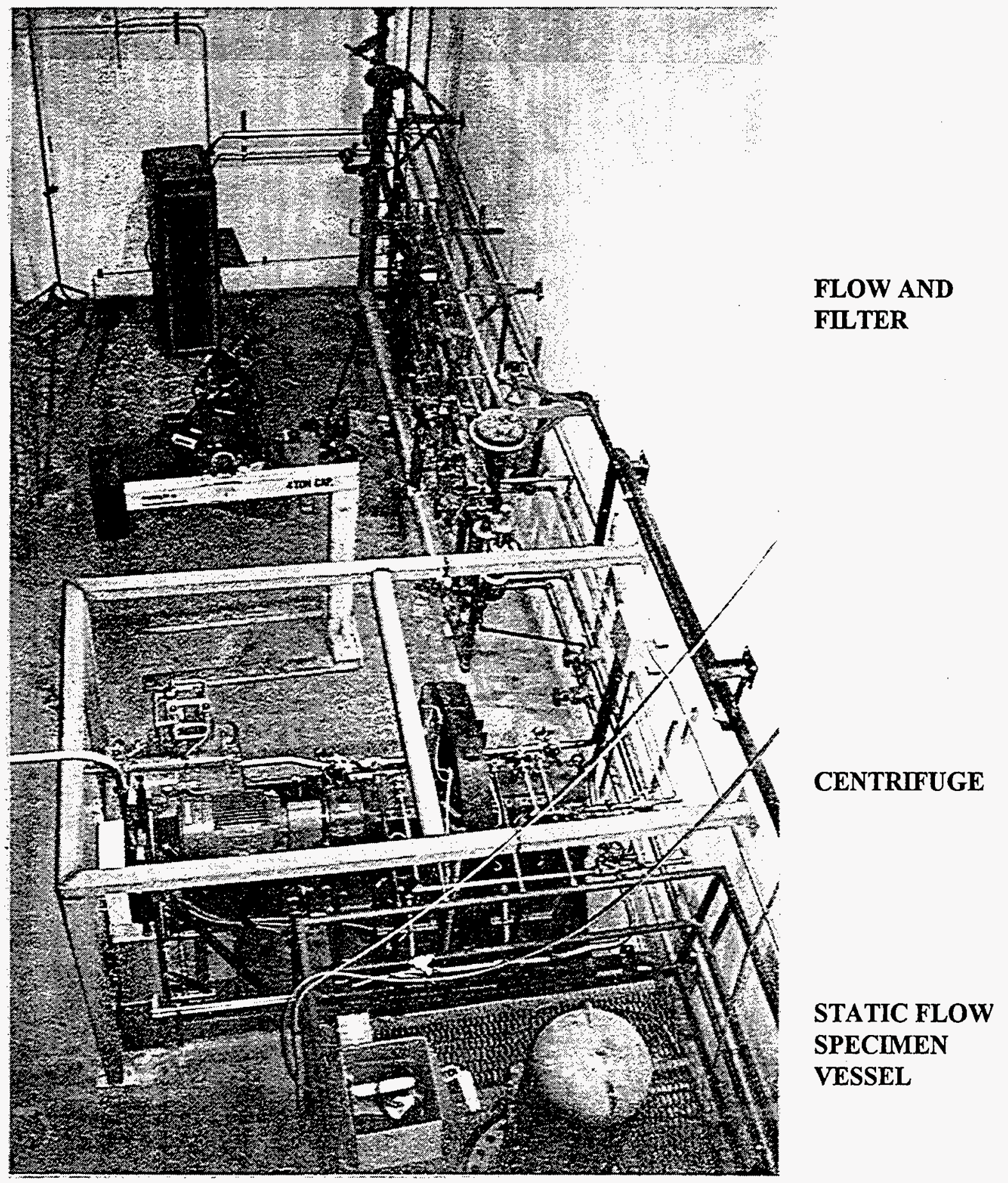

Figure 8.1/8.2-5. Overall Steam Purity System (photo) 


\section{STEAM PARTICULATE MEASUREMENTS}

Two types of steam particulate measurement techniques were employed in this study. The first, superheater steam filtration, was used for only a few measurements and found to be unsuitable to ATS requirements. The second, condensate filtration, was found to be more conventional and accurate and was used for the measurements reported here.

Condensate Filtration. The steam particulate sampling approach used primarily in this study involved filtering sampled steam condensate instead of steam itself. The steam flow in the 5.1-cm (2-in.) i.d. piping on each side of the filter bank was sampled using upstream-facing probes isokinetically (inlet velocity equals free stream velocity). The steam samples were then directed to the sample condensers (cooled with plant cooling water) and then directed to Millipore ${ }^{8}$ 47-mm filter holders equipped with cellulose acetate filters to capture steam particulates. This approach enabled the use of standard water filtration media.

Filters were removed from the holders after exposure and placed in plastic petri dishes where they were allowed to air dry. The filters were then cut in half with one half being sent for wet chemical analysis and the other sectioned for scanning electron microscope (SEM) imaging and a corollary SE microprobe chemical analysis.

\section{OVERALL STEAM PURITY APPARATUS}

Figure 8.1/8.2-6shows the filtration system during the filtration tests. Two filter holders were provided in the event that large particulates were found, but only the upper filter housing was used in these experiments; the bottom unit was valved off.
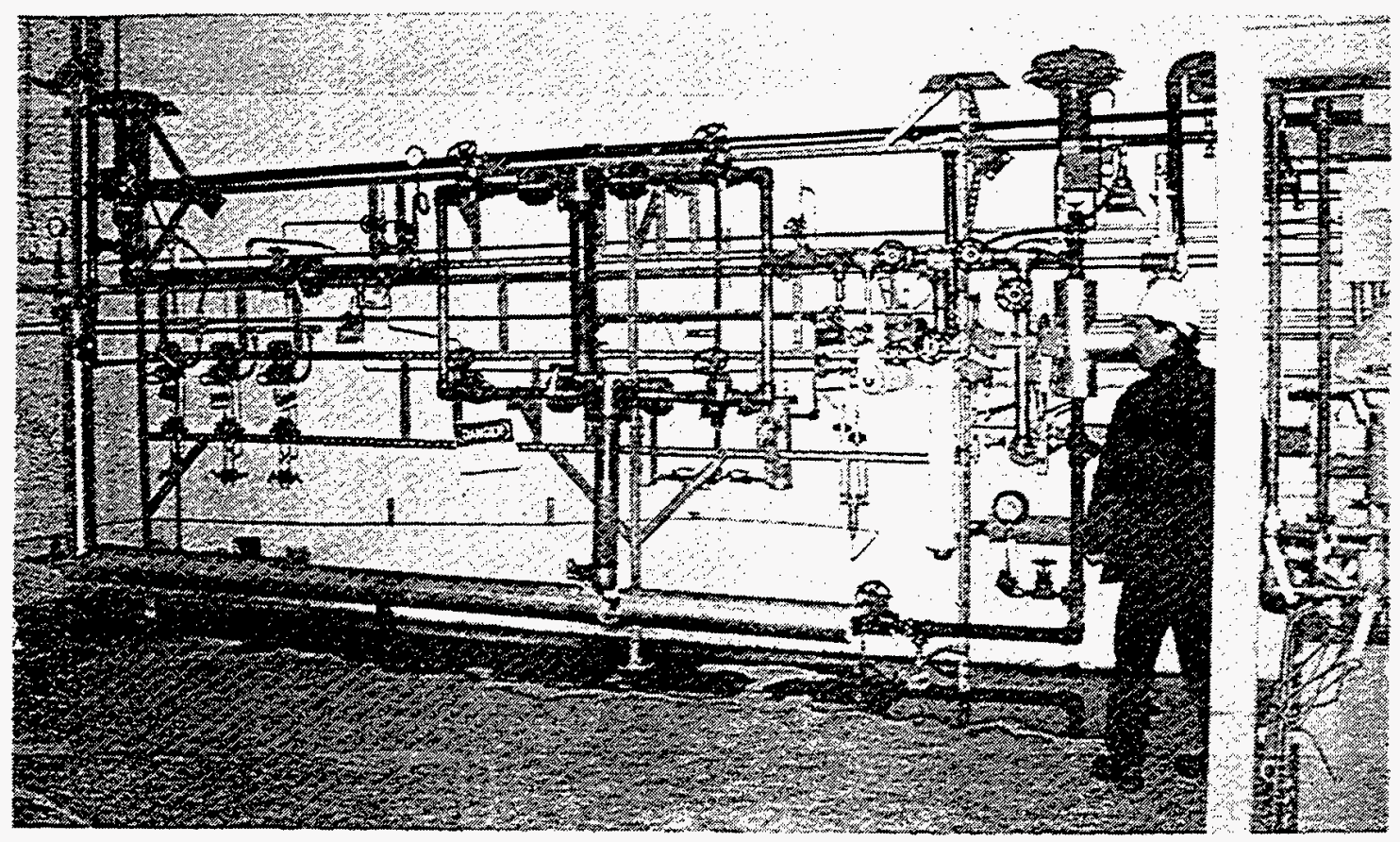

Figure 8.1/8.2-6. Filtration Characterization and Control System at Power Plant 


\section{CENTRIFUGE SYSTEM}

The objective of the centrifugal deposition rig test was to subject simulated bucket tip turn specimens to the same G-fields that they would see in service in the AGT. For the purpose of the experiment, the entry channel tip turns for the longest steam-cooled bucket were specified.

\section{MECHANICAL DESIGN}

The centrifuge was designed to be safe as well as productive. The two rotor arms were designed using finite element analysis for the yokes holding the $1.1 \mathrm{~kg}(2.5 \mathrm{lb})$ specimens in the $15,600 \mathrm{G}$ field. The rotor and shaft material is a 15-5PH stainless steel chosen for both strength and corrosion resistance. The steel used and allowable creep stresses limit the maximum rotor arm temperatures to $372 \mathrm{C}(700 \mathrm{~F})$ or less. Since the steam will adiabatically compress and heat almost $26 \mathrm{C}(80 \mathrm{~F})$ from the center to the rotor tip, the entry steam will be kept below 323C (550F) for the centrifuge operation. Missile containment was assured by designing the housing to withstand loss of a tip and yoke by using a thick circumferential steel housing lined with aluminum blocks as mechanical energy absorbers. In addition, first full speed trials on ATS Phase 3 will use a blast mat to cover the plane of rotation until the full speed operating conditions are deemed safe.

The rotor shaft cross section in Figure 8.1/8.2-7 shows details of steam flows and sealing. The rotor shaft is supported on flowing oil lubricated pillow block journal bearings with the bearing at the driven end of the shaft also handling thrust loads. Steam is admitted on the driven end of the shaft through ducts bounded by rotary seals that are close coupled to the rotor housing. Vents from the rotary seals are ducted to the plant condenser as shown earlier in the P\&ID. The housing also serves as a vacuum chamber to reduce rotor windage losses. 


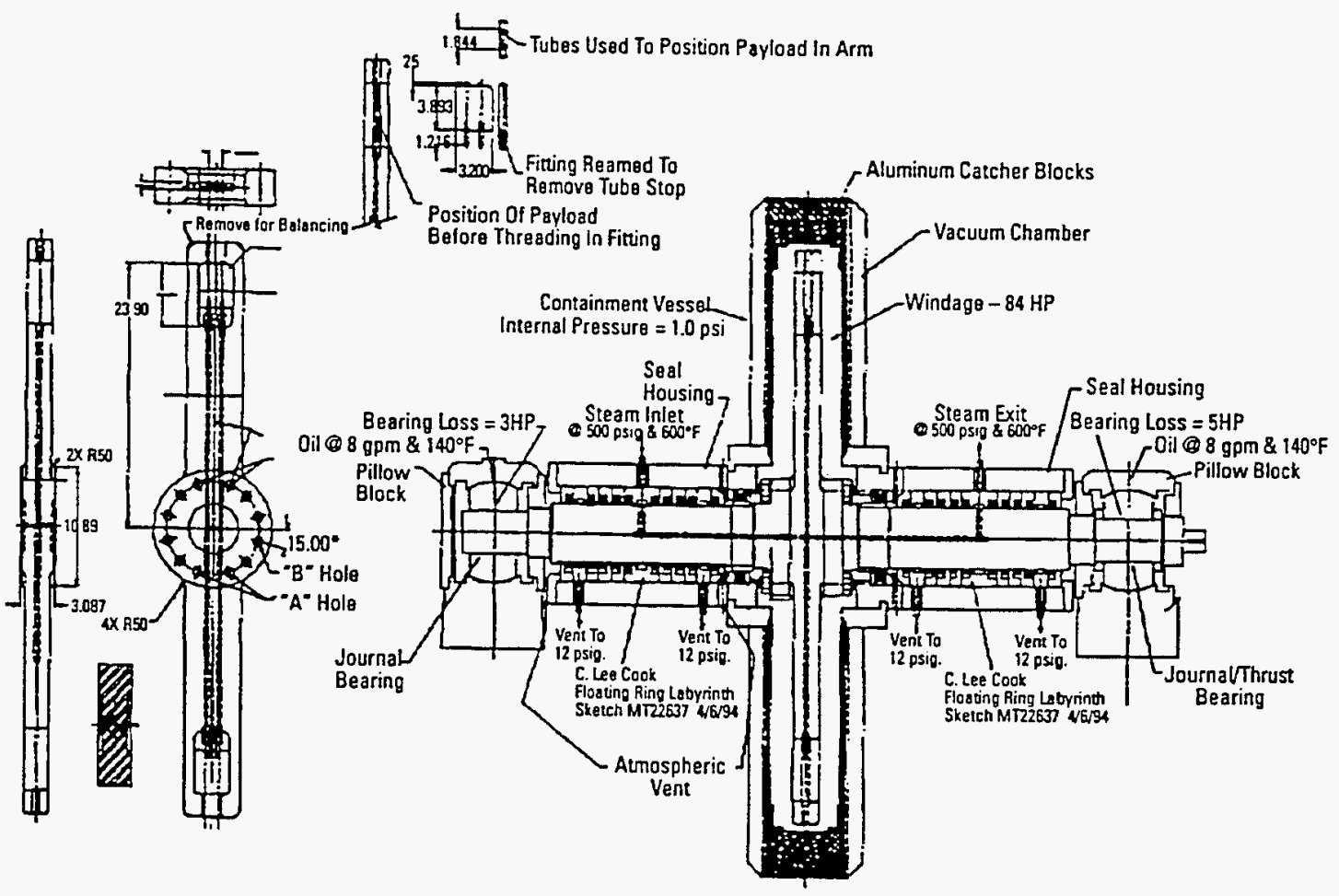

Figure 8.1/8.2-7. Rotor/Shaft Cross Section 


\section{COLD SPIN TEST}

A cold spin test was conducted at the GE Power Systems Steam Turbine Development Laboratory in 1995. The unit was spun up without steam or main rotary seals to determine its mechanical stability. The unit passed smoothly through its major critical speed and was run up to $4300 \mathrm{rpm}$. Overall, the system behaved very smoothly and stably. The unit was then once again put on a flatbed trailer and taken to Ocean State Power (OSP).

\section{INSERTION INTO STEAM FLOW APPARATUS}

At the power plant the installation required considerable modification to the existing piping system to provide extraction and return valves for both the centrifugal deposition rig and static specimen apparatus. The centrifugal deposition rig was then mounted in place in the basement of the power plant adjacent to the steam flow/filtration apparatus. The centrifugal deposition rig was designed to accept $0.16 \mathrm{~kg} / \mathrm{s}(0.35 \mathrm{lb} / \mathrm{sec})$ of steam flow to meet conditions expected in each of the two bucket tip turns operating in parallel.

\section{STATIC SPECIMEN SYSTEM}

While the centrifugal deposition rig was targeted at verifying the suitability of the OSP steam quality for use as a bucket coolant with respect to sedimentation, there was also a concern that any of the deposition mechanisms noted might create localized deposits in static channel specimens typical of nozzle and tip shroud cooling channels. The major concern was the necessary use of heat transfer enhancement structures that might act as localized traps for contaminants or that might be strongly affected by them.

Discussions with hot gas path component (nozzles, buckets, shrouds) designers indicated that two categories of interior surfaces would be typical. The first type involved the use of ridges ("turbulators") cast into the steam-side of channel walls, generally normal to the flow, so as to increase local heat transfer. If those ridges proved to be collection sites for contaminant deposits, the heat transfer coefficients might actually drop below smooth wall values. The second type involved the use of impingement cooling structures. These include a plenum within the cooling channel which has an array of holes selectively drilled into it so that steam is directed as jets onto the inside of a wall whose exterior is exposed to the flowing hot gas. The concern was that deposits might form at the holes, causing a reduction and redistribution of steam flows different from design intent, or that a deposit might form on the wall from the decelerating jet of steam. Both types of structures involve small critical dimensions 500-1900 microns (20-75 mils), and the thermal performance of both needs to be maintained over ATS life in order to assure reliability and availability of the power plant as well as its overall efficiency.

\section{SPECIMENS}

A turbulated convective specimen and an impingement convective specimen were constructed for these trials.

The convective specimen was a reworked commercial gas turbine bucket with turbulators in the leading edge cooling channel. This specimen had been used earlier in flow studies at GE- 
$\mathrm{CRD}$ and had been brazed several times to place pressure ports on it. The flow channels were plugged on the trailing edge, and a return flow was directed out of the leading edge tip channel. This specimen is shown in Figure 8.1/8.2-8. The flow is into the bottom (from the right), where plates join the 3/4-inch SS tubing entrance fitting to the dovetail; steam exits at the top through a similar fitting.

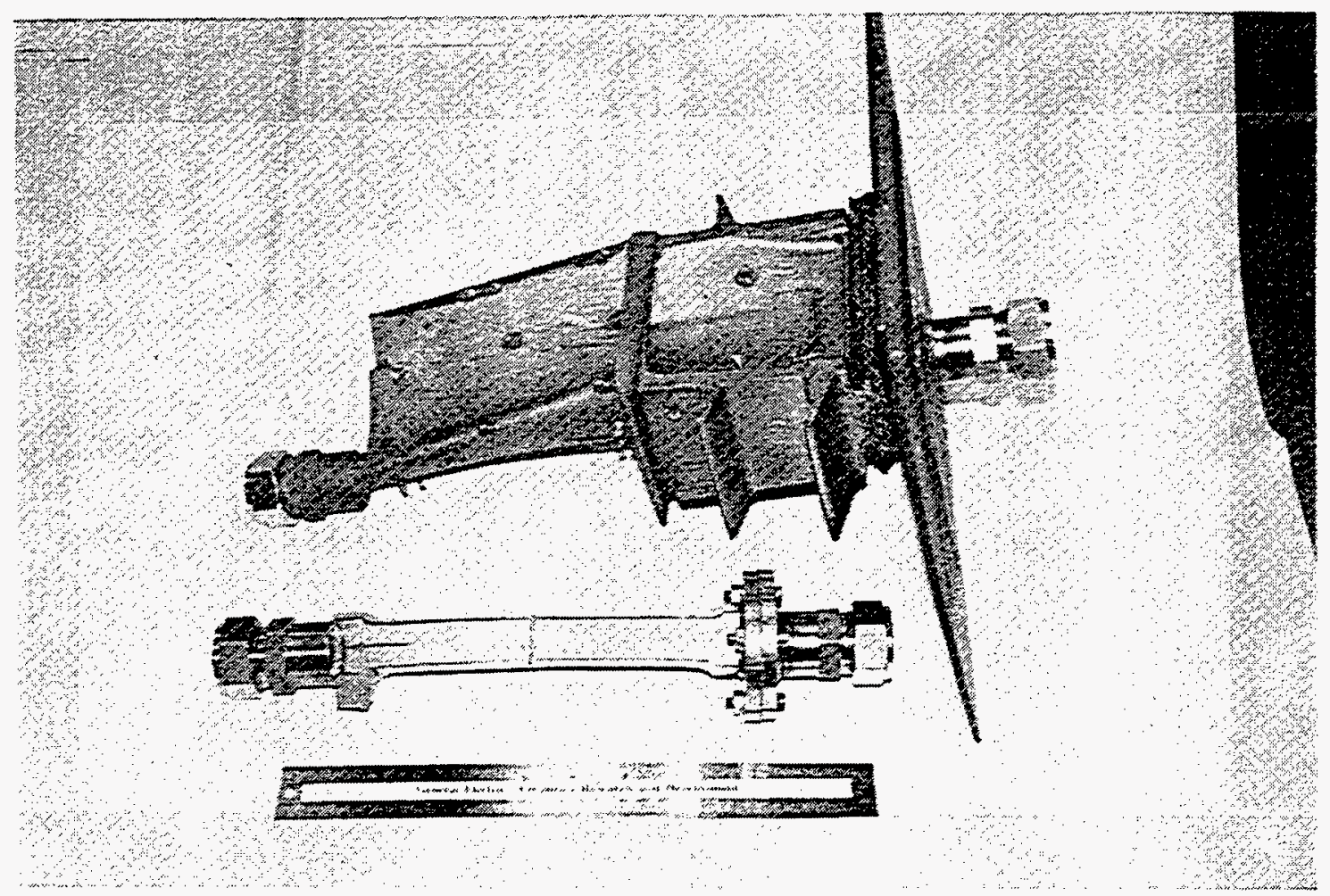

Figure 8.1/8.2-8. Convection (top) and Impingement Specimens (photo)

The impingement specimen was made from an early casting of a prototype first-stage nozzle and is shown disassembled in Figure 8.1/8.2-9. The internal impingement tube was made removable from the nozzle sector wall so that examinations could be made of both the distributor- and wall-sections of the assembly using the borescope. 


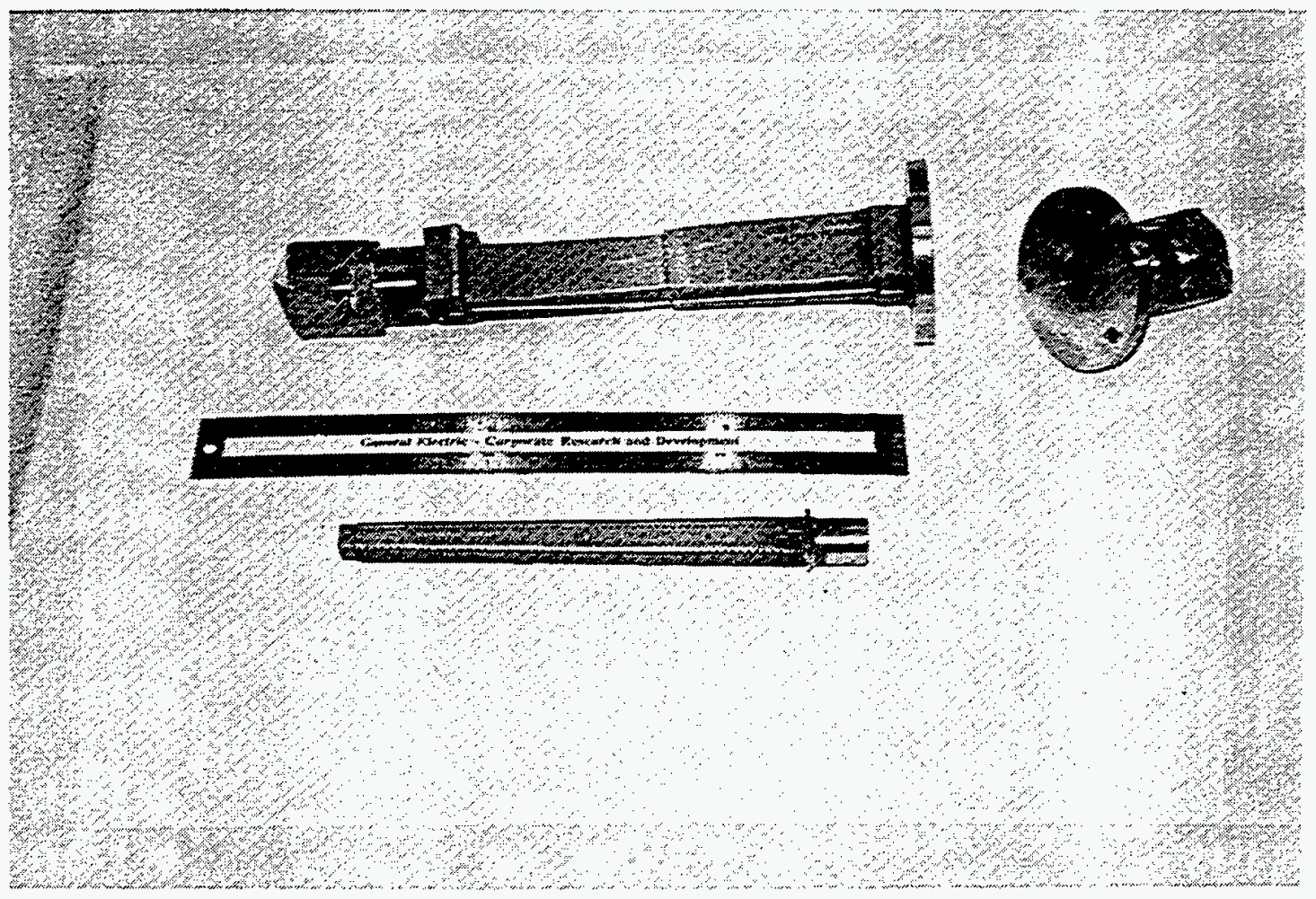

Figure 8.1/8.2-9. Impingement Flow Specimen Disassembled (photo)

\section{CONTAINMENT}

The two specimens were mounted in a pressure vessel especially designed for high-pressure steam flow channel testing. The vessel was designed to code for 500 psig steam use from 304SS. Flows into and out of the vessel were made through the bottom hemi-head, which was fixed on a platform. Specimen assembly could be completed in the open with the top of the vessel removed. This technique also allowed a final pressure check of specimen integrity by pressurizing the specimens with great care and caution in the open to observe visually that there were no leaks. After depressurization of the specimens, the vessel top would be rebolted into place before operations began.

The use of the vessel served two purposes. It enabled safe operation with flow specimens that did not themselves meet ASME code requirements for personnel exposure. And the vessel and specimens could be preheated by putting steam on the vessel shell to avoid condensation in the specimens on startup.

\section{BORESCOPE ANALYSIS OF SPECIMENS}

To enable visual inspection of the deposits within the flow specimens, a specially constructed borescope with a $2-\mathrm{mm}(80-\mathrm{mil})$ tip was obtained that could also be equipped with a right angle mirror for looking at specimen sidewalls. The borescope uses a CCD video camera to 
capture the images that are stored on videotape. These images should identify any localization of deposits that could lead to problems not predicted by the 3D CFD analyses.

\section{OPERATING PROCEDURES}

A full operating procedure document was prepared and is kept updated as the experiment proceeds.

\section{RESULTS}

\section{SUPERHEATER STEAM SAMPLE FILTRATION RESULTS}

These few measurements were made before the steam filtration apparatus was completed. SEM analysis of the material captured on this filter was conducted. It is clear that the material is chips of oxide approximately 2 microns thick that have become trapped in the filter disks. $\mathrm{SE}$ microprobe analysis indicated that the chips were magnetite.

\section{CARTRIDGE FILTER SYSTEM RESULTS}

\section{Operations}

Over 1800 hours of exposure of the filter cartridge were accomplished during this study. Tabulations of manual flow data were recorded. During this exposure, the filter was examined approximately midway and at the end.

\section{Screen Filter Observations}

Comments on exposure. During the exposure, the filter system was exposed to several unusual events which also helped to provide insight into the filter performance.

Mechanical toughness of filter. The original filter housing provided for these trials was inadvertently made about $6 \mathrm{~mm}(0.25 \mathrm{inch})$ too short for the cartridge by the vendor. When the unit was assembled at the site, this added length was not noticed while bolts fitting the housing over the screwed-in filter were drawn up. On the next disassembly, the filter was found to have been crushed axially, making the bottom section bow out radially. The filter cartridge was taken back to the manufacturer for testing and repair. It was found to have retained its gas bubble point, indicating that there were no increases in porosity. Nevertheless, the lower section was replaced with a new one and retested while the steam housing was also increased in length.

\section{POWER PLANT APPARATUS INSTALLATIONS}

As part of this ATS Phase 2 program, two installations were made in preparation for Phase 3 . The centrifugal deposition rig was installed to enable the exposure of simulated bucket tip turn passages to long-term steam flow for examination of bucket deposit amounts and locations. The static flow specimens were installed to expose actual cooling flow channel structures to long-term steam flows, for deposit amounts and deposit locations. Two experiments were 
designed to verify the analytical prediction that the AGT channels would not need to be cleaned more often than every 24000 hours.

\section{Static Flow Specimens}

The static flow specimens were initially pressure tested with steam inside the vessel with its vent opened. The absence of steam from the vent was considered an indication that there were no leaks. When a pressure test was done in the open, several small leaks were found on the specimen. It was sent back twice for repair, but has developed leaks both times. The issue seems to be earlier use of low temperature brazes and alloy cracking. If this specimen cannot be fixed, another will be secured. In the meantime, the impingement specimen, which has retained its integrity, will be put on-line in Phase 3 to accumulate exposure.

\section{DISCUSSION}

\section{SUPERHEATER STEAM FILTRATION}

The superheater measurements were conducted and chips of oxide were found in them, but they were not considered to be representative of the real steam circuit. The long sample tube length, plus the flow changes engendered by installing the hot filter may have caused a significant spallation of material from the tubing interior. As a result, only the condensate filtration was considered realistic.

The particulate concentrations measuring under 1 ppbw was consistent with plant measurements of OSP boiler drum iron concentrations. These routinely measured as "less than 10 ppbw" [Ref. 15] without further routine analysis. Since the drum drying systems would be expected to allow less than $1 \%$ of this concentration to carry over into the superheater, the concentration corroborates the result noted earlier, that the superheater is the primary source of the particulate contamination.

\section{TECHNOLOGY APPLICATION}

The results of the steam purity work have been already employed to both specify a steam filter for the commercial plant as well as providing a steam purity specification that such a filter must provide. Moreover, the research staff has been working intimately with the plant anxilliaries staff to provide a steam system design that provides the reliability and quality assurance required. For example, the research staff first defined the filter housing and flow design, and have specified provisions for steam trapping, progressive steam pressurization (through small bypass valves), steam sampling stations, and other process features. These contributions are primarily based on the hands-on experimental experience gained in the ATSfunded, real power plant trials at Ocean State Power.

\section{PLANS FOR PHASE 3}

The steam screen filter is left inline in the steam flow train at OSP so that the downstream centrifuge and static flow specimens (turbulated and impingement) see a steam as close to that which we expect in the ATS plant as possible. This inline filter has been specified for GE's 
prototype plants to provide assurance of clean steam for the advanced gas turbine. The steam sampling filters will be periodically exposed and analyzed to be sure that conditions of the steam indeed meet the steam purity specifications. These sampling filters are cellulosic and actually filter steam sampled isokinetically before and after the screen filter unit.

\section{CONCLUSIONISUMMARY}

\section{OSP STEAM PURITY}

The particulate mass found in the OSP extracted steam was determined to be less than 1 ppbw iron in the steam, in all measurements over short and long sampling times. The primary source of the iron was confirmed to be the superheater tubing rather than boiler carryover. Particle sizes ranged from 20 microns down to 0.25 micron.

\section{SEDIMENTATION RATE OF PARTICULATES}

Theoretical prediction of deposition rates by both Stokes Law continuum and 3D CFD particle tracking computations have agreed to show that particles under 0.4 micron should pass through the AGT almost completely while particles of 10 microns or more will not escape the bucket tip turn at any time in the proposed high-G fields.

It is predicted that with $98 \%$ capture of all particles over 2 microns by a full-flow steam filter, the AGT can achieve 24000 hour Time Between Outages for bucket cleaning with $40 \%$ margin for steam of at least the purity of a modern power plant such as that measured at OSP.

\section{STEAM PARTICLE FILTRATION}

The two-micron stainless steel cartridge filter element appears to have adequate filtration performance, low pressure drop (both clean and with projected low loading), and robustness that it should be recommended as a full-flow steam filter for the GE/AGT. The existing filter will continue to be used as the filter medium to gain increased exposure time.

\section{STEAM CENTRIFUGE OPERATION}

With the retrofit of new rotary steam seals and the completion of the computer shutdown of the centrifugal deposition rig installed at OSP, it should be possible to get the required information on particle sedimentation. rates from filtered steam to verify the low deposit levels predicted based on the steam characterization work reported here.

\section{STEAM PARTICLE DEPOSITION ON STATIC CHANNEL SPECIMENS}

The system put into place at OSP should be adequate to determine whether local heat transfer features can enhance particle deposition in an unexpected way. 


\section{TASK 8.2.1 - MATERIALS COOLANT COMPATIBILITY}

\section{INTRODUCTION}

GE is using steam as a cooling medium for hot gas path components in advanced turbine systems for power generation machines. Existing data for advanced materials that are candidates for such rotor components do not include mechanical behavior in a steam environment. In particular there are concerns relative to cyclic deformation, time-dependent fatigue effects, and fracture under these conditions. The ability of advanced materials to withstand ATS conditions for long durations without failure is required.

The emphasis in ATS Phase 2 was on constructing equipment and developing techniques to characterize any potential interaction between steam and the materials to be utilized in construction of components in advanced power generation turbine systems. Some initial screening of material properties was done as the equipment and techniques were being established. The Phase 2 work established the capability needed to obtain material properties required to meet Phase 3 objectives in the area of steam compatibility. Phase 3 will emphasize screening of materials, suporting design efforts, and evaluating component life and failure mechanisms.

\section{OBJECTIVE}

The objectives of this task are to evaluate the effects of materials in the steam cooling environment expected for advanced gas turbine operating conditions, identify potential barrier problems, and provide solutions to those problems.. While emphasis will be on development of techniques for testing, some testing was performed on early material/process trials to begin an understanding of the materials behavior. Testing will include fatigue crack propagation, low cycle fatigue, creep, and slow strain rate tensile testing. Comparisons will be made to air environments.

\section{TEST EQUIPMENT AND TEST TECHNIQUE DEVELOPMENT}

\section{INTRODUCTION}

The challenge of screening materials in a steam environment, at temperatures consistent with the ATS operating environment, required the development of new testing capability. This task included modification of existing equipment and/or construction of new equipment. CRD was able to do this by drawing upon the substantial experience gained with our in-house environmental testing in autoclaves for the nuclear industry. The commonly used operating condition for nuclear industry is hot water at $288 \mathrm{C}(550 \mathrm{~F})$ at $14 \mathrm{MPa}(2000 \mathrm{psi})$. Our ability to develop test techniques for characterizing time-dependent fatigue behavior was aided greatly by over 25 years experience of related testing for GE's aircraft engine and power generation businesses.

The fatigue crack propagation (FCP) testing, low cycle fatigue (LCF) testing and notched, sustained peak low cycle fatigue (SPLCF) testing were accomplished by incorporating the capability for steam environment testing into existing servo-control, hydraulic test stations. Six new creep stations with steam environment capability were constructed. 


\section{TEST EQUIPMENT}

The methodology for delivering a steam environment to the various test machines used for characterizing the materials investigated for fatigue crack propagation (FCP), low cycle fatigue (LCF), creep, and sustained peak low cycle fatigue (SPLCF) behavior, was substantially the same. The basic delivery system is discussed first; after which the particular differences are discussed for the specific test setups. Tests in an air environment were also conducted to provide a baseline for the effect, if any, of the steam.

\section{Steam System}

The steam delivery system for each of the four types of tests consisted of a water supply board, a steam generator, and a vessel containing the particular test specimen. The water supply originated from a central facility for producing deionzed water for all needs in the CRD Metallurgy and Ceramics Building.

Individual steam generators consisted of a stainless steel pipe surrounded by a resistively heated furnace. This steam generator was controlled to $538 \mathrm{C}(1000 \mathrm{~F})$. A low flow of water was dripped into one end of the pipe and flashed to steam at nominally atmospheric pressure. The steam exited the other end of the pipe and flowed through heated stainless steel tubing to the test vessel used for that particular test. Some heat loss occurred in delivering the steam to the test vessel, but the temperature during geographic transfer was never allowed to drop low enough to allow condensation back to the liquid state. The exception to the process described above was for the creep tests, where the water from the holding tank was pumped directly to the steam generator and which was heated to only $316 \mathrm{C}(600 \mathrm{~F})$.

\section{Test Vessels}

For FCP and SPLCF tests, the test vessel was a 4-liter (1-gallon) internal volume, stainless steel autoclave manufactured by Autoclave Engineers Inc. The autoclave head was fitted with numerous feed-throughs to accommodate the steam entry tube, the main pull rod that transmitted the force from the test machine actuator to the test specimen, thermocouples, and the current and voltage leads used to monitor crack length on the FCP specimens or crack initiation on the SPLCF specimens. Also mounted on the autoclave head was a four-column test cage that served as the small load frame inside the autoclave that reacted the applied forces. The test vessel and head were supported by a stainless steel plate attached to the lower crosshead of the test machine load frame. Figure 8.2.1-1 is a schematic of the FCP test setup and the SPLCF setup. 


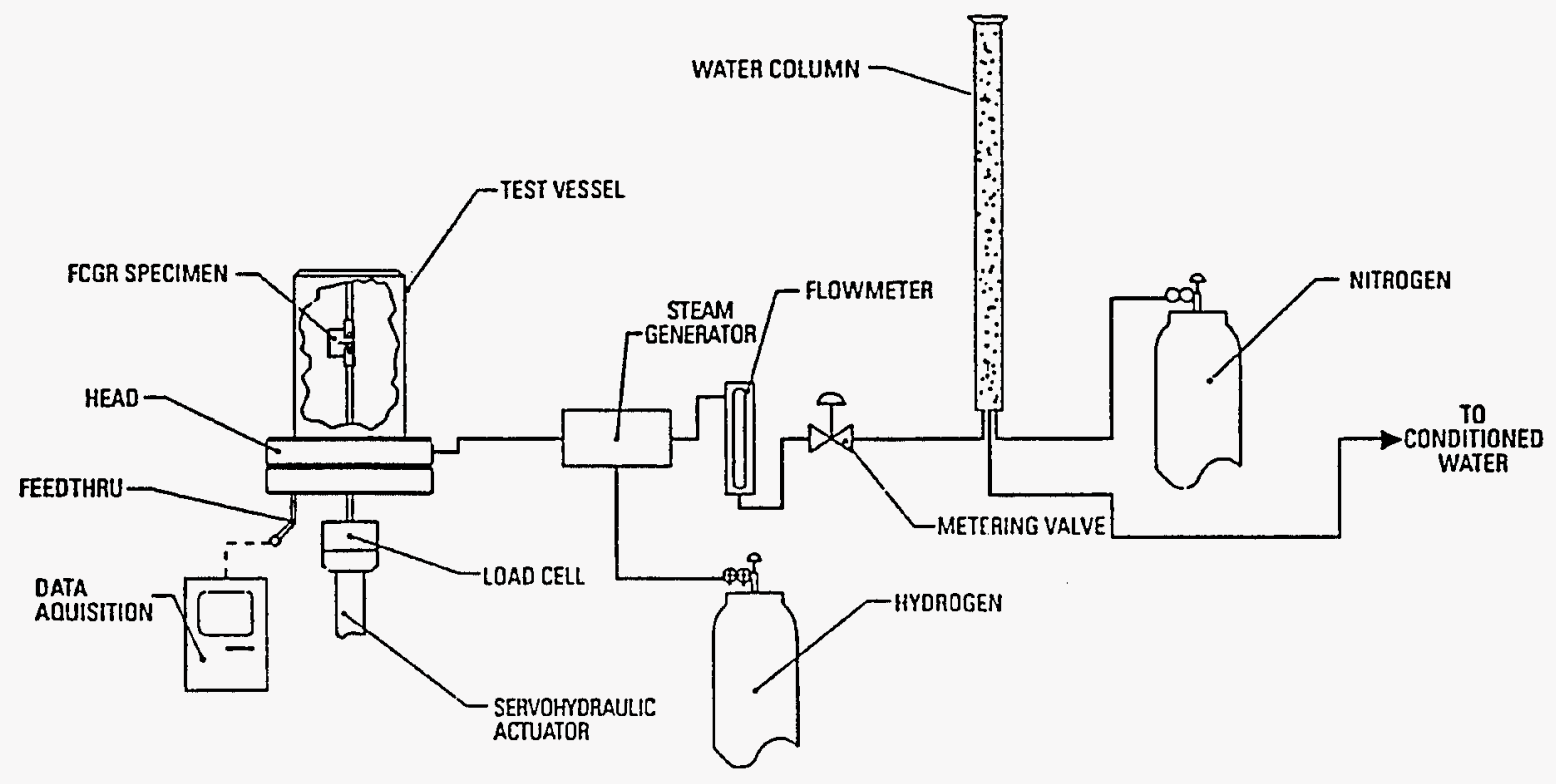

Figure 8.2.1-1. Schematic of Fatigue Crack Propagation Test Setup

For the creep tests, a similar setup was employed except that the load bar was attached to a traditional lever arm and knife-edge assembly typically used in conventional creep load frames. Six of these creep machines were constructed with the autoclave assemblies supported by a table constructed of angle iron. The autoclave heads (identical to the FCP and SPLCF heads) for the creep stations were purchased from Autoclave Engineers, but the autoclave body was constructed using stainless steel pipe with a stainless steel plate welded to the end opposite the head. This construction allowed for a larger internal volume and provided for additional ability to heat the vessel with a three zone furnace to provide the greater temperature uniformity required for creep tests. Figure 8.2.1-2 is a schematic of the creep facility. Steam flow was the same for FCP, SPLCF and creep testing. In these tests the steam generator was fed water at a rate of $10 \mathrm{~cm}^{3} / \mathrm{min}(1.3 \mathrm{lb} /$ hour $)$. 


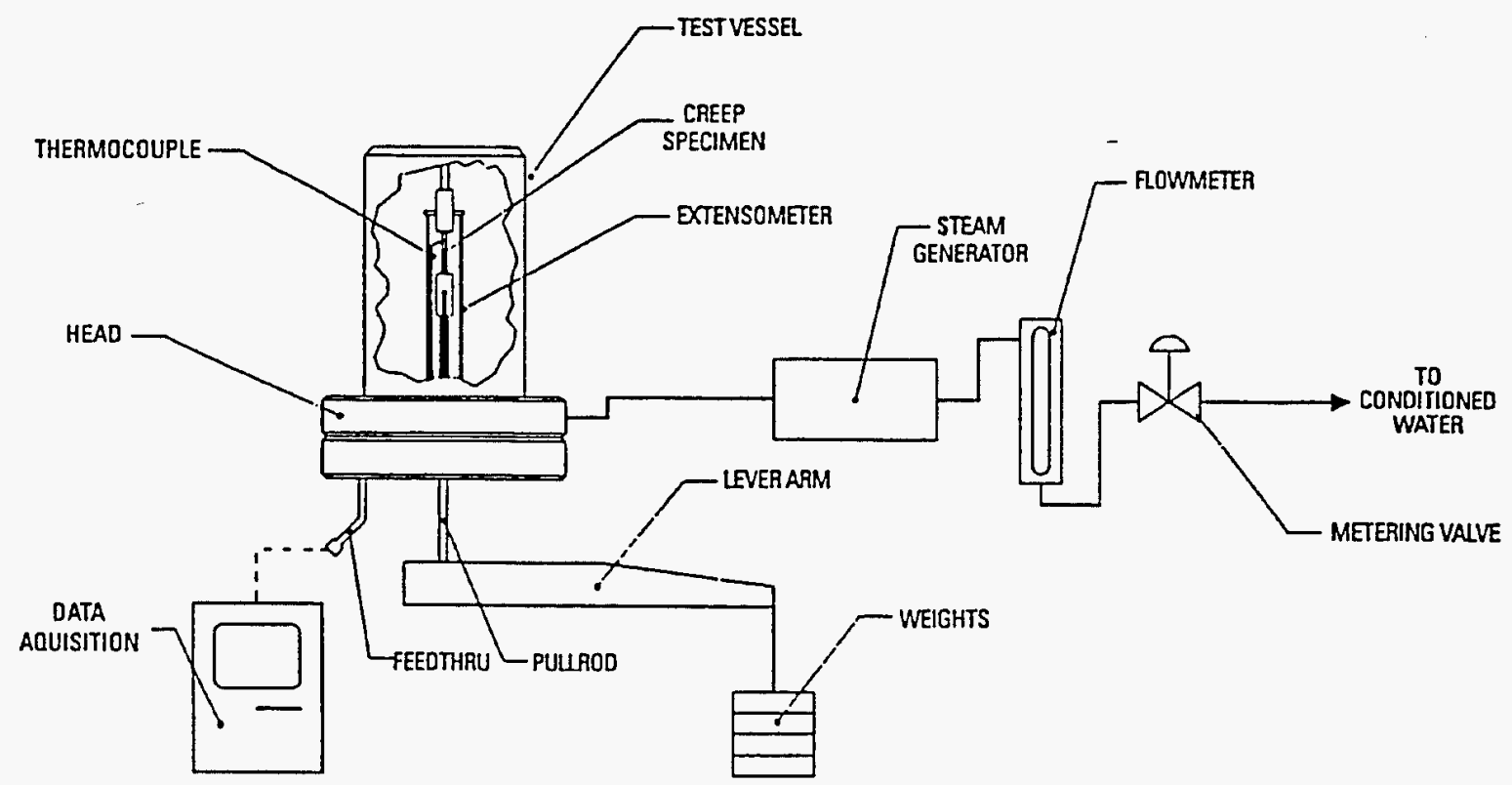

Figure 8.2.1-2. Schematic of the Creep Testing Facility

For the LCF tests, the test specimen itself served as the test vessel. A standard 0.25 inch diameter test section button-head LCF specimen (see Figure 8.2.1-3) had a $1.25 \mathrm{~mm}(0.05$ inch) diameter hole electro-discharge machined (EDM) down the center; effectively making the specimen its own pressure vessel. The steam was brought from the steam generator, via heated tubing to a super heater to bring the steam temperature back to $427^{\circ} \mathrm{C}\left(800^{\circ} \mathrm{F}\right)$, before entry into specially constructed grips that channeled the steam into the inside of the LCF specimen. The steam passed through the specimen, exited through the lower grip and condensed into a catch basin. The outside of the specimen was inductively heated using a copper tubing coil connected to $5 \mathrm{~kW}$ Lepel induction heater as shown in Figure 8.2.1-4. The temperature of the LCF test specimen was monitored using an optical pyrometer focused on the middle of the test section. The induction heater was controlled by thermocouples spot welded to the shoulder region of the specimen based on an experimental calibration of the shoulder temperature to the test section temperature. For the steam flow used $\left(0.07 \mathrm{~cm}^{3} / \mathrm{min}\right.$ of water) and for a steam entry temperature of approximately $427 \mathrm{C}(800 \mathrm{~F})$, the temperature gradient from the outside diameter of the test section held at 593C (1100F) to the inside diameter was approximately $6 \mathrm{C}(10 \mathrm{~F})$. This gradient was determined by an ANSYS thermal analysis of the test setup. Although, several assumptions had to be made for the boundary conditions, it is believed that the analysis is a good representation of the temperature gradient. Strain control was provided for these tests via the $12.7 \mathrm{~mm}(0.5$ inch) gauge length extensometer shown in Figure 8.2.1-2. Quartz rods with knife edges were used to contact the specimen. 


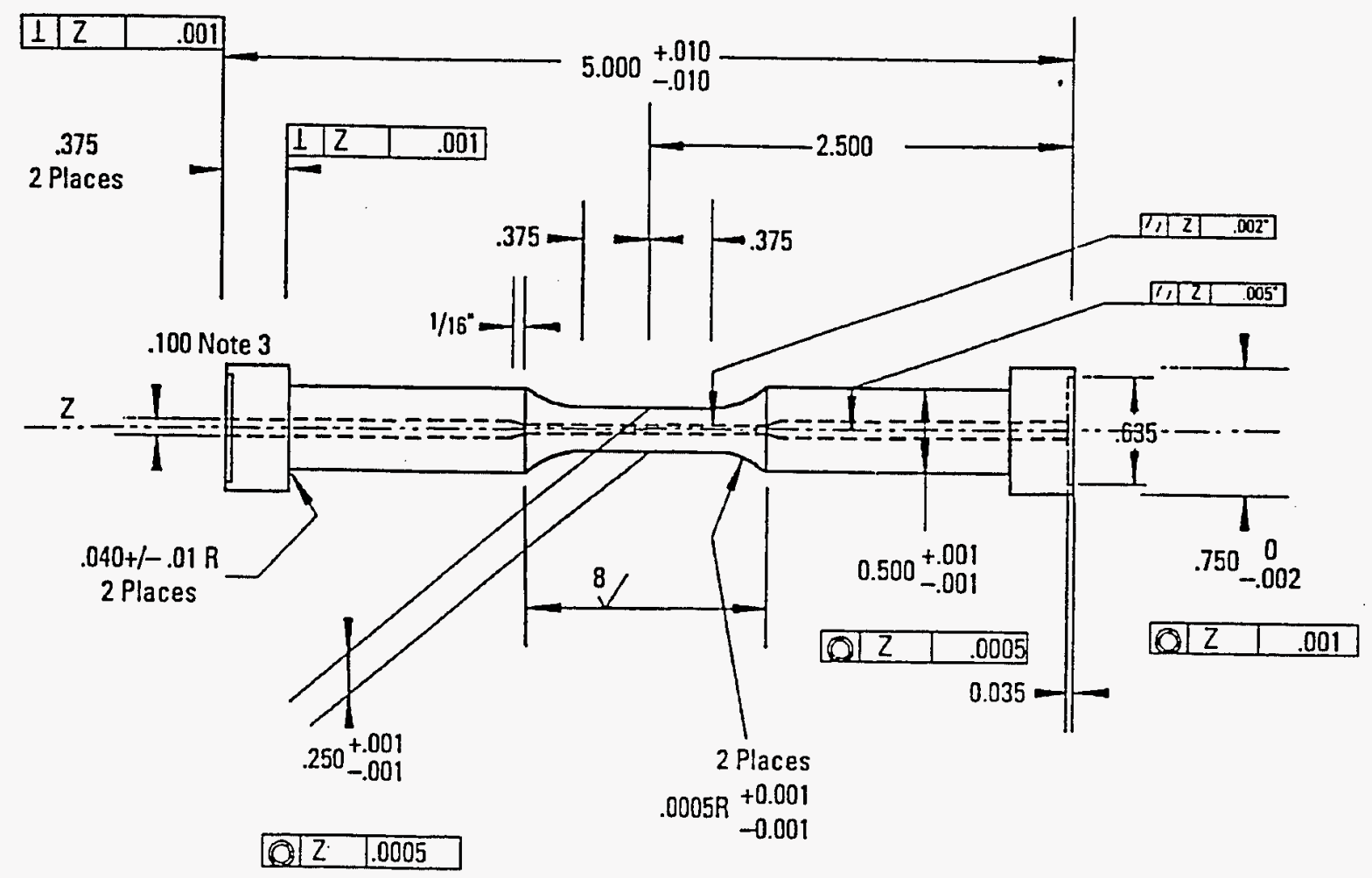

Figure 8.2.1-3. Button-Head LCF Specimen

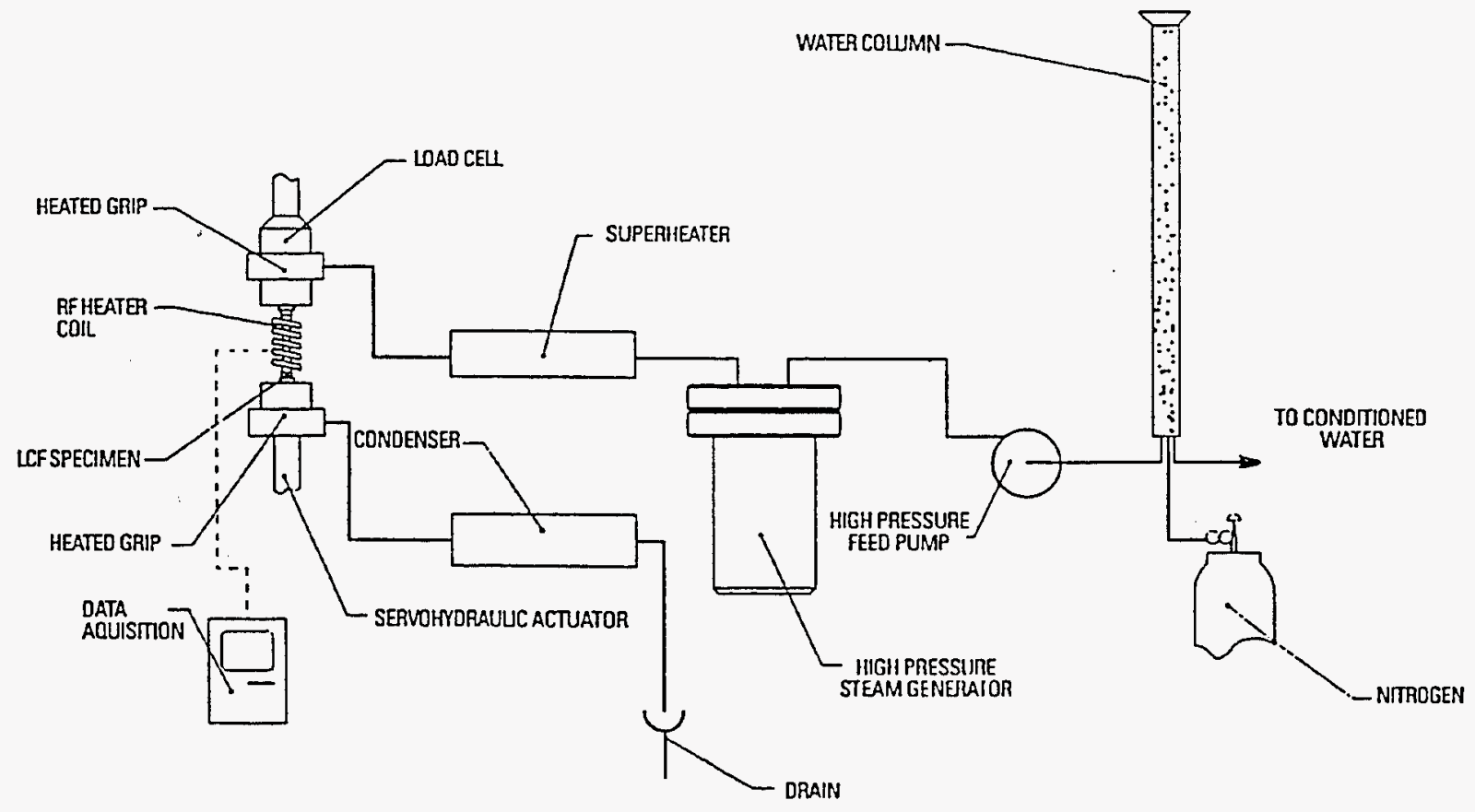

Figure 8.2.1-4. Schematic of LCF Test Setup 


\section{Steam Oxygen Content}

The oxygen content of the feed water was less than one part per billion $(\approx 0.2$ to $0.5 \mathrm{ppb})$. The steam systems for all the test setups were basically at atmospheric pressure. This allowed leakage of minute amounts of air into the steam generators, tubing, and test vessels. By the time the steam flowed through the test system, the oxygen content had increased to several hundred parts-per-million (ppm). Since the application for which these data are relevant will likely operate at near one ppb of oxygen, hydrogen was injected into the steam generator to reduce the oxygen in the test vessel, reducing the oxygen content to approximately $0.5 \mathrm{ppb}$ as measured by the Orbitsphere Oxygen Analyzer at the discharge side of the test vessels.

\section{FATIGUE CRACK PROPAGATION}

\section{Introduction}

Fatigue crack propagation (FCP) studies were used to screen potential structural and gas path materials for any reduction in life that might occur under service conditions in the ATS gas turbine as a result of the interaction of the steam coolant with an existing crack. Testing was conducted in both steam and air environments to enable comparisons. Further work was initiated to determine the temperature-dependence of environmental degradation.

Environmental degradation of the FCP properties of materials frequently occurs as a result of a phenomenon known as "time-dependent" crack propagation, which can become a significant contributor to crack advance in gas turbine applications in which components are exposed to an aggressive environment at high temperature and under sustained loading. A brief description of this phenomenon follows.

When the fatigue crack growth rate (FCGR) of many materials is measured as function of cyclic period, the data can be plotted as is shown schematically in Figure 8.2.1-5. In the graph at the top, the cyclic crack growth rate, da/dN, is plotted versus cyclic period. At low cyclic periods, da/dN is typically found to be insensitive to cyclic period. This regime of behavior is designated as time-independent FCP. It is the regime of behavior on this graph where the slope is zero. However, as the cyclic period is increased above a critical value, $\mathrm{da} / \mathrm{dN}$ is found to increase as cyclic period is increased. This regime of behavior is designated as timedependent FCP because crack extension becomes dependent on time, rather than on cycle count alone. It is the regime of behavior on this graph where the slope is anything other than zero. At longer cyclic periods or hold times, the slope of this time-dependent region may be found to have a value very close to unity, indicating that $\mathrm{da} / \mathrm{dN}$ is directly proportional to hold time. This behavior has been designated as fully-time-dependent crack propagation because crack extension becomes dependent on time alone. It is the regime of behavior on the graph at the top where the slope is unity or the regime of the graph at the bottom, where the slope is zero. Previous work in gaseous environments has shown that time-dependent crack propagation typically occurs intergranularly, whereas time-independent crack propagation typically occurs transgranularly. 

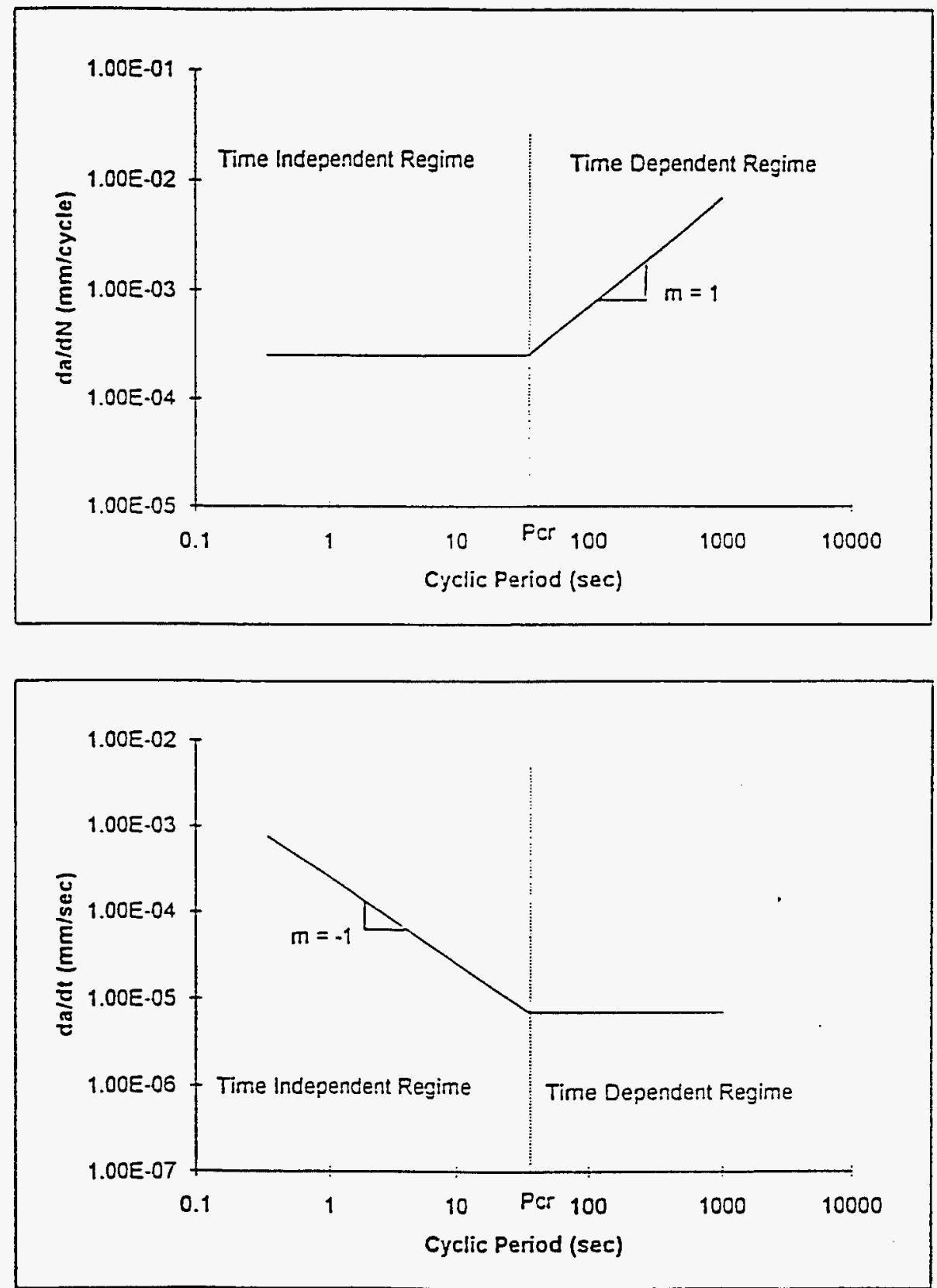

Figure 8.2.1-5. Schematic Illustration of the Transition to Time-Dependent Fatigue Crack Propagation with Increasing Cyclic Period: (top) da/dN vs. cyclic period; (bottom) da/dt vs. cyclic period 


\section{Experimental Procedure}

Compact tension (CT) specimens were used for all Phase 2 work. All specimens had a fracture mechanics width of $40.6 \mathrm{~mm}$ (1.6 inches) and a thickness of $6.35 \mathrm{~mm}$ ( $0.25 \mathrm{inch})$. All other specimen dimensions were in accordance with ASTM standards.

The equipment used for this work is described in detail in the earlier section on Test Equipment and Test Technique Development. Fatigue testing in steam environment was accomplished by dripping high purity water into a steam generator heated to $538 \mathrm{C}(1000 \mathrm{~F})$, thereby producing steam. The steam was then transported through heated stainless steel tubing to a 4- liter (1-gallon) autoclave containing the compact tension specimen. The steam flow rate was controlled at a rate of $10 \mathrm{~cm}^{3} / \mathrm{min}$.

Crack length monitoring was performed using the reversing dc electrical potential drop method. This real time crack length monitoring method was used to provide feedback control to an automated system that controlled the stress intensity factor applied to the sample by the servohydraulic testing equipment. In this manner, a programmed stress intensity range or a constant cyclic load range could be maintained during testing of a specimen. During the testing of a single specimen, the cyclic period was varied over several orders of magnitude, with a specified number of fatigue cycles being applied at each cyclic period. Crack length and cycle count data collected using this method allowed the crack growth rate to be determined for each cyclic period at a single stress intensity range.

For screening purposes, a maximum test temperature of 593C (1100F) was selected for structural alloys and a maximum test temperature of $760 \mathrm{C}(1400 \mathrm{~F})$ was selected for gas path materials. These temperatures represent an upper bound on the expected service temperatures for the two applications. Hold times at maximum stress in excess of 12 hours are expected in service. Because it is impractical to test samples with these long hold times in the laboratory, the hold time was varied during testing of a single specimen to determine the effect of hold time on the fatigue crack growth rate (FCGR). The range of hold times that were investigated spanned several orders of magnitude for all materials. As will be discussed, experimental data indicate that data collected at shorter hold times can be reliably extrapolated to longer hold times for materials that exhibit time-dependent behavior at the shorter hold times. For materials that do not exhibit time-dependent crack propagation behavior at shorter hold times, an upper limit for the crack propagation rate can be reliably predicted. For cyclic periods equal to or less than 3 seconds, a sinusoidal waveform was used for cyclic loading. For cyclic periods in excess of 3 seconds, a hold time at maximum stress was inserted into a sinusoidal waveform having a period of 3 seconds.

All test specimens were supplied by GE Power Systems (GEPS) and were taken, where possible, from gas turbine components. The orientation of the specimen relative to the component was chosen such that the crack propagation plane would be as expected in service.

\section{Results and Discussion}

Experimental results of FCP testing will be presented and discussed in the following sections. Results of screening tests on structural and gas path materials in steam and air will be 
presented first. Further work to understand the temperature-dependence of environmental degradation for two structural alloys will then be presented.

\section{Structural Materials}

For all these specimens, time-independent crack propagation was found to occur transgranularly, while time-dependent crack propagation was found to occur intergranularly.

Previous work has shown that fully time-dependent crack propagation is a thermally activated process. To establish the activation energy for fully-time-dependent crack propagation in the alloys selected, work was initiated under ATS Phase 2 to measure the fully-time-dependent crack propagation rate for each alloy at several temperatures in both steam and air environments.

The N5 results are not yet thought to be significant because crack growth occurred significantly out of plane in specimens tested in both air and steam. Further testing of single crystal N5 using side grooved specimens that should force crack propagation to occur in a plane perpendicular to the axis of the remote stress is planned in Phase 3.

\section{LOW CYCLE FATIGUE}

\section{Introduction}

Low cycle fatigue (LCF) is a material behavior characteristic that is critical to the design and life prediction of rotating components in advanced turbine systems. Existing LCF data were not available to evaluate the potential effects of a steam environment, particularly for waveforms of long periods or waveforms with extended hold times. This task included an experimental program to evaluate the effects of both waveform and environment on the fatigue crack initiation resistance of materials that are candidates for an advanced turbine system. The testing was done using the tubular specimens described earlier in the section on Test Equipment and Test Technique Development.

During Phase 2, a need arose to evaluate a new potential life prediction criterion to handle time-dependent LCF. To evaluate the criterion for notched specimens, the two sustained peak low cycle fatigue (SPLCF) stations (described under Test Equipment and Test Technique Development) were constructed. Both stations were equipped with steam capability and with instrumentation for electrical potential drop monitoring of crack initiation.

\section{TESTING}

Screening tests for both smooth LCF and notched SPLCF resistance were performed on a variety of material/process combinations that are candidates for structural components. Screening tests for smooth LCF resistance were performed on a variety of material/process combinations that are candidates for gas path components. Tests were conducted over a range of temperature from $538 \mathrm{C}(1000 \mathrm{~F})$ to $760 \mathrm{C}(1400 \mathrm{~F})$. Strain ranges of 0.45 to 1.5 percent were tested. Waveforms included $20 \mathrm{cpm}, 2$-minute times and 20-minute hold times. To model anticipated component service conditions, structural materials were tested at an A-ratio 
of 1.0, and gas path materials were tested at an A-ratio of -1.0. A-ratio is defined as the ratio of the strain amplitude to the mean strain.

Fractographic analysis was performed on the tested specimens. For the tubular tests, this fractography allowed determination of whether crack initiation had occurred on the air or steam side of the specimen wall (or both). Specimens were evaluated for fracture mode (transgranular or intergranular) and identification of microstructural features causing crack initiation.

These screening tests will provide one of the criteria for initial materials selection, and guide the layout of design databases required in Phase 3.

\section{CREEP/RUPTURE}

\section{Introduction}

As part of Phase 2, the effects of steam on creep behavior of candidate materials for structural and gas path components were investigated. Initial efforts were concentrated on measuring the creep resistance of candidate materials in the steam environment as compared to air. Standard creep rupture tests of smooth bar specimens under static load were run in both steam and air environments under a range of stresses and temperatures.

The results were evaluated using the Larson-Miller parametric approach of quantifying material creep strength versus time and temperature. The Larson-Miller Parameter (LMP) is of the form:

$\operatorname{LMP}(C)=T(C+\log t)$

where $\mathrm{T}$ is absolute temperature, $\mathrm{t}$ is the time of interest, and $\mathrm{C}$ is a constant. The time to failure would be used for $t$ to analyze rupture data and the time to a specific strain level would be used for $\underline{t}$ to analyze creep data. The creep strength of many materials has been shown to vary with LMP in a predictable manner.

A secondary objective was to investigate the notch sensitivity in creep of candidate materials and the effect on it of the steam environment. Finally, the test program was structured and conducted with an intent to contribute to mechanistic understanding of the creep process, and its relationship to the rapid intergranular cracking behavior observed in crack propagation testing of some candidate materials in steam.

\section{Results}

Testing during Phase 2 focused on the prime candidate structural alloys.

A small number of notched bar creep rupture tests were performed in steam and air.

To evaluate a comparison structural material, several smooth bar rupture tests were performed for Phase 2. 
No conclusions are possible for data taken to date in Phase 2.

Creep testing of gas path materials in Phase 2 was limited. Several rupture tests of single crystal René N5 were performed.

\section{Discussion}

More notch specimen testing is required before a firm conclusion can be drawn on the notch sensitivity of any of the alloys. As a result, interrupted creep tests are planned to investigate the effects of periodic unloading on the rupture time. There are a number of different micromechanisms that might contribute to reduced creep performance in a specimen experiencing unloading even at very long periods.

It also emphasizes the need for testing of materials which are candidates for use in the advance machine gas path components and which will contain grain boundaries perpendicular to a high applied stress.

\section{SLOW STRAIN RATE TENSILE TESTS}

\section{Introduction}

Slow strain rate tensile testing has been used as an effective way to screen materials for susceptibility to stress corrosion cracking phenomena. If the strain rate is slow enough, there is time in a tensile test for the environment to interact with the metal while it is being dynamically strained and under a high stress. Establishing such a technique in this program would provide a screening vehicle to define the boundaries of conditions (environment and temperature) might occur for a variety of alloys.

\section{Testing}

This technique was tried on one of the structural materials to compare steam, air, and inert environments. For screening purposes, a temperature of $593 \mathrm{C}(1100 \mathrm{~F})$ and a strain rate of $0.6 \%$ per hour were chosen. Tests were run on solid, round, uniform-gauge section specimens. The tests were run in displacement control in an autoclave, and time and load were measured. This testing mode results in a plastic strain rate that is essentially constant, although the strain rate in the elastic regime is considerably slower. The testing mode allows calculation of engineering stress and engineering plastic strain.

\section{Discussion}

The technique looks like a good one to enhance the studies to be conducted in Phase 3 .

\section{MICROSTRUCTURAL AND FRACTURE SURFACE ANALYSIS}

\section{Introduction}

During hold-time cycling, fatigue cracks that are time-dependent tend to grow intergranularly. Since the local grain boundary environment (e.g., types of precipitates and amount of grain 
boundary coverage by precipitates) may influence the fatigue crack propagation (FCP) behavior of Ni-base superalloys, transmission electron microscopy (TEM) has been used to characterize the alloy sample microstructure. This was done both far from the crack tip and just ahead of the crack tip. In order to develop an understanding of how the test environment and alloy chemistry may affect the susceptibility to time-dependent crack propagation, Auger spectroscopy and TEM were used to study the types and sequences of oxide layers formed during the test.

\section{Sample Preparation Methods}

TEM was done on FCP samples that were broken open after testing, and on specimens ("damage zone samples") that were not broken open, allowing examination of areas ahead of the crack. Grain boundaries close to and far from cracks were examined by extraction replication and thin foils. In some damage zone samples, the crack was filled with epoxy, and the sample was then ion milled. This allowed examination of the oxide layers in the crack.

Auger analysis was done on samples broken open outside the Auger chamber. Spectra were taken prior to sputtering, and after sputtering at 2-minute intervals, generating compositional profiles through oxide layers. Profiles were taken on the fracture surface at different distances from the notch, and on the sample side.

\section{Auger Analysis}

\section{Experimental Variability}

Auger spectroscopy was used to characterize the composition of oxide layers on the fracture surface at various distances from the notch, and oxide layers on the side of the sample near the fracture surface and far from the fracture surface.

Initial Auger spectra helped establish the best parameters for this work, and the degree to which the data could be interpreted quantitatively.

On fracture surfaces there were extremely large fluctuations in oxide thickness, as measured by sputtering in the Auger microscope, which did not correlate with testing exposure time. Some variability resulted from different sputtering conditions. However, the main factor was the angles between individual grain facets or boundaries and the ion beam. Small differences in angle can result in very large differences in apparent oxide thickness even when sputtering conditions are nominally the same. Because of this variability, compositional data are shown as a function of sputtering time, and not layer thickness.

There can also be errors in concentrations calculated from the Auger electron peaks. This is especially high for elements that were not present in large amounts, such as $\mathrm{Ti}, \mathrm{Al}, \mathrm{Mo}$, and $\mathrm{Nb}$. For major elements, such as $\mathrm{Ni}, \mathrm{Fe}, \mathrm{Cr}$ and $\mathrm{O}$, the values are semi-quantitative, and can be used for comparisons between regions. 


\section{Damage Zone Samples}

A rim microstructure structural alloy FCP sample was tested under hold-time conditions at $482 \mathrm{C}(900 \mathrm{~F})$ in steam, in order to allow development of a "damage zone" ahead of the crack tip if such a phenomenon will occur. On extraction replicas, precipitates on a grain boundary that intersected the crack close to the crack tip were identified as MC carbides and eta-phase. This result is consistent with observations made on alloy rim microstructure far from possible influence of the crack environment. There was no evidence of oxidation of intergranular phases, and no oxides were extracted from grain boundaries or from the matrix regions near the crack.

The microstructure of the matrix and grain boundaries near the crack tip was very similar to those far from the crack. It is possible that there are changes in grain boundaries near the crack tip, such as the presence of diffused oxygen, but this would not be detected by TEM analysis.

\section{TECHNOLOGY APPLICATION}

The materials properties data obtained in this task will be utilized in the design of the steamcooled ATS machine components.

\section{PLANS FOR PHASE 3}

Phase 3 will emphasize screening of materials, supporting design efforts, and evaluating component life and failure mechanisms.

\section{SUMMARY}

The effort on Task 8.2.1 (Materials Coolant Compatibility) has been completed.

This Phase 2 effort has established the test capability to evaluate environmental effects on candidate structural and gas path materials under consideration for use in advanced turbine systems. A summary of that test capability is given Figure 8.2.1- 6 . 
Crack propagation in steam and steam $/ \mathrm{H}_{2}$ mixtures is fully developed with one standard station and one partial pressure control station
There are now six stations capable of steam testing of creep and/or dead weight loaded crack propagation specimens
Capability is fully developed to perform steam testing on tubular low cycle fatigue (LCF) specimens with one dedicated station
Two stations are fully configured for notched, sustained peak low cycle fatigue testing in steam

Figure 8.2.1-6. Summary of Existing Test Equipment with Steam Environmental Capability

Initial testing has begun to characterize the behavior of these materials. The emphasis has been on testing in steam environment under loading histories consistent with advanced turbine systems. These results are being used to guide materials selection.

This task has also included initial work on establishing mechanistic understanding of timedependent crack growth. 


\section{TASK 8.2.2 - ROTOR MATERIALS COOLANT COMPATABILITY}

\section{OBJECTIVE}

The objective of this task is to evaluate the effect of oxygen partial pressure on high-temperature crack propagation and crack tip oxidation in a material anticipated for rotor structural application in ATS gas turbines. This evaluation will be accomplished by using hydrogen/water vapor/inert gas mixtures to control the equilibrium atmospheric oxygen partial pressure in the test chamber over a wide range of values. Compact tension specimens will be used to evaluate crack propagation properties.

\section{PROCEDURE}

\section{STARTING MATERIALS}

Compact tension specimens were taken from a structural alloy forging. Specimen orientation was L-R (loading axis along longitudinal forging direction, crack propagation direction along radial forging direction).

\section{CRACK PROPAGATION TESTING APPARATUS}

Crack propagation testing was performed on a servohydraulic test frame using reversing dc electrical potential drop (RDCEPD) crack length monitoring to provide a constant stress intensity through closed-loop load control.

The test specimen was enclosed in a 4-liter (1-gallon) stainless steel autoclave. The loading actuator entered the autoclave at its base and was sealed with a vacuum bellows. Electrical potential drop wiring and control thermocouples were introduced to the test chamber through 3/8-inch stainless steel Swagelock feedthroughs. The flowing gas mixture used to maintain the atmospheric oxygen partial pressure entered and exited the test autoclave through heated 1/4inch stainless steel tubing and Swagelock fittings.

For all but one test specimen, oxygen partial pressure in the test atmosphere was controlled using a flowing gas mixture containing various partial pressures of hydrogen, water vapor and argon. One additional test was performed using a mixture of oxygen, argon, and water vapor. The moisture content of the test atmosphere was controlled using the delivery system shown schematically in Figure 8.2.2-1. 


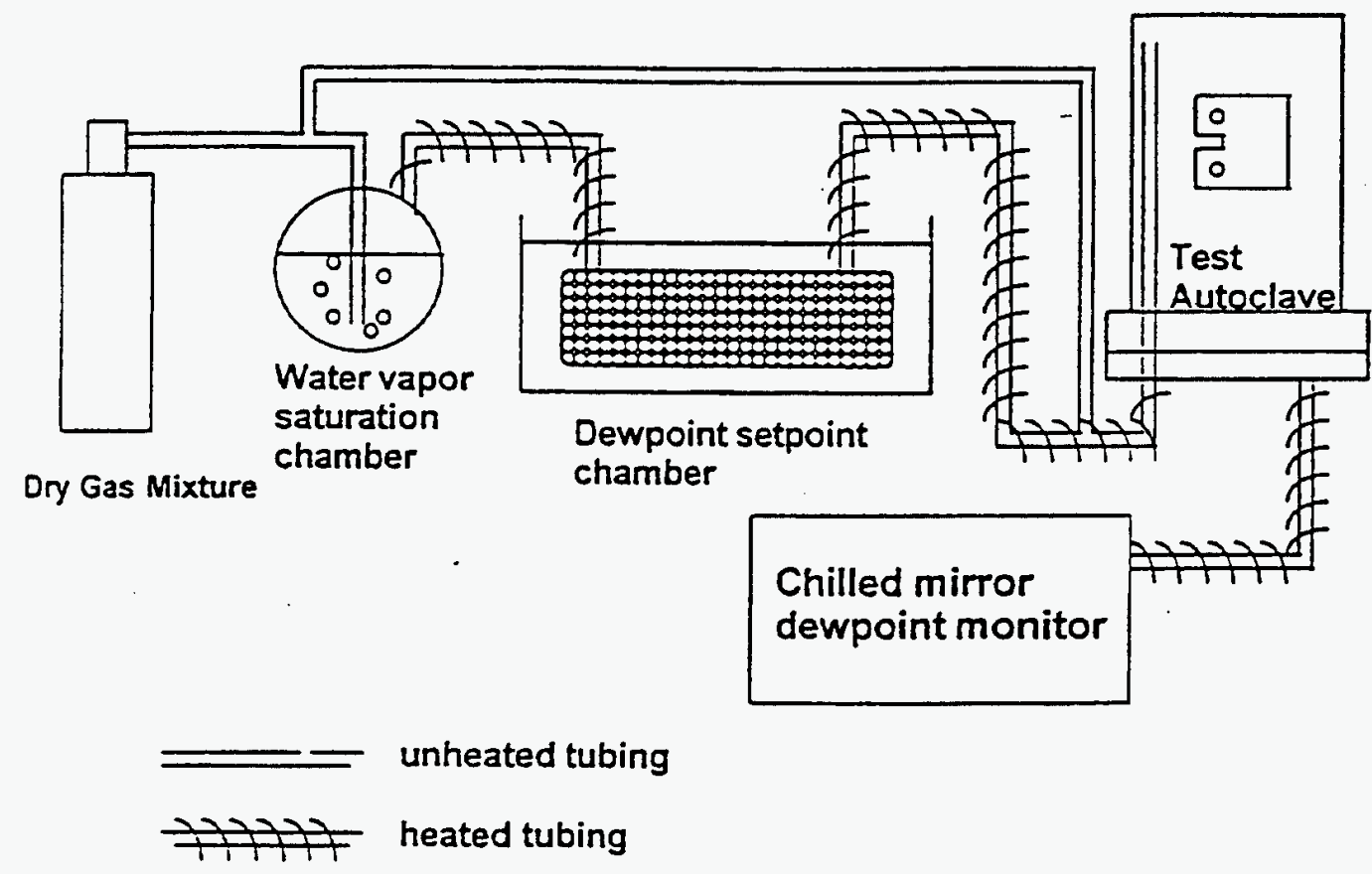

Figure 8.2.2-1. Schematic Diagram of the Gas Moisture Control and Delivery System Used in this Study

Incoming gas mixtures were introduced into the top of the test autoclave, while effluent gasses were removed through the base of the autoclave through heated 1/4-inch stainless steel tubing. The measured dewpoint of moist gas mixtures was found to be within $\pm 1^{\circ} \mathrm{C}$ of the constant temperature water bath temperature, and all dewpoint measurements were within $\pm 0.5^{\circ} \mathrm{C}$ of the reported average value.

\section{TEST SPECIMEN AND CRACK PROPAGATION DATA ANALYSIS}

Compact tension specimens with a fracture mechanics width of $40.6 \mathrm{~mm}$ (1.6 inches) and a thickness of $6.35 \mathrm{~mm}(0.25 \mathrm{inch})$ were used for all testing. All other specimen dimensions conform to ASTM standard E647.

\section{TRANSMISSION ELECTRON MICROSCOPY AND AUGER ELECTRON SPECTROSCOPY}

Transmission electron microscopy (TEM) was performed on compact tensions specimens that had been tested in a given environment at 593C (1100F) and were then sectioned using a diamond saw, and thin foils containing the crack tip were prepared by ion-milling of a dimpled foil. Phase identification was performed using X-ray compositional spectra and analysis of selected area diffraction patterns. 
Auger electron spectroscopy (AES) sputter depth profiling was used to perform compositional analysis through the oxide scale at various locations on the fracture surfaces of specimens that had been tested in a given atmosphere at various cyclic frequencies. Analysis was performed with a Phi 600 Scanning Auger Electron Spectroscope operated at $10 \mathrm{kV}$. Spectra were obtained from a single location in the sputter crater at 2-minute intervals.

\section{RESULTS}

\section{FATIGUE CRACK PROPAGATION}

Three studies of the effects of oxygen partial pressure and water vapor partial pressure on the time-dependent crack propagation ratein structural alloys were performed.

In the first study, crack propagation rates were measured at a constant stress intensity range of $\Delta \mathrm{K}=27.5 \mathrm{MPa} \mathrm{m} \mathrm{m}^{1 / 2}\left(25 \mathrm{ksi} \mathrm{in}^{1 / 2}\right)$, load ratio of $\mathrm{R}=0.1$ and a temperature of $593 \mathrm{C}(1100 \mathrm{~F})$ as a function of cyclic period for a given gas mixture. For each gas mixture, these data were collected from a single specimen by periodically increasing the cyclic period during a test. The final condition was one in which the cyclic loading was stopped entirely and a constant stress intensity of $30.5 \mathrm{MPa} \mathrm{m}^{1 / 2}\left(28 \mathrm{ksi}^{\text {in }}{ }^{1 / 2}\right)$ was maintained. Gas mixtures of dry hydrogen, moist argon, and laboratory air were investigated.

In the second study, crack propagation rate was measured as a function of oxygen partial pressure at a constant sustained stress intensity of $\mathrm{K}=30.5 \mathrm{MPa} \mathrm{m}^{1 / 2}$ and temperature of $593 \mathrm{C}$ $(1100 \mathrm{~F})$. This testing was performed on a single specimen by periodically changing the gas mixture composition during testing. Thirty six orders of magnitude in oxygen partial pressure were spanned during this testing by varying the hydogen:argon ratio and dewpoint of the gas mixture.

A third experiment was run in which oxygen partial pressure was maintained at a constant value while the dewpoint was varied from $-57.5 \mathrm{C}$ to $+43 \mathrm{C}$. This was accomplished using a dry gas mixture of $0.5 \%$ oxygen in argon and adding various amounts of water vapor to the mixture. The amount of oxygen present in the dry gas mixture was orders of magnitude higher than any oxygen that would be generated from dissociation of added water vapor, and the oxygen partial pressure was therefore essentially constant for all dewpoints.

\section{TRANSMISSION ELECTRON MICROSCOPY AND AUGER ELECTRON SPECTROSCOPY}

TEM was used to perform oxide phase characterization from very near the crack tips of compact tension specimens in which sustained load crack propagation had occurred at a constant stress intensity of $30.5 \mathrm{MPa} \mathrm{m}{ }^{1 / 2}$ and a temperature of $593^{\circ} \mathrm{C}$. Thin foils were taken from three specimens, each of which had been exposed to a different gas mixture, corresponding to three very different oxygen partial pressures. In each case, an area of the fracture surface that was within $50 \mu \mathrm{m}$ of the crack tip was investigated. 


\section{CONCLUSIONS}

It cannot be determined from the results presented here whether diatomic oxygen or water vapor partial pressure plays the dominant role in controlling the rate of time-dependent crack propagation in the alloy tested. This task will be continued in Phase 3. 


\section{TASK 8.3: DETERMINATION OF DRIVING FORCES FOR THERMAL BARRIER COATING FAILURE}

\section{TASK 8.3.1 - TBC TESTING AND ANALYSIS}

\section{OBJECTIVES}

Development of thermal barrier coatings (TBCs) with improved life and reliability will require a comprehensive understanding of the mechanisms of degradation that occur during gas turbine service. There were multiple objectives in this task. One objective was the development and confirmation of methods to measure and predict TBC stress states as a function of thermal and mechanical strains. This capability is fundamental to all quantitative TBC design and life prediction methodologies. An additional objective was the development of a practical, versatile laboratory-scale thermal gradient exposure facility that is capable of simulating the extreme thermal conditions anticipated for TBCs in an advanced gas turbine. This atmospheric E-beam high gradient test facility will then be used to evaluate TBC-coated specimens in the thermal and stress states expected in service.

The specimen design ("tophat" specimen) for the E-beam thermal gradient test facility required further analysis and modification to ensure that it properly mimics the thermal and strain fields present in critical regions of a first-stage nozzle in an ATS gas turbine. Results from instrumented specimens were then used to compare observed versus predicted thermal and strain fields. Several geometric variables in the tophat design were varied to confirm analyses and define improved specimen configurations.

Improved instrumentation and detectors were developed for characterization of temperatures, fluxes, and strains in specimens tested in the E-beam thermal gradient test facility. Types of instrumentation and detectors developed include thin-film thermocouples, thin film strain gages, IR pyrometers, surface profile monitors and laser fluorescence of the thermally grown alumina layer. The measurement techniques must be compatible with the extremely harsh testing conditions and provide minimal interference with the intended temperature and thermal flux fields. The techniques will be used to further confirm validity of specimen designs and to provide monitors for feedback control during routine testing.

A new test specimen geometry for use with the atmospheric E-beam thermal gradient test facility was designed and analyzed to simulate thermal and stress conditions in the TBC near-critical fillet region of the first-stage nozzle. The fillets are between the airfoil and the inner and outer bands. The specimen geometry encouraged creation of TBC microstructures of the type generated in regions such as fillets that have restricted plasma torch access. Also, the new specimen was

designed to approximate geometry-dependent lifting stresses that are believed to contribute to TBC delamination. 


\section{TASK RESULTS/DISCUSSION/DESCRIPTION}

\section{FINITE ELEMENT MODEL VALIDATION}

Experimental measurements from thermally tested instrumented E-beam specimens ("tophats") were compared to thermal and strain fields predicted by using finite element analysis (FEA). Several geometric variables in the tophat design and test conditions were varied to confirm analyses. Overall, good agreement was obtained between thermocouple, pyrometer, and strain gauge readings in the experiment, and FEA predictions. The specimens were instrumented with strain gauges at 6 locations and with thermocouples at 13 locations. The strain gauge and thermocouple readings were compared with predicted values for several TBC surface and backside metal temperatures. The difference between the predicted temperatures and experimental results for all thermocouples was less than 20C. The FEA predictions of strain on the backside of the substrate also compared reasonably well with the results of the experiment.

\section{FLUX TEST AND TBC SURFACE TEMPERATURE CALIBRATION}

The objective of the flux test was to determine the TBC surface temperature error derived from the 10-micron Land Pyrometer. In this test, a set of 5 thermocouples was imbedded in the interface between the bond coat and the metal and a corresponding set of thermocouples was tack welded on the cold side of the metal of a tophat specimen. After installation of the thermocouples, the specimen was bond coat and TBC coated. The sample was thermally tested in the E-beam rig at various conditions, and calculations were performed using the thermocouple readings and the metal substrate properties to determine the $1 D$ thermal flux through the metal substrate. This ID thermal flux was then used to calculate the TBC surface temperature of the properties of the bond-coat/TBC layer.

\section{TBC OPTICAL PROPERTIES AND MEASUREMENT}

Reflectance data measured at Surface Optics Corporation for dense vertically microcracked $(\mathrm{DV} \mu \mathrm{C})$ and porous air plasma sprayed (APS) TBC yielded values of the index of refraction vs. wavelength. These data are important for various thermal transport calculations. For example, for the first time, the wavelength-dependent optical sampling depth can be computed for our TBC samples. We concluded that $98 \%$ of the radiation from a hot TBC coating comes from the top mil of the coating for wavelengths $(\lambda)$ longer than $13 \mu \mathrm{m}$. At a common pyrometer wavelength of $10.6 \mu \mathrm{m}, 98 \%$ of the signal emanates from the top 4 mils of the TBC (which may be a large percentage of the TBC thickness). Clearly, given that there are significant thermal gradients for the conditions in which TBCs are used, longer wavelength pyrometers provide less ambiguous "surface" temperatures.

A TBC surface temperature measurement facility was set up using a liquid-nitrogen-cooled mercury cadmium telluride $(\mathrm{HgCdTe}) \mathrm{IR}$ detector that is sensitive up to $15 \mu \mathrm{m}$. A $14 \mu \mathrm{m}$ filter was installed to allow only $14-15 \mu \mathrm{m}$ measurements. An optical system was set up (including cone-defining apertures, a focusing lens, and a chopper). Initial tests were performed by measuring the apparent surface temperature of a $\mathrm{NiCrAl}$ sample that was heated in air to $930 \mathrm{C}$ with a torch flame. The metal temperature was read with a welded thermocouple. With 
no filter in front of the detector, the signal at the detector was strong and indicated that the major flux was at $2.5 \mu \mathrm{m}$ at $850 \mathrm{C}$ (in good agreement with the peak of the blackbody curve at this temperature, $2.6 \mu \mathrm{m}$ ). Since it is preferable to measure TBCs at $\lambda>13 \mu \mathrm{m}$ to avoid TBC transparency, the detector was also tested with filters. Calibration and measurements at 2.5 $\mu \mathrm{m}$ and $\lambda>14 \mu \mathrm{m}$ have been carried out and show sufficient sensitivity of the detector at the expected measurement distance for the E-beam testing facility.

\section{EVALUATION OF TBC/BOND COAT/SUBSTRATE THERMAL PROPERTIES BY TRANSIENT HEATING}

Several thermal response experiments were performed and calculations made to evaluate the thermal properties of the TBC/bond-coat/substrate due to transient heating. If energy is delivered in a transient manner (e.g., a short pulse or a step or periodic function) to the top of the TBC, and the temperature of the top of the TBC is recorded vs. time, the product of thermal resistance, density, specific heat, and thickness can be deduced for the TBC. By comparing this with data from a sample with no TBC, the effusivity (i.e., the product of thermal conductivity, density, and specific heat) of the coating can be deduced. The temperature vs. time plot for these composite materials shows changes in slope corresponding to the transition regions between materials. The changes in slope are related to the square root of the ratio of the effusivities, with larger values resulting in more easily recognized signals.

\section{FILLET REGION TBC TEST}

Four cast single-crystal fillet tophats (Figure 8.3.1-1) were TBC coated. APS masking (Figure 8.3.1-2) was used to provide the geometric constraints found in the real hardware of the ATS gas turbine. This masking was used to ensure that the fillet tophat received the same TBC that will be applied to the actual part, since the nozzle platform and airfoil restrict access of the APS torch to the fillet region during TBC application and induce local flow fields, recirculation, and over-spray deposition peculiar to this area. Two coating trials were run to evaluate TBC deposition uniformity and microstructure. The first TBC coating run used the APS deposition parameters employed for the nozzle cascade test. These parameters resulted in a significant buildup in TBC thickness in the fillet. The second TBC coating run used robot programming modifications that improved the TBC microstructure and uniformity in the fillet and produced the expected ATS gas turbine. TBC microstructures. The fillet masking was then removed, a fillet protection masking applied and the flat portion of the tophat that had been exposed to the E-beam was TBC coated. Masking modifications were made to produce a smooth junction between the fillet region TBC and the tophat flat TBC. Four cast fillet tophats (Figure 8.3.1-1) were then TBC coated using this second set of coating parameters. These samples will be tested in the E-beam rig at conditions that closely simulate the high surface temperature, high thermal gradient, and high stress of the ATS gas turbine-application. 

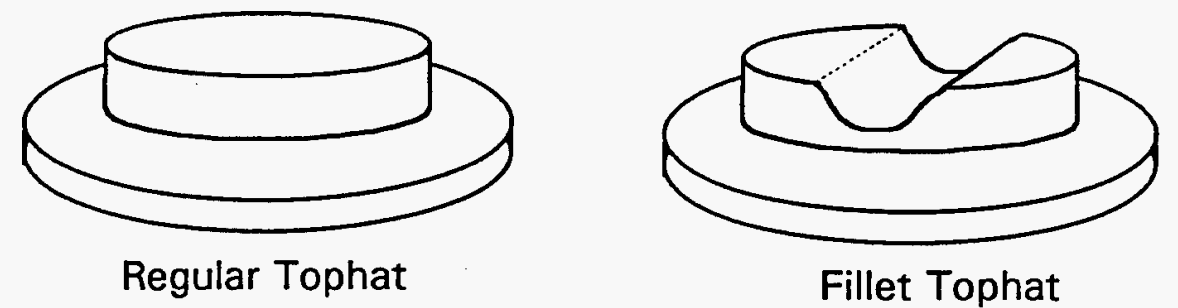

Fillet Tophat

Figure 8.3.1-1. Regular Tophat and Fillet Tophat

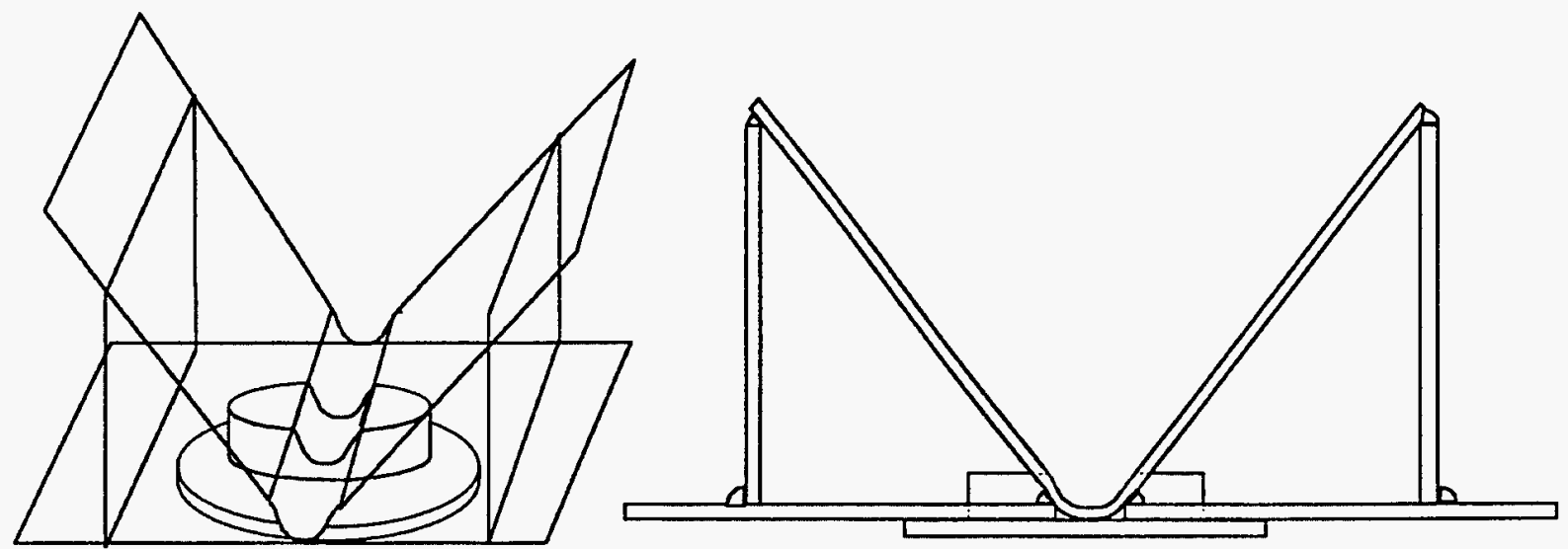

Figure 8.3.1-2. APS TBC Masking 


\section{TECHNOLOGY APPLICATION}

The TBC properties determined in this task will be used by GEPG designers to more accurately model TBC properties and life in ATS gas turbine conditions. The tophat numerical model and experimental instrumentation that was developed or refined in this task will be used to design and analyze future E-beam test samples to more accurately simulate ATS gas turbine conditions for TBC testing.

\section{PLANS FOR PHASE 3}

The E-beam test program will be continued in Phase 3.

\section{CONCLUSIONS}

The numerical model used to calculate the testing conditions required for particular TBC and substrate conditions (to simulate the ATS gas turbine) was validated by comparing experimental measurements from thermally tested instrumented tophats to FEA predicted thermal and strain fields. Modifications of the numerical model were then made to more accurately fit the experimental data. Several geometric variables in the tophat design and test conditions were varied to confirm the analyses. Overall, good agreement was obtained between thermocouple, pyrometer, and strain gauge readings in the experiment, and FEA predictions.

Optical data for porous and DV $\mu \mathrm{C}$ TBC have been taken, and analysis has extracted the desired optical parameters. This work determined that longer wavelength pyrometers provide less ambiguous TBC surface temperatures. The work was instrumental in selecting an optical pyrometer wavelength for precise TBC surface temperatures. Using this information, a TBC surface temperature measurement facility has been set up using a filtered $\mathrm{HgCdTe}$ detector. Calibration and measurements at $\lambda=2.5 \mu \mathrm{m}$ and $\lambda>14 \mu \mathrm{m}$ have been carried out. This detector will be installed in the E-beam testing facility.

A new "fillet tophat" test specimen was designed and analyzed to simulate thermal and stress conditions in the TBC near critical fillet region of the first-stage nozzle. The specimen geometry encouraged creation of TBC microstructures of the type generated in regions such as fillets that have restricted plasma torch access. APS robot programming modifications were made which improved TBC microstructure and uniformity in the nozzle fillet, to produce expected ATS gas turbine TBC microstructures in this region. These samples will be tested in the E-beam testing facility at ATS gas turbine conditions. 


\section{TASK 8.3.2 - LCF LIFE AND CRACK PROPAGATION}

\section{OBJECTIVE}

The objective of this task was to evaluate the low cycle fatigue (LCF) life of critical regions of the ATS turbine nozzle. LCF data were used to aid nozzle material selection and to determine cooling requirements. High thermal gradient E-beam testing was used to expose superalloy-TBC specimens to temperature and stress levels both representative of the ATS turbine nozzle and far in excess of expected conditions, to determine LCF life of the metal within reasonable test durations. Efforts have been focused on testing in support of the turbine nozzle development.

\section{APPROACH}

This task comprised pre-test design and analyses, testing of specimens under thermal-mechanical conditions representative of the ATS turbine nozzle life-limiting regions, and post-test data analyses and material evaluations. The principal method for developing the required conditions for the evaluation of LCF life is the generation of thermal and stress fields via CRD's High Thermal Gradient Electron Beam facility. This facility, and its attendant support equipment and instrumentation capabilities, is more fully described under Task 8.3.1.

The present task was initiated with a technical plan outlining the basic steps involved in reaching the objective. The plan in brief was:

- Several tophat specimens will be prepared for testing with helium cooling. The representative geometry to be used in this testing program is the plain tophat. Ribbed and fillet specimens may also be used in some limited fashion, but the geometry definition will be handled under a separate task. The number and severity of cycles for these pieces will be defined based upon analyses. Testing will serve to provide initial LCF data, to gain confidence in the LCF life of the turbine nozzle, and to validate the specimen analytic model.

- Each specimen will continue to be exposed to cycles, either the same or accelerated in strength, until failure occurs. It may also become desirable to deliberately spall the TBC. Failure will be defined as either TBC loss, or cracking of the substrate, or both. This testing will use helium as the coolant, but may also use steam if this provides more representative metal temperatures. These specimens will then be destructively evaluated. This data will further support LCF predictions and nozzle survival confidence.

- Model analysis will be performed for strains considered to be in the elastic range to match test data. If necessary, creep analyses may be employed to help interpret test results from accelerated conditions. 


\section{RESULTS}

\section{STRESS AND LIFE ANALYSES}

\section{Preliminary Analyses}

Design analyses carried out by CRD and GEPS engineers prior to the initiation of this task established the basic specimen geometries and their gross behavior with the main controlling parameters.

These analyses were used for the purpose of matching predicted stress levels in the lifelimiting regions of the ATS turbine nozzle, under design condition assumptions regarding material properties and TBC durability. The present testing seeks to obtain this same maximum stress level while also maintaining a reasonable match on temperature level and thermal gradient. Modifications to the system have been sought to increase this stress to the desired level. Several options were considered: (a) improved insulation over the perimeter top of the specimen; (b) addition of more integral rim material around the top of the specimens; (c) alteration of the E-beam profile; (d) coolant redistribution; (e) trussing the specimen brim region; and (f) stepping the substrate top thickness. All of these options seek to maintain the tophat sides in a colder state such that higher stresses are developed in the central region of the substrate. After analyses indicated a desirable outcome, two of these alternatives were chosen to act in conjunction,. The principal improvement was an increase in insulation efficiency.

Efficiency refers to the amount of E-beam flux that is allowed to penetrate through the insulation to the sides of the specimen. Perfect efficiency will not be obtained, but there appears to be sufficient leeway here to adjust the efficiency to the desired level. Provision for this increased insulation was made through a water-cooled copper shield placed above the specimen and fixture. This shield has a $5.08-\mathrm{cm}$ (2-inch) diameter hole in the center to pass through the E-beam flux to the specimen top surface. In conjunction with this action, the helium coolant impingement nozzle was modified to help maintain the tophat side walls at lower temperatures. It was also found that providing more "cold" rim material on the specimens could yield the desired stress states, but since this option involved more substantial changes to the basic specimen geometry, it was not pursued.

\section{LCF Analyses}

During the course of initial LCF testing, tophat analyses were performed by CRD and GEPS engineers in concert to determine a set of new test conditions required to obtain reasonably short test times while maintaining metal stress levels within the range of available isothermal LCF data.

Post-test analyses to validate temperature and strain predictions were performed using the experimental data from the LCF \#1 specimen. Analyses were carried out at two low temperature conditions. These temperatures resulted in cold-side metal temperatures which allowed survival of the instrumentation. In both cases, the comparison between the finite element model thermal prediction and the thermocouple readings from the interior of the tophat was very good, lending confidence to the thermal boundary conditions used in analysis. 
Experimental strain data included both radial and hoop strains. Again in both cases, the hoop strains indicated on the colder side walls of the tophat were in good agreement with prediction. However, the radial strains are not as close. Because of the thermal gradient increase, the magnitude of the measured strain increase between conditions did not follow the expected increase.

\section{Creep Analyses}

Creep analyses of the tophat specimen, under accelerated E-beam test conditions were performed to investigate the magnitude of the stress relaxation in the various materials and the resulting stress redistribution in the specimen. Parametric analyses of a tophat with creep effects in both the N5 substrate and the bond coat were completed. Results indicate that creep of the bond coat has a negligible effect on the substrate or TBC stresses, but does yield lower bond coat stresses. Creep of the N5 substrate results in considerable stress relaxation during the heat-up and hold periods, and puts the bond-coat/metal interface in a state of very high tension in cool-down. This creep, or inelastic deformation, occurs primarily in the first cycle, with minor changes in cycles thereafter.

Tensile stresses in the N5 at the metal/bond-coat interface increase by $8 \%$ after the second cool-down, and increase another $4 \%$ after the third cool-down. With a bond coat creep rate 100 times greater than that of $\mathrm{N} 5$, the bond coat creep effects appear to have little influence on TBC or N5 stresses.

Compared with the previously conducted elastic analysis, effects of stress relaxation in the N5 begin during the heat-up portion of the cycle, increase greatly during hold, and then go into very high tension upon cool-down. The tensile stresses are predicted to be greater than onehalf of the elastic stresses, probably due to permanent deformation. The alternating stress component is greater than one-half of the elastic stress, and there was a mean tensile stress. These analyses provide insight into the observed LCF specimen behavior noted later for specimens LCF \#1, \#2, and \#3, in which creep deformation was observed in the center of each specimen.

\section{HIGH THERMAL GRADIENT TESTING}

\section{Preliminary Testing}

Prior to making any of the test rig modifications described above, a fully instrumented tophat specimen coated with porous TBC was tested to determine the extent to which the current test system could push conditions. This test was a gauge to estimate the necessary extent of the modifications. The specimen was run for approximately 550 cycles. Each cycle consisted of a 15-second ramp up to maximum condition, a 2-minute hold time at maximum flux, and a 15 -second ramp down to zero E-beam flux. The TBC surface temperature reached approximately $1350 \mathrm{C}(2460 \mathrm{~F})$ as indicated by the pyrometer. The only failure that occurred was in the instrumentation lead connections away from the specimen. As the conditions were increased greatly from previous validation test conditions, the entire fixture temperature began to rise, indicating the absence of needed side wall cooling. Confirmation was obtained concerning the current maximum conditions and their resulting effect, as well as pointing to 
the regions requiring improvement. Additionally, it was found that the pyrometer needed to be calibrated against a known thermal source such that it may be reasonably extrapolated to the higher TBC surface temperature range expected in the next LCF tests.

E-beam rig modifications were completed to achieve higher specimen temperatures while maintaining elevated metal/TBC interfacial stress levels. The insulating cover of zirconia felt was replaced with a water-cooled copper plate with a center aperture for passing the required E-beam energy flux. The helium cooling jet array geometry was modified to direct more coolant to the tophat side walls and less to the top itself, thereby allowing high stresses to be developed at higher temperatures; i.e., in the tophat design, the cold side walls play a major role in stress developed at the metal/TBC interface. Also, a dielectric mirror was placed in front of the optical pyrometer, and the system was recalibrated for higher temperature capability against a black-body source. The pyrometer now senses TBC surface temperatures up to approximately $1700 \mathrm{C}(3090 \mathrm{~F})$.

\section{LCF Testing - LCF \#1}

Following modifications, LCF \#1, a new fully instrumented, plain tophat specimen, was installed in the rig. LCF \#1 has porous, Class C TBC, eight strain gauges, and thirteen thermocouples. The specimen was first tested at relatively low energy flux to measure the substrate cold-side strains and temperatures as a reference point prior to the imminent failure of the conventional strain gauges. Approximately 200 cycles were put on the specimen at this condition. A cycle is defined by a 15-second ramp up to peak level, a 2-minute hold at peak, and a 15-second ramp down to zero power.

The E-beam power level was subsequently increased to obtain the elevated conditions determined by analysis. After completion of 1200 cycles of testing without substrate failure, the specimen was removed for nondestructive evaluation (NDE). The specimen had developed a $4 \mathrm{~mm}$ by $4 \mathrm{~mm}(0.157 \times 0.157$ inch) blister in the TBC, near the center of the tophat. The TBC region in question showed evidence of cracking as well as lifting. NDE included eddy current inspection, thermal wave imaging, profilometry, and photography. The thermal wave imaging indicated the presence of a 6-mm (0.236-inch) diameter spot, which was interpreted as a delamination without spall. The specimen was replaced in the test rig and cyclic testing continued to 1500 cycles. Most of the cycles develop approximately $-830 \mathrm{MPa}(-120 \mathrm{kpsi})$ stress in the substrate at the interface with the bond coat. No substrate failure and no significant growth in apparent TBC delamination occurred. The specimen was again removed for NDE and subsequent destructive metallographic evaluation.

\section{LCF Testing - LCF \#2}

LCF \#2 was a duplicate of LCF \#1, coated with $250 \mu \mathrm{m}$ (10 mils) of NiCrAlY bond coat and $375 \mu \mathrm{m}$ ( 15 mils) of APS DV $\mu \mathrm{C}$ topcoat, nominally. TBC was tested to failure in the E-beam facility.

At approximately 1200 cycles, a large region of TBC spalled from the surface. This region was approximately $1.26 \mathrm{~cm}(0.5 \mathrm{inch})$ in width and extended across the entire hot region of the tophat. When the TBC that had spalled was removed, a large crack was clearly visible in 
the metal, approximately $0.6 \mathrm{~cm}(0.25 \mathrm{inch})$ in length and transverse to the TBC spall "path" or band. The test was halted, and the specimen removed for NDE and metallographic evaluation.

\section{LCF Testing - LCF \#3}

LCF \#3, coated with $250 \mu \mathrm{m}$ (10 mils) of NiCrAlY bond coat and $375 \mu \mathrm{m}$ (15 mils) of APS $\mathrm{DV} \mu \mathrm{C}$ topcoat, nominally, was tested under the same accelerated cyclic loading conditions as LCF \#1 and \#2. LCF \#3 was examined with ultrasound prior to testing, to acquire a baseline for possible crack detection via ultrasound at specified test intervals. The specimen was run for 350 cycles and removed for ultrasound inspection; no cracks were detected. The specimen was then run for another 160 cycles ( 510 total cycles), at which time a small blister was observed in the TBC, approximately $5 \mathrm{~mm}(0.2 \mathrm{inch})$ in diameter. Testing was halted, and the specimen was sent for ultrasound inspection. LCF \#3 will not be tested for further cycles.

\section{LCF Testing - LCF \#4}

LCF \#4, which has the same geometry and TBC as LCF \#3, completed cycle testing with no apparent distress. LCF \#4 was the first such specimen to have been processed without the Sibased masking tape which may have provided surface contamination to earlier pieces. This specimen also was run with somewhat reduced metal/TBC interface temperatures to avoid the apparent creep observed in the center of LCF \#3. The reduced conditions still developed approximately $-830 \mathrm{MPa}(-120 \mathrm{kpsi})$ in the substrate metal at the interface, but only with $815 \mathrm{C}(1500 \mathrm{~F})$ interface temperature. Ultrasound inspections at $0,500,1050$ cycles showed no signs of metal cracking.

\section{Bond Coat Crack Propagation Tests}

In addition to the LCF concerns associated with the superalloy substrate material of the turbine first-stage components, the bond coat between the substrate and the TBC has been identified as a possible source of crack initiation and propagation to the substrate. The current protective coating system to be used on the ATS turbine nozzle, calls for a NiCrAlY bond coat to be applied in a thickness of 0.25 to $0.50 \mathrm{~mm}(0.010$ to $0.020 \mathrm{inch})$ prior to application of the TBC topcoat. The bond coat provides both oxidation resistance and the roughened surface for topcoat adhesion. The bond coat is only slightly diffusive in nature, and provides a mechanically compliant layer between the load-carrying substrate material and the very much weaker TBC material. The NiCrAlY material is however not a single crystal material, and is known to crack. GE Aircraft Engines uses a PtAl, diffusive bond coat in much thinner layers, and has experienced the propagation of cracks initiated in the PtAl into the load-carrying substrate. PtAl is a much more brittle material than NiCrAlY. Based on the GEAE experience and the critical nature of the ATS turbine component protective system, it was decided to perform confirmation testing with the E-beam apparatus to determine the nature and extent of cracking in both $\mathrm{PtAl}$ and $\mathrm{NiCrAlY}$ coatings on N5 tophat specimens.

Three tophat specimens were prepared with various coatings, but without TBC. One tophat has approximately $75 \mu \mathrm{m}(0.003$ inch) diffused PtAl, the second has approximately $0.25 \mathrm{~mm}$ $(0.010$ inch $) \mathrm{NiCrAlY}$, and the third $0.50 \mathrm{~mm}(0.020 \mathrm{inch}) \mathrm{NiCrAlY}$. The test plan calls for 
exposing each tophat to approximately 1500 cycles, 500 at moderate conditions and 1000 at conditions similar in stress to that of LCF \#4. None of these specimens were expected to fail under these conditions, but each was expected to develop cracks within the bond coat. Posttest destructive measurements will determine the nature and extent of such cracking, and whether the cracks from NiCrAlY may be expected to propagate into the N5 substrate metal.

\section{PtAl Diffusion Bond Coat Specimen (DR3)}

The first of these specimens, DR3, has completed 1500 cycles of testing. Periodic fluoropenetrant inspections (FPI) have been performed to detect the initiation and growth of cracks in the PtAl, and whether these cracks grow into the substrate metal. After only 100 cycles, small cracks were detected in the PtAl, but these were only visible with the aid of FPI. During the course of testing, these cracks became more numerous and grew longer, but still only have slight opening widths of perhaps $12.7 \mu \mathrm{m}$ ( 0.0005 inch).

Due to the orientation of the current single crystal tophat specimens, which simulates the life-limiting region of the ATS turbine nozzle, the primary axis is oriented parallel to the face of the specimen. For such an arrangement, because the PtAl will prefer to crack along a direction perpendicular to the principal strain, surface cracks may be more likely to propagate along the surface rather than into the substrate. However, due to the biaxial stress state of the tophats, this conclusion can only be confirmed by metallography.

\section{NiCrA/Y Bond Coat Specimen (DR2)}

The DR2 specimen has $0.508 \mathrm{~mm}$ ( 0.020 inch) of NiCrAlY bond coat, which represents the design condition bond coat thickness for the leading edge of the ATS turbine nozzle. This specimen has completed the same number and severity of cycles as DR3. Under 100x magnification, cracks are apparent in the bond coat surface, but are not aligned in any particular direction, rather they appear to zig-zag through the valleys in the surface topography. As with DR3, these cracks have not appeared to widen with exposure time.

\section{NiCrAlY Bond Coat Specimen (DR1)}

The DR1 specimen has $0.254 \mathrm{~mm}$ ( 0.010 inch) of NiCrAlY bond coat, which represents the design condition bond coat thickness for the ATS turbine nozzle airfoil outside the leading edge region. At the time of this report, This specimen is being fixtured for future testing.

\section{NONDESTRUCTIVE EVALUATION AND METALLOGRAPHY}

\section{LCF \#1}

The first LCF specimen, LCF \#1, was sectioned for metallographic analysis. Magnified photographic inspection of the sections revealed several LCF cracks in the base metal, corresponding to cracks observed in the bond coat. A "reddish" material was also observed at the metal-TBC interface location in all areas where the TBC had lifted. 
Nine sections were made through the damaged region of the N5 substrate. Multiple cracks were identified in the metal along two predominant crack paths. According to the orientation of the specimen crystal, cracks propagated along the $\langle 111\rangle$ directions, which are the axes of highest Young's Modulus, and hence also form the highest thermal stresses. Cracks were predominantly Stage II type, being perpendicular to the loading, with little or no Stage I type, although some curvature was present in the cracking. This result is typical of N5 in uniaxial loading. For this biaxially loaded LCF specimen, this tends to support the design life methodology of using principal stresses; i.e., life is controlled by the maximum thermal stress. Cracks were initiated at the bond coat/N5 interface where mechanisms such as recrystallization depletion and grit blast cratering may be contributors, though no definite crack initiator could be identified. Observed bond coat cracking is thought to have little or no effect on LCF life; though many such cracks did correspond to the location of metal substrate cracks.

The red substance was analyzed and found to contain $\mathrm{Fe}, \mathrm{Cr}$, and $\mathrm{Ni}$. It was determined that the instrumentation vendor who has been installing thermocouples and strain gauges on each tophat specimen, was using an adhesive masking tape of unknown composition to "protect" non-instrumented surfaces during processing. This practice is in conflict with CRD requirements to use non-contact shielding for this purpose. A sample of this tape was obtained and analyzed and showed major elements to be $\mathrm{Si}, \mathrm{Ca}$, and $\mathrm{Fe}$, plus many more in small quantities. It was concluded that the most likely source of the red substance is the Fe from the tape, and is then in fact an iron oxide. At this time, it is unknown to what extent this contaminant may have contributed to specimen failure. Among specimens used in this task, LCF \#3 is the last specimen to have had the possibility of such contamination.

\section{LCF \#2}

Specimen LCF \#2 has undergone ultrasound inspection, revealing several major and minor cracks in the metal, in addition to the largest crack seen visually. This specimen has been sectioned to allow the fracture of the cracked region for fractography analysis to determine, if possible, the number of cycles to crack initiation.

The specimen was cut up to form a fatigue specimen, and then fatigued until fracture under well-controlled conditions. Scanning electron microscope (SEM) observations were made to characterize the initial metal crack. Macroscopically, the fatigue crack appeared to be heavily oxidized and had the classic "thumbnail" shape that is common for surface-initiated fatigue cracks (surface of the metal). The total crack depth was approximately $75 \%$ of the total metal substrate thickness. Well-defined fatigue striations were clearly present on the fracture surface. There was strong evidence for multiple initiation sites on the main crack. It appears that at least three cracks initiated and linked up later to form the main crack. No obvious metallurgical flaw could be associated with initiation. It was not possible to conclude whether crack initiation occurred in the TBC, bond coat, or substrate, although it can be said with confidence that the cracks did not initiate below the surface of the substrate. 
A high resolution SEM analysis was then performed to allow analysis of striations on the fracture surface. Both striation count and spacing were determined. The results showed that the fracture surface contained between 800 and 900 striations, and the crack propagation rate was lowest when the crack length was short, and highest at crack lengths greater than 0.686 $\mathrm{mm}(0.027 \mathrm{inch})$. Striation spacing appeared to be very uniform.

This specimen was exposed to 1500 cycles, the first 300 of which were somewhat slightly lower in stress. The engineering criterion for crack initiation is the formation of a $250-\mu \mathrm{m}$ (0.010-inch) crack. By this measure, the specimen had experienced 500 to 600 cycles since crack initiation, and therefore had a life of approximately 900 to 1000 cycles prior to crack initiation. This estimate is still somewhat unclear, since TBC lifting without removal occurred after approximately 1200 cycles.

\section{LCF \#3}

Post-test creep analysis of LCF \#3 specimen showed a permanent substrate deformation approximately $50-\mu \mathrm{m}(0.002$-inch) in the center of the tophat after two cool-down cycles of exposure. A surface scan of this specimen indicated a $125-\mu \mathrm{m}(0.005$-inch) TBC displacement near the center of the piece. This specimen had received approximately 510 accelerated cycles before developing a blister in the TBC, at which time exposure was halted. The analysis has indicated a high compressive strain in the TBC at the center of the tophat, which may be responsible for the TBC blister and metal deformation. The center of the tophat represents a singularity in the geometry. These results help explain the observed tophat behavior under accelerated conditions. Tests at lower temperature levels and gradients have not shown this behavior, and indicate that it is desirable to run LCF testing at somewhat less severe conditions even though test durations will be extended. That is precisely what was done for LCF \#4.

LCF \#3 specimen had been fatigued opened and is in process of examination and striation counting. A "peninsula" of material approximately $50 \mu \mathrm{m}$ wide by $75 \mu \mathrm{m}$ deep $(.002 \times 0.003$ inch), having the chemistry of bond coat, appears to be the site of crack initiation. A high temperature oxidized region is present in the substrate around this site. There are at least three thumbnail cracks. The initiation site is thought to be due to either machining galling or a substrate "flaw" that was filled by molten bond coat.

All of the LCF specimens reported on in this task were machined prior to coating. While this set of tests represents a fairly self-consistent data set, it is unlikely that it can be compared directly to other LCF data from uniaxial coupon tests. LCF testing to be performed under Phase 3 will use only as-cast surfaces for coating, which will more closely represent the machine design conditions for surface preparation.

\section{LCF \#4}

At the time of this report, no destructive evaluation has been performed on LCF \#4. 


\section{TECHNOLOGY APPLICATION}

Cyclic testing data obtained in the high thermal gradient E-beam test rig will be used in the design of improved TBCs for the $7 \mathrm{H}$ and $9 \mathrm{H}$ gas turbines.

\section{PLANS FOR PHASE 3}

Items left open at the time of this report will be completed under Phase 3. This includes testing of bond coat specimen DR1, destructive evaluations for LCF \#4 and bond coat specimens LCF \#1, $\# 2$, and \#3, as well as any associated post-test analyses.

Phase 3 efforts will focus on a set of best possible LCF test specimens that incorporate all of the experience gained from Phase 2 in order to obtain a database for LCF life prediction. 


\section{TASK 8.3.3 - BOND COATS FOR IMPROVED TBC THERMAL CYCLE LIFE}

\section{OBJECTIVE}

Recent experiments with alternate bond coat application techniques and alternate bond coat chemistries indicate that significant improvements in the thermal cycle life of a TBC system can be achieved through bond coat modification. An experimental matrix containing a bond coat chemistry other than the one proposed for use in the ATS TBC system will be established to assess the role of optimized bond coat processing on TBC thermal cycle life.

Bond coat process parameters will be selected to alter bond coat mechanical properties. All bond coats will be coated with an approximately 0.038 -cm-thick (0.015-inch-thick), dense, vertically microcracked $(\mathrm{DV} \mu \mathrm{C})$, air plasma sprayed (APS) TBC and evaluated in thermal exposure. Compressive shear resistance and other mechanical properties of the various TBC systems will be evaluated as a function of exposure time, exposure frequency, and exposure temperature in cyclic oxidation tests. The influence of bond coat properties on TBC life will be determined for the new system.

\section{BACKGROUND}

The experimental test matrix for sorting out failure mechanisms focuses on N5 as the alloy of choice coated with NiCrAlY Ni211 bond coat applied at a standard gun-to-substrate distance. In addition, two bond coats-NiCrAlY Ni211 and CoNiCrAlY Co129-applied at a longer than standard gun-to-substrate distance are also used. All specimens are coated with a top coat consisting of APS 8YSZ applied with torch parameters designed to produce a DV $\mu \mathrm{C}$ TBC microstructure.

Two thermal exposure cycles are used. One is a furnace cycle test (FCT) that heats up rapidly (approximately $75 \mathrm{C} / \mathrm{min}$ ) from ambient room temperature to a 45 -minute hold time at the selected maximum temperature with a forced air quench on each return to room temperature (cooling rate around $110 \mathrm{C} / \mathrm{min}$ ). The other is a furnace exposure test (FET) that uses a furnace power heat-up at approximately $40 \mathrm{C} / \mathrm{min}$ from room temperature to a 10 -hour hold at the selected maximum temperature followed by a furnace-power-off cool-down at around $45 \mathrm{C} / \mathrm{min}$. Tests run with FCT and FET are providing insight into the influence of cycle frequency and hold time at temperature on crack growth and failure in the thermally grown oxide, the bondcoat, or the ceramic layer.

The FCT matrix was expanded to examine in more detail the relationship between the number of cycles to failure and furnace-dwell-time/cycle for the NiCrAlY bond coated samples. FCT tests were to be conducted using dwell times of 6 minutes, 45 minutes, 10 hours, and 20 hours per cycle, at temperatures of 1037C (1900F), 1093C (2000F), and 1149C (2100F). 


\section{EXPERIMENTAL DETAILS}

\section{OPTIMIZED BOND COATS}

\section{Specimen Preparation}

Approximately 250 alloy buttons required for the study were prepared. Experiments were conducted to assess the effect of variations in bond coat parameters on bond coat microstructure.

The major differences in microstructures were in the amount of oxide in the bond coat layer and in the amount of unmelted particles in the coating. There was no distinguishable difference produced by using air instead of $\mathrm{N}_{2}$ as the carrier gas. Increasing the gun to substrate (GTS) distance increased the amount of oxide in the coating.

Metallographic assessment of the microstructural differences provided only a qualitative distinction between parameter changes. A more definitive measure was required before making a final selection of the parameters for the study. The elastic modulus of freestanding bond coats was chosen as the quantitative basis for coating selection, with lower moduli being better.

An attempt to free the bond coats from the steel substrate by differential etching in warm $\mathrm{HCl}$ was unsuccessful since attack of the bond coats was also observed to occur. Removal of the cold-rolled substrate was accomplished by mechanically machining the substrate away. The Young's modulus of the free-standing bond coats was measured by acoustic resonance techniques and by three point bending. The intent was to find a parameter for discriminating between changes in mechanical properties produced by variations in torch parameters.

\section{Furnace Exposure Testing and Furnace Cycle Testing}

Tests run with FET and FCT cycles were used to provide insight into the influence of cycle frequency and hold time at temperature on crack growth and failure in either the thermally grown oxide, the bondcoat, or the ceramic layer. FCT tests were conducted at four times for each temperature. The times were selected such that groups of specimens could be extracted at increasing times of exposure and, consequently, various degrees of thermal distress. The fourth time group was cycled to failure. FET tests were cycled only to failure without extractions at intermediate times.

Sample groups extracted prior to failure were evaluated metallographically to determine oxide growth rates and to determine the length, location, and nature of propagating cracks. The scanning electron microscope is used to evaluate microstructural changes in fracture surfaces of the TBC as a function of exposure time. Mechanical properties of the coatings at various stages of thermal cycling were assessed using tests for tensile pull strength, compressive shear strength of the attached coating, and Young's modulus of the detached coating. 


\section{Effect of Furnace Cycle Frequency}

\section{Specimen Fabrication}

The specimens were cut from a plate 4.5 -inch $\times 9.5$-inch $\times 1 / 8$-inch-thick cast singlecrystal with a $1 / 8$-inch stiffening rib running lengthwise along one side. The orientation of the single crystal relative to this stiffening rib was (001). Prior to coating, each plate was ultrasonically washed in isopropyl alcohol and grit blasted to produce a rough surface. A type $\mathrm{K}$ thermocouple was then spot-welded to the back face of each plate in order to monitor the substrate temperature during spraying. In the spray fixture, each plate was oriented with the stiffening rib at the top and facing away from the spray direction. The 10-mil bond coat and 20-mil TBC were then applied. After spraying, the plates were heat treated in a vacuum furnace at $1080 \mathrm{C}(1975 \mathrm{~F})$ for 4 hours and then $900 \mathrm{C}(1650 \mathrm{~F})$ for 4 hours consistent with the current planned GEPG heat treatment schedule.

The coated plates were water-jet cut to yield $25.4-\mathrm{mm}$ (1-inch) diameter button specimens. An orientation and identification number was scribed into the back of each button. In order to record the orientation and location of each sample, photographs were taken of each slab. The buttons were then removed, and the connecting tabs were ground flat.

\section{Furnace Calibration}

Furnace cycle testing was conducted in three new $\mathrm{CM}$ bottom-loading furnaces. Prior to testing, each furnace was calibrated.

\section{Furnace Cycle Testing}

Furnace cycle testing was conducted using four $\mathrm{CM}$ bottom-loading furnaces running simultaneously. Each furnace was programmed to yield the same soak temperature, and the same heating/cooling cycle ( 9 minutes to soak temperature, 10 minutes cool-down) but different dwell times at the soak temperature. The four dwell times chosen were 0.1 , $0.75,10$, and 20 hours per cycle. It is believed that the 0.1 hour/cycle is the shortest dwell time that can be achieved without significant corrections.

A typical FCT schedule for each furnace was designed to keep the furnaces as full as possible during testing. (N5 dummy specimens were not substituted for TBC specimens that were removed.) In each furnace there were 30 available specimen slots into which 14 groups, containing 3 specimens each, were cycled and replaced over the course of the FCT. Groups 1-3 yielded preliminary tensile data (at 5, 10, and 25\% of assumed life) which were used to estimate the total number of cycles required for failure. Groups 4-6 and 10 provided additional tensile data at intermediate times (up to approximately $90 \%$ life). In addition to the specimens cycled to failure (groups 11-13), a series of cumulative damage specimens were tested. In groups 7-9, samples were cycled for a specified number of cycles at one dwell-time/cycle, transferred to another furnace, and then cycled to failure. It was thought that these specimens would indicate the sensitivity of the TBC life to the previous thermal history of the TBC specimens. 


\section{RESULTS}

\section{OPTIMIZED BOND COATS}

\section{Furnace Cycle Testing}

FCT testing to failure at 1093C (2000F), 1149C (2100F), and 1204C (2200F) has been completed for all specimens. As anticipated, FCT lives are found to be shorter than FET lives at the same temperature for all specimens.

The furnace cycle lives of the specimens exceeded the initial estimates. In order to accumulate exposures representing 25,50 , and $75 \%$ of life, additional cycles were added to specimens that had been withdrawn prior to failure. All furnace cycling of fractional life specimens has been completed, and all fractional life specimens have been tested for tensile adhesion. Fractional life specimens are being examined for microstructure and thickness of thermally grown oxide. Modulus specimens have been prepared and are awaiting testing.

\section{TECHNOLOGY APPLICATION}

The information obtained regarding the cycle frequency influence on the temperature dependence of the bond coat failure mechanism will be incorporated into TBC design criteria.

\section{PLANS FOR PHASE 3}

There is no Phase 3 follow-on program.

\section{SUMMARY AND CONCLUSIONS}

An improvement in FET and FCT life over that previously observed for ATS standard bond coat applications was obtained by altering the bond coat application technique and/or the bond coat chemistry. Degradation of the optimum bond coat systems with furnace cycle exposure at different temperatures was evaluated using tensile adhesion testing and correlated with failure mechanisms identified via metallographic observations. The temperature dependence of the failure mechanism was found to be sensitive to the cycle frequency, an observation which should be taken into account when developing design criteria. Through extrapolation of data from hightemperature tests, two bond coats were identified which will satisfy the temperature design criteria of the ATS machine.

Quantitative studies of the dependence of TBC life on furnace cycle frequency have begun. 


\section{TASK 8.3.4 - CRITICAL TBC PROPERTIES}

\section{OBJECTIVE}

Accurate measurements of the thermal conductivity of thermal barrier coatings (TBC) are important for the thermal analysis and design of coated turbine components. Current practice uses conductivities that are measured using laser flash techniques that directly evaluate thermal diffusivity. The objective of this task was to develop a methodology and apparatus for measuring TBC thermal conductivity by an independent means. The effective thermal conductivities of various TBC systems - including TBC, bond coat, and metal substrate - are determined by a steady-state technique using one-dimensional heat flux. A comparative method was developed that uses a series of reference samples with known conductivities and compares their resultant steady-state temperature distribution with that of a TBC-coated specimen. By holding all boundary conditions constant during a series of tests, it is possible to deduce the unknown apparent thermal resistance of the TBC.

\section{SUMMARY OF THE METHOD}

The methodology of the thermal conductivity comparative technique is summarized in Figure 8.3.4-1. A flat disk with a large diameter-to-thickness ratio was chosen as the test specimen geometry in order to approximate a one-dimensional (axial) conduction network. An insulating medium is used as the fixture around the specimen in order to insure minimal radial heat losses. The energy source is a natural-gas/oxygen fired torch with output directed toward one face of the sample (for TBC-coated specimen, the "hot side" is the TBC side). Forced air cooling is used on the opposite face to set up a steady-state temperature gradient through the thickness of the specimen. The resulting steady-state temperature distribution in the specimen is dictated not only by the convective and radiative boundary conditions (e.g., flame temperature) but also by the apparent thermal resistance, $\mathrm{L} / \mathrm{k}$ ( $\mathrm{L}=$ thickness and $\mathrm{k}=$-thermal conductivity), of the specimen. As indicated at the right of Figure 8.3.4-1, two different specimens with identical thermal resistances will have identical surface temperatures if the boundary conditions are held constant. This concept is exploited in the present method by varying the thermal resistance of a reference specimen until it matches that of a similar TBC-coated specimen as determined by matching surface temperatures. 


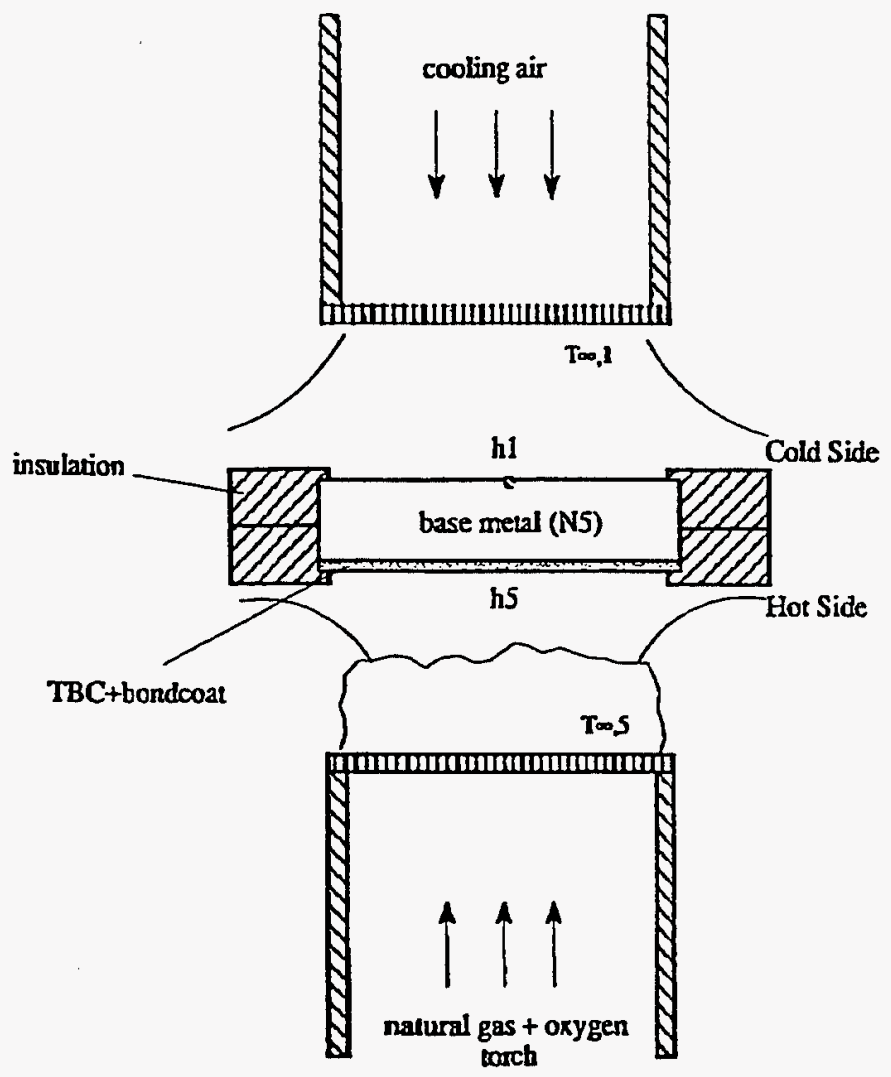

\section{Thermal Resistance Matching}
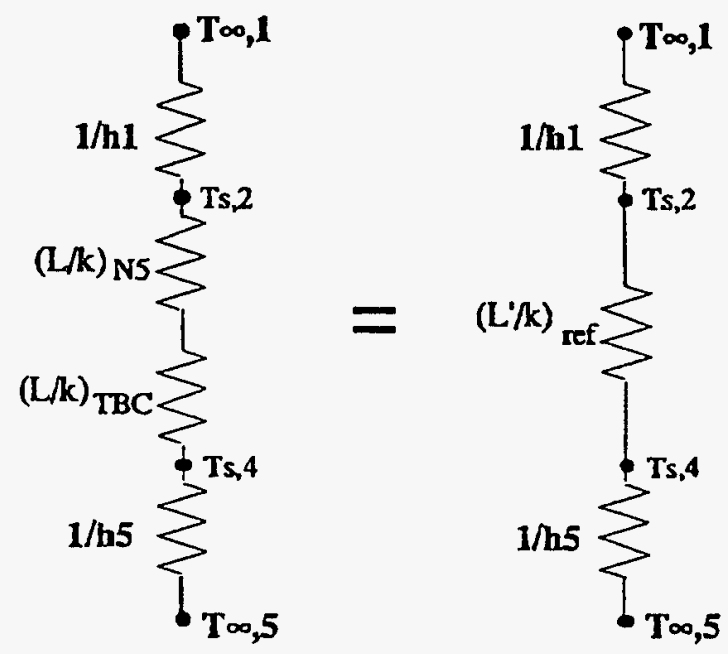

Figure 8.3.4-1. Steady-State TBC Thermal Conductivity Test Methodology

The reference specimens to date were fabricated of structural alloy material, which also acts as the base metal for the TBC-coated specimen. Reference disks of various thicknesses were fabricated in order to bracket the suspected thermal resistance of a TBC-coated specimen with a coating thickness of up to 0.040 inch. The experimental technique involves setting up steady-state boundary conditions with the cooling air and torch and, subsequently, rotating each specimen into the heated zone until steady-state conditions are achieved. The surface temperatures of the specimen are determined by infrared thermography or thermocouples welded to the surface. After all samples have been rotated through the test zone, the surface temperatures of the reference samples are compared with those of the TBC-coated sample. The apparent TBC thermal conductivity is deduced by determining the thickness of the reference sample that gives the best surface temperature match and then calculating the TBC conductivity that yields an identical thermal resistance.

\section{EXPERIMENTAL APPARATUS}

A sketch of the experimental rig is shown in Figure 8.3.4-2. Currently, a stainless steel disk capable of holding five specimens is used as the test support. The heating torch and coolingair nozzle are rigidly fixed relative to the disk so that they are not disturbed during a run. A gear assembly attached to the drive shaft rotates the specimen wheel remotely as required to bring a new specimen to the hot zone for evaluation. A consistent positioning of the new specimen relative to the flame and cooling jet is achieved by a tapered locating pin and 
machined locating holes in the specimen wheel. The specimens are 1 -inch diameter flat disks with thicknesses ranging from 0.125 to 0.500 inch. The fixture used to support and insulate the specimen is a 4-inch diameter split ring fabricated of machinable alumina silicate with a thermal conductivity of $1.08 \mathrm{~W} / \mathrm{m} / \mathrm{K}$.

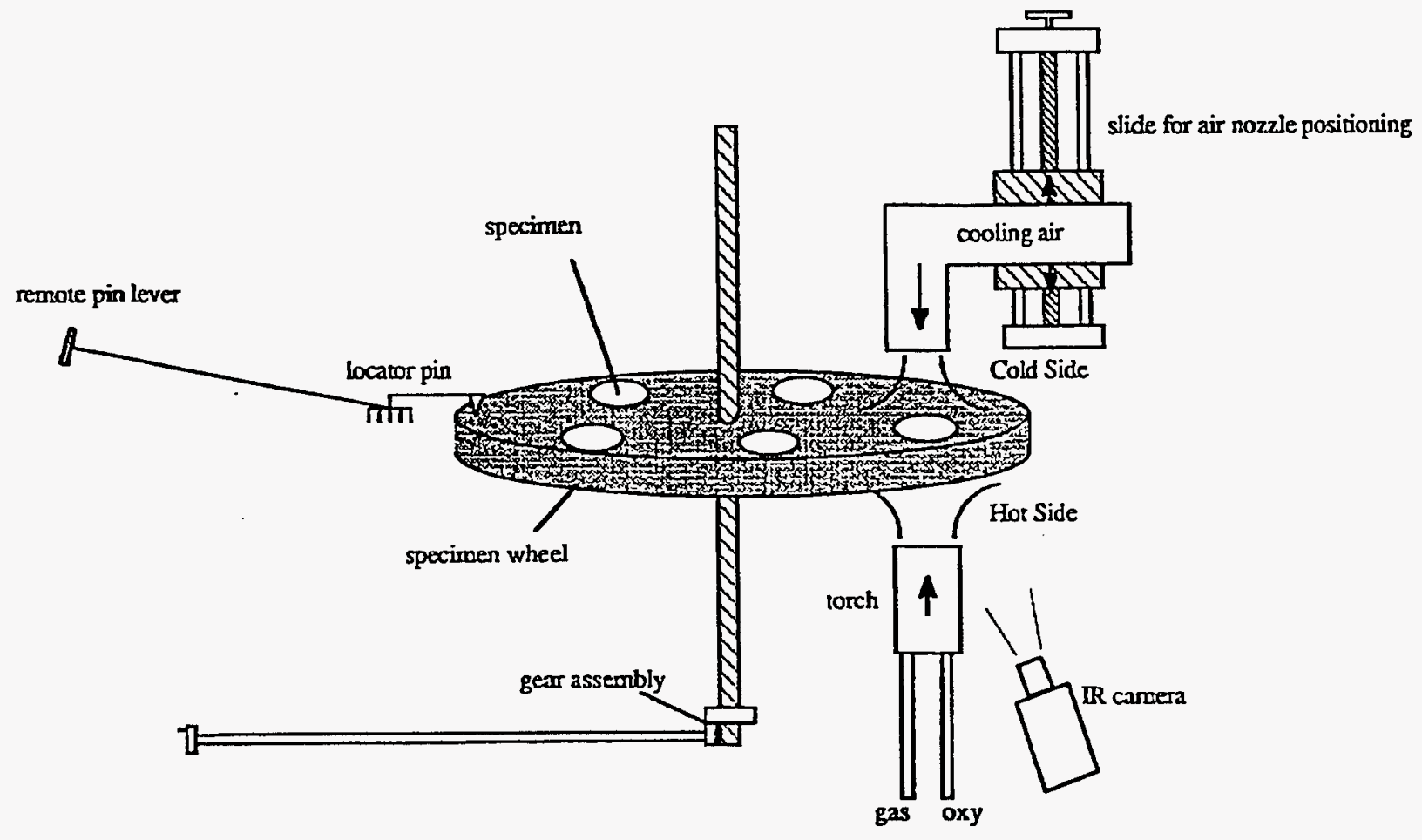

Figure 8.3.4-2. Sketch of TBC Thermal Conductivity Rig 


\section{RESULTS}

Before the experimental phase of this program was begun, a steady-state, one-dimensional heat conduction model was developed in order to guide the experiments and provide a method to determine the expected results. This model contains radiative and convective boundary conditions on both sides of a disk with no radial losses (ideally one-dimensional). The material properties for TBC, bond coat, and sample disk are all assumed constant at values consistent with the mean temperature of the sample. The analytical model is useful because it makes it possible to quickly assess the effect of the many variables involved for both reference and TBC-coated samples. Most important, the effect of varying the reference sample thickness for fixed boundary conditions is easily simulated to give the expected trends in reference sample surface temperatures as a function of thickness. Figure 8.3.4-3 is an example of the model results for a mean sample temperature of approximately $1900 \mathrm{~F}$. Increasing the reference material disk thickness should, according to the one-dimensional model, increase the hot-side surface temperature, decrease the cold-side temperature, and increase the temperature difference across the sample for fixed boundary conditions.

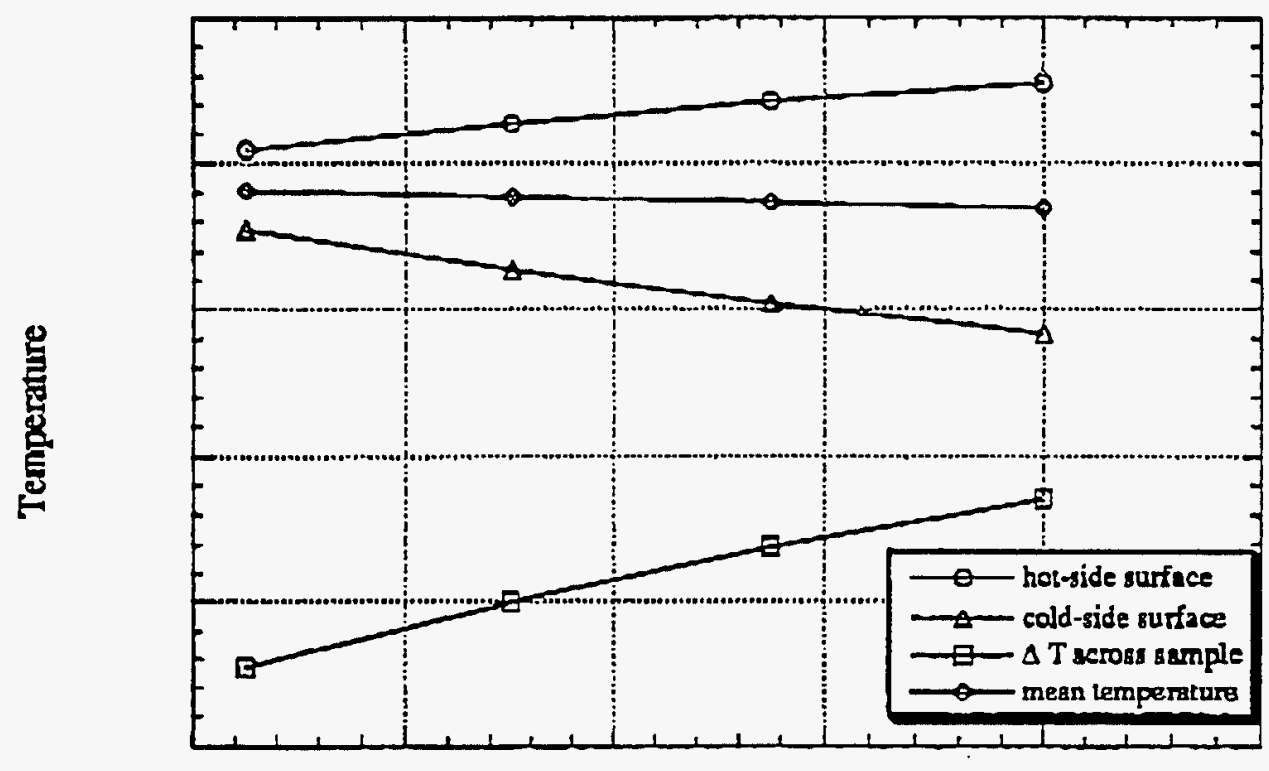

Thickness

Figure 8.3.4-3. Example of Modeling Results

The first sets of experiments with the thermal conductivity rig were used to document the extent to which a steady-state system could be achieved and to map the operating limits of the existing equipment. To examine how steady a "steady-state" condition the rig produced, long-term monitoring of the system temperatures was carried out at various operating conditions. Figure 8.3.4-4 is a representative plot of cold-side surface temperature over a 20 -minute period after sample heat-up had been completed. Excellent long-term stability of the system is shown with typical surface temperature variations of less than $\pm 0.5 \%$ for temperatures up to $1850 \mathrm{~F}$. Clearly this long-term stability is important since a typical run of five specimens may take up to 20 minutes. 


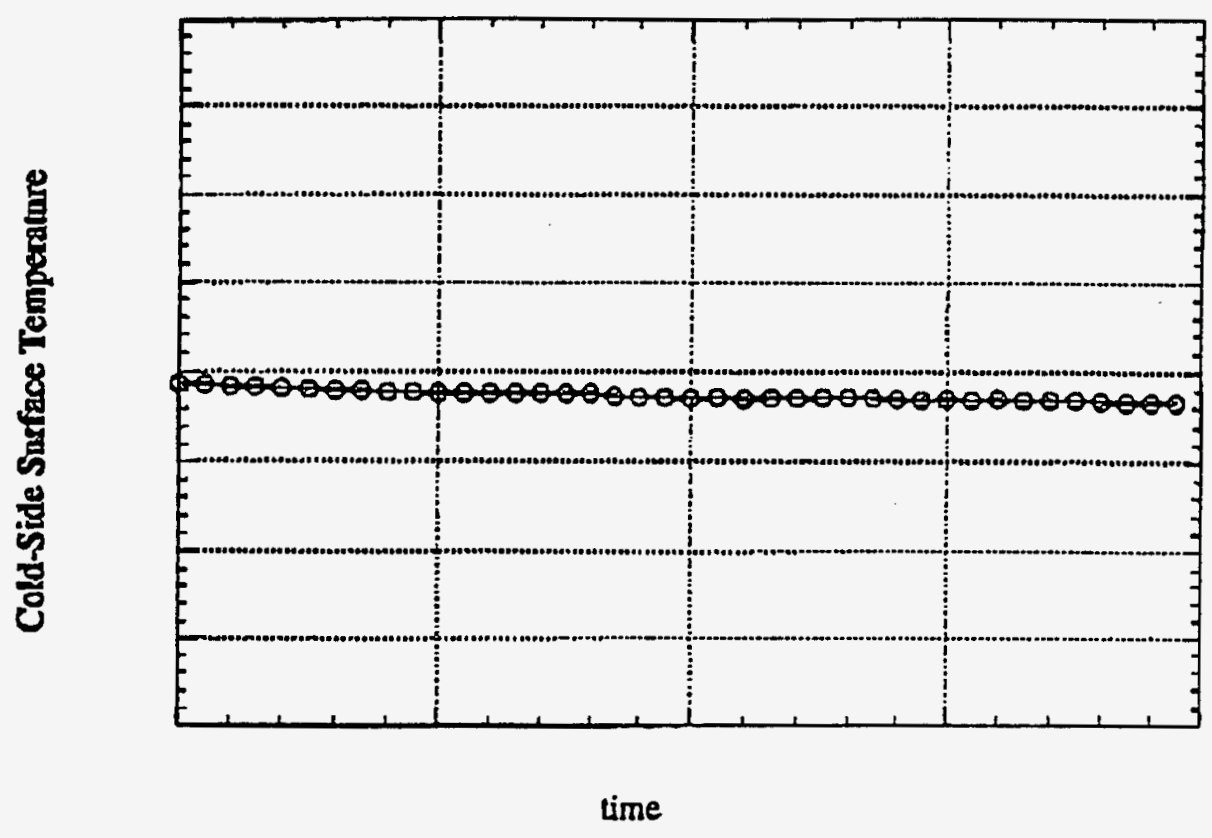

Figure 8.3.4-4. Example of Long-Term Monitoring Runs for Rig Thermal Stability

At the completion of the stability tests, several experiments were conducted to determine the operating limits of the rig; i.e., how high a surface temperature could be achieved and how large a thermal gradient could be generated across a typical specimen. It was determined that the natural-gas/oxygen torch was more than adequate to generate hot-side surface temperatures in excess of $2200 \mathrm{~F}$. In fact, flame temperatures exceeded the capability of a typical type B thermocouple that is rated to $3092 \mathrm{~F}$. The mean temperature in the specimen is controlled by the fuel flowrate to the torch and the flowrate of the cooling air, both of which are easily controlled. Figure 8.3.4-5 shows a typical distribution of surface temperatures at various fuel flow settings (mean sample temperatures) for a 0.313 -inch thick disk specimen. At the highest temperature shown, the temperature difference is approximately $800 \mathrm{~F}$, which translates to a gradient of $2.6^{\circ} \mathrm{F} / \mathrm{mil}$ through the disk sample. Should higher temperature gradients be required in future tests, additional fuel to the torch and cooling air to the jet can be added simultaneously. 


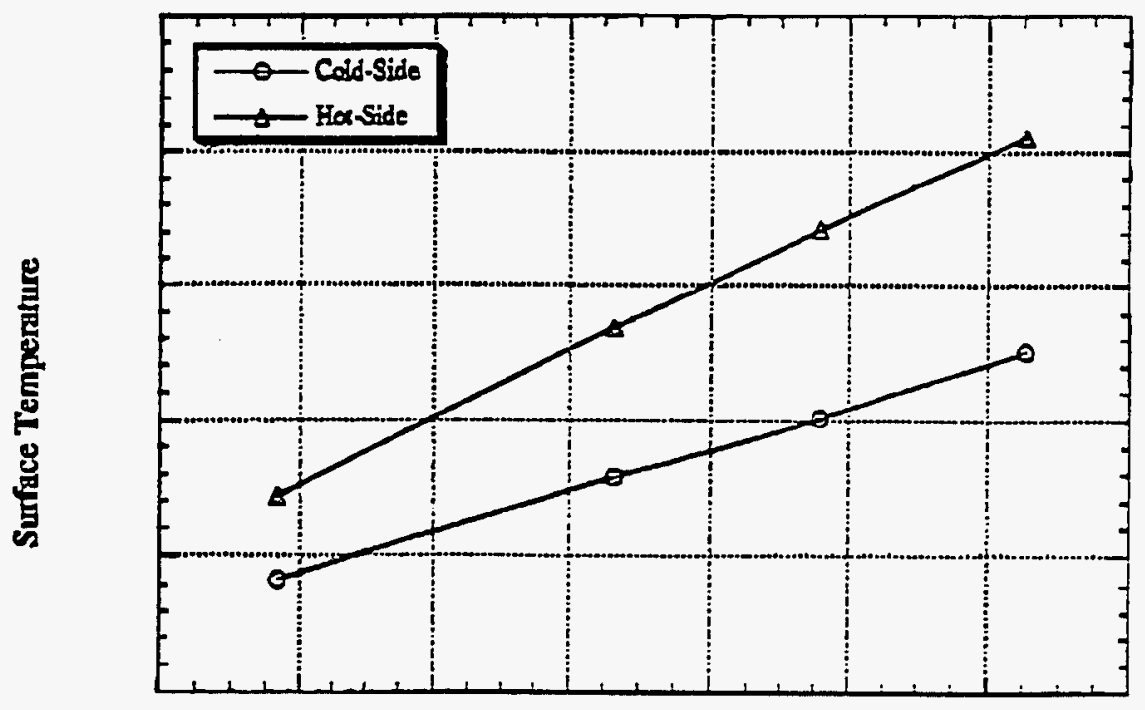

Mean Specimen Temperature

Figure 8.3.4-5. Typical Operating Range for 0.313-inch Thick Specimen

In order to test the feasibility of the method, the surface temperatures of the reference samples were measured at a fixed set of torch and cooling jet operating conditions and compared to the expected trends indicated by the model (see Figure 8.3.4-3 for representative trends). Figures 8.3.4-6 and 8.3.4-7 show the cold-side temperature and hot-side temperature dependencies on sample thickness, respectively, at two different boundary condition settings. Notice that the cold-side temperature decreases linearly with sample thickness as predicted by the analytical model. However, the hot-side temperature does not show a linear increase in temperature with sample thickness as the model suggests; instead, the hot-side temperature shows a gradual decrease. The figures show typical results of several runs that were made in an effort to investigate the cause of this unexpected trend. Many parameters affect the energy balance on the hot-side of the specimen including: surface emissivity, surface roughness, flame radiation, and radial conduction losses. At the conclusion of our initial tests, we have yet to determine the cause or solution to the unexpected hot-side temperature distribution. Systematic tests are needed to define the most important variables that determine hot-side temperature. Subsequently, closer control of those parameters should lead to a self-consistent set of TBC thermal conductivity measurements. 


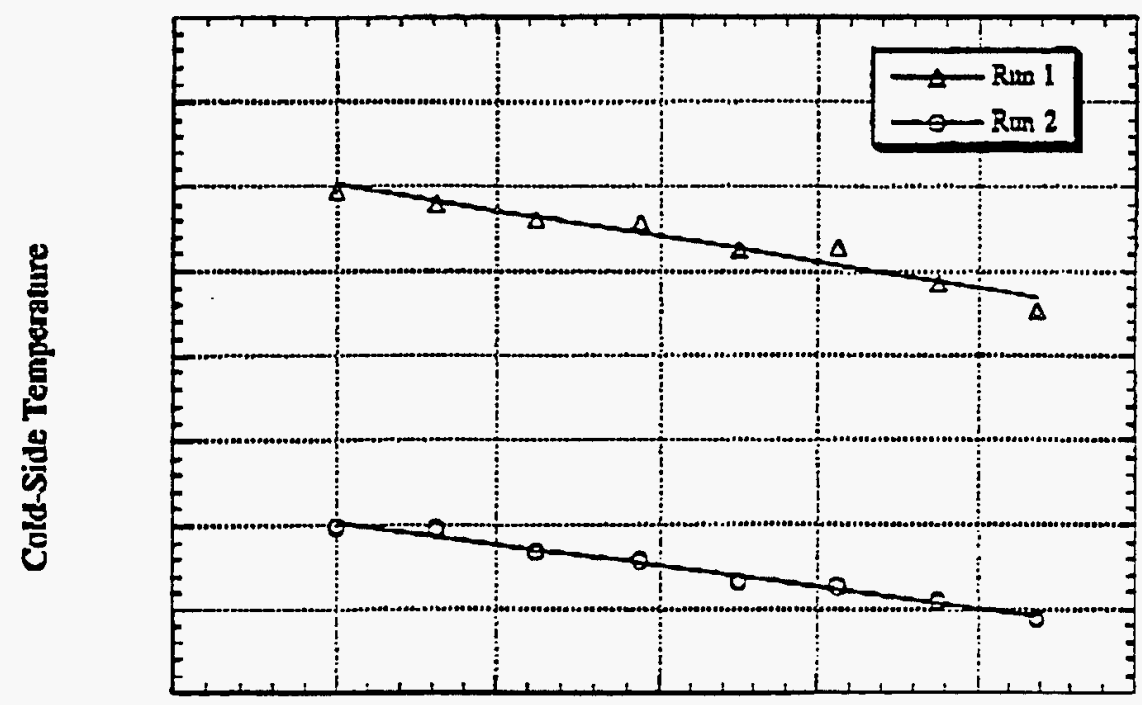

Reference Sample Thickness

Figure 8.3.4-6. Cold-Side Temperature Dependence on Sample Thickness

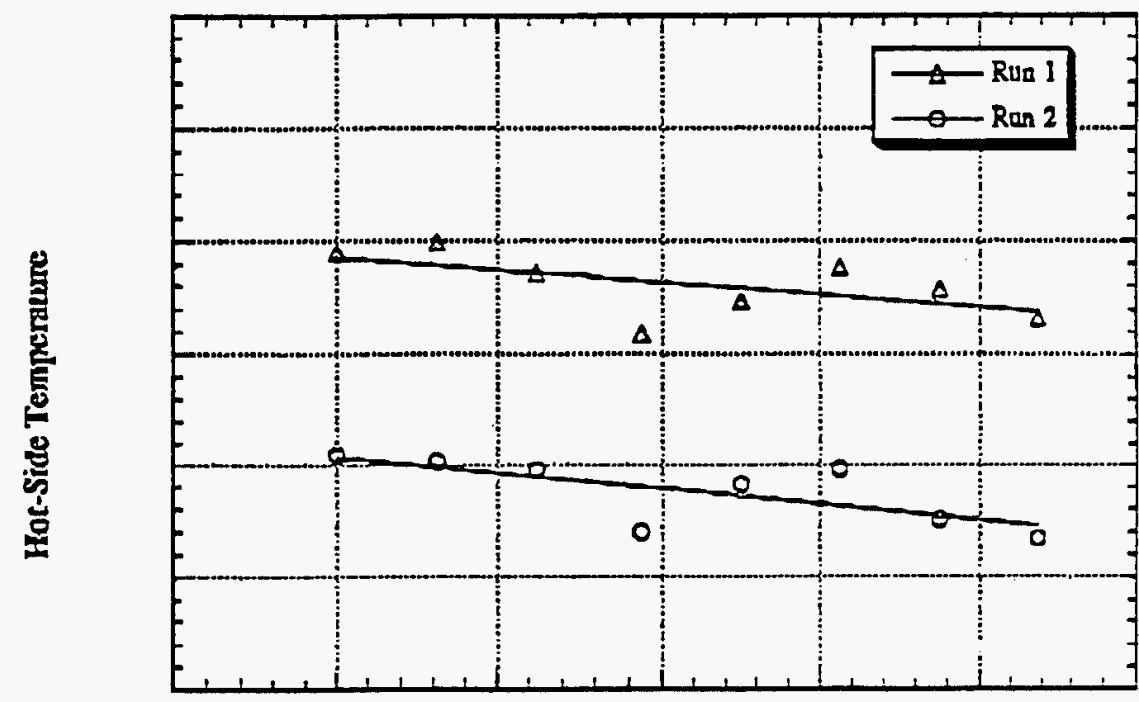

Relerence Sample Thickness

Figure 8.3.4-7. Hot-Side Temperature Dependence on Sample Thickness 


\section{TECHNOLOGY APPLICATION}

TBC thermal conductivity data will be used in the design of hot section coatings for the $7 \mathrm{H}$ and $9 \mathrm{H}$ gas turbines.

\section{PLANS FOR PHASE 3}

Work will continue under a Phase 3 program in order to resolve the differences between the actual and expected hot-side surface temperatures.

\section{SUMMARY AND CONCLUSIONS}

An experimental method for objectively determining the apparent thermal conductivity of TBC systems has been developed. A thermal resistance matching technique that utilized reference samples of known thermal resistance to deduce the apparent thermal resistance of TBC-coated specimen was employed. Tests have shown excellent long-term thermal stability of the system and substantial operating versatility for the study of TBC thermal conductivity. One primary advantage of the current method over conventional laser flash diffusivity is that it reproduces many of the thermal conditions present in a typical TBC environment in a gas turbine engine; i.e., high flame temperatures, significant thermal gradients, and surface radiation effects. However, initial tests with the conductivity rig indicate unexpected trends in the hot-side surface temperature of the reference samples. These discrepancies between the actual results and the expected results need to be investigated further before meaningful TBC thermal conductivity values can be generated with the present technique. 


\section{TASK 8.4.1 - ADVANCED MACHINE HOT GAS PATH SEALS}

\section{INTRODUCTION}

The primary objective of this task is to develop advanced hot gas path seals for the ATS gas turbine. The effort was initiated in 1994 with the development of cloth seals-design, analysis and leakage testing - using the GE-developed "Two-Can" room temperature vibratory seal test rig. The seals were tested at room temperature, under various pressure ratios, pressure differentials, and mechanical misalignment. This testing was needed for a quick evaluation of a variety of sealing concepts. In 1995, the decision was made that selected advanced seal concepts had to be tested at turbine operating conditions of temperature, pressure, and mechanical misalignment to validate their performance. The goal of the 1995-96 effort on this project was to upgrade the existing Two-Can Seal Test rig so that it could be used for testing at high temperatures. This effort included design evaluations, detailed design, and fabrication to prepare the facility for testing static seal concepts at ATS gas turbine conditions. After a thorough review of requirements for upgrading the existing Two-Can seal test rig, it was determined that simple upgrading was not adequate. Therefore the 1995 objective was modified to design, fabricate, and install a high temperature static seal test rig capable of testing advanced seal concepts at ATS gas turbine temperature, pressure, and air-flow conditions.

\section{TASK OBJECTIVES}

\section{OBJECTIVES}

Identify and specify critical sealing requirements in the advanced machine system. Through room temperature component testing and analysis, develop seals for the following applications in the ATS gas turbine:

1. Transition piece to first-stage nozzle inner, outer, and side seals.

2. Nozzle-shroud seals for first-stage nozzle.

3. Nozzle-shroud seals for second and third stages.

4. First-stage nozzle inter-segment seals.

\section{OBJECTIVES}

Build and validate a high temperature static seal test rig capable of testing advanced seal concepts at ATS gas turbine conditions: $537 \mathrm{C}(1000 \mathrm{~F})$ and $2.412 \mathrm{MPa}(350 \mathrm{psi})$, providing $0.45 \mathrm{~kg} / \mathrm{s}(1 \mathrm{lb} / \mathrm{sec})$ of air flow. The rig will be checked out for proper operation using some of the seals being developed for the ATS gas turbine.

\section{BACKGROUND}

A turbine stator (shroud) is built up of several annular segments that are packed together at circumferential and axial junctions (Figure 8.4.1-1). The junctions between these segments must be sealed in order to maintain high efficiency. Typically the junctions have slots on the mating edges. Seals are used in the slots, bridging adjacent members, to block off any leakage 
(Figure 8.4.1-2). The hot gas/air in these locations sees high pressures of $2.142 \mathrm{MPa}(350 \mathrm{psi})$, temperatures $810 \mathrm{~K}(1000 \mathrm{~F})$ or higher, and pressure differences of over $1.03 \mathrm{MPa}(150 \mathrm{psi})$. The seals themselves see temperatures of approximately $1000 \mathrm{~F}$.

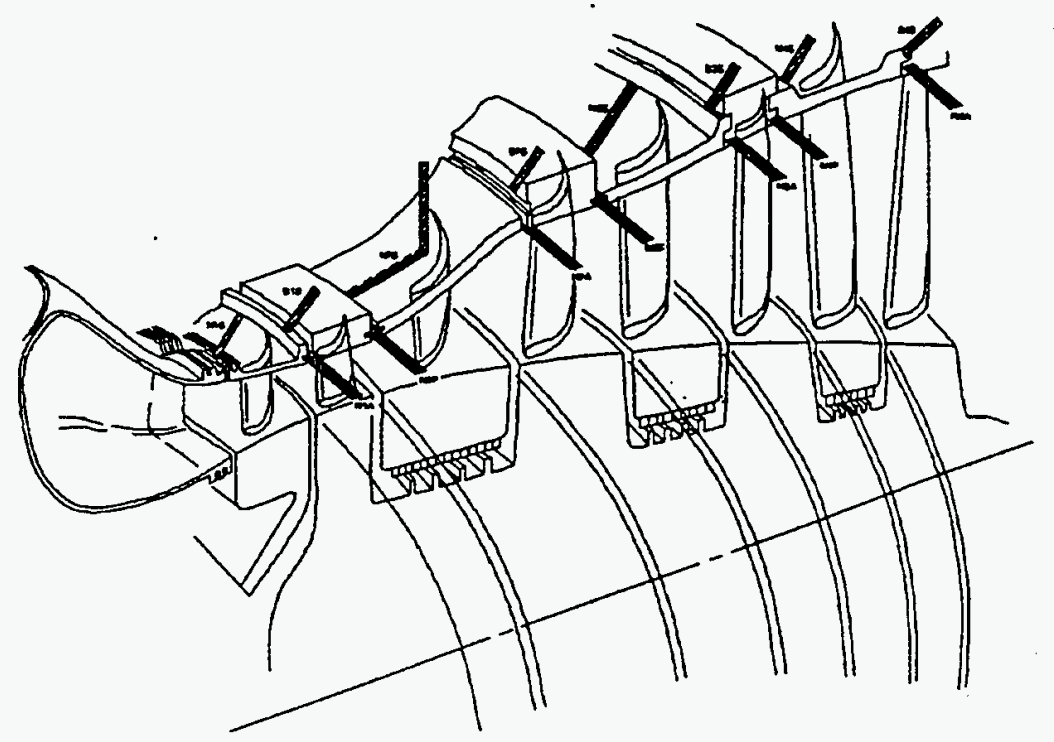

Figure 8.4.1-1. ATS Gas Turbine Hot Gas Path

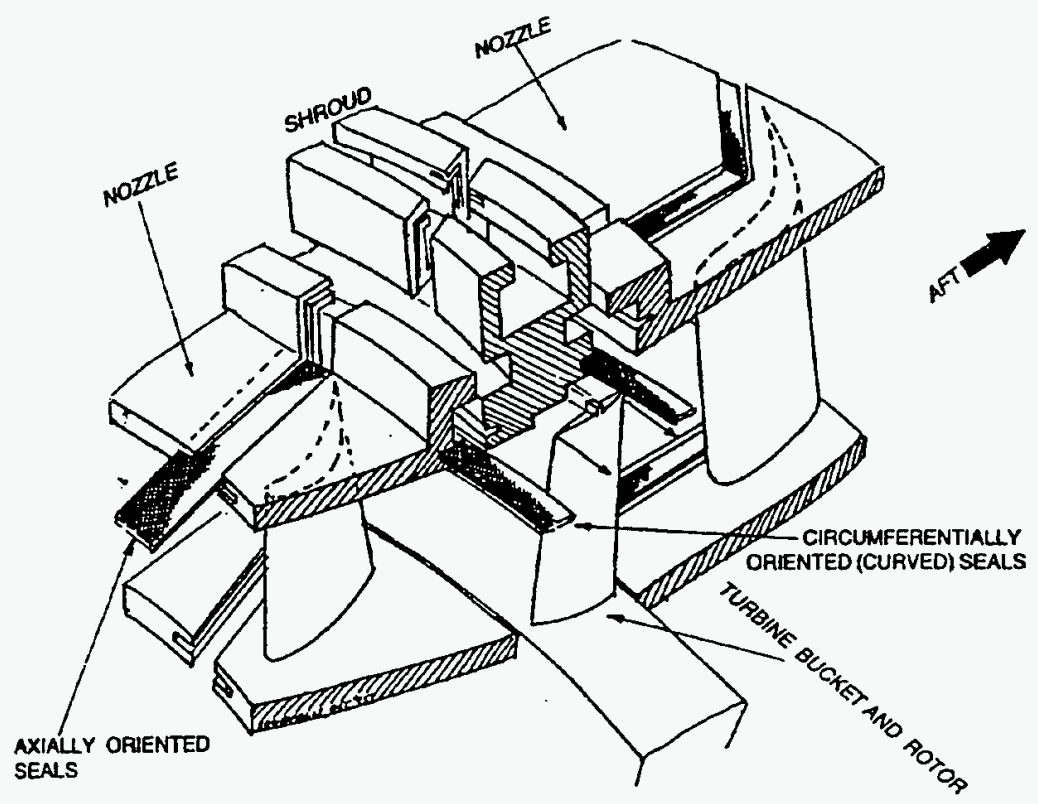

Figure 8.4.1-2. ATS Gas Turbine Hot Gas Path Seals 
In order to make "standard" leakage measurements on the various seals tested, which allow a before-after comparison of various concepts, 304.8-mm (12-inch) long (standard size) seal samples were tested in a controlled temperature, pressure, and misalignment environment. Two seal test rigs were used. Various common elements of advanced seals that will influence the designs for the ATS gas turbine were developed and tested using, first, the room temperature Two-Can rig and, later, the high temperature "Shoebox" rig developed under this task in 1995-96.

\section{DISCUSSION OF RESULTS}

\section{CLOTH SEAL TESTING USING THE ROOM TEMPERATURE TWO-CAN RIG}

Seal testing in 1994 was performed in the Two-Can rig (Figure 8.4.1-3). This rig continues to be useful for quick evaluation of seals.

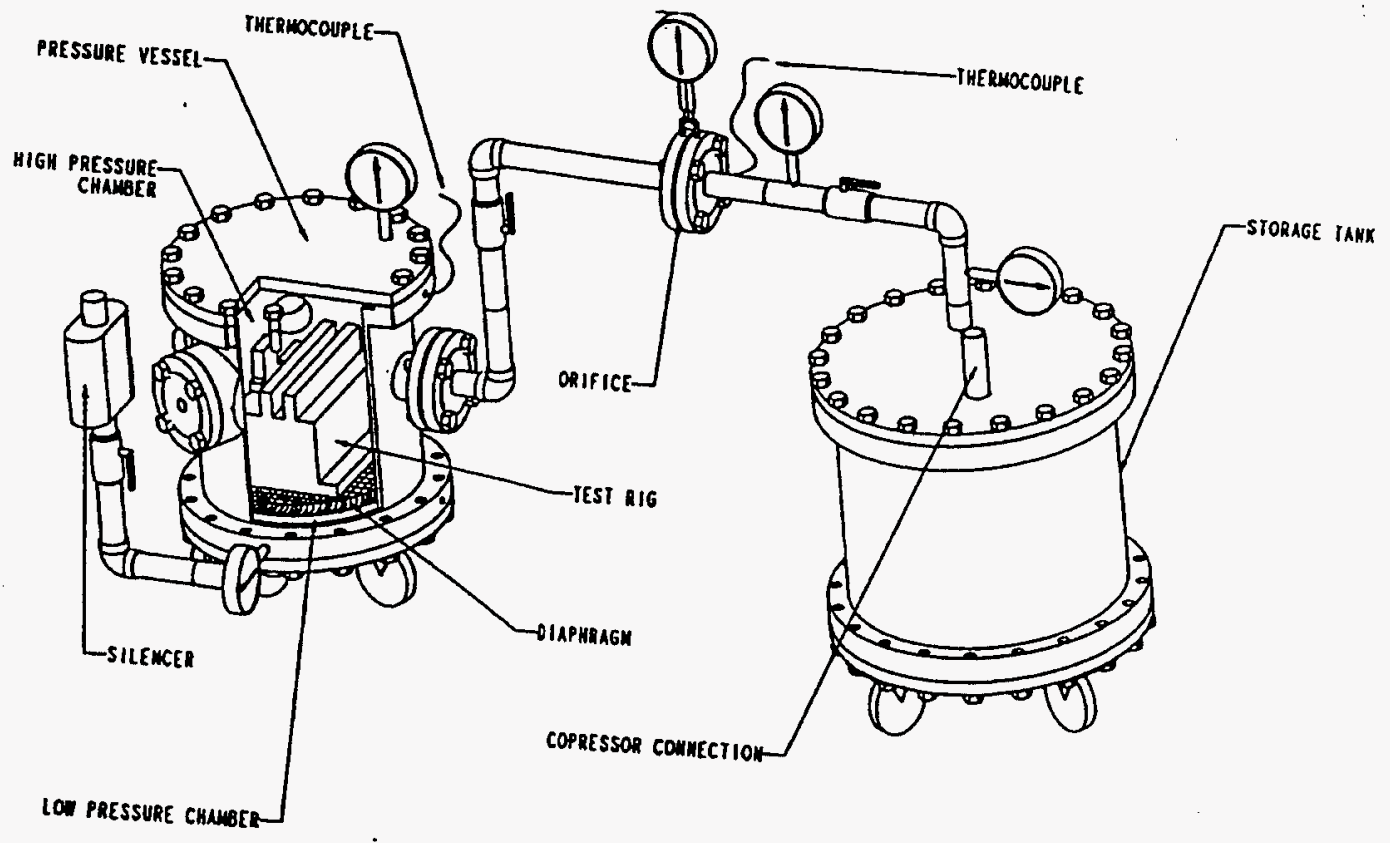

Figure 8.4.1-3. Two-Can Seal Test Rig

\section{Room Temperature Test Rig}

The Two-Can rig was used to test some seal concepts. Air flow for these tests was provided by bottled compressed air. Tests were conducted at a number of inlet pressures, but always with the inlet-to-exit-pressure ratio in the ATS turbine. The rig comprises a pressure vessel divided into a high-pressure chamber and a low-pressure chamber by a diaphragm plate carrying adjustable seal jaws that can be assembled (with test seals) at specific values of gap, offset, and mismatch (skew) representative of turbine conditions (Figure 8.4.1-4). 

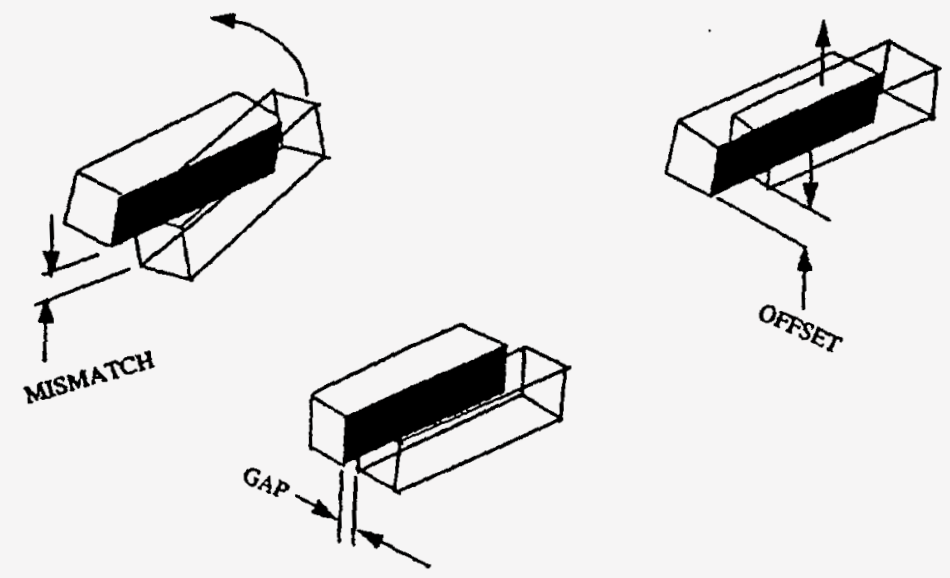

Figure 8.4.1-4. Relative Mismatch, Offet, and Gap in Mating Turbine Elements 
Figure 8.4.1-5 is a close-up of the adjustable jaw unit capable of accepting a variety of standard size (304.8-mm [12-inch]) seal samples. High-pressure air is supplied by air bottles. Mass flowrate is measured via (replaceable) orifice plates, a differential pressure gauge, a thermocouple, and an upstream pressure gauge.

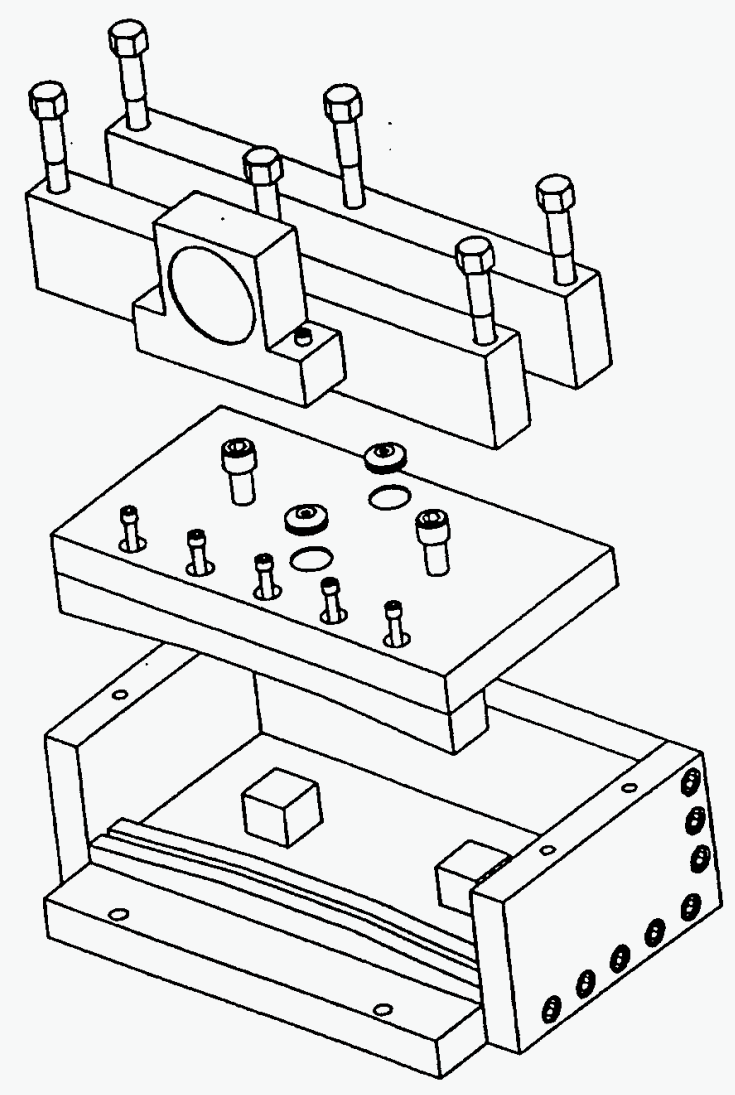

Figure 8.4.1-5. Details of the Two-Can Rig Jaw Unit 
Leakage is expressed in terms of Equivalent Gap at the junction being sealed. It is calculated using the relationship

$$
\frac{W \sqrt{T}}{P_{h} G_{e q} L}=\phi\left(\frac{P_{l}}{P_{h}}, R, \gamma_{0}\right)
$$

where,

$$
\begin{aligned}
& W=\text { Mass flow rate, } \mathrm{kg}(\mathrm{lb}) \mathrm{per} \mathrm{sec} . \\
& T=\text { Absolute temperature }{ }^{0} \mathrm{~K}\left({ }^{0} R\right) \\
& P_{h}=\text { Absolute pressure, supply side, } \mathrm{MPa} \text {. (psi) } \\
& P_{l}=\text { Absolute pressure, downstream side, MPa. (psi) } \\
& G_{e q}=\text { Equivalent gap, mm (inch) } \\
& L=\text { Length of seal, mm (inch) } \\
& \phi=\text { Isentropic flow function } \\
& R, \gamma_{0}=\text { Gas constants }
\end{aligned}
$$

The mass flowrate, $W$, is calculated from measurements at the orifice plate, using the basic flow equation:

$$
\Delta P_{O R F}=\frac{W^{2}}{2 \rho A^{2} C_{d}^{2}}, \text { the pressure drop across the orifice }
$$

with

$$
\begin{aligned}
& C_{D} \approx 0.7 \\
& A=\text { Orifice area } \\
& \rho=\text { Air density at pressure and temperature }
\end{aligned}
$$

\section{ROOM TEMPERATURE TEST RESULTS}

A variety of seals for the hot gas path were designed and tested. They can be classified as Axially Oriented (straight), and Circumferentially Oriented (arched) seals, respectively, for axial and circumferential junctions (Figure 8.4.1-2). Typically, the straight seals are for sealing between (annular) shroud segments. The arched seals are for sealing between stages; i.e., between a tip shroud and the nozzles forward and aft of it. Two geometries were explored: Seal $A$, which fit into slots along both edges, and Seal $B$, which fit into a slot along one edge, and leaned under contact pressure on a vertical face. The seals consisted of one or two layers of Inconel-750 shims wrapped with cloth woven with L605 wire. Design variations included number of shims, number of layers of cloth, shim thickness, materials, etc. Finite element 
analyses were performed on each configuration to confirm that they would not yield under pressure loads, and under extremes of misalignment.

Figures 8.4.1-6 through 8.4.1-8 show progressively improved versions of seal $A$. The first version was composed of two shims wrapped with a layer of cloth contacting a ramped slot (Figure 8.4.1-6). The seal was improved by hooking the shim to the contacting surface (Figure 8.4.1-7). The effect of seam-welding the seal along one edge was then evaluated (Figure 8.4.1-8). The seals were tested under nominal and offset (misalignment) conditions.

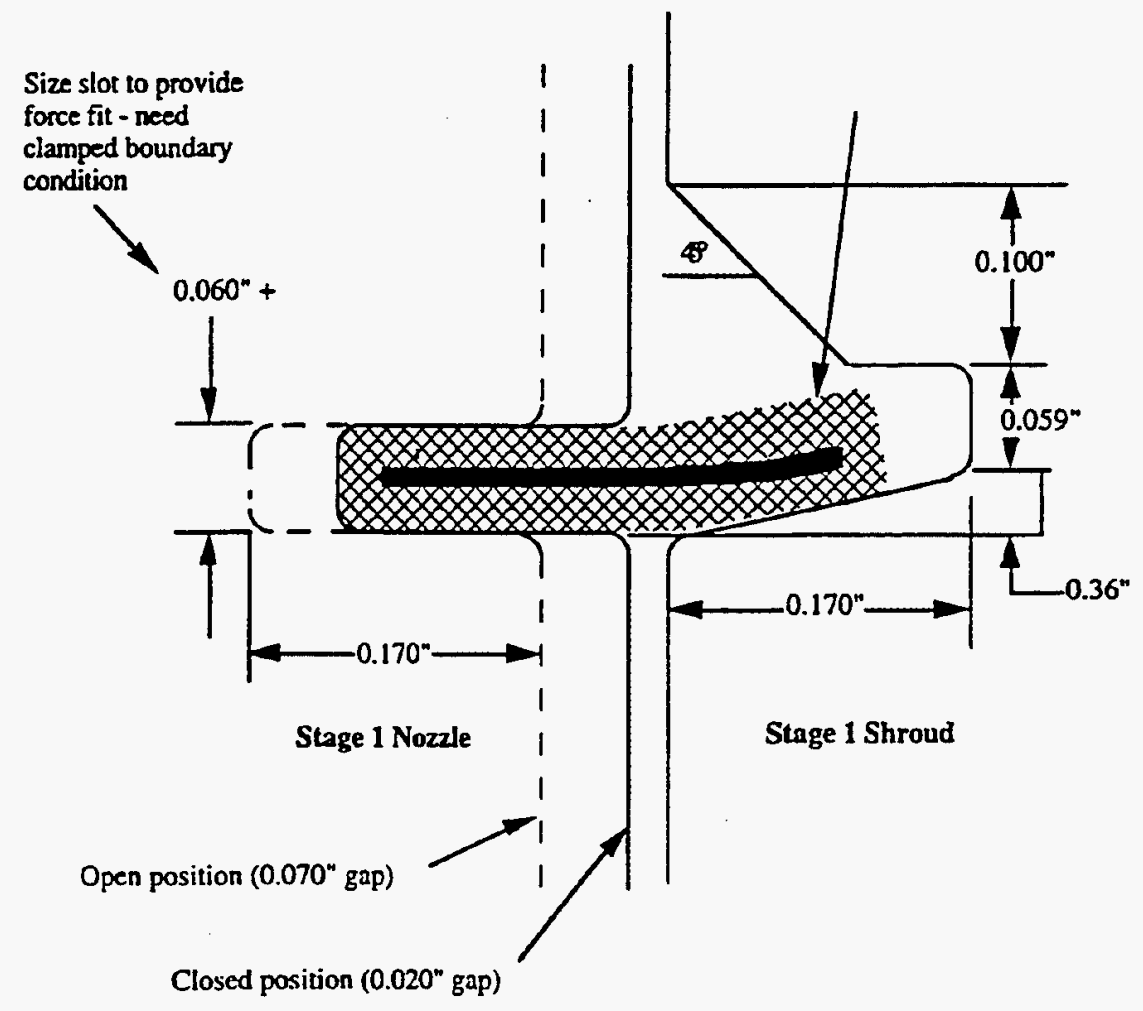

Figure 8.4.1-6. Arched (Circumferential) Cloth Seal $A$, Design \#1: Plain 


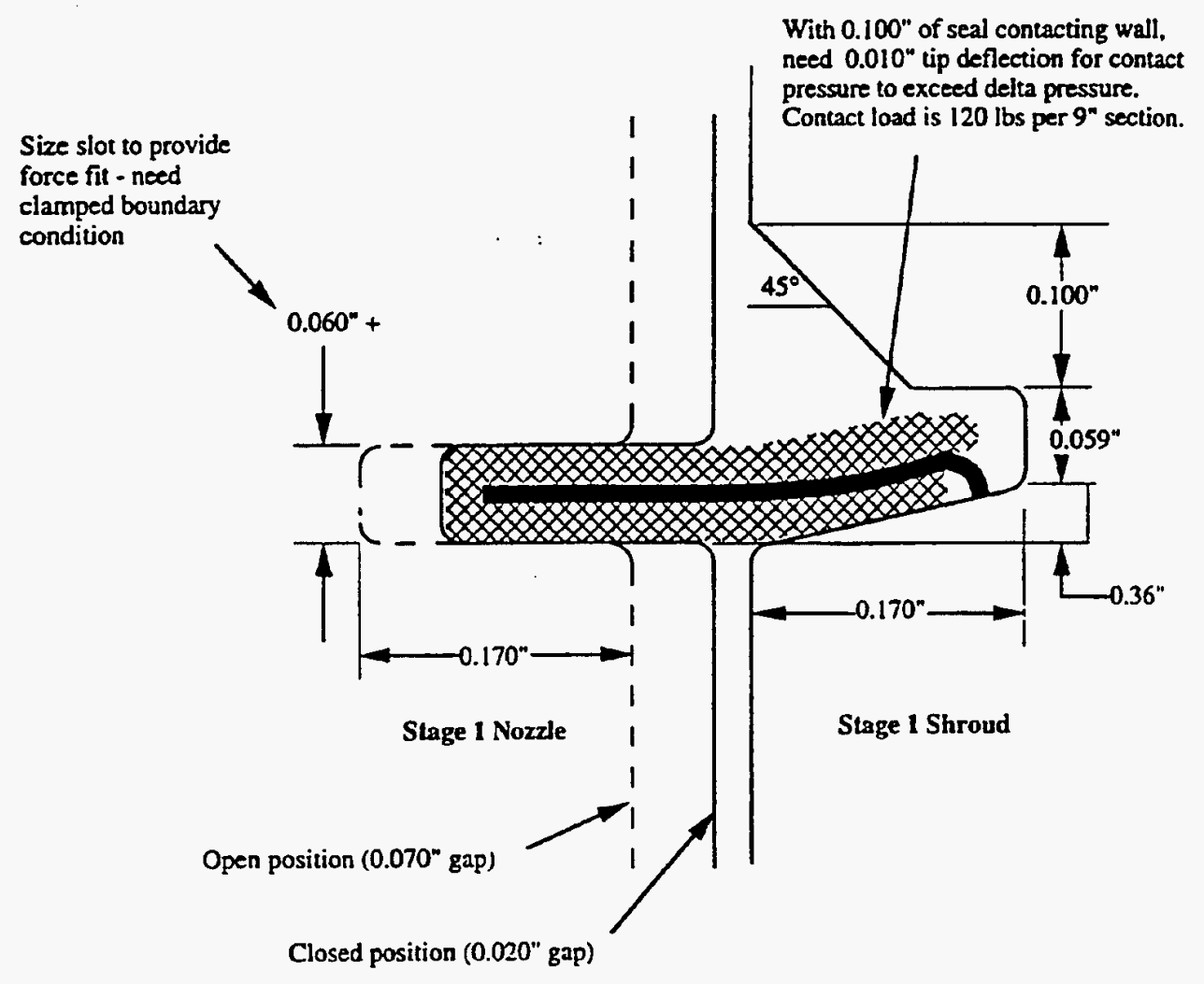

Figure 8.4.1-7. Arched (Circumferential) Cloth Seal $A$, Design \#2: with Hook 


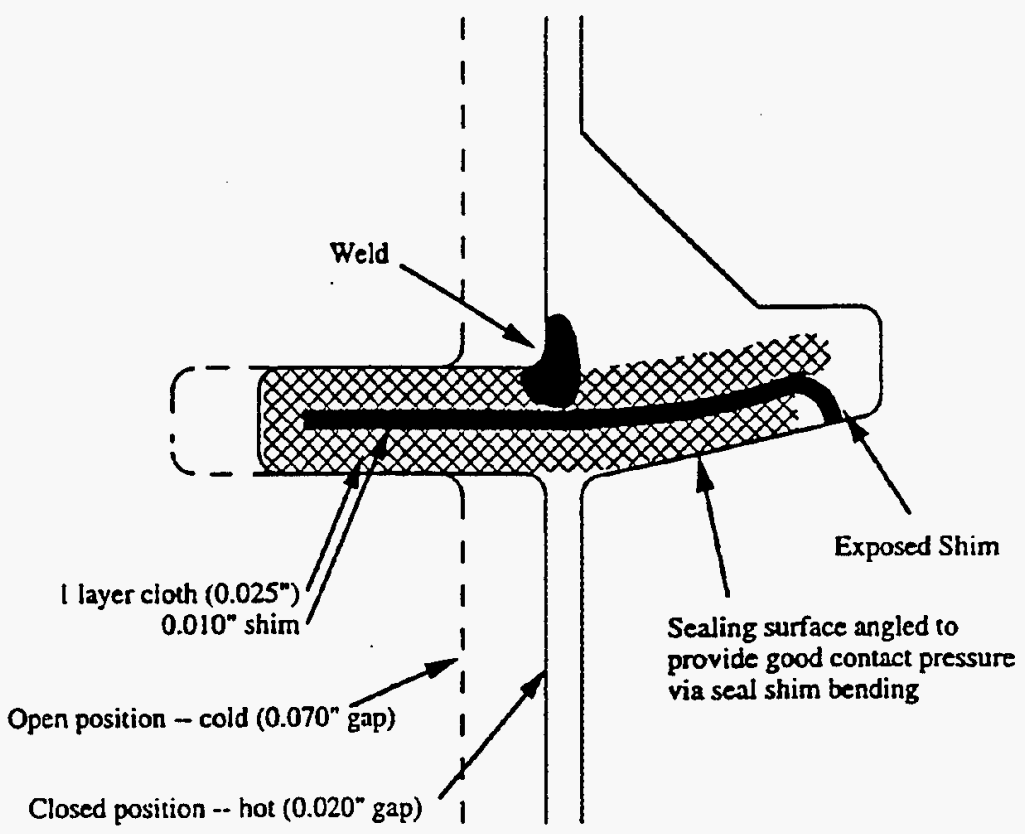

Figure 8.4.1-8. Arched (Circumferential) Cloth Seal $A$, Design \#3: with Hook and Weld Seam 
Figures 8.4.1-10 and 8.4.1-11 are versions of Seal B. The leakage numbers with these seals were not promising. Since these seals were difficult to configure along an arch, this seal design was not pursued further.

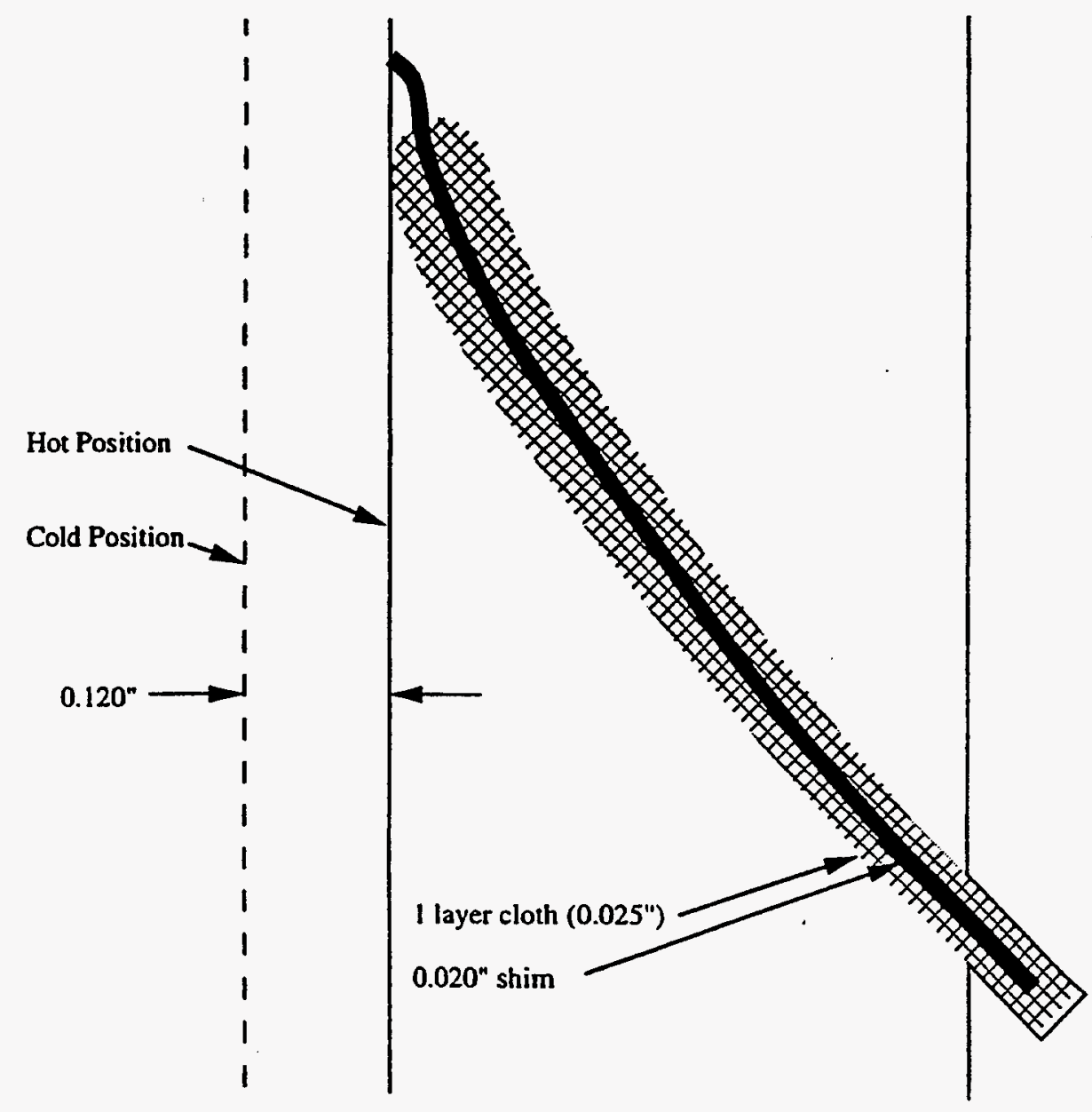

Figure 8.4.1-10. Arched (Circumferential) Cloth Seal B, Design \#1: with Hook 


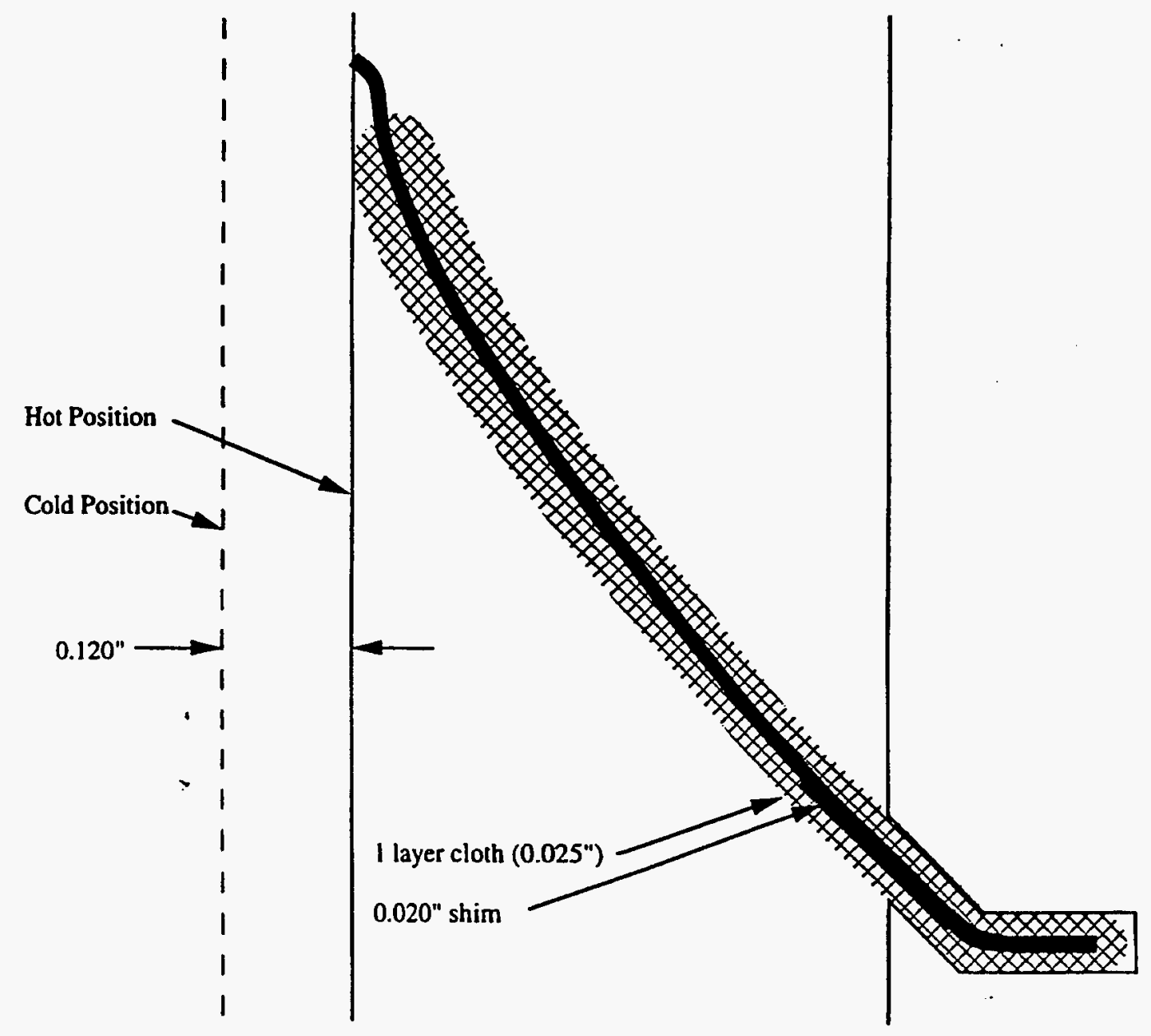

Figure 8.4.1-11. Arched (Circumferential) Cloth Seal $B$, Design \#2: with Hook and Fold

Several transition-piece/first-stage nozzle sealing concepts were designed and tested as straight segments and compared with the "rigid" floating seals currently in use. Because of its adaptability and flexibility, a preliminary wedge-shaped cloth seal showed very good sealing performance as well as an ability to adapt to large thermal differential growth. Test results are summarized in Figure 8.4.1-12. 


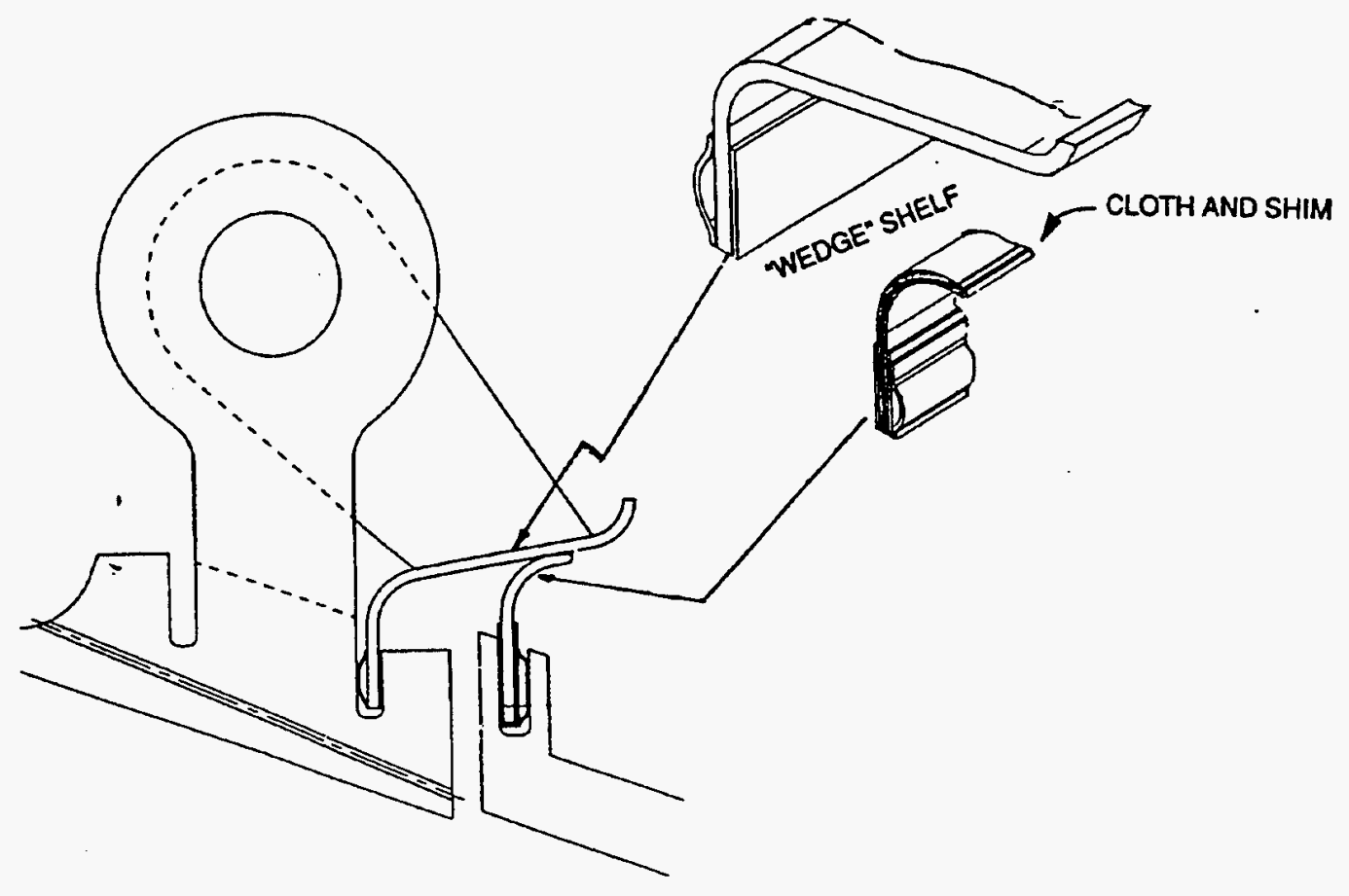

Figure 8.4.1-12. Wedge-Shaped Transition-Piece/First-Stage Nozzle Cloth Seal; Sealing Effectiveness Compared with Other Designs

\section{HIGH TEMPERATURE RIG DESIGN}

In the first phase of this task, testing was performed in the Two-Can rig. It was decided by the team that sealing performance should be verified by testing at ATS gas turbine conditions of temperature and pressure. The second phase focused on rig enhancement design evaluations, detailed design, and fabrication to prepare the facility to test static seal concepts at ATS gas turbine conditions. Evaluations of various rig-enhancement schemes indicated that it would be difficult to enhance the Two-Can rig for turbine operating conditions since major components of the rig would have to be re-designed or discarded. The objective, then, was to design, fabricate, and install a high temperature static seal rig and test its operation on a few seal concepts.

\section{DESIGN REQUIREMENTS}

The High Temperature Seal Test rig must be capable of testing a variety of seal designs of standard size (304.8 mm [12 inches]) under a range of controlled mismatch, offset, and gap conditions representative of those between mating members forming the turbine hot gas path. Typical turbine junctions in a hot gas path see offsets and mismatch conditions of over 2.54 $\mathrm{mm}(0.1$ inch) and gaps that range from almost 15 to $20 \mathrm{~mm}(0.59$ to 0.7 inch), cold, to approximately $7.6 \mathrm{~mm}$ ( $0.3 \mathrm{inch})$, hot. In addition, one must be able to control and measure pressures on the upstream (high-pressure) and downstream (low-pressure) sides independently; the highest pressure being $2.412 \mathrm{MPa}$ (350 psi) and the pressure ratios (of the downstream to the upstream sides) being in the turbine range of 0.4 to 0.9 . It must be possible 
to measure leakage flows using orifices and differential pressure gauges. The rig is designed to withstand pressures of $2.412 \mathrm{MPa}(350 \mathrm{psi})$ and temperatures of up to $810 \mathrm{~K}(1000 \mathrm{~F})$ at flowrates of $\sim 0.454 \mathrm{~kg} / \mathrm{s}(1 \mathrm{lb} / \mathrm{sec})$.

\section{RIG DESIGN}

The seal rig design covered conceptual rig design, preliminary rig design, detailed rig design and analysis, and system design including piping, valving, instrumentation, and facilities layout. A High Temperature Seal Test rig design concept, the Shoebox, was selected from among four candidate designs. Detailed design and analysis have been performed on the Shoebox rig design including the internal adjustable jaw holders (Figures 8.4.1-13 and 8.4.1-14). This rig has been designed to ASME pressure vessel code. It will handle pressures of up to $2.412 \mathrm{MPa}(350 \mathrm{psi})$ and temperatures of approximately $810 \mathrm{~K}(1000 \mathrm{~F})$. The hot air requirement is a maximum of $0.4535 \mathrm{~kg} / \mathrm{s}(1 \mathrm{lb} / \mathrm{sec})$. The design of the rig is summarized in Table 8.4.1-1.

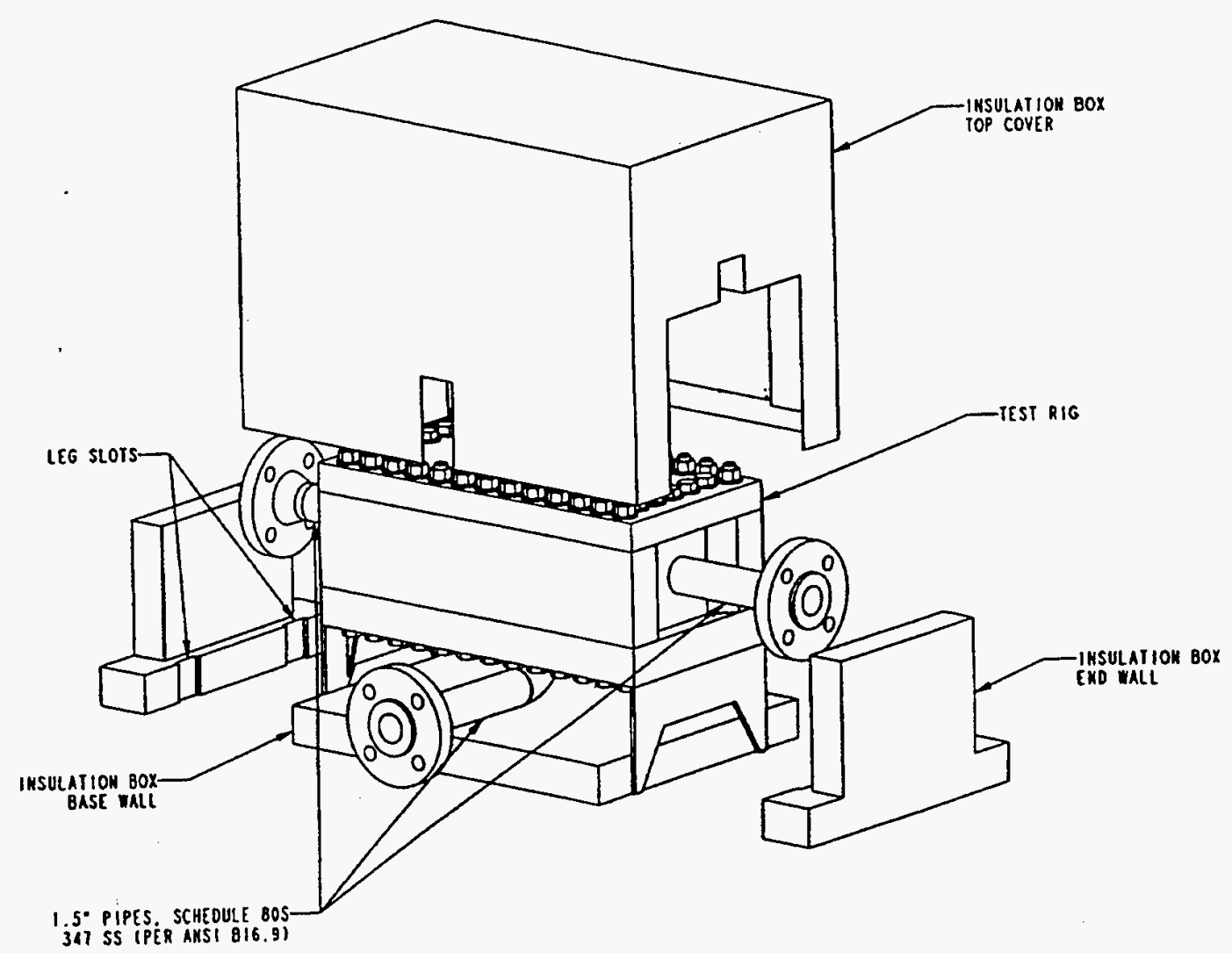

Figure 8.4.1-13. High Temperature Shoebox Rig Shown with Insulation 
Table 8.4.1-1.

RIG CAPACITY: $1000 \mathrm{~F} \frac{\mathrm{g}}{600 \mathrm{PSI}}$

Shoebox Rig Design Summary

RIG MATERIAL: $347 S S$

ASME: $\quad$ SA-240-347

PLATE THICKNESSES:

TOP:

$1.5^{n}$

BOTTOM:

$2.0^{n}$

LONG SIDES:

$2.0^{n}$

SHORT SIDES:

$1.125^{n}$

PLATE STRESSESTHHICKNESS:

(600 psi 1000F)

Max. Stress (ASME Allowable): $\quad 14400$ psi

1-TOP\&BOTTOM:

Flange Thicknes Required:

(Per ASME P.V. Code, Sec. 8, App. 2, 2-5(e))
Operating
$1.380^{n}$
Gasket Seating
$1.276^{n}$
Design Thickness:
$1.5^{n}$ (top) 2.0" (Bottom)
2- SIDE WALLS
Max. Stress Calculated: $\quad 11542.6$ psi
3- END WALLS:
Max. Stress Calculated: 6637 psi

(Per ASME P.V. Code, Sec. 8, Div. 1, UG-36(c)(3)

No reinforcement is required for plates of $\downarrow 3 / 8^{n}$

with holes of $d<2.375^{\prime \prime}$ )

BOLTS:

WELDS:

$36 \times 5 / 8-11$ UNC $3475 S$

ASME: $\quad$ SA-193-B8

Max. Stress ASME allowable (S) $=13400$ psi

Stres Area/bolt $(\mathrm{Ab})=.226 \mathrm{in}^{2} \quad P=600 \mathrm{psi}$

Design Press. Load $(L)=62400 \mathrm{lbf}$

\# Bolts required $=L(S x A b)=23$

\# Bolts used $=36$

Preload: Long Studs: $\quad T \min =25.75 \mathrm{ft}-1 \mathrm{~b}$ (Joint seperation limit)

$T \max =36.87 \mathrm{ft}-1 \mathrm{~b}$ (Stress limit)

Short Bolts: $\quad T$ min $=21.31 \mathrm{ft}-\mathrm{lb}$ (Joint seperation limit)

Design Torque $=32 \mathrm{ft}-1 \mathrm{~b}$

Tmax $=33.43 \mathrm{ft}-\mathrm{lb}$ (Stress limit)

Corner (main) welds:

Designed per ASME P.V. Code, Sec.8, Div.1, Fig. UW-13.2 (f)

Max. Stress (ASME Allow.) : 10080 psi

Max. Stress (Design) : $6393.7 \mathrm{psi}$

Pipe-to-Vesel welds:

Designed per ASME P.V. Code, Sec.8, Div.1, Fig. UW-16.1 (k)

Max. Stress (ASME Allow.) : 7920 psi

Max. Stress (Design) : 1096.73 psi

Pipe-to-Pipe welds:

Designed per ASME Press. Piping Code B31, Fig. 328.4.2 (a)

Max. Stress (ASME Allow.) : 10080 psi

Max. Stress (Design) : 8378.5 psi 


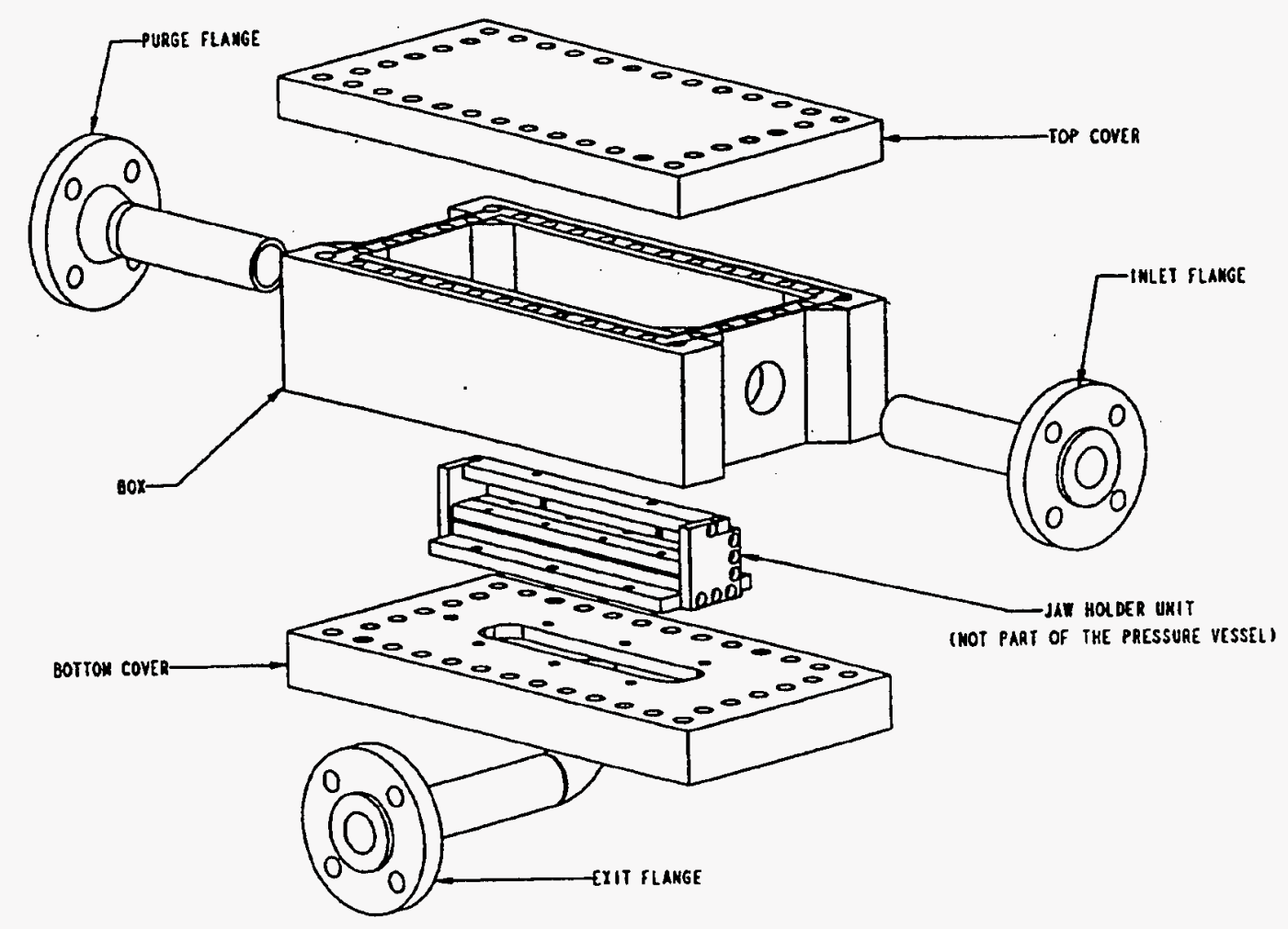

Figure 8.4.1-14. Exploded View of the Shoebox Rig Showing Adjustable Jaw Unit Inside

The High Temperature Seal Test rig is a pressure vessel divided into a high-pressure chamber and a low-pressure chamber by a diaphragm. A jaw unit is bolted on the hole (Figure 8.4.1-15). This jaw unit comprises a pair of jaws with slots, each of which is $304.8 \mathrm{~mm}$ (12 inches) long. The rig is designed to accept a variety of jaw units with a selection of slots. Tests are performed using jaws with slot geometries appropriate to the ATS gas turbine. Test results will be used to finalize the definition of the slot geometries. Mismatch, offset, and gap conditions can be varied by means of the jaw unit assembly. 


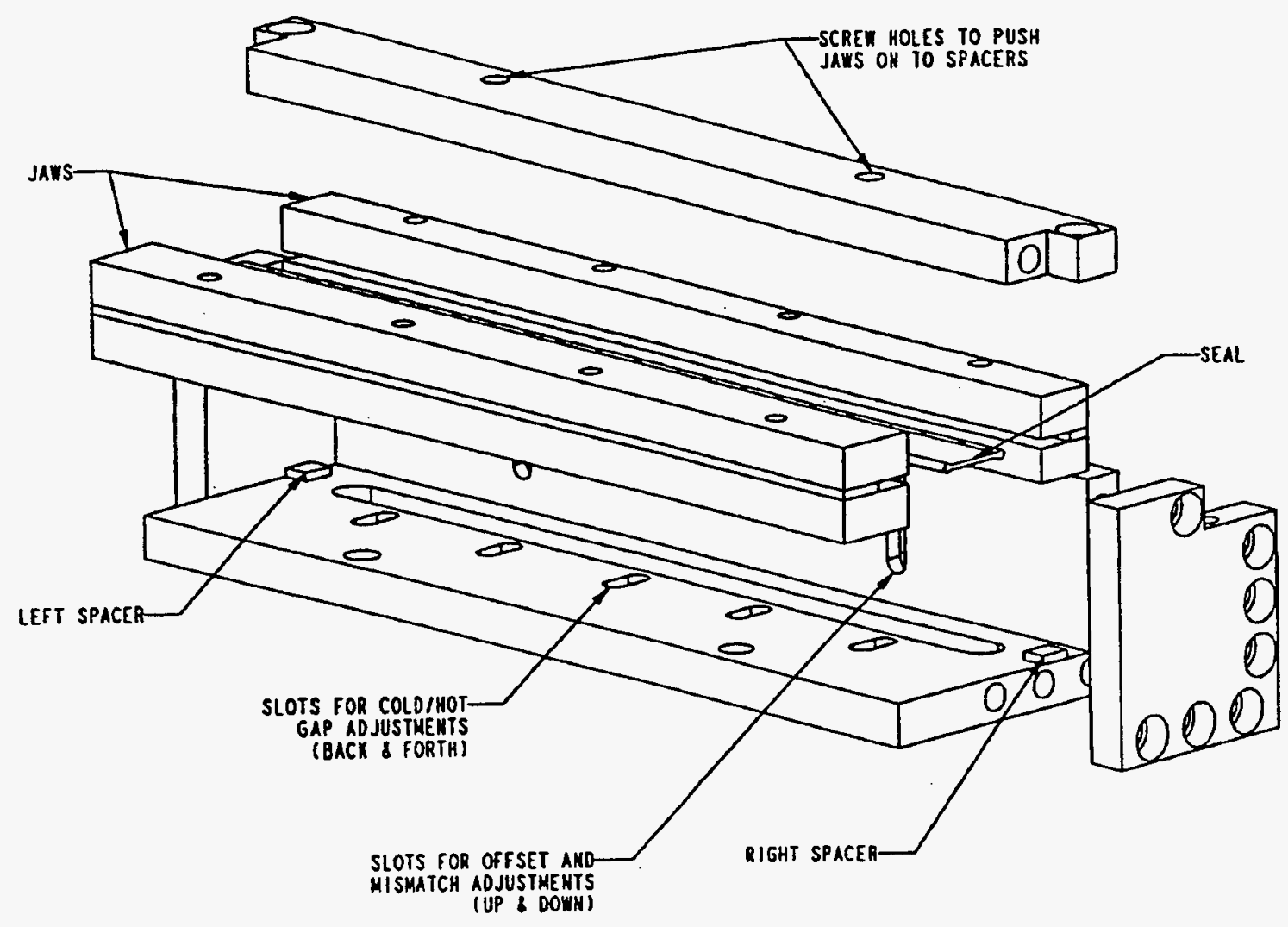

Figure 8.4.1-15. Details of the Jaw Unit Showing Adjustable Jaws and Test Seal 


\section{SYSTEM DESIGN}

Figure 8.4.1-16 is a system diagram of the high temperature seal test system, including the Shoebox rig. It shows the location of the inlet and exit valves, the pre-heating line, upstream and downstream pressure gauges, thermocouple locations, etc. Figure 8.4.1-17 shows how the system has been configured.

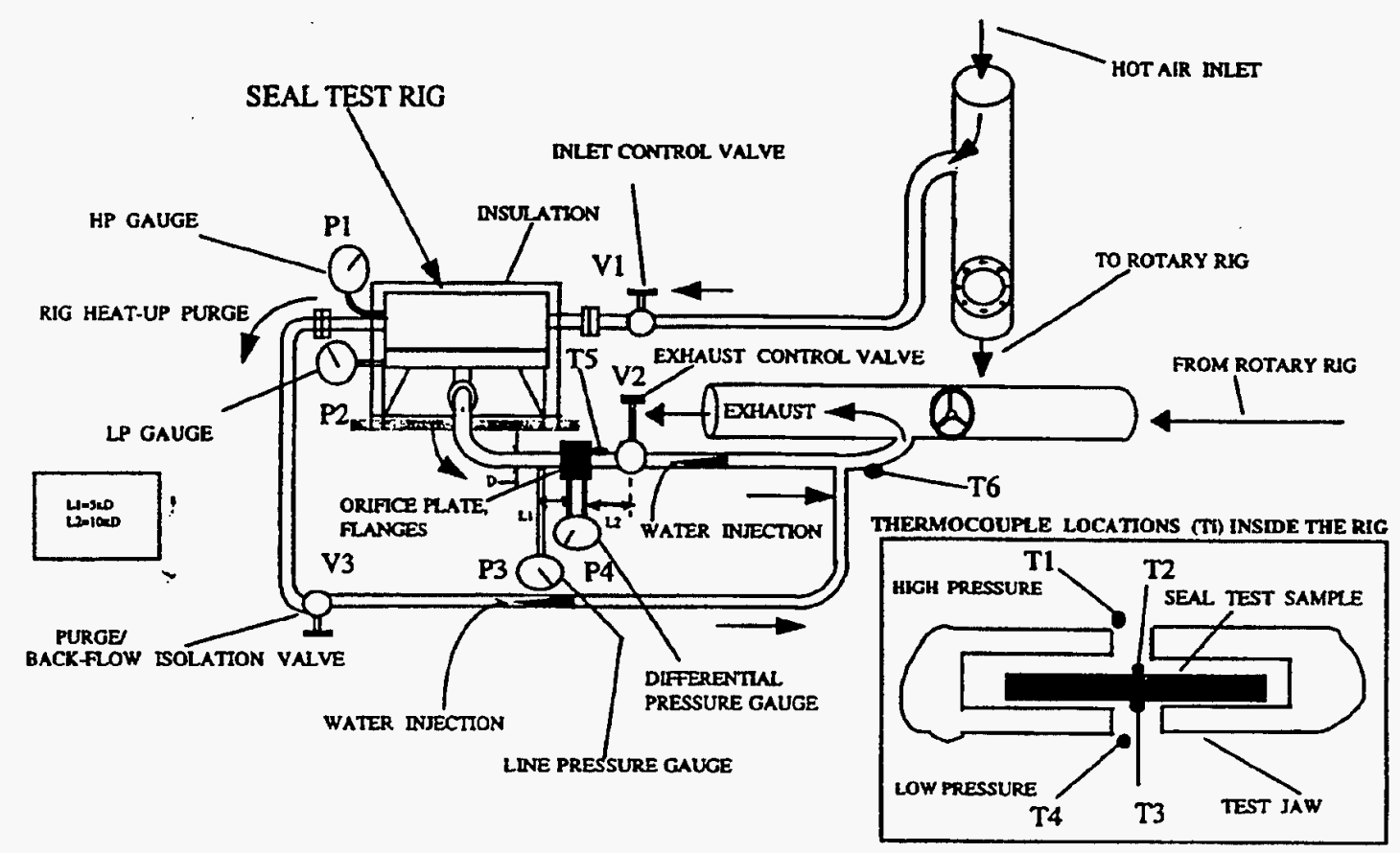

Figure 8.4.1-16. High Temperature Seal Test Rig System Diagram 


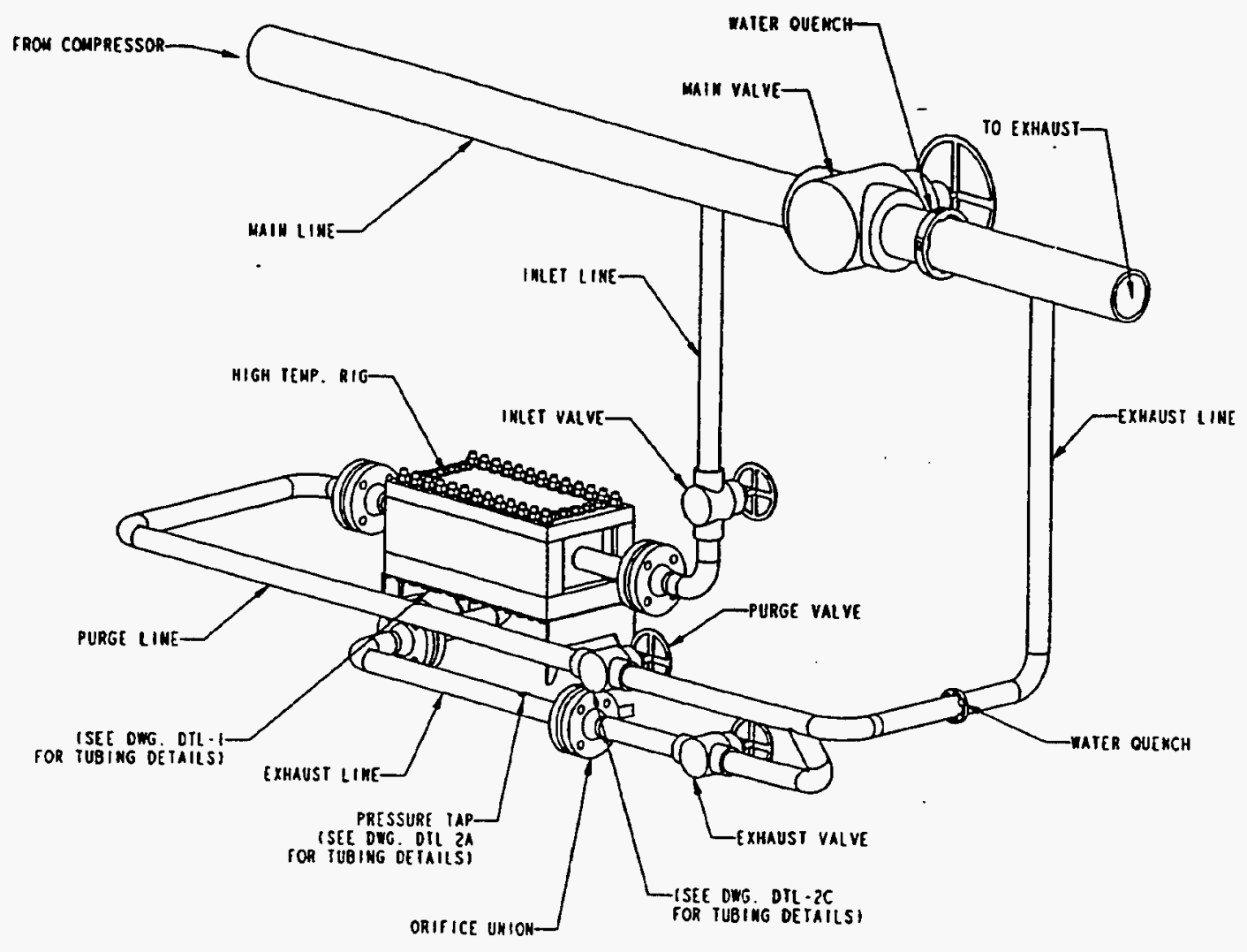

Figure 8.4.1-17. High Temperature Seal Test Rig System Configuration 


\section{STANDARD OPERATING PROCEDURE}

A detailed Standard Operating Procedure (SOP) document has been written and posted near the rig. It covers emergency procedures and details of system start-up, operation, and shutdown. Table 8.4.1-2 is summary of items covered in this document.

Table 8.4.1-2.

\section{Standard Operating Procedure Outline}

1. EQUIPMENT DESCRIPTION

2. SPECIFIC SAFETY AND HEALTH CONSIDERATION

Pressure

Temperature

Personnel

3. SAFETY PRECAUTIONS

4. POWER/FACILITIES FAILURE

5. TRAINING

6. OPERATING PROCEDURES

Start-Up

Pre-start Check list

Normal Operation

Shut-Down

Emergency Shut Down

7. ROUTINE MAINTAINACE

8. QUALITY ASSURANCE/QUALITY CONTROL

Pressure Calibration

Temperature Calibration

9. MANPOWER REQUIREMENTS

10. ASSEMBLY PROCEDURES

11. PARTS LIST

\section{CHECKOUT TESTS}

The Shoebox rig has been installed and the entire system has been tested for high temperature operation. Tests were performed for bias leakage, and room temperature leakage results were verified by comparison with results obtained using the Two-Can rig. The rig has a bias leakage equivalent to $0.0127 \mathrm{~mm}(0.0005 \mathrm{inch})$. Leakage measurements were made on a cloth seal sample that was tested earlier in the Two-Can rig. A comparison of the results is shown in Figure 8.4.1-18. The difference between the two, though small, is being further evaluated. A number of possibilities may account for the discrepancy: the bias leakage may have changed; the orifice plates, as fabricated, may have errors in geometry; the differential pressure gauge may not be sufficiently sensitive. 


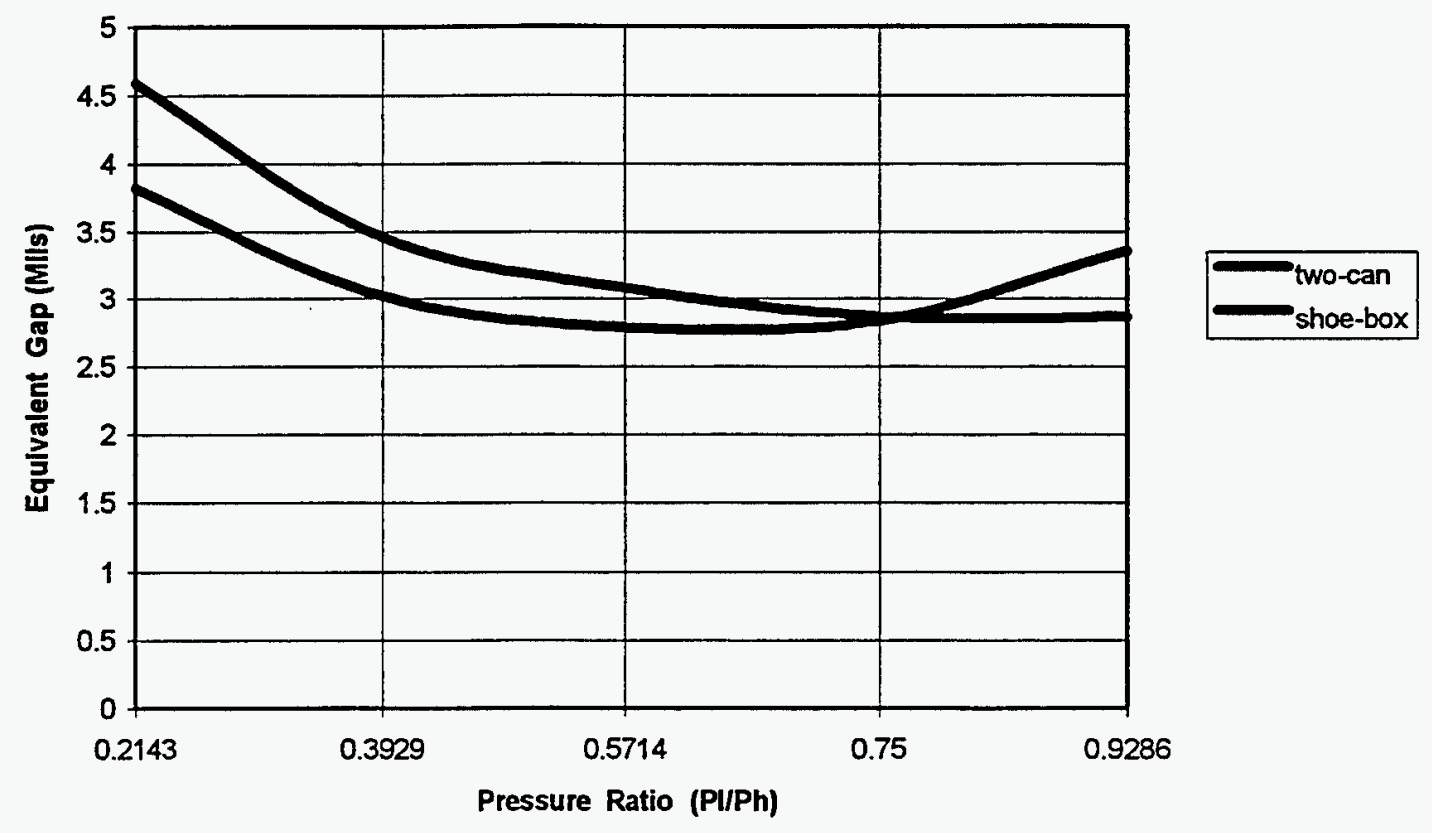

Figure 8.4.1-18. Comparison of Leakage Performance: Two-Can vs. Shoebox

\section{TECHNOLOGY APPLICATION}

Using rig test results of flexible metal cloth seals of various designs, it has been decided that this type of seal will be used in the ATS gas turbine to achieve efficiency gains (by reducing leakage in the turbine stages), and NOx reduction (by reducing leakage at the transition piece/first-stage nozzle junction).

\section{PLANS FOR PHASE 3}

High-temperature testing will be performed in Phase 3 using the "shoe box" rig developed as part of Phase 2. Improved sealing concepts will be designed and tested for optimum sealing at various locations within the turbine gas path.

\section{CONCLUSION}

The flexible metal cloth seals developed under Phase 2 are a major advance in sealing technology. Continued development of these seals will allow for reduced gas path leakage while improving assembly of the ATS gas turbine. 


\section{TASK 8.5 - ENHANCED IMPINGEMENT HEAT TRANSFER}

\section{BACKGROUND}

Cooling of turbine buckets and nozzles by impingement of coolant jets on the heated surfaces is an important consideration in their design. An experimental study on heat transfer performance of impingement cooling by air jets on a heated surface with crossflow was conducted at the Texas A\&M University Turbine Heat Transfer Laboratory. The work evaluated different geometries and flow orientations for heat transfer effectiveness resulting from crossflow produced by varied exit configurations. Effects of surface roughness and crossflow blockage were also studied. A schematic of the test configuration is shown in Figure 8.5-1.

\section{OBJECTIVE}

Task objective is to determine influences of different configurations and flow conditions on heat transfer.

Tests will be performed to evaluate a new concept for backside impingement cooling aimed at lessening the adverse effect of crossflow on air jet thermal dilution and to determine the upper limits for jet heat transfer at higher air supply pressures.

For long impingement channels, the spent jet impingement air represented as crossflow mixes and raises the temperature of the cold air jet before it strikes the hot wall.

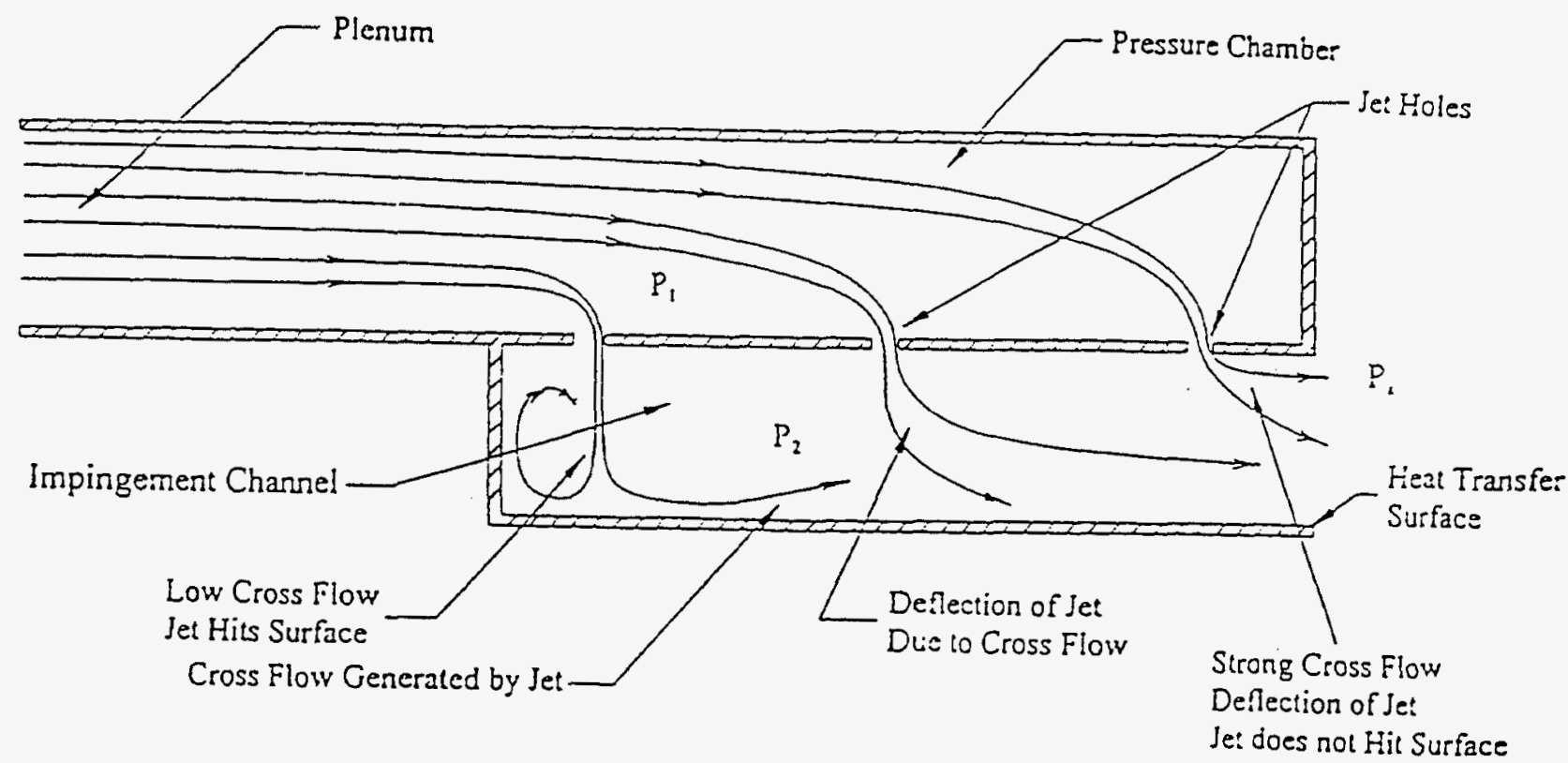

Figure 8.5-1: Schematic Of The Jet Impingement Test Section 


\section{TEST METHODOLOGY}

Three flow orientations and five impingement surfaces were used to determine the pressure differences and heat transfer results for multiple jet impingement with surface roughness and flow conditions. The same impingement jet plate ( 12 rows of 4 holes) was used for all of the test cases run.

The parameters studied are described below:

1. Effect of opening orientation on heat transfer. The cross flow developed in the impingement channel from the spent jets is dependent on the exit opening orientation. Three flow exit configurations were tested.

2. Effect of impingement jets on smooth surface.

3. Effect of Plexiglas pins. Reduction of crossflow and jet interaction. The crossflow from spent jets deflects the jet flow and reduces the impingement strength.

4. Effect of dimples on the impingement surface. The heat transfer area and surface roughness are increased by dimples.

5. Effect of dimples and long Plexiglas pins combined. The heat transfer pattern with the combined effect of dimples and long pins. The dimples increase heat transfer area, while the pins isolate the impingement jets from cross flow.

6. Effect of short copper pins. The effect is similar to dimples.

The various surfaces were placed on a copper plate fixture which was instrumented with thermocouples. The copper plates were heated with a power supply. Air passed from the plenum through the impingement jet plate into the impingement channel.

\section{TECHNOLOGY APPLICATION}

The results of this test were used in the design of the air-cooled turbine hardware for the GE90based industrial ATS being designed at GE Aircraft Engines.

\section{PLANS FOR PHASE 3}

There is no Phase 3 program for the GE Industrial ATS.

\section{CONCLUSIONS}

This experiment shows pressure difference and heat transfer results for multiple jet impingement for several surface roughness and flow conditions. It was oobserved that the impingement jets create a large amount of turbulence mixing, and that additional surface roughness did not increase cooling under the flow regions studied. 


\section{TASK 8.6.1 - ROTATIONAL HEAT TRANSFER - BUCKET COOLING}

\section{BACKGROUND}

Prior work dating back over 40 years has shown both analytically and experimentally that the effect of Coriolis and buoyancy forces present in rotating radial ducts with heat addition can dictate the heat transfer coefficients present in these ducts with large local variations in both radial and circumferential directions. In view of the complexity required to obtain sufficiently accurate data at high centrifugal accelerations, the bulk of the measurements reported to date are at Reynolds number and Buoyancy number values much below those present in today's gas turbine designs.

\section{OBJECTIVE}

Prediction of gas turbine blade life requires sufficient accuracy in the prediction of both the local hot gas side and coolant side heat transfer coefficients present at the relevant blade surfaces. While a considerable data base exists for the hot gas side coefficients, the data base for the rotating blade coolant passages is very limited. Only recently have measurements in rotating simulated blade passages become available that cover the conditions of interest to aircraft gas turbine blades. At the conditions present in the ATS turbine, extrapolation of the existing data base is needed. An effort is presently underway at CRD that will provide the required heat transfer data base over the range of dimensionless parameters of interest to the ATS turbine.

\section{APPROACH}

Considering the little understood coupling between passage geometry and body forces due to rotation at conditions present in gas turbine buckets, it was decided to obtain data at full-scale dimensions. To limit cost and complexity, however, a higher density working fluid was selected in order to reduce the required angular velocity by more than two-to-one. A gas with a molecular weight of 102 (R-134A) was chosen. By first investigating two identical duct geometries-one with smooth walls and one with turbulated walls-the enhancement available with a given turbulator design was directly defined.

\section{TEST FACILITY}

A rotating test facility was installed in a test cell that consisted of a $143-\mathrm{cm}$ ( 56.3 -inch) outer radius arm equipped with a yoke to hold the test section (Figure 8.6.1-1) and suitable passages for the working fluid, power leads, and thermocouples. A heated balance arm was employed to permit balanced operation by equalizing the temperatures in each arm. The balance arm was equipped with locations at which weights could be changed to achieve final balance. Each arm was partially enclosed by stream-lined fairings to minimize drag. The arm assembly fits into a shaft that supports the slip rings between roller bearings.

The air-cooled Wendon slip rings allow for 12 heaters and 80 thermocouples. A Deublin rotary union, shown in Figure 8.6.1-1, was employed to lead the working fluid in and out of the arm assembly. To avoid the use of a large radius rotating vacuum seal, the arm was operated at one atmosphere in its floor-mounted enclosure. A 75-hp variable frequency speed-controlled motor 
was needed to achieve the desired operating range considering the drag of both arms. A vent clearance was left at the inner radius of the enclosure, and a suction-fan-driven discharge port was provided at the outer radius of the enclosure to obtain the desired enclosure air temperature when operating at high speed and test section temperature. At low speeds and operating temperatures, heaters were added under the enclosure insulation to hold air temperatures close to the test section temperature for minimum heat loss. All control wiring and instrumentation were led outside the test cell, where the controls and the PC-based data acquisition system (HP3852) were installed. The shaft was supplied with accelerometers and vibration sensors that shut the system down if certain levels were exceeded. A view of the test facility is shown in Figure 8.6.1-2.

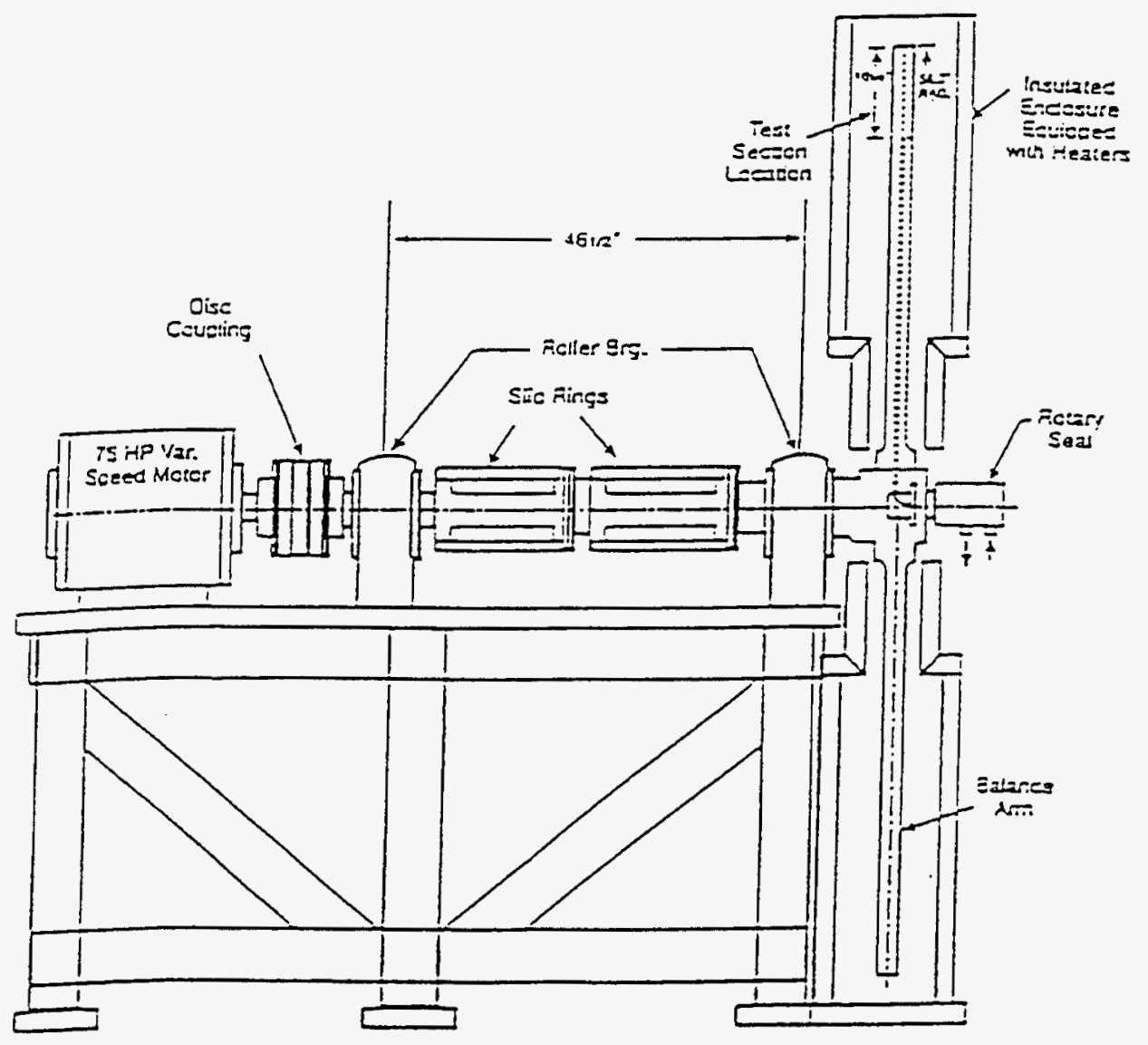

Figure 8.6.1-1. Configuration of Rotating Test Rig

A schematic of the R-134A gas supply system is shown in Figure 8.6.1-3. A 5-hp single-stage oilfree reciprocating compressor was employed using a compressor bypass loop to control flow. A nitrogen purge allows venting of any oil that passes through the crankcase seal. The minimal amount of gas that passes the cylinder seal is also vented. 


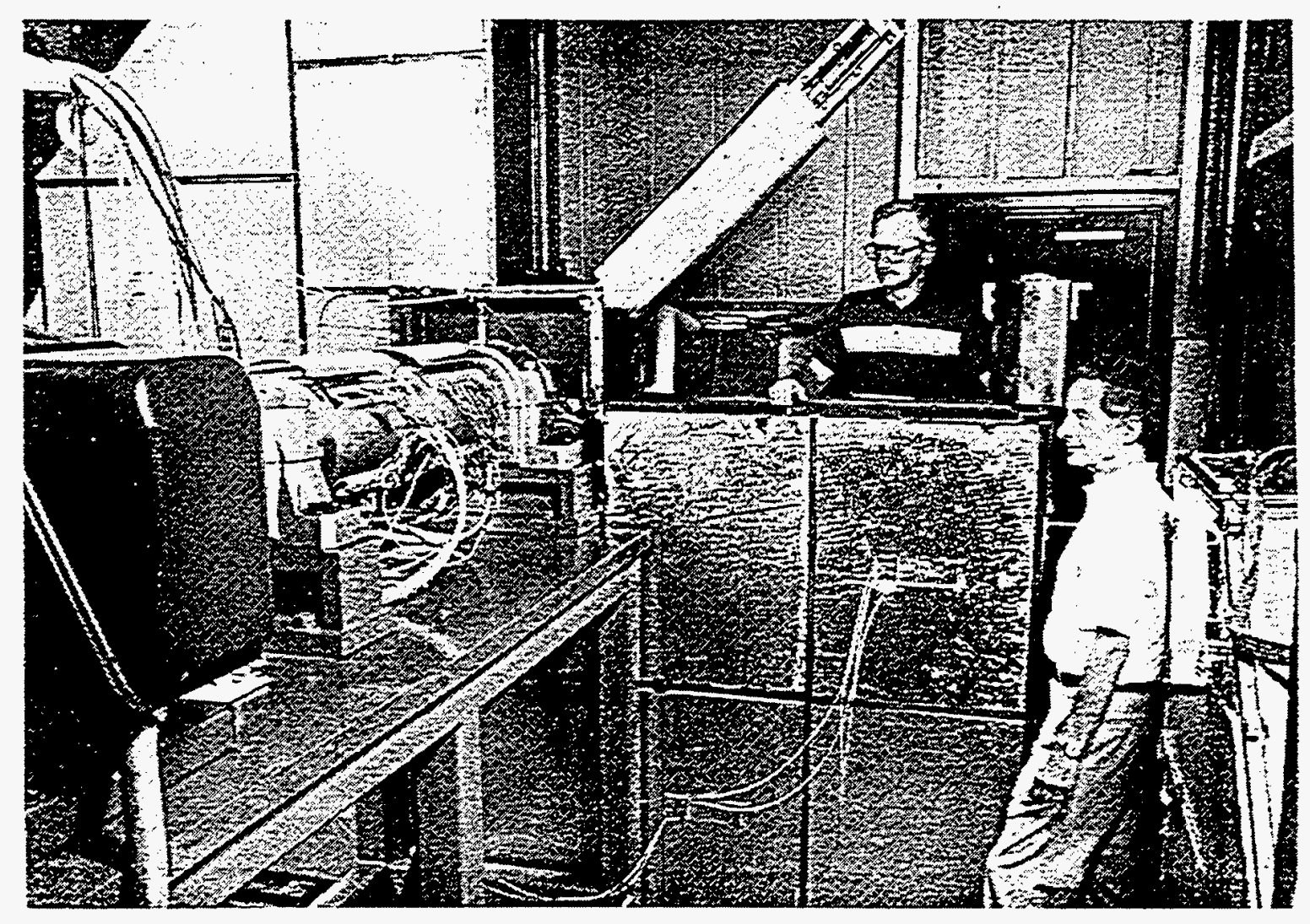

Figure 8.6.1-2. Rotational Test Facility

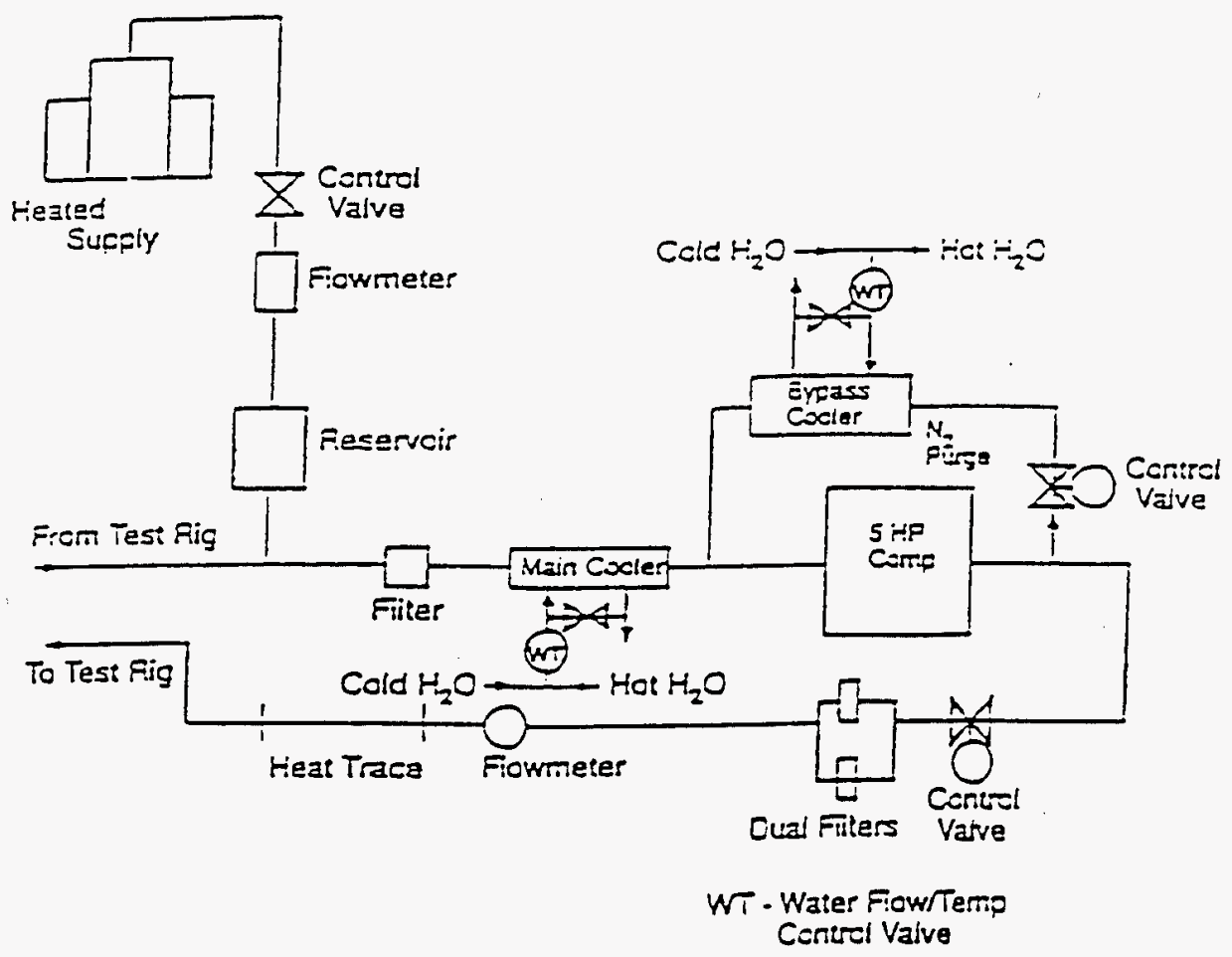

Figure 8.6.1-3. Schematic of R-1345A Supply System 


\section{TEST SECTIONS}

For all test sections, the primary objective was to measure the heat transfer coefficients on each side of the rectangular duct at as many radial locations as possible, consistent with the high centrifugal forces and with the space available for heater and thermocouple leads. A maximum of five radial segments was allowed, resulting in twenty separate segments, each instrumented by at least two thermocouples.

A conduction analysis showed that, with a small air gap between the five radial copper segment sets, a thin-walled continuous cartridge heater would supply heat to each of the four duct sides with acceptable radial conduction effects. The radial variation of net heat flux into a test duct side was calculated to be about $\pm 20 \%$, a value that is close to that subsequently measured. The heat input to each side was independently controlled to permit either temperature or uniform heat flux control to each side. The temperature difference between the thermocouple location and the inner test duct wall was generally about 1.5 percent of the wall-to-fluid temperature difference involving a maximum correction of 7 percent at the maximum heat flux value employed in the data reported here. The radial and lateral heat flow corrections to each segment, as well as the anticipated heat loss to the environment, was calculated to be acceptable provided they were accounted for in the data reduction process. The experimental accuracy obtained over a range of conditions is discussed under experimental results.

Two thermocouples were supplied in each manifold to measure the mixed fluid inlet and outlet temperatures. The inlet and outlet lines that passed through holes in the arm were supplied with spacers to minimize vibration. A suitably pinned expansion bellows was provided in each line where it entered the yoke section to take up the radial load due to the line itself from the inner radius at the shaft as well as that due to thermal expansion. The stainless-steel-sheathed thermocouples, which were brazed into the copper segment and the steel-clad heater conductors were fastened into grooves cut around the periphery of the arm and attached to a terminal board at the shaft. In this manner sufficient strength was allowed in the load assembly, and it is readily removed for test section replacement. A streamlined fairing was placed around the test section with an outer and inner cap to decrease drag and reduce the heat loss from the test section.

\section{EXPERIMENTAL RESULTS}

The experimental data were obtained by heating the enclosure at low angular velocities while setting the required flowrate and pressure levels. When these were stabilized, the desired angular velocity and heating condition were set. Data were recorded at predetermined intervals until steady state was obtained. For most runs a uniform wall temperature was set equal at all four walls by adjusting the heat input. Data were also obtained with reverse rotation since the turbulator locations were different on the "lead" and "trail" sides. This was the case for both radial outflow and radial inflow operation.

For the heat loss calibration runs, the test loop was evacuated to eliminate heat removal by the test duct. The combined convective and radiation heat transfer coefficient from the test section to the enclosure environment was then experimentally evaluated. The heat losses affected the measurement accuracy only at the minimum heat transfer coefficients present in the test duct. 


\section{TECHNOLOGY APPLICATION}

Since the data were obtained over a wide range of Buoyancy and Reynolds number, as well as for smooth and turbulated ducts, they are applicable to any turbine stage in the 7 and 9 series machines were rectangular ducts are present. They have already been used to change the initial first-stage cooling passage configuration in the $9 \mathrm{H}$ to allow it to operate in the high performance regime, and will be incorporated into the $7 \mathrm{H}$ design.

\section{PLANS FOR PHASE 3}

In view of the limitations placed on the designer by the presence of the measured low performance region, the main thrust of the Phase 3 activity will be to develop a passage geometry that will eliminate the low performance region without causing an excessive pressure drop penalty.

\section{SUMMARY}

The results obtained clearly indicate the strong effect of duct aspect ratio, Reynolds number, and Buoyancy number on the heat transfer in turbine bucket cooling passages. This is in addition to the effect of the heating mode (i.e., four side heated vs. lead and trail side only heated) found by other workers for square and rectangular ducts. The results obtained in this investigation were employed to design the bucket cooling passage dimensions in a manner that avoided the dimensionless parameter values at which poor enhancement was measured. They also encouraged the further investigation of other turbulator configurations that will provide better performance than the configuration investigated here. 


\section{TASK 8.6.2 - ROTATIONAL HEAT TRANSFER - WHEELSPACE COOLING}

\section{OBJECTIVE}

The interstage turbine wheelspace, diaphragm, and outer seal design, as well as the operating conditions for the ATS gas turbine, are sufficiently different from existing gas turbine experience to render the use of normal purge flow criteria questionable for preventing hot gas ingestion and for providing sufficient cooling of this region. CFD computations have been used to select a design concept that will be verified in the proposed experiments. An existing GE Freon gas rotational test facility will be modified to simulate the ATS gas turbine wheelspace geometry. The Rotational and Radial Flow Reynolds numbers present in the ATS gas turbine design can be matched using a 3:1 reduced scale model operating with R-134A at about 21 psia in the cavity. Leakage across the nozzle stage and the effect of the circumferential pressure variation on ingestion will be measured. This testing will allow rapid evaluation of various design approaches.

\section{BACKGROUND}

The minimum coolant flowrate needed to prevent hot gas ingestion at the outer turbine disc seal has been investigated by many workers using simple axial or radial clearance seals. The characteristics of more realistic seal designs have been shown for a few configurations, where the strong dependence of the minimum coolant flow on the specific seal geometry is noted. The effect of rotor seal eccentricity has been studied and found that a $10 \%$ change in the circumferential seal clearance resulted in a $35 \%$ increase in the required coolant flowrate. More recently, the effect of circumferential pressure gradients on the minimum coolant flowrate has been shown to be proportional to the square root of the pressure amplitude up to amplitudes of about $1 \%$ of the static pressure. The pressure amplitude and the period (i.e., the angular width of the pressure variation) are the main variables. The published experimental data are generally limited to simple seals and to Reynolds numbers that are more than an order of magnitude less than the values in the Advanced Machine. Clearly the correlations for the minimum coolant flow needed to prevent hot gas ingestion have not been verified at the operating conditions of interest and have not been generated for the seal designs considered for the Advanced Machine. While some verified seal flow design methods are available for currently operating machines (e.g., established aircraft gas turbines), these seal geometries are also different from those used in the Advanced Machine and have been qualified in a lower Reynolds number range and for different values of the circumferential pressure gradients.

Given the lack of verified seal flow predictive methods, it was decided to build a scale model of the seal space between the first-stage turbine and the second-stage stator to model the operating conditions present in the Advanced Machine and to allow the evaluation of the effect of circumferential pressure gradients. The modeling approach and the design of the test rig are summarized below.

\section{APPROACH}

Employing the R-134A closed loop test facility that has been used at CRD to develop heat transfer data for aircraft gas turbine rotor-stator cavities, it was found that the axial and rotational 
Reynolds numbers present in the Advanced Machine can be modeled at about 2 atm pressure. This was possible using a 3.75:1 scale model at $2500 \mathrm{rpm}$. A hot gas stream at about $100 \mathrm{C}$ would be employed with a coolant gas stream at about $30 \mathrm{C}$ where traversing thermocouples would allow the measurement of the extent of hot gas ingestion at the outer and inner angel wing seal locations. The circumferential pressure variation can be generated using a circumferentially varying orifice area downstream of the seal location. This orifice would be easily replaceable to test different circumferential pressure gradients.

The number and scaled geometry of the cooling gas nozzles that supply the seal space was equal to the full-size nozzles. The seal flow that passes through the stator seals was modeled using multiple orifices in the passages that connect the seal space to the second stage turbine seal space. The pressure ratio across the stator was the same as that in the application.

A 3D CFD model of the tested seal geometry was generated and compared to the data in order to verify or modify the CFD model. The verified CFD model can then be employed to evaluate seal designs of the type being considered for the Advanced Machine.

\section{TEST RIG}

The test rig shown in Figure 8.6.2-1 consists of a $62.5-\mathrm{cm}$ diameter laminated wood rotor mounted on an aluminum disc. A steel inlet manifold supplies a uniform flow to the hot gas annulus. Downstream of the seal space the simulated stator section contains the inlet plenum for the cold gas flow, the seal gas bypass lines to the discharge manifold, and the instrumentation for the seal space.

Before entering the discharge manifold, which operates at about 1 atm, the flow passes through an orifice, which can be variable in circumferential cross-section, with the same pressure ratio across it as the pressure ratio across the stator section in the ATS turbine. The seal space shown in the enlarged view in Figure 8.6.2-1, has a stainless steel rotor seal ring with the two angel wing seals and a steel stator seal ring that match a current seal design. The seal cavity also matches a current design in which, in place of the rotating stator seal and the stationary seals between the stator segments, the coolant flow through the stator seals can be varied by orifices installed in the eleven flow passages that connect the seal space to the discharge manifold. The rotor cavity inside the seal space inner radius is a dead cavity into which a small bleed flow of cool gas can be supplied to hold the cavity temperature close to that in the seal space. The twenty-two coolant flow nozzles are set at $15^{\circ}$ to the tangential direction and sized to provide the same ratio of nozzle discharge velocity-to-circumferential rotor velocity at the total design seal flow as the ratio in the gas turbine. 


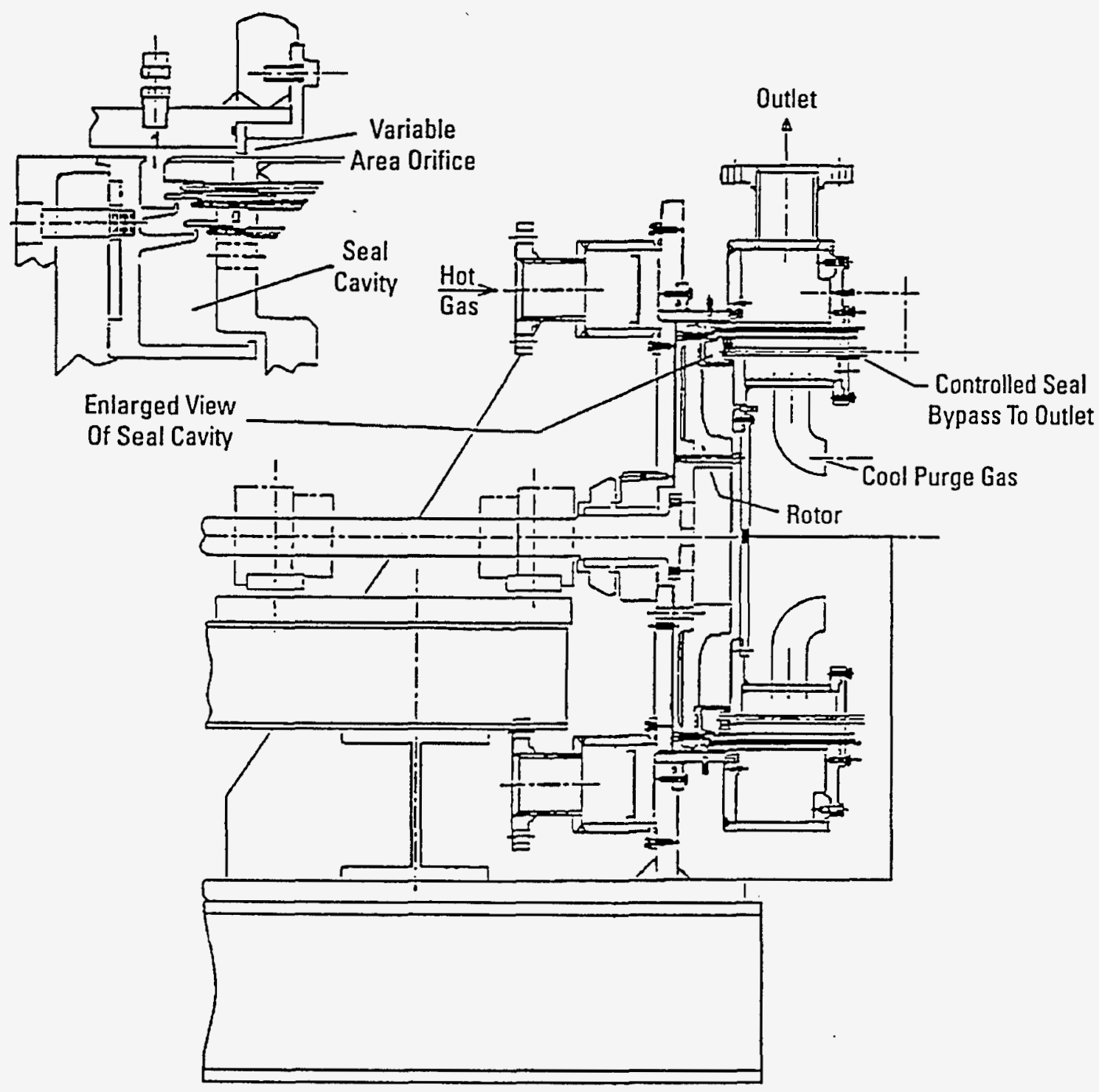

Figure 8.6.2-1. Wheelspace Cooling Test Rig Configuration

The axially traversing thermocouple probes are located at the inner and outer and can also be used, instead of the velocity probes, in the outer seal space. Eleven inner seal and twenty-one outer seal probes are located around the circumference. Eight of the more critical outer seal probes are concentrated in the first of eleven equal sectors that will match the eleven sets of variable areas that will be located in the orifice plate. The remaining ten outer seal probes are circumferentially spaced to check repeatability. The eleven inner seal temperature probes are located at selected maximum and minimum area values of the planned variable orifice plate. The eleven probes located in the outer seal space can be either velocity probes, to measure the 
circumferential and radial velocities, or temperature probes. Five of these locations are in the first of the eleven sectors, as above, with the remaining six at corresponding angular locations in three of the other eleven sectors. To measure the circumferential static pressure distribution at the seal space, twenty-three static pressure taps are located in the outer radius of the annulus. Ten of these are again located in the first of the eleven sectors, with the remainder placed at corresponding angular locations in three of the other eleven sectors. The intent of this instrumentation placement is to determine the degree to which the symmetrically induced circumferential pressure profile causes a symmetrical distribution of hot gas flow ingress when insufficient coolant flow is present.

The construction and assembly of the test rig has been completed, including rotor balancing and the instrumentation is ready for connection.

\section{VARIABLE ORIFICE DESIGN}

In order to determine the circumferential pressure distribution allowed by the variable area orifice located $2.5 \mathrm{~cm}$ downstream from the seal space, a 3D CFD model of the seal space geometry was employed to calculate the velocity and pressure field. A typical design point condition was simulated first using a uniform orifice that produced the 1.7 pressure ratio across the orifice. This axisymmetric computation showed negligible hot gas ingestion even at one-quarter of a nominally conservative seal flowrate. In order to conform to typical circumferential pressure gradients that can be present in gas turbines, it was decided to design the test rig orifice to yield eleven equal sectors of pressure oscillations with an amplitude of 1 to $3 \%$ of the static pressure level. A larger number of sectors would limit the instrumentation in each sector excessively, and a smaller number would tend to be unrealistic. The CFD model showed that using a maximum orifice area ratio of $3: 1$ available in the annulus for reasonable values of the flow coefficient, a $11 / 2$ to $2 \%$ pressure amplitude will exist at the seal location. For this pressure profile, significant hot gas ingestion was calculated at the outer seal at the originally selected nominal seal flowrate.

\section{SUMMARY}

The turbine rim seal design and operating conditions present in the Advanced Machine are sufficiently different from those for which verified seal flow predictive methods are available to warrant the construction of a scale model of the seal space. This scale model must operate at the dimensionless parameters present in the ATS turbine and must allow simulation of typical circumferential pressure gradients that may be present at the seal location. A test rig design is described that will satisfy these requirements as determined by a 3D CFD model of the seal space with the desired circumferential pressure gradients in place. This test rig has been constructed and installed. 


\section{TASK 8.7 - TURBINE INLET NOZZLE HEAT TRANSFER}

\section{OBJECTIVES}

Task objectives include the investigation and determination of the external heat transfer coefficient distribution for the ATS turbine inlet nozzle airfoil, as well as the validation of computational heat transfer predictions supporting the design. The task includes the characterization of external heat transfer due to the effects of inlet flow preparation including turbulence intensity level and swirl, aifoil surface roughness, and Reynolds number. A 1/2-scale linear airfoil cascade designed to model the appropriate nondimensional turbine nozzle parameters, including inlet flow Reynolds number, nozzle pressure ratio, and airfoil Mach number distribution is used for testing. The test airfoil surface may be coated in various ways to provide well-characterized roughness distributions. The flow entering the cascade section is conditioned to model the turbulence intensity level and swirl that would be obtained with a Dry Low $\mathrm{NO}_{\mathrm{x}}$ (DLN) combustor under cold flow conditions, including the actual swirler geometries and development sections. In addition, a range of axial turbulence intensities without swirl is available through the use of perforated plates at the cascade inlet.

Since the ATS turbine inlet nozzle is primarily a non-film-cooled airfoil, the conventional airfoil protection afforded by film cooling is not present; hence the sensitivity of the airfoil design to the specific external heat load distribution is greater. This sensitivity extends to the major factors that influence external airfoil heat transfer, i.e., surface roughness, Reynolds number, and freestream turbulence intensity. This task will quantify the sensitivity of the turbine inlet nozzle to these major parameters, and provide design data at the appropriate non-dimensional design operating condition.

\section{TASK RESULTS}

\section{DESIGN, FABRICATION, AND ASSEMBLY}

The major facility hardware (i.e., piping, flanges, flow preparation pressure vessel, inlet and exit flow control valves, monitoring instrumentation, cast pre-swirlers, and raw material) was purchased and received in late 1993. The test facility was constructed and the majority of the rig assembled by April 1994. During this same period, the cascade section proper was fabricated and assembled. The pressure vessel and cascade section were hydrostatically tested to a pressure roughly 2.7 times that of the anticipated operating level of $5 \mathrm{~atm}$. Several thrust supports and a pressure vessel rupture disk were installed. Safety reviews were held to determine any additional facility requirements.

The cascade section is a $1 / 2$-scale linear representation of the ATS turbine inlet nozzle airfoil. The test section consists of five airfoils and four flow passages. The height of the cascade is slightly less than $1 / 2$-scale to accommodate the available flow from the compressors; however, the passage throat aspect ratio is maintained at a value of approximately 4.5 , which provides adequate simulation of the aerodynamics of the ATS turbine The cascade hub and tip surfaces are straight planar sections, rather than the slightly convergent flowpath of the actual turbine nozzle. The cascade outer walls are constructed of aluminum; the central three airfoils used 
for all airfoil measurements are of 304 stainless steel. Three airfoils were fabricated with several static pressure taps each in order to determine the Mach number distributions of the two center flow passages. A fourth airfoil was fabricated as a thin-walled airfoil shell, with wall thickness of $1.27 \mathrm{~mm}$ ( 0.050 inch). This airfoil was instrumented with 38 imbedded thermocouples for the determination of local external heat transfer coefficients. Thermally insulating cascade endwall inserts were also fabricated to isolate the heat transfer airfoil from the surrounding cascade aluminum. All of these airfoils are removable for maintenance and desired changes.

Several flow preparation pieces were fabricated for the development of the appropriate freestream turbulence intensity levels and swirl that are incident upon the nozzle cascade. A $1 / 2$-scale sheet metal model of a DLN combustor liner was made, which attaches to a symmetrically convergent transition piece. The transition piece does not model the actual Stype design, but transitions radially and circumferentially from a circular cross section to the four-passage rectangular section of the cascade inlet. A 1/2-scale version of the DLN-3 swirler head-piece was constructed using cast pre-swirlers and fabricated diffusion swirlers. An alternate generic swirler vane set was also fabricated for generating variable degrees of swirl in a solid body rotation fashion. Turbulence-generating methods include perforated plates located just upstream of the cascade airfoil leading edge, and a larger bar grid located between the combustor liner and the transition piece. All of the flow preparation devices described above are modular so that they may be inserted or removed as desired.

The facility design conditions call for the supply of approximately $7.7 \mathrm{~kg} / \mathrm{sec}(17 \mathrm{lbm} / \mathrm{sec})$ air flow through the cascade, with inlet total conditions of $25 \mathrm{C}(76 \mathrm{~F})$ and $5 \mathrm{~atm}$. To achieve these flow conditions, it is necessary to combine the outputs of three compressors. The piping system is therefore arranged with two supply lines, such that any one compressor may be used, or any two compressors in combination, or all three compressors.

\section{FLOW TESTING}

Initial flow testing began on 20 April 1994. The cascade was assembled with airfoils in the middle three positions, which contain static pressure instrumentation for flow through the center two air passages. All test rig pressure transducers were calibrated at this time. Air flow was initiated through the cascade, initially at low flow and low pressure. During this time, the instrumentation was verified to be displaying correct information. Mainstream air supply was brought to the cascade in separate tests using both supply lines. When the cascade is operated at full conditions, these two lines shall be flowing in parallel. Operation through the larger of the two lines allowed verification of the total flow orifice station for the cascade via comparison with another orifice located farther upstream in this supply line. Static pressure distribution measurements made during the flow tests showed Mach number distributions appropriate for the cascade pressure ratio used, though this pressure ratio was initially low. The suction side of the central airfoil showed static pressures that were inconsistent with the other surrounding measurements. After eliminating other flow effect possibilities, this airfoil was removed for inspection.

Flow testing resumed on 27 June 1994. The central airfoil indicated a flow on its suction side, downstream of the throat location, which was expanding significantly beyond the desired 
level. This pointed to the need to "relocate" the boundary wall which contains the flow on the suction sides of the cascade. A fabricated $2.5^{\circ}$ wedge piece was installed in the cascade and testing continued. The cascade Mach number distribution was determined with the modified exit flow geometry. While the distribution of flow amongst the cascade passages is not periodic, the Mach distribution around the central instrumented airfoil is satisfactory. To go one step further, the Mach distribution about the center airfoil appears to be controllable over a wide range with change in the cascade pressure ratio. This behavior allows for greater flexibility of the test parameters. Once the Mach distribution was determined to be acceptable, testing was initiated to map the distribution as a function of cascade pressure ratio. During these later tests, the $2.5^{\circ}$ wedge piece serving to alter the exit flow was liberated from the containing wall. Every attempt had been made to assure secure adhesion and smooth boundary transitions, but epoxy erosion and eventual pressure differential lift-off resulted in the release of the wedge. Since the geometry is acceptable, a more permanent modification is appropriate. A new wedge piece was fabricated. The containing wall of the cascade has been modified to allow the mechanical fixturing of the wedge piece into this wall. A recessed pocket with several bolts will eliminate any possibility of future failure.

The cascade was flow tested again on 13 September 1994, using the combined output of all three facility compressors. Flow testing showed an apparent choked condition in the flow path, since the pressure ratio of the cascade could not exceed approximately 1.65 . The cascade pressure ratio reached 1.93 , with slightly supersonic flow on the suction side of the airfoils. Also of importance, the cascade measurements show the cascade to be nearly periodic in flow for each passage. Previous tests, which did not indicate periodicity, apparently were affected by the loss of the insert wedge.

Subsequent flow tests were conducted on 28 September 1994 at conditions that yielded an inlet Reynolds number similar to that of the ATS turbine nozzle. Airfoil static pressure measurements were recorded for the two central airflow passages at cascade pressure ratios of $1.46,1.55,1.67,1.78,1.86$, and 1.93, providing Mach number distributions over this range of conditions. At the highest pressure ratio, the cascade is slightly transonic, providing turbine representative local flow Mach numbers for heat transfer testing.

\section{HEAT TRANSFER TESTING}

Upon completion of the preliminary flow testing, the cascade was partially disassembled, and the center airfoil removed. In preparing the thin-walled, thermocouple instrumented airfoil for placement into the cascade, the adhesion method for application of the thin-foil surface heater was found to be unsatisfactory. The photographic mounting film was chosen as the best overall adhesion method, providing uniform thickness without voids, and capability up to $94 \mathrm{C}$ (200F).

During re-assembly with a smooth surface test airfoil, some problems were encountered in assembly with the thin-foil surface heater buss bar touching adjacent metal parts, resulting in short circuiting. Modifications were completed to the cascade endwalls to eliminate any possibility of electrical shorting. Repairs were also made to the instrumented airfoil to recover a broken thermocouple and replace the heater wire leads. The cascade was run with low flow to check out operation of all thermocouples and the heater. 
Smooth airfoil tests were performed during this period. The airfoil surface was that of the applied thin-foil Inconel heater, having a measured centerline average roughness of 0.4 micron (16 $\mu$ inches). The flow configuration consisted of three different average inlet turbulence intensity levels of approximately $4.5 \%, 5.6 \%$, and $9.6 \%$, with no inlet swirl.

\section{TECHNOLOGY APPLICATION}

Accurate knowledge of the heat loads for the turbine inlet nozzle is required for the successful design of the component. This requirement is amplified in the current application by the elimination of film cooling. Each major contributor to heat transfer-including surface roughness, turbulence intensity, and Reynolds number-must be assessed in a way that models the expected conditions for the turbine nozzle. Insufficient data exist in the literature to determine the effects of these parameters with the required accuracy for the ATS turbine. This task has developed the test apparatus and methodology, and performed baseline smooth airfoil testing in preparation for obtaining the desired information. Design condition test data will be obtained under the Phase 3 task that extends this effort.

\section{PLANS FOR PHASE 3}

All further efforts concerning ATS Turbine Inlet Nozzle Cascade were transferred to a Phase 3 activity at this point.

\section{SUMMARY AND CONCLUSIONS}

The measurements obtained with vane cascade smooth airfoils were used to characterize the external heat transfer due to the effects of turbulence intensity level and swirl. Heat transfer coefficient results were of the form expected and entirely consistent as Reynolds number and turbulence level were altered. These measurements will be repeated under the next series of rough surface tests to verify the intensity levels obtained. 


\section{TASK 8.7.3 - NOZZLE END WALL IMPINGEMENT}

\section{OBJECTIVE}

The objective of the present work was to measure the pressure drop and heat transfer coefficient distributions for two impingement jet modules having different jet geometries and to compare the results with the design tool calculations. The first module had uniform jet diameters where cross flows are expected to have a significant effect. The second module had jet diameters and configurations which varied along the cross flow direction with the intent of maintaining a constant coolant side heat transfer. This task provided test data for verification of design tool calculations, and ultimately, to ensure sufficient cooling of the nozzle end wall.

\section{INTRODUCTION}

For the closed circuit cooling design considered, impingement cooling was chosen as the effective system for first-stage nozzle endwall cooling. The first design was composed of several impingement modules connected in series and/or in parallel to cover the various regions of the airfoil endwall. The impingement hole patterns in each module were tailored to accommodate the hot gas side thermal loads and maintain wall temperatures at acceptable levels.

\section{TEST SECTION}

The test section presented in Figure 8.7.3-1 consists of two impingement cooling modules connected in series where the cooling air exiting the first module is used to provide impingement cooling of the second module. The cooling air to the test rig is supplied by the Worthington compressor. The air flowrate was measured by means of instrumented venturi meters and controlled by flow control valves. The tests were performed at air flowrates of $0.0453,0.0906$, and $0.1359 \mathrm{~kg} / \mathrm{s}(0.1,0.2$, and $0.3 \mathrm{lb} / \mathrm{sec})$ which correspond to impingement jet Reynolds numbers ranging from 8,000 to 72,000 which are representative of the design conditions. 

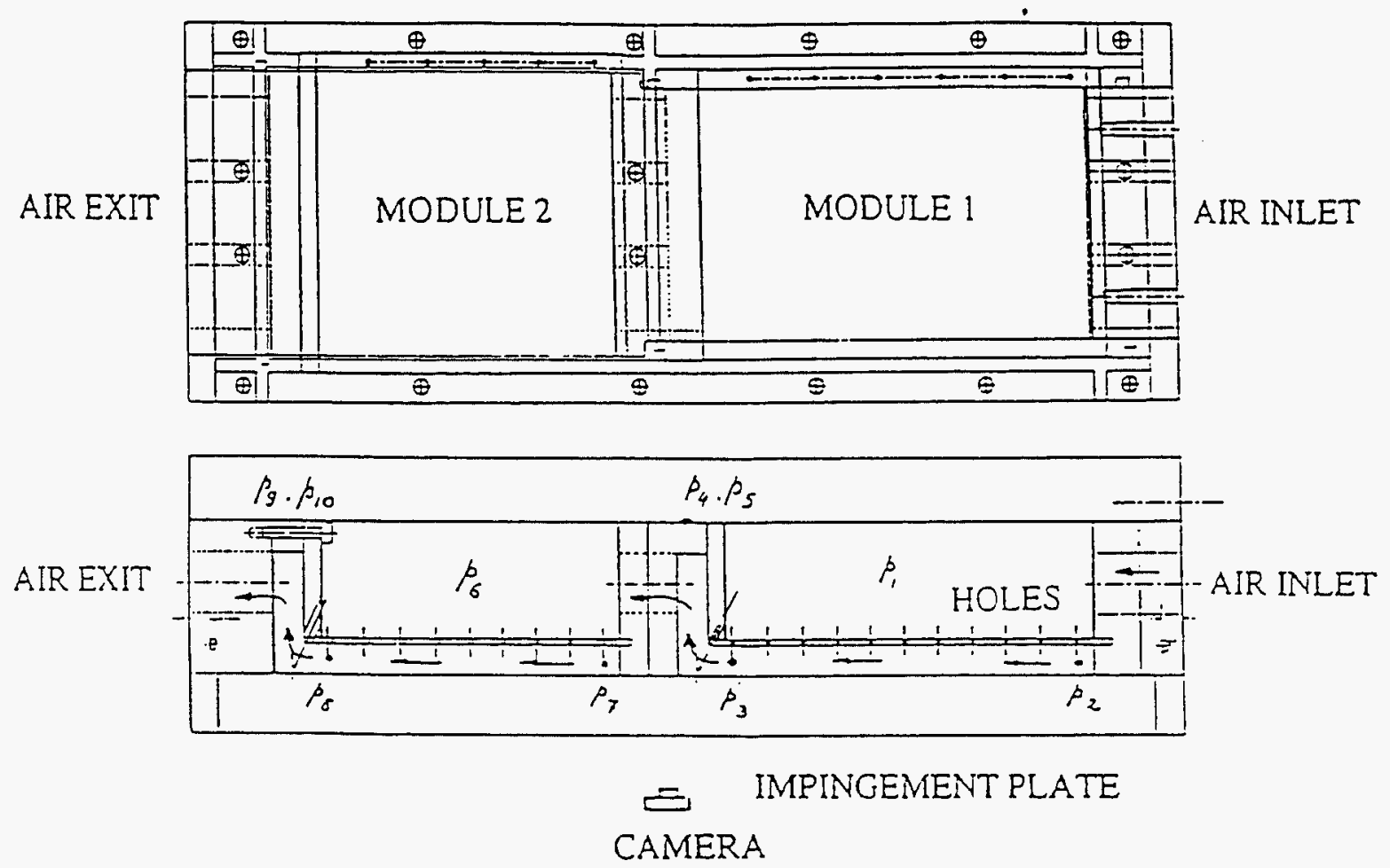

\section{Figure 8.7.3-1. Schematic of the Test Section with Two Impingement Modules and Locations of Pressure Taps}

Module 1 consisted of an impingement supply chamber with air entering the supply chamber through three holes machined on the side wall. The impingement holes were distributed over a plate consisting of twelve rows of holes, with each row having eight holes. After impinging on the bottom surface, the air flowed along a channel turned through a $90^{\circ}$ bend at the end of the impingement surface. The last row of holes (Row 12) was inclined at an angle in order to provide impingement air in a region close to the $90^{\circ}$ bend for cooling. The air then turned through a second $90^{\circ}$ bend and fed the supply chamber of the second impingement module through three holes. The bottom impingement surface was covered with a liquid crystal sheet and a thin foil heater. The heater provided a uniform heat flux boundary condition on the heat transfer surface of interest, and the color spectrum of the liquid crystal allowed the visual measurements of the surface temperature contours and their photographic recordings for future data analysis. 


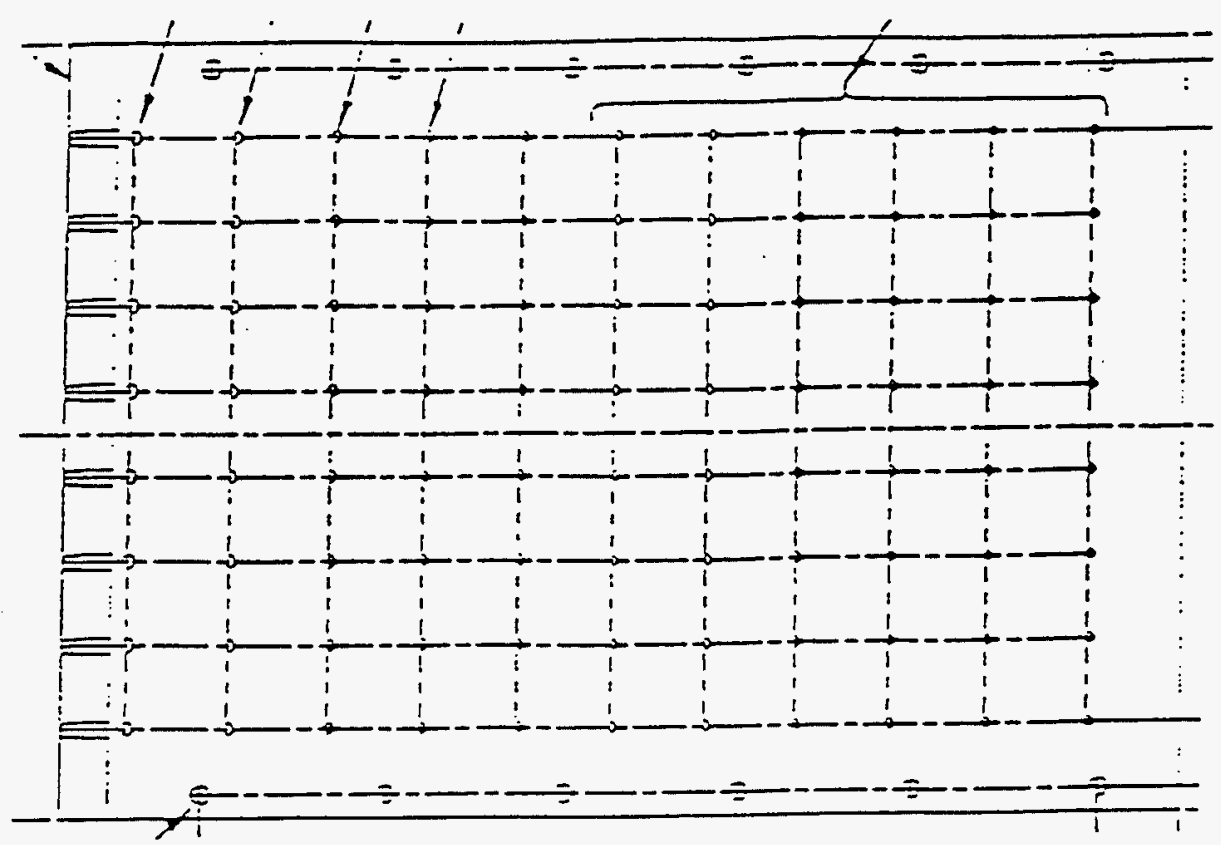

MODULE 1

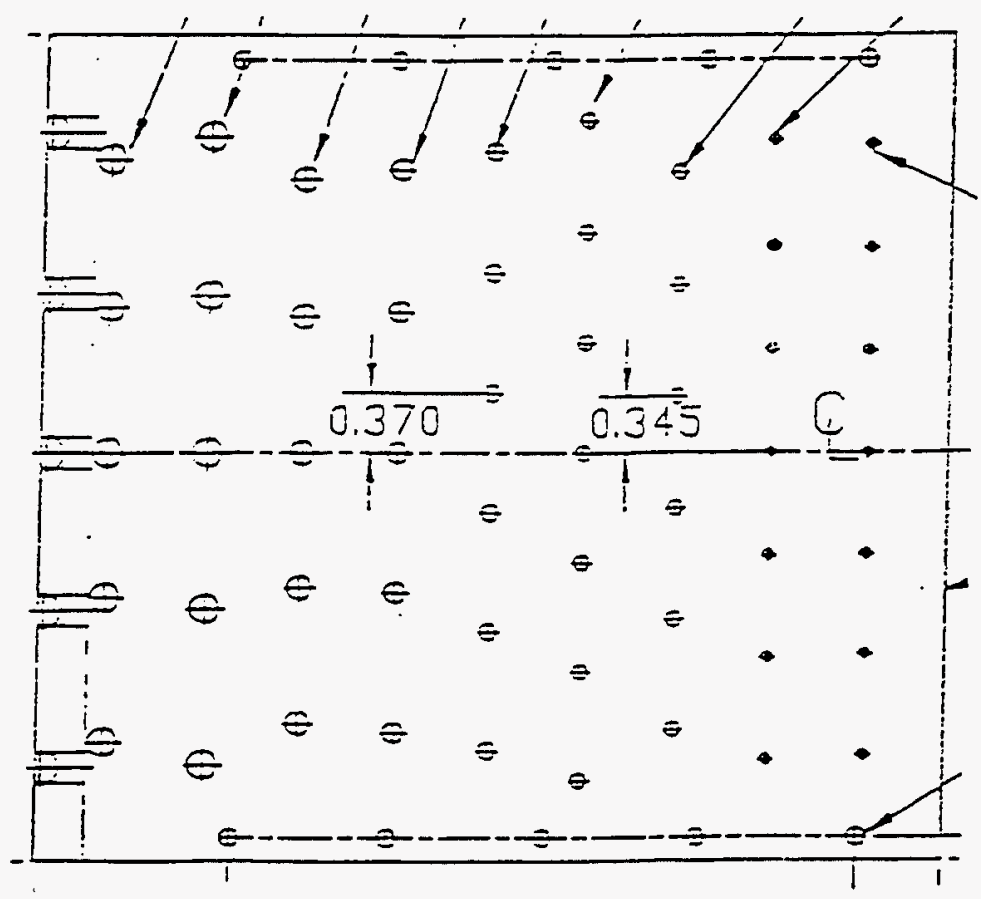

MODULE 2

Figure 8.7.3-2. Impingement Hole Patterns for Modules 1 and 2 
Module 2, presented in Figure 8.7.3-1, consisted of an impingement supply chamber of slightly different dimensions than Module 1 . The air entered the supply chamber through three $2.54-\mathrm{cm}$ holes on the side wall. The impingement holes were distributed over a plate, consisting of ten rows of holes, with each row having a different number of holes ranging from 7 to 5 depending on the row. After impinging on the bottom surface, the air flowed along a channel and turned through a $90^{\circ}$ bend at the end of the impingement surface. The last row of holes (Row 10) was once again inclined at an angle in order to access a region close to the $90^{\circ}$ bend and cool this critical region. The air then turned through a second $90^{\circ}$ bend and discharged into the ambient through three 1-inch holes. The bottom impingement surface was again covered with a liquid crystal sheet and a thin foil heater for the heat transfer tests.

The air supply temperatures were measured at each supply chamber by means of two thermocouples. Five static pressure taps were drilled in each module. The first static pressure tap measured the air supply pressure. The second and third static pressure taps were located at the center of the impingement cross flow passage at the first and last impingement hole location. The fourth and fifth static pressure taps were located at the top wall of the two $90^{\circ}$ bends to measure the pressure before the transition to the second module or discharge to the atmosphere. The fourth hole was on the top of the center discharge hole; the fifth was located on the top wall between two discharge holes.

\section{PRESSURE DROP TESTS}

\section{TEST PROCEDURE}

The test procedure for the pressure drop tests consisted in setting up a given air flowrate through the given module and then measuring the pressure distributions across each module. Some of the preliminary tests did not have taps $4,5,9$, and 10 . In some tests only one of the modules was investigated, and in some of the tests the pressure distributions of both modules were recorded during the same experiment.

\section{PRESSURE DROP RESULTS}

\section{Impingement Hole Discharge Coefficients}

To calculate the discharge coefficients across the impingement holes in Modules 1 and 2, we used the supply chamber pressure ( $\mathrm{p} 1$ for Module 1, and $\mathrm{p} 6$ for Module 2), and the exit pressure downstream of the impingement holes ( $\mathrm{p} 3$ for Module 1, and p8 for Module 2). Using a computer program that models the mass continuity, momentum, and energy equations for the impingement jet geometries and cross flow regions, the acceleration pressure drops due to the cross flow for the three flowrates of the experiments were calculated. The predictions agree closely with the measured pressure drops. These results show that the pressure drop in the cross flow region is governed by the drop in the static pressure due to the acceleration of the cross flow caused by the addition of more cooling flow resulting from the consecutive impinging jets, and that the frictional losses are small when compared to this accelerational pressure drop. 


\section{HEAT TRANSFER TESTS}

\section{TEST PROCEDURE}

The test procedure for the heat transfer tests consisted in setting up a given air flowrate through the given module, and then applying a given uniform heat flux to the thin foil heater. The dissipated heat in the heater was calculated from the measurements of the voltage drop across the heater and the current drawn. Once steady state conditions were reached, the liquid crystal surface color distributions were recorded photographically for further analysis. The impingement supply chamber pressure and temperature were recorded as well as the static pressure distributions along the module. The heat flux was then increased and, at the new steady state conditions, the same data were recorded for analysis. Once the liquid crystal color spectrum was exhausted, the system was cooled and the tests repeated at different flowrates. The liquid crystal color spectrum was calibrated in a constant temperature water bath.

\section{HEAT TRANSFER RESULTS}

Heat transfer coefficient distributions were recorded photographically. As the heat flux is increased, the temperature (color) distributions vary and at the highest heat flux, the liquid crystal has gone through the color spectrum. For each photograph the appropriate heat transfer coefficient was calculated from the dissipated heat flux, the measured inlet air temperature, and the wall temperature corresponding to the green color. The various photographs were then superimposed to calculate an average heat transfer coefficient for a typical jet of each row.

\section{TECHNOLOGY APPLICATION}

The flow, pressure, drop, and heat transfer tests performed during this activity showed that the design tools used were able to calculate the data quite accurately. Based on the comparisons of these results, an optimization design tool was developed and verified for impingement cooling calculations. The method and optimization tool are being applied to the ATS Stage 1 nozzle.

\section{PLANS FOR PHASE 3}

Investigate the effect of surface enhancements (bumps) on the impingement heat transfer coefficients. Develop design methodology for enhanced surfaces. Determine the effect of missing bumps on the heat transfer and the metal temperatures.

\section{TECHNOLOGY APPLICATION}

The flow, pressure drop, and heat transfer tests performed during this activity showed that the design tools used were able to calculate the data quite accurately. Based on the comparisons of these results, an optimization design tool was developed and verified for impingement cooling calculations. The method and optimization tool are being applied to the ATS Stage 1 nozzle impingement cooling design. 


\section{PLANS FOR PHASE 3}

Investigate the effect of surface enhancements (bumps) on the impingement heat transfer coefficients. Develop design methodology for enhanced surfaces. Determine the effect of missing bumps on the heat transfer and the metal temperatures.

\section{CONCLUSIONSISUMMARY}

1. The flow and pressure drop tests showed that the design tool was able to calculate the data quite accurately. The acceleration pressure drop is the dominant one, and the frictional losses are relatively small.

2. The two modules tested showed that the heat transfer performance of each module was in agreement with the design tool predictions. The verification proved that the optimization program was working as expected in generating the appropriate impingement jet pattern to reduce the cross-flow effects.

3. The impingement heat transfer coefficients were compared with calculations performed with correlations existing in the open literature (Florschuetz, Truman and Metzger (1981) and Kercher and Tabakoff (1969)). The comparison showed that the correlation of the Florschuetz, Truman and Metzger (1981) had a wider applicability than the one of Kercher and Tabakoff (1969) in allowing "in-line and staggered configurations", non-square jet patterns, and thus, was chosen as the one used in the optimization design tool. 


\section{TASK 8.7.5 - 1ST STAGE BUCKET}

\section{OBJECTIVE}

The objective of this task was to perform non-rotating heat transfer tests with scaled models of the first stage bucket serpentine cooling circuit in the advanced gas turbine. These tests were designed to measure the local heat transfer coefficient distributions using thin foil heaters and liquid crystal sheets.

The test rig consists of two acrylic models, one representing the leading edge passage and the other representing the remaining passages of the turbulated serpentine cooling circuit in the bucket. The cooling passage geometrical parameters were kept as close as possible to design geometry. The test rigs were also instrumented with static pressure taps to provide information on the related pressure drops as a function of coolant flow rates. The models were designed and constructed prior to the initiation of this task.

\section{EXPERIMENTAL APPARATUS AND TECHNIQUES}

\section{SERPENTINE PASSAGE TEST RIG}

The serpentine passage test rig, shown in Figure 8.7.5-1, was an acrylic model of the internal cooling passages of the advanced gas turbine first stage bucket. It modeled all of the passages in the circuit except the leading edge passage. The $2 \mathrm{X}$ scale model, designed and constructed in 1994, kept cooling passage geometrical parameters as close as possible to the first stage bucket design geometry. The leading edge passage was modeled separately and is discussed below.

Air was used as the coolant and was supplied to a plenum attached to the model inlet and discharged to atmosphere after passing through the entire cooling circuit. Air flowrate was measured using a venturi mass flowmeter. Air inlet temperature was kept at ambient (approximately 70F). Inlet pressure and temperature were measured just inside the inlet.

Four design cross sections were used to specify the geometry of the model at the root, at $40 \%$ of span, at $50 \%$ of span, and at $90 \%$ of span. The geometry of each section was simplified and increased in size by a factor of two. Linear interpolation was used to determine geometry at intermediate locations.

\section{HEAT TRANSFER MEASUREMENT}

Thin foil heaters, thermochromic liquid crystals, and liquid crystal video thermography (LCVT) were used to measure the heat transfer coefficient distributions. This type of liquid crystal has the property of changing color with temperature, which allows temperature distributions to be measured by using a digital image processing system (the LCVT) to convert the color distributions to temperature distributions. 


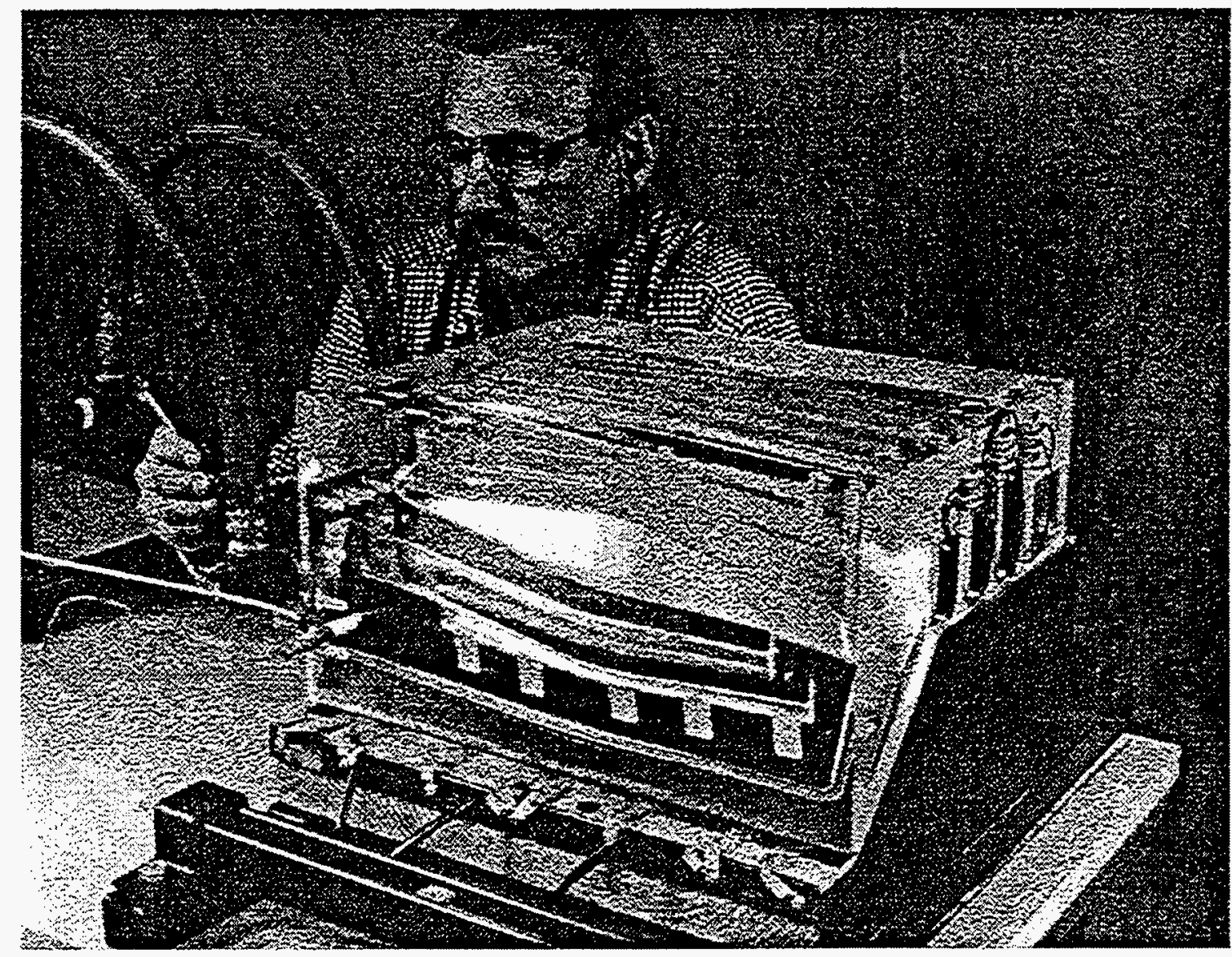

Figure 8.7.5-1. Acrylic Model of First-Stage Bucket Serpentine Cooling Passages, Including View of $180^{\circ}$ Turn Heaters

heat transfer surfaces were built up from a Minco heater, constructed from 0.01-mm $(0.0005$ inch) thick Inconel foil on top of a $0.05-\mathrm{mm}$ (0.002-inch) layer of Kapton to support the foil, and a commercially produced $0.1-\mathrm{mm}$ (0.004-inch) thick Mylar sheet with a liquid crystal layer deposited between the Mylar and a black plastic sealing material. The heater and the liquid crystal sheet were glued down to the acrylic support surface using optically clear epoxy. For all but the $90^{\circ}$ tests, the liquid crystals were sandwiched between the heater and the acrylic and were viewed through the acrylic surface. The $90^{\circ}$ heater arrangement is discussed below.

Power to each heater was supplied by a low voltage, high current dc power supply, producing a known, uniform heat flux boundary condition over the entire surface of the heater. The bulk temperature distribution of the coolant in the serpentine passage was calculated from the coolant mass flowrate, the heat flux, and the heater geometry. Conduction losses through the acrylic surface were calculated using a 1D conduction model which included the effects of radiation from the acrylic surface to the room. These losses ranged from $8 \%$ of the supplied heat flux in the lowest $h$ regions to $1 \%$ in the highest $h$ regions. Radiation losses from the heater surface to the unheated walls in the serpentine passage were negligible, as were the temperature differences between the heater and the liquid crystal layer. Given the heat flux, 
the LCVT measured surface temperatures, the conduction losses, and the mixed mean fluid temperature distribution, heat transfer coefficient distributions were calculated from:

$$
h=\left(\dot{q}_{\text {supplied }}^{\prime \prime}-\dot{q}_{\text {loss }}^{\prime \prime}\right) /\left(T_{0}-T_{\text {bulk }}\right)
$$

\section{LIQUID CRYSTAL VIDEO THERMOGRAPHY}

Liquid crystals have a color response over a limited range of temperatures. For the crystals used here, that range was from $37.3 \mathrm{C}(99.14 \mathrm{~F}$ ) (red) to $39.4 \mathrm{C}(102.9 \mathrm{~F})$ (green-blue). For a given uniform heat flux, that temperature range covers a limited range of $h$. In a single liquid crystal image then, only a small portion of the heater surface will have active crystals. To measure $h$ over the entire region of interest several images had to be acquired, each at a different heater power setting. The partial $h$ distributions were then combined to produce complete $h$ distributions.

It was a relatively simple procedure to digitally correct the serpentine passage images for spatial distortion. The two surfaces of the main serpentine passage heater were held at a $45^{\circ}$ angle to each other so that is was impossible to simultaneously view both surfaces perpendicularly.

To correct the geometric viewing distortion of the leading edge passage data because the liquid crystal/heater surface is curved would have added a significant amount of work without significantly adding to the quality of the results. Therefore, the leading edge data were not corrected for distortion.

\section{DISCUSSION OF SERPENTINE PASSAGE RESULTS}

\section{Flow Parameters}

Heat transfer coefficient distributions were measured at 3 different coolant flowrates: $\dot{m}=0.045,0.091$, and $0.14 \mathrm{~kg} / \mathrm{sec}(0.1,0.2$, and $0.3 \mathrm{lb} / \mathrm{sec})$. The limit of $\dot{m}=0.14 \mathrm{~kg} / \mathrm{sec}$ of air was set by the capability of the heat transfer surface. The compressor used to supply the coolant flow was capable of flowrates up to $1.8 \mathrm{~kg} / \mathrm{sec}(4 \mathrm{lb} / \mathrm{sec})$, but the $10 \mathrm{amp}$ power supply used to power the heater could not heat the surface adequately at higher flowrates to get the liquid crystals into their active range. The maximum heat flux from the surface was $\dot{q}^{\prime \prime}$ $=8200 \mathrm{w} / \mathrm{m}^{2}\left(2600 \mathrm{Btu} / \mathrm{hr} / \mathrm{ft}^{2}\right)$. The fully turbulated case was the only one tested at the highest flowrate. 


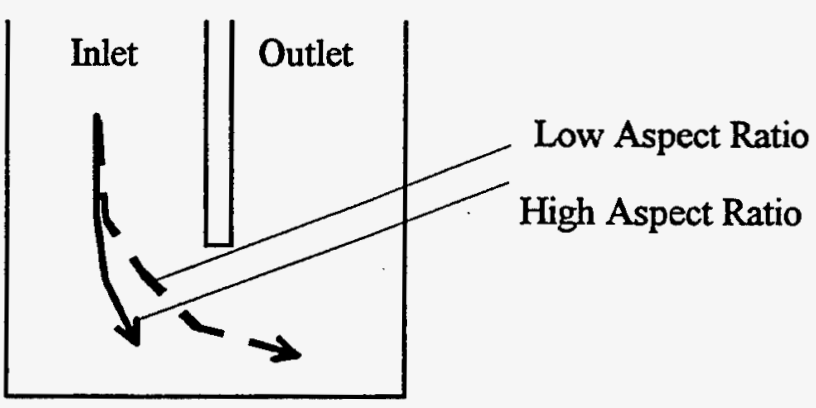

Since the flow upstream of the tip heaters was not heated, there was a uniform temperature profile in the flow approaching the heater. Turning on the main serpentine passage heater might have altered the measured heat transfer coefficients by changing the shape of this temperature profile. This effect is likely to be small, since the turbulent, three-dimensional flow in the $180^{\circ}$ turns will mix out the thermal boundary layers in the approaching flow quickly. This should be tested experimentally, but has not been done in the present set of experiments.

\section{DISCUSSION OF LEADING EDGE PASSAGE RESULTS}

\section{Turbulator Results}

Heat transfer data were acquired using the same thin foil heater/liquid crystal technique as for the serpentine passage. The foil heater was adjacent to the flow; the liquid crystal/Mylar ${ }^{\mathrm{TM}}$ sheet was between the heater and the acrylic surface; and the liquid crystal color response was viewed through the acrylic surface. The passage was heated only on the suction and pressure walls, not on the rib wall. Images were acquired from two different points of view so that the entire surface could be seen. Conduction losses from the foil to the acrylic and radiation losses from the foil to the opposite side of the passage were found to be less than $1 \%$ and were considered negligible.

Mean heat transfer enhancements were calculated for the fully developed region of the leading edge (i.e., the downstream half) by area averaging: a) the area completely covered by the suction side turbulators, $b$ ) the area completely covered by the pressure side turbulators, and c) the stagnation region between $\pm 2 \cdot e$ on either side of the stagnation line where the heat transfer enhancement was lowest.

\section{APPLICATION OF RESULTS}

The flow Reynolds numbers tested were significantly lower than those in the actual bucket. The effect of higher Reynolds numbers on the heat transfer enhancement could not be investigated in these tests because of the influence of high Mach number effects.

In spite of these restrictions, these tests were still an excellent screening tool to find potential problem areas in the cooling circuit design. The most significant examples were the low levels of $h / h_{\mathrm{db}}$ found in the trailing edge passage and the high levels found in the tip $180^{\circ}$ turns.

Based on the results of this and other tasks, the design of the first-stage bucket cooling circuit has changed significantly since this test rig was designed. The trailing edge is now cooled by 
round, small-diameter, turbulated, high-pressure-drop passages electrochemically machined (ECM) into the bucket. The total number of passages in the serpentine cooling circuit was reduced.

\section{PLANS FOR PHASE 3}

The low heat transfer enhancement in the turbulated leading-edge passage was unexpected. There will be a Phase 3 task to evaluate alternative turbulator geometries for the first-stage bucket leading-edge passage by performing non-rotating heat transfer and pressure drop tests at high Reynolds numbers on scaled models of the leading-edge passage. 


\section{TASK 8.7.6 - COMBUSTION INSTABILITY}

\section{BACKGROUND}

Existing design methodologies for designing a combustion system take into account the thermal, aerodynamic, and mechanical performance of the combustor. In general, no measure regarding combustion instability is included. Accurate models to predict combustion instabilities are needed in the design process to avoid combustion dynamics which can severely limit the operation of lean-premixed systems.

\section{OBJECTIVES}

The objectives of this task are (1) to understand the physical mechanisms responsible for the onset and sustenance of dynamics in lean premixed combustion systems, (2) to obtain detailed experimental data (consisting of frequency, amplitude, rms level, mode shape, and correlations) in the combustor for various upstream and downstream boundary conditions and various fuel delivery system boundary conditions, and (3) to enhance computational capabilities in the form of improved sub-models to better quantify upstream and downstream acoustic boundary conditions and fuel delivery system impedances and their effects on dynamics.

\section{CONFIGURATIONS TESTED}

- Nozzle Bars, No Splitter

- No Nozzle Bars, No Splitter

- Nozzle Bars, Splitter

- No Nozzle Bars, Splitter

\section{RESULTS}

1. Two DLN burners were mounted side-by-side within a rectangular combustor followed by water-cooled nozzle bars as shown in Figure 8.7.6-1. An air-cooled splitter plate was installed between the burners to separate the burner combustion zones and to create a gap at the exit of the combustors where the two could communicate. The aim of this setup was to simulate the possible coupling of two combustors on a gas turbine via the gap between the transition piece and first-stage nozzle. A PCB dynamic pressure transducer was positioned near the two burners to sense whether dynamics between the combustion zones were in-phase or out-ofphase in a push-pull mode.

The expectation for these tests was that without the splitter plate the longitudinal dynamics within the combustor would be in-phase. With the splitter plate in place and a significant gap present at the exit, a push-pull (i.e., $180^{\circ}$ out-of-phase) coupling would occur, as had been observed in previous field tests. As the gap was reduced and the combustor-to-combustor coupling decreased, the dynamics were expected to return to the in-phase behavior. With the splitter plate removed, the dynamics in the combustor top-to-bottom were found to be inphase as expected. The dynamics amplitude, however, was much higher with the nozzle bars removed. Next, a splitter plate was installed that extended all the way to the nozzle bars; i.e., there was no exit gap. With the splitter in place, the dynamics between the two combustion 
zones were clearly out-of-phase in a push-pull mode. The dynamics frequency depended on whether the nozzle bars were present. The push-pull mode was expected for configuration 4 since the absence of the bars made strong coupling between the combustors possible. With the bars in place and no gap, however, it was surprising that the combustors coupled so effectively in a push-pull mode.

Hence, the system reacted in such a way as to couple in a push-pull mode with the splitter plate in place even though no exit gap was present. Several attempts were made to eliminate the apparent coupling. Splitter plates were added to the upstream air paths to isolate them, and choked orifices were added in the fuel system. Nevertheless, the dynamics remained coupled $180^{\circ}$ out-of-phase whenever the splitter plate was present.

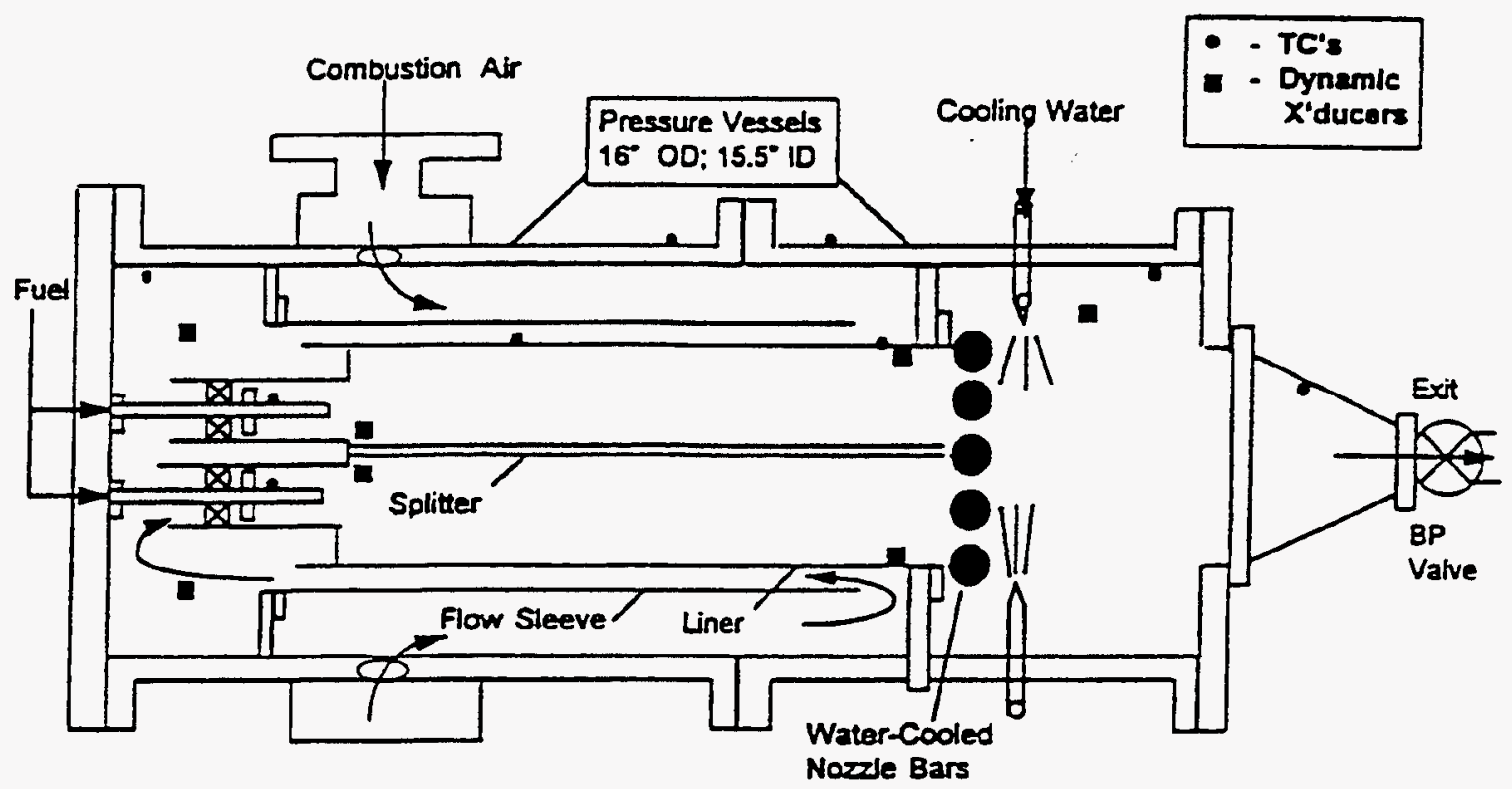

Figure 8.7.6-1. Schematic of the Two-Burner Test Rig with Splitter Plate and Nozzle Bars

Several tests were run with various exit gaps to determine whether the dynamics behavior was affected. In all cases the dynamics at the nominal conditions selected the push-pull mode. However, during ignition and ramp-up to the nominal conditions, a mode switch from inphase to out-of-phase dynamics was observed. In fact, the region of operation over which the in-phase dynamics persisted increased as the gap was increased.

2. A better understanding and improved models for the dynamic response of the air and fuel systems are needed to develop accurate tools for combustion instability. A special high-speed rotating valve was designed and built to provide controlled periodic pressure oscillations within the combustion chamber under cold flow to simulate the oscillations observed during combustion dynamics. The rotating valve was bench tested using a small pressure vessel. Several design changes were made to improve the alignment and smoothness of valve operation. The test results confirmed that strong pressure oscillation strength could be generated with the valve, particularly when matched to the resonant frequency of the vessel. 
The oscillation strength depended simply on the area ratio created by blockage. When choked flow across the valve was imposed, oscillation strengths as high as $10 \%$ of the mean pressure were demonstrated with the bench system, which was in agreement with predictions. Modifications to instrument the fuel nozzle were completed to support dynamic pressure measurements inside the fuel passage. The nozzle was based on a production low- $\mathrm{NO}_{\mathrm{x}}$ combustor nozzle. The spinning valve was to have been installed in the test rig and tested for operability and oscillation strength with actual air flow and production hardware. Once a reasonable oscillation strength is demonstrated in the actual test rig, measurements of the dynamic response of the fuel and air systems would then be taken with controlled oscillations using the spinning valve system, and the results used to validate dynamic models. This phase of the development was not completed largely because the test rig was not available for the tests because of other commitments for the facility.

3. Work was performed on developing submodels that can be used to create a model for combustion instability. Models for the impedance of the fuel delivery system were advanced and added to the acoustic circuit model of the fuel passage to allow the internal pressure oscillations to be calculated for comparison to data. A fully unsteady one-dimensional reacting flow computational fluid dynamics (CFD) model, including a pressure-loss inlet and choked flow exit, was assembled to directly simulate an oscillating reacting flow in a simple tube. The model demonstrated self-sustained limit-cycle oscillations under certain conditions. Oscillation amplitude and frequency were found to depend strongly on reaction rates and the boundary conditions. This model could be used to simulate experiments in a largely ID facility.

\section{TECHNOLOGY APPLICATION}

The two-burner results demonstrated that both in-phase and out-of-phase combustor-coup;ling modes can be important and that the size of the exit gap between combustors can have an influence on mode-jumps. The boundary conditions employed in instability design models should, therefore, include both end conditions. The results from tasks aimed at developing combustion submodels for instability and for obtaining experimental data to validate dynamics models have improved our capabilities at predicting combustion instability, but a comprehensive predictive model suitable for design processes has not been completed.

\section{PLANS FOR PHASE 3}

There are no specific follow-on tasks included in Phase 3 for combustion instability. However, combustion dynamics will be measured and characterized as it pertains to the effects of heated fuel.

\section{SUMMARY}

Both in-phase and out-of-phase modes of dynamics were observed whether the splitter plate was absent or present. The size of the exit gap had an influence on mode jumps during startup of the combustors, but at the nominal conditions tested the exit gap had no effect in that the gap was not necessary for the combustion zones to couple effectively $180^{\circ}$ out-of-phase. 


\section{TASK 8.7.7 - EFFECT OF HOT FUEL ON COMBUSTION DYNAMICS}

\section{BACKGROUND}

Fuel heating provides a means of boosting the thermal efficiency of a gas turbine without increasing pressure ratio or firing temperature. In this approach fuel is regeneratively heated prior to mixing with air by using heat from the exhaust of the gas turbine. In the ATS gas turbine cycle, fuel heating from ambient temperature $20 \mathrm{C}(68 \mathrm{~F})$ to $350 \mathrm{C}(662 \mathrm{~F})$ can increase overall combined thermal efficiency by 0.25 percentage points while slightly reducing the output power of the machine.

The current state-of-the-art for GE gas turbines is to heat fuel to $177 \mathrm{C}(350 \mathrm{~F})$. The issues for fuel heating to higher temperatures in the ATS gas turbine with dry low $\mathrm{NO}_{\mathrm{x}}$ (DLN) combustors include the following:

- Fouling of heat exchanger piping, fuel manifolds, control valves, and fuel injectors due to heated gas

- Corrosion of heated fuel piping due to increased reactivity

- Influence of variations in the fuel temperature on combustion dynamics and emissions

- Reduced autoignition/flashback margin in the premixer

- Design and rating of control valves, piping, and instrumentation for high temperature service

- Increased number of failure modes in the fuel handling system leading to lower overall reliability

- Safety issues associated with fuel leaks of heated natural gas

Under ATS Phase $2++$ the first three issues were identified as the biggest technical risks, and the program was structured to resolve these issues. Combustion testing was not performed as part of Phase $2++$ since it was the primary activity in the Phase 3 proposal.

\section{OBJECTIVES}

The overall objective is to develop the capability to use heated natural gas fuel (350C) in DLN combustors. Heated fuel can provide improved thermal performance for the ATS gas turbine but experiments and analysis are required to evaluate the effects of hot fuel on system performance and combustion dynamics.

\section{TASK 1:}

Determine the tendency to form carbon deposits in the heat exchanger and fuel system when fuel is heated. In this task, a series of short-term exposure tests, using natural gas with various impurity loadings, will be run for conditions representing the operating range of the ATS gas turbine. 


\section{TASK 2:}

Determine the influence of heated fuel on the fuel delivery system and fuel injectors. Predict the impact of heat on combustion dynamics. Develop a fuel control strategy to address these systems issues.

\section{TASK 3:}

Develop techniques to coat large in-situ piping with coke barrier coatings $(\mathrm{CBC})$ to reduce heat exchanger fouling.

\section{TASK RESULTS/DISCUSSION/DESCRIPTION}

\section{TASK 1: HEAT EXCHANGER FOULING}

\section{Background}

The first step in understanding the risk of deposits and corrosion from heated natural gas was to review the literature from all available sources (the open literature and internal GE sources). A review of topics related to gas composition and fuel heating was conducted and revealed only a few papers on the subject. The background literature and relevant GE experience are summarized below:

Knowing the composition of natural gas is an essential first step to determining the technical issues associated with heating natural gas fuel for gas turbines. Currently there is no accepted standard for the composition of natural gas in the United States. The composition of natural gas is set by industry norms and is typically specified by contracts between natural gas producers, distribution companies, and users. Increased competition as a result of deregulation of the gas industry appears to have increased the variability of natural gas composition as users purchase gas from a wider variety of sources.

In the absence of a national standard for natural gas, a published survey sponsored by the Gas Research Institute is used as a source of information on gas composition. The GRI report summarizes the results of gas composition measurements from 26 major urban areas in the United States. The major constituents of natural gas are identified, and properties such as heating value, Wobbe number, molecular weight, and flammability limits are tabulated (Table 8.7.7-1). A review of gas composition outside the U.S. yielded similar data for Europe and Canada. 
Table 8.7.7-1.

Weighted National Statistics for Natural Gas in 26 Major Urban Areas of the United States

\begin{tabular}{|l|r|r|r|r|r|}
\hline & \multicolumn{1}{|c|}{ Mean } & \multicolumn{1}{|c|}{ Minimum } & \multicolumn{1}{c|}{ Maximum } & $10^{\text {th }}$ \%-ile & $90^{\text {th }}$ \%-ile \\
\hline Methane (mole \%) & 93.9 & 74.5 & 98.1 & 89.6 & 96.5 \\
\hline Ethane (Mole \%) & 3.2 & 0.5 & 13.3 & 1.5 & 4.8 \\
\hline Propane (Mole \%) & 0.7 & 0.0 & 2.6 & 0.2 & 1.2 \\
\hline C4+(Mole \%) & 0.4 & 0.0 & 2.1 & 0.1 & 0.6 \\
\hline CO2+N2 & 2.6 & 0.0 & 10.0 & 1 & 4.3 \\
\hline Heating Value (MJ/m3) & 38.46 & 36.14 & 41.97 & 37.48 & 39.03 \\
\hline Heating Value (Btu/scf) & 1033 & 970 & 1127 & 1006 & 1048 \\
\hline Specific Gravity & 0.598 & 0.563 & 0.698 & 0.576 & 0.623 \\
\hline Wobbe Number (MJ/m 3 ) & 48.79 & 44.76 & 52.85 & 49.59 & 50.55 \\
\hline Wobbe Number (BTU/scf) & 1336 & 1201 & 1418 & 1331 & 1357 \\
\hline Air/Fuel Ratio (Mass) & 16.4 & 13.7 & 17.1 & 15.9 & 16.8 \\
\hline Air/Fuel Ratio (Volume) & 9.7 & 9.1 & 10.6 & 9.4 & 9.9 \\
\hline Molecular Weight & 17.3 & 16.4 & 20.2 & 16.7 & 18.0 \\
\hline Critical Compression Ratio & 13.8 & 12.5 & 14.2 & 13.4 & 14.0 \\
\hline Methane Number & 90.0 & 73.1 & 96.2 & 84.9 & 93.5 \\
\hline Lower Flammability Limit (\%) & 5.00 & 4.56 & 5.25 & 4.84 & 5.07 \\
\hline Hydrogen/Carbon Ratio & 3.92 & 3.68 & 3.97 & 3.82 & 3.95 \\
\hline Source GRI Report 92/0123 & & & & &
\end{tabular}

Source: GRI Report 92/0123

There are two practices in the natural gas industry which involve adding a relatively high concentration of oxygen (as a constituent of air) to natural gas. Although the final concentration of oxygen in the gas is too low to change flammability characteristics significantly at ambient conditions, it could have a significant effect on the behavior of heated natural gas. The first practice is known as peak-shaving and involves adding propane and air to natural gas to maintain gas supplies in some regions of the northeastern United States in the winter. The amount of propane can be as high as $23.7 \%$ (mole basis) with air added as a diluent to keep heating value within accepted limits. The second practice is limited to the state of Colorado and involves diluting natural gas with air to keep the heating value at the low levels associated with historical sources of gas. The presence of relatively high levels of oxygen in the resulting fuel increases the rate of formation of deposits on surfaces exposed to heated liquid fuel since oxygen is involved in deposit formation, and it is likely that the same chemical mechanisms apply to natural gas. In addition, increased oxygen levels could increase the tendency for autoignition or flashback since pre-ignition reactions between fuel and oxygen are more likely to occur.

The minor constituents of natural gas play an important role in corrosion, formation of deposits, and autoignition characteristics. A GRI survey reports sulfur loading for several locations as a function of time and found variations between 0.1 and 1 grains/100 $\mathrm{ft}^{3}$. The highest single measurement was 1.5 grains $/ 100 \mathrm{ft}^{3}$ at a New York location. The level of sulfur is of concern to the gas industry because low levels are required as odorants, but high levels are associated with corrosion in pipelines. The increased activity of sulfur at elevated 
temperatures makes sulfur loading a concern for fuel heating applications. More data on sulfur compounds is available in a companion GRI study entitled "Minor Constituents of Natural Gas". These data provide an extended database of sulfur-bearing compounds $\left(\mathrm{H}_{2} \mathrm{~S}\right.$, thiophanes, etc.).

The formation of carbon deposits occurs very slowly for high quality natural gas. Chin et al. report deposition data from heating methane and natural gas mixtures to temperatures of up to $900 \mathrm{~K}$. The thermal deposition characteristics of gaseous, high-purity methane, several methane-hydrocarbon mixtures, and a typical natural gas fuel were evaluated using an electrically heated, stainless steel tube test apparatus. The deposit formation characteristics of mixtures were established and compared with the deposition characteristics of high-purity methane. Testing was conducted at wall temperatures of up to $900 \mathrm{~K}$ for exposures of up to 60 hours. Measurements of deposit mass indicated that there was essentially no deposit buildup for wall temperatures below $650 \mathrm{~K}$. Deposit began to form at wall temperatures between $650 \mathrm{~K}$ and $775 \mathrm{~K}$. Above $775 \mathrm{~K}$, there was a rapid monotonic increase in deposition.

The formation of carbon deposits from heated liquid fuels, which contain heavy hydrocarbons (>C6), can cause fuel system fouling. Carbon deposits formed at relatively low temperatures $(100-500 \mathrm{C})$ are termed "resin" deposits and are primarily made up of carbon, hydrogen, and oxygen. The rate of formation of deposits peaks at a temperature of $350 \mathrm{C}$, which is the same temperature as the ATS target for fuel heating. The reactants that form deposits are oxygen and high carbon number hydrocarbons. Aromatic hydrocarbons have been identified as the primary source of deposit precursors in jet fuel. Similar compounds are present in natural gas and similar chemistry could be present.

Consider the following analysis showing that even trace amounts of deposit precursors in natural gas could lead to significant amounts of solid deposit in an ATS gas turbine. The daily fuel consumption of an ATS gas turbine is approximately 1.4 million kilograms. If the concentration of deposit precursors was $50 \mathrm{ppmw}$ and the conversion efficiency to deposits was $10 \%$ the rate of carbon deposit formation would be $7 \mathrm{~kg} /$ day. This would at least cause fouling of the heat exchanger and at worst could cause the fuel control valve to stick followed by plugging of the fuel injection holes as pieces of deposit broke free.

The sources of deposit precursors can be classified in two groups; those always present at low levels in natural gas and those present as a result of upset conditions in the gas processing and distribution system. An estimate of the steady-state levels of deposit precursors can be obtained from the GRI report on "Minor Constituents of Natural Gas". Levels of C6+ hydrocarbons can range from 0.05 to $0.25 \mathrm{~mol}$ percent and include aromatic hydrocarbons such as xylene and toluene. Under certain conditions of concentration, temperature, and pressure these heavy hydrocarbons can form liquids in the pipeline. The propensity to form carbon deposits is expected to be caused mostly by liquids because "resin" deposits form as precipitates out of a liquid.

Liquids can also be present as a result of upset conditions in the gas processing and distribution system. Table 8.7.7-2 lists sources of types of liquids that are found in a pipeline. 
Table 8.7.7-2.

Types of Liquids Found in Gas Pipelines

\begin{tabular}{|l|l|}
\hline Liquid & Source or Cause of Liquid in Pipeline \\
\hline $\begin{array}{l}\text { Hydrocarbon Condensates } \\
\text { - paraffins (C6-C14) } \\
\text { - aromatics (benzene, xylene, etc.) }\end{array}$ & $\begin{array}{l}\text { - Hydrocarbon stripping plants go off-line, feedstock prices } \\
\text { change } \\
\text { - Pipeline pigging (cleaning) operations } \\
\text { - Refinery off-gas added to fuel } \\
\text { - Seasonal variations in pipeline temperature and flow }\end{array}$ \\
\hline $\begin{array}{l}\text { Glycols } \\
\text { - ethylene glycol (EG), di-EG, } \\
\text { tri-EG }\end{array}$ & - Upset in dehydration unit used to remove moisture \\
\hline $\begin{array}{l}\text { Compressor Lube Oil } \\
\text { - distillate-based lube oil } \\
\text { - synthetic lube oil }\end{array}$ & $\begin{array}{l}\text { - Mist from pipeline compressor or compressor upstream of gas } \\
\text { turbine }\end{array}$ \\
\hline Sources: IGTI, GRI, GE field personnel \\
\hline
\end{tabular}

The best way to deal with deposit precursors in natural gas is to remove them from the gas stream prior to heating. If the precursors are in the form of liquid, scrubbers and absolute filters provide appropriate filtration. However, no filter system is perfect and the example above illustrates that even a part-per-million level of contamination can lead to significant amounts of deposits. In addition the cost of an absolute filtration system would increase the capital and maintenance costs of the plant. Therefore, this experimental program of Task 1 was organized to understand the formation of deposits from liquids found in natural gas pipelines.

\section{Lube Oil Thermal Exposure Tests}

The thermal stability of a typical lubricating oil was determined by heating samples in a beaker for 10 hours under a nitrogen atmosphere. Mobil DTE-105, a distillate-based lube oil, was used in these tests. The range of temperatures spanned $200 \mathrm{C}(392 \mathrm{~F})$ to $500 \mathrm{C}(932 \mathrm{~F})$. Formation of gas products was observed at $400 \mathrm{C}(752 \mathrm{~F})$, and at $500 \mathrm{C}(932 \mathrm{~F})$ it was not possible to maintain a steady temperature and pressure. For thermal exposure at $350 \mathrm{C}(662 \mathrm{~F})$ and below, the appearance of the lube oil was unchanged by the test. A gas chromatograph/mass spectrometer (GC/MS) analysis confirmed that the composition as observed by the GC spectra was unchanged. At $375 \mathrm{C}(707 \mathrm{~F})$, there was a slight darkening of the liquid but otherwise there was no change. At $400 \mathrm{C}(752 \mathrm{~F})$ there was significant thermal breakdown; the liquid was darker in appearance, a suspension of black particles could be seen, and the viscosity of the liquid was reduced. The GC/MS analysis confirmed that the chemical structure of the remaining liquid had changed and consisted of lighter hydrocarbon fragments. Thermal breakdown of this type of lube oil is not apparent from visible inspection or from GC/MS analysis at the ATS target temperature of $350 \mathrm{C}(662 \mathrm{~F})$. 


\section{Atmospheric-Pressure Natural Gas/Lube Oil Exposure Tests}

Preliminary thermal stability tests of mixtures of natural gas and lubrication oil were performed by passing mixtures through a set of heated tubes. There tests were performed at atmospheric pressure and had a residence time similar to an ATS turbine fuel heat exchanger. The initial results are encouraging because negligible deposits are observed.

\section{High-Pressure Natural Gas/Lube Oil Exposure Tests}

A preliminary test was conducted at high pressure using the same single-pass configuration as in the atmospheric pressure tests. Again there was no deposit in the heat exchanger tube, and the composition of the liquid sample collected downstream of the heat exchanger was unchanged.

\section{Eight-Hour High-Pressure Natural Gas/Liquid Exposure Tests}

The high-pressure exposure rig was modified from a single-pass horizontal orientation to a three-pass vertical orientation. A schematic of the facility is shown in Figure 8.7.7-1. This orientation was selected because it provides a low spot in the U-tube between tube 1 and tube 2 where liquid can accumulate. This is intended to simulate stagnant regions in a heat exchanger where liquids have a long residence time to form deposits. Natural gas at low pressure is compressed using an air-driven compressor to 20 bar. Gas flows from the compressor through stainless steel tubing to a tee just upstream of the heat exchanger tubing. Liquid is stored in a cylinder pressurized with nitrogen. Fine needle valves are used to control the flow of liquid into the gas flow. Flow of liquid was monitored using a positive displacement flowmeter and totalizer (Max Flowmeter) that displays the flowrate and the total volumetric flow. The heat exchanger tubing is encased in $50-\mathrm{mm}$ diameter copper block that is inserted into a furnace. A thermocouple used to control the furnace temperature is inserted into the center of the copper blocks. A condensing vessel is mounted just downstream of the heat exchanger. This vessel recovers most of the liquid sample and can be used after the test to cross-check the total flow of liquid. A coalescing filter is used downstream of the condenser to collect any remaining liquid and to protect the back-pressure valve from contamination. The flow and pressure of natural gas are adjusted by varying the speed of the gas compressor and setting the back pressure valve. A gas flowmeter downstream of the back-pressure valve monitors the flow of natural gas. A computer data acquisition system was used to record all critical experimental parameters such as flow, temperature, and pressure.

The test procedure is as follows: First the rig is assembled with new heat exchanger tubing and thermocouples. The liquid cylinder is cleaned and filled with the liquid for a given test. Care is taken to maintain a nitrogen atmosphere above the liquid in the cylinder. The liquid passages are flushed with fresh liquid up to the tee with the gas tubing. The totalizer on the liquid flowmeter is set to zero. Then the rig is pressurized and gas flow is established. All the pipe connections are checked for leaks. The furnace is then turned on with the set point at $350 \mathrm{C}(662 \mathrm{~F})$. When the furnace temperature is within $15 \mathrm{C}(59 \mathrm{~F})$ of the target temperature (typically after one hour), the liquid flow is initiated. The rig then operates in steady-state operation for the duration of the test. At the end of the test the liquid flow is stopped and the

furnace is turned off. Natural gas flow continues for a minimum of 15 minutes and is then shut 
off. Test time is defined as the period of time during which liquid is flowing. The actual test time is longer because of the heat-up time of the heat exchanger. When the rig is cold, the heat exchanger tubing is removed from the copper blocks and the tubing is analyzed for deposits.

A series of relatively short, high liquid loading exposure tests was conducted using a variety of liquids that might be present in a natural gas supply (e.g., those listed in Table 8.7.7-2. All the liquids produced some deposits or discoloration at ATS temperature and pressure machine conditions. The heaviest deposits resulted from using a synthetic lube oil. The lightest deposits resulted from the paraffin mixture and dodecane. The formation of deposits in these tests indicates that natural gas conditioning upstream of the heat exchanger will be key to avoiding heat exchanger fouling.

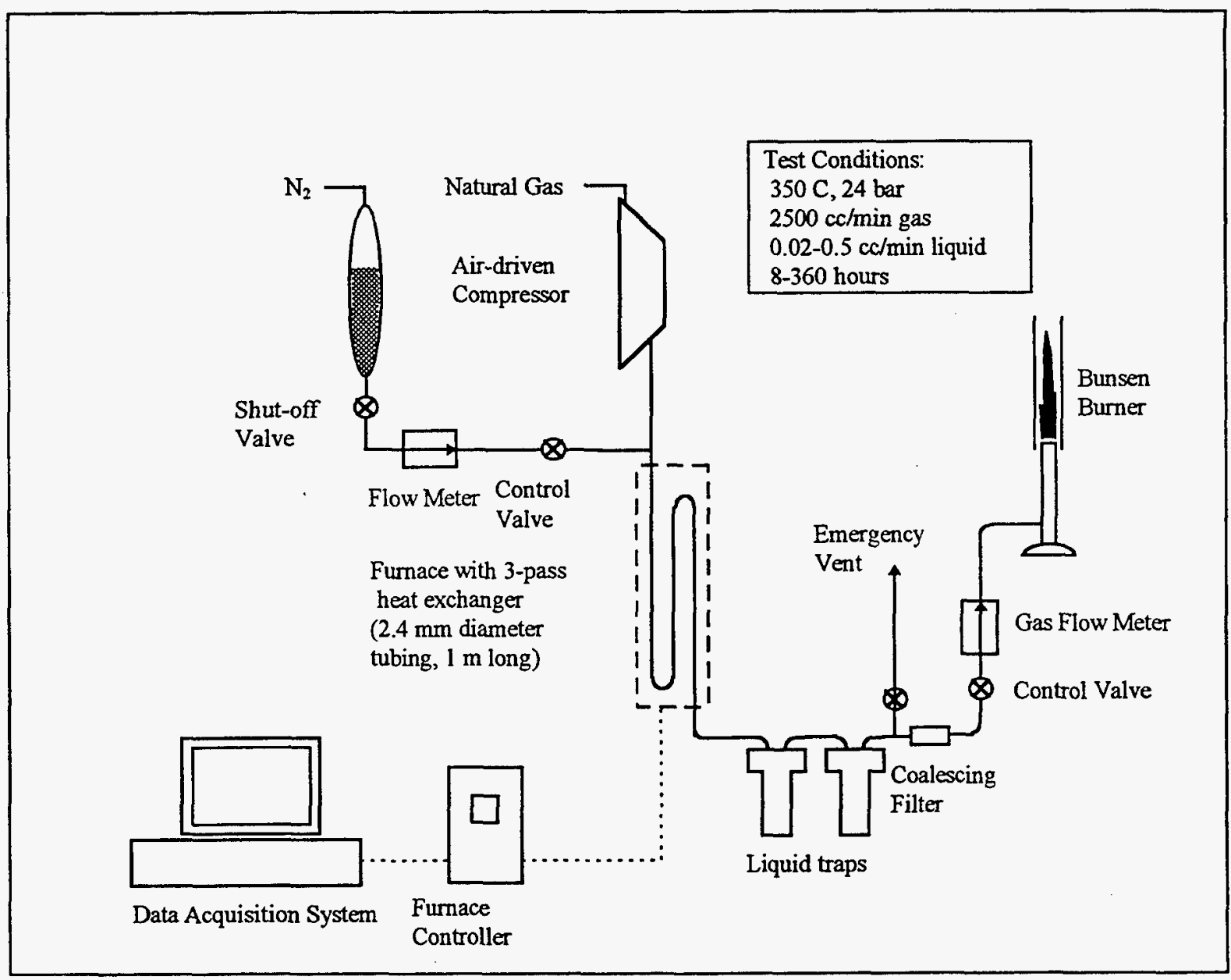

Figures 8.7.7-1. Schematic of High-Pressure Thermal Exposure Test Facility 


\section{Longer Duration High-Pressure Natural Gas/Lube Oil Exposure Tests}

Two natural gas/lube oil exposure tests of longer duration ( 85 hours and 360 hours) were conducted to provide a basis for extrapolating the results of 8-hour tests. Standard conditions for these tests were the same as the previous tests: $350 \mathrm{C} \mathrm{(662F),} 24 \mathrm{bar}$, and a natural gas flow rate of $2500 \mathrm{cc} / \mathrm{min}$. For the 85 -hour test the liquid flow rate was $0.5 \mathrm{cc} / \mathrm{min}$ with a total liquid flow of $255 \mathrm{ml}$. The hard, dark, varnish-like deposits were similar in appearance and thickness to the results of previous 8-hour tests that had the same total liquid flow. For the 360 -hour test, the liquid flowrate was $0.23 \mathrm{cc} / \mathrm{min}$ with a total liquid flow of $500 \mathrm{ml}$. The deposits were slightly thicker but otherwise the same as the other deposits. These data support an important conclusion of this work, that the formation of deposits is controlled by the quantity of liquid passing through the heat exchanger and is relatively independent of the liquid loading in the gas.

\section{Exposure Tests with Liquid Additives}

In a separate facility, four additives from Betz Process Chemical were tested to determine their potential for reducing the rate of deposit formation at $350 \mathrm{C}(662 \mathrm{~F})$. There was not sufficient reduction in deposits to warrant further testing of additives.

\section{TASK 2: ANALYSIS OF HEATED FUEL SYSTEM}

A HYSIM computer model of the fuel delivery system was developed that includes the heat exchanger, valves, filters, and piping. This models the detailed gas composition and has been run as a function of gas temperature. A schematic of the major components of the fuel heating system is shown in Figure 8.7.7-2.

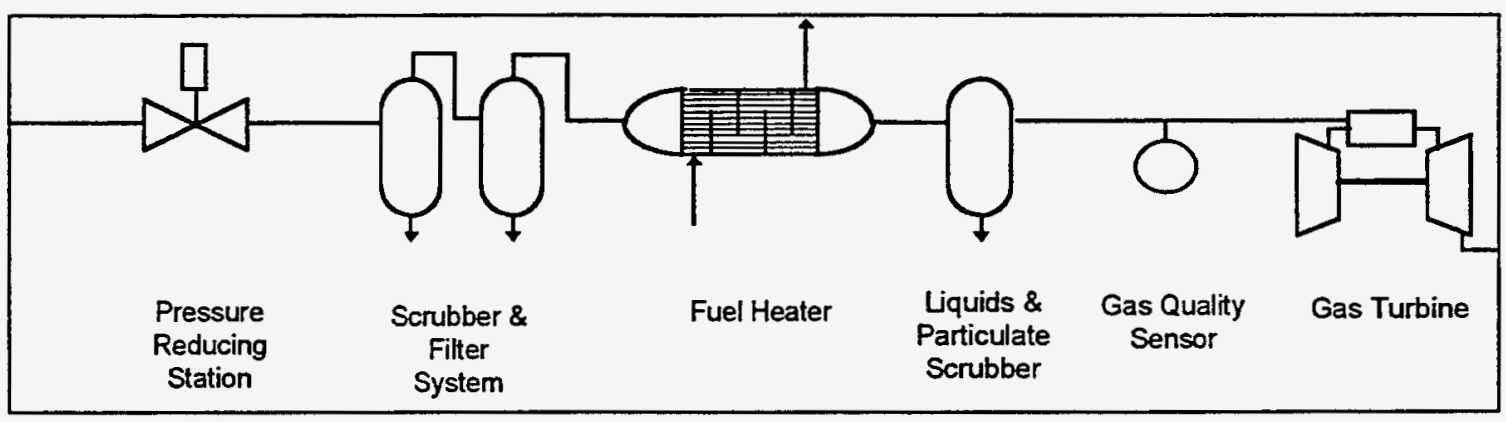

Figures 8.7.7-2. Schematic of Components of Fuel Heating System for ATS Gas Turbine

TASK 3: CBC DEPOSITION WITHIN ANISOTROPIC SUBSTRATES

\section{Background}

As discussed in the introduction to Task 1, sulfur attack has previously been shown to occur when gas is heated to 500C (932F) for 1000 hours. Barrier coatings, typically applied in low pressure reactors, have been shown to stop reaction between iron (in piping) and gas-phase 
sulfur. Coke barrier coating (CBC) deposition is normally performed by hot-walled, low pressure chemical vapor deposition (CVD) where the substrate to be coated is placed within the evacuated reaction chamber and the precursor reagent effused over and through the heated substrate so a that uniform high quality coating is made. It was recognized that for a GEIPS turbine to use CBC in a heated fuels cycle it would be necessary to produce the coating inside of large diameter tubing of great $(>10 \mathrm{ft}$.) length. When our program began, there were no CVD reactors capable of containing parts of that size so that we were unable to use CBC. As Task 3 of the hot fuels program, we investigated an alternate CVD method for producing the coating that uses the part as its own vacuum chamber/reaction vessel to produce the coating in situ.

\section{Test Setup}

The test substrates selected were 3/4-inch OD 6-foot long stainless tubes. Attempts were made to coat them internally using a traveling zone heater. CVD precursor reagents were supplied through vacuum-tight fittings at the tube inlet. A second vacuum-tight fitting was used at the outlet to connect the tube to a set of condensers and vacuum pumps.

\section{Results}

The interior coatings of tubes were examined by splitting the tube lengthwise with a cut-off saw. As would be expected for a conformal dielectric (transparent) coating, visual inspection shows no distinct features. The coatings were etched in spots using $50 \%$ hydrofluoric acid. Etching reveals a series of interference fringes from which the thickness of the coating can be determined

The protective nature of the coating was demonstrated by heating sections of the tube to $700 \mathrm{C}(1292 \mathrm{~F})$ in air. After 24 hours the exterior surfaces and the etched spots showed brown coloration from the oxidation of the metal whereas the coated portion of the interiors showed no change.

\section{TECHNOLOGY APPLICATION}

Fuel heating is a technology that can be directly applied to the ATS gas turbine to increase the thermal efficiency. The implementation of this technology must meet the following requirements:

1. A fuel filtration system is required to minimize levels of contaminants that could form deposits or change autoignition characteristics of the fuel.

2. A heat exchanger is required to heat the fuel. The material selection must take into account corrosion-resistance characteristics from sulfur compounds in the fuel.

3. A second scrubber is required to detect and remove liquids from the hot side of the upstream heat exchanger in the event of a leak.

4. A gas control valve must be selected that can handle the high fuel temperature It must be of a design that is resistant to binding resulting from deposits.

5. A gas quality monitor may be required to ensure that the gas meets the specified gas quality. 
6. A combustor development program is required in order to ensure that the combustor operability is acceptable for heated fuel applications.

\section{SUMMARYICONCLUSIONS}

Work under ATS Phase $2+$ has provided a preliminary assessment of the technical risks associated with fuel heating to $350 \mathrm{C}(662 \mathrm{~F})$. Natural gas/liquid exposure testing at ATS conditions of 24 bar and $350 \mathrm{C}$ (662F) indicated that deposits can form in heat exchanger piping when liquids are present in natural gas. While the conversion of liquids to deposits is very low, the deposits introduce a risk to the gas control valves (by causing sticking of the valves) and a risk to natural gas injection holes (by causing plugging). Compressor oils resulted in the thickest deposits, and synthetic oil was much worse than distilled oil. Deposition is related to total liquid throughput, not liquid loading in gas. Finally, the amount of oxygen appears to play a role in deposition and further work needs to be done to assess the risk of deposition in the presence of higher levels of oxygen. 


\section{TASK 8.7.8 - TURBULENCE INTENSITY PROBES}

\section{OBJECTIVES}

A turbulent heat transfer probe has been designed to allow measurement of free stream turbulence in a DLN combustion system under full fired operation. This effort will provide for testing of this probe in a combustion environment using one or more of CRD's combustor rigs. This task will also provide testing support in available GEPS combustor test stands, including the ATS Full Scale Nozzle Cascade Test Stand. Thin-film microsensor probes in combustion-fed environments are being tested to evaluate the ATS turbine inlet nozzle freestream turbulence intensity level, which has a major and direct bearing on the heat load for the nozzle airfoil and endwall.

The ATS Turbine Nozzle Cascade will be improved by replacing the aluminum flowpath frame with a stainless steel frame. Other modifications will be made to improve the durability and interchangeable nature of the instrumented airfoils.

\section{TURBULENCE INTENSITY PROBE DESIGNS AND METHODOLOGY}

\section{INITIAL AND RE-DESIGNED TURBULENCE INTENSITY PROBES}

GE Power Systems funding was used during the first three quarters of 1994 to design and procure three turbulence intensity probes. These probes are all of a similar construction. The prototype development and probe fabrication were carried out by Vatell Corporation of Blacksburg, Virginia. In the initial design, the probe consists of an outer stainless steel cylinder of $1.27-\mathrm{cm}(0.5$-inch) diameter and an inner cylinder of smaller diameter. The probe is cooled by air or water entering the inner tube and returning via the outer flow annulus. The external surface of the outer cylinder has two pieces of instrumentation deposited in thin-film form via vacuum sputtering techniques. A heat flux microsensor (HFS) is located on the surface in a region roughly 2.5 by $5.0 \mathrm{~mm}(0.1 \times 0.2$ inch). A resistance temperature sensor (RTS) is located immediately adjacent to the HFS element.

The HFS is a relatively new instrument, having been under development at the Virginia Institute of Technology and Vatell Corporation for the past several years. The HFS is a multilayer, vacuum deposited device, which forms a thermopile element on the surface of the metal. An initial layer of electrically insulating material, such as $\mathrm{Al}_{2} \mathrm{O}_{3}$ is sputtered onto the surface first. The voltage signal of the thermopile is directly proportional to the surface heat flux through the element, while the RTS element provides knowledge of the local surface temperature. These devices, including insulating and protective layers, have a total thickness of about 2 microns ( 80 micro-inch), making them virtually invisible to the external flow field. The HFS delivers a signal of typically $20 \mu \mathrm{V}$ per $\mathrm{W} / \mathrm{cm}^{2}$. The device response is as high as $100 \mathrm{kHz}$, with capability at least to $500 \mathrm{~W} / \mathrm{cm}^{2}\left(440 \mathrm{Btu} / \mathrm{ft}^{2} / \mathrm{sec}\right)$ heat flux. The probes will be operated in warm or hot flow streams such that the HFS detects the cylinder stagnation point heat flux. Using information gathered on the gas temperature, the stagnation point heat transfer coefficient will be determined. The gas turbulence intensity level is then deduced from an established relationship between cylinder heat transfer and free stream turbulence. 
The prototype probe was received in July 1994, and a second probe was received in September 1994. By early 1995, the probe manufacturer determined that they could not produce a reliable probe of the intended design, nor could they duplicate the result obtained with the prototype probe. A new design for the probe was therefore deemed necessary. The redesigned probe retains the essential outward characteristic of a $1.27 \mathrm{~cm}$ diameter tube, but utilizes the more reliable HFM-6 sensor. The miniature plug-type sensor is imbedded into the tip of the probe, encased in nickel. The sensor area is actually slightly smaller than the earlier design. The instrument leads run inside a tube that is internal to the cooling tube of the probe and sealed against coolant leakage. This design is far more durable although it detracts slightly from the cooling ability of the internal probe and the predictability of cooling. Because the probe uses a tested heat flux microsensor design in the HFM-6, it can be constructed more quickly.

The first two of three replacement probes (replacing the original design) were received by GE CRD on 31 March 1995, and the third in early April. These heat flux sensors have been calibrated only to the extent allowed by use of standards-traceable thermal radiation lamps in a room environment, about $220 \mathrm{C}(425 \mathrm{~F})$. The resistance temperature sensors have been calibrated to $350 \mathrm{C}$ (660F). To ensure settling of the sensitivities, the probes were cycled to high temperature several times prior to calibration.

\section{"STATIC" PROBE DESIGN}

A second probe design was completed, and two units were received from Vatell Corporation. This probe incorporates the same heat flux microsensor as the original probe, but is reversed such that the sensor is effectively imbedded behind a shield wall of metal. This design will not be capable of dynamic-mode heat flux response but will provide a more durable static-mode heat flux through the probe surface. The shield surface is thin so that there is little lateral conduction of flux. One of these probes was calibrated against the response of a dynamic probe (i.e., the original design) using a propane torch as the external heat load, and internal water cooling. As expected, the new probe has a slower response as a result of the added protection of the tube external wall, but it still develops a comparable signal strength. The second probe was calibrated with a radiation spot heater and is water cooled.

\section{PROBE TEST RESULTS}

\section{GE POWER SYSTEMS COMBUSTOR TEST}

On 9 May 1995, one of the turbulence probes, \#0130, was present in the fired combustor tests run in the GEPS Combustor Test Stand \#6 for 9G combustor testing at sub-scale flow conditions. Tests were run for two days on the combustor system, with the water-cooled probe installed for the entire duration. After initial ignition of the combustor on the first day of testing, the probe survived for about 1.5 hours of hot flow.

After tests were completed, the probe was removed for inspection. The probe housing was entirely secure, indicating the success of the cooling method. The probe sensors and body were covered with carbon deposits from the combustion products; both natural gas and oil 
were used as fuels at various times during the tests. Data from this test were analyzed to determine turbulence intensity level for each data point taken with and without combustion.

As limited as these results are, they indicate a very wide range of instantaneous turbulence intensity, here from $4.5 \%$ to $16.6 \%$. The fact that turbulence intensity and heat flux fluctuate may be significant to the inlet nozzle heat loads, and it will be important to determine the rate of such fluctuations in further testing. It should be noted that the present data are not considered of design quality at this time.

\section{FULL SCALE NOZZLE CASCADE TEST AT GE AIRCRAFT ENGINES}

On July 21, 1995, a turbulence probe was tested in the first fired test of the 9G Full Scale Nozzle Cascade at GEAE, in which the facility was configured as combustor and nozzle bars. In this test, probe data were acquired only as steady-state averages for several operating points. Probe \#0131 was located approximately at midspan in the forward portion of the nozzle box, ahead of and between two thermocouple rakes. The probe indications showed good readings for the first three data points as flow conditions were being increased.

The next data point was taken approximately three hours later, after flow conditions had been raised substantially. The great increase in both flowrate and pressure level caused the heat flux voltage signal from the amplifier to exceed its maximum of 6 volts. No further data points were taken at lesser conditions, and there was no opportunity to reduce the amplifier gains, so no indications of additional turbulence intensity were obtained during this test. The probe was inspected after test cool-down and found to have no electrical continuity.

\section{CRD CATALYTIC COMBUSTION RIG TEST}

A turbulence intensity probe was installed in the Catalytic Combustion Rig in Test Cell \#1 at $\mathrm{CRD}$, to obtain information on probe operation under controlled, stable conditions with moderate gas temperatures. Probe \#0129 was installed in the adiabatic mixing section just downstream of the preburner. The probe sensor faced directly into the oncoming flow (axial).

\section{SECOND TEST IN FULL-SCALE NOZZLE CASCADE}

In preparation for the second series of combustor tests in the Full Scale Nozzle Cascade facility at GE Aircraft Engines, a new dynamic turbulence probe was fabricated and delivered to the GEAE test engineer. At the time of delivery, GEAE indicated that the probe amplifier and shielded signal cable from the previous test could still be used in the current test. The new probe was installed in the nozzle box in December 1995.

On January 15, 1996, the nozzle test was started. Upon system setup in the control room, it was suspected that the probe signals (at room temperature and zero heat flux) were not correct. The probe signal lines were checked and the amplifier found to have an open circuit on the resistance temperature sensor (RTS), and the heat flux sensor (HFS) circuit of the amplifier was putting out a $4 \mathrm{~V}$ signal, when no signal should have been present. The amplifier was apparently damaged at some time between the last use and this date, either mechanically or electrically or both, though no one could identify any cause or circumstance. The amplifier was located in a cable tray on the floor, and certainly somewhat exposed to potential harm. 
GEAE had also replaced the rechargeable batteries of the unit with non-rechargeable batteries, which might have an impact on voltage source strength, i.e., over-voltage.

Concurrent with the amplifier problem, the installed probe was checked and said to have the correct sensor resistances per specification. On 13 January, the probe was checked again and found to have an incorrect reading on the RTS sensor. These readings were verified on 15 January. No explanation could be given for the change, but it is clear that the sensor or the termination leads must have been damaged at some point between installation and final rig closing. After combustor testing was completed, the probe was removed and shipped back to $\mathrm{CRD}$. The probe casing was bent by about $20^{\circ}$ at some time during handling or installation at GEAE, which may have caused breakage of the brazed sensor wires, and hence loss of sensor continuity. This probe may also have been left uncooled at some time during testing, since the sensor head is no longer present, having been fractured/melted off.

CRD will not be attempting any further testing in the FSN Cascade. The remaining effort will concentrate on probe tests within CRD's DLN combustor development rig (Cell 6). This rig is a single burner rather than the full set of six, and does not model actual liner lengths nor transition piece geometry. Turbulence intensity is not expected to decay very much within the liner and transition piece though, so representative measurements should still be possible. The DLN rig gives the advantage of hands-on control over the flow rates, temperatures, and probe cooling, as well as locating the probe lead connections in a non-aggressive environment. A combustor liner for use in CRD's DLN combustion development rig has been slightly modified to allow insertion of a turbulence probe.

Further testing in CRD's DLN combustor development rig will be continued under a Phase 3 task.

\section{ATS TURBINE INLET NOZZLE CASCADE IMPROVEMENTS}

Three improvements have been made to the ATS turbine inlet nozzle cascade.

1. A stainless steel cascade frame has been fabricated from a single ingot of material. The frame consists of the inlet and outlet flanges of the cascade, and the side walls of the flow path (spanwise walls). In the present cascade, the frame is composed of five separate aluminum parts bolted together with interfacial $\mathrm{O}$-ring seals. The improved frame design eliminates all minor leakages, simplifies the design through removal of parts and bolts, and makes the unit more durable with respect to threaded holes for the endwalls. This design also has the advantage of higher pressure and temperature capability for future testing in which it may be required. The original frame served its function as a flexible design allowing for relatively quick modifications during the period of cascade startup and debugging.

2. The cascade endwalls have been modified to allow removal and replacement of the central instrumented airfoil, which is used for heat transfer measurements, without dis-assembly of any other cascade parts. Endwall sub-covers have been incorporated to engage and disengage the center aifoil. This modification reduces wear on parts that may remain in the cascade when heat transfer changes are made, and also simplifies the change-out 
process for any surface modifications to be made periodically on the center airfoil. This modification is complete and in use at this time.

3. A table and rail system will be installed to improve the safety and reduce the time involved with cascade dis-assembly and assembly from the inlet vessel. This is especially important once the heavier stainless steel frame is installed.

\section{TECHNOLOGY APPLICATION}

The freestream turbulence intensity produced by any particular fluid flow system is dependent upon many factors. In combustor systems, the turbulence intensity level that is incident upon the turbine inlet nozzle is very much tied to the specific combustor geometry and flow field, as well as the combustion mode. The heat load on the turbine inlet nozzle is dependent on this turbulence intensity level, especially in the airfoil leading edge region, and so this becomes an important factor for the accurate design of the component for full service life. There have been very few measurements of turbulence intensity in combustion systems under fired conditions, the measurements that have been taken are different for different designs. The turbulence intensity levels measured in this effort will be used directly as design input for the ATS turbine inlet nozzle. The effect of varying intensities on airfoil heat transfer is the subject of a separate task.

\section{PLANS FOR PHASE 3}

There is no Phase 3 continuation of this task.

\section{SUMMARY AND CONCLUSIONS}

Innovative turbulence intensity probes have been designed and fabricated for obtaining information in the ATS turbine nozzle inlet under full-fired combustor conditions. Tests performed in three separate combustor facilities have measured turbulence intensities under various conditions and provided valuable information for the improvement of the probes for future tests in CRD's DLN development combustor rig. 


\section{TASK 8.7.9 - TURBULENT HEAT TRANSFER - STATIC COMPONENTS}

\section{OVERALL OBJECTIVE}

The objective of this task is to predict the metal temperatures and gradients of the first-stage nozzle airfoils, as influenced by the cooling mechanisms used in the various portions of the nozzle airfoil. Although highly effective in keeping the airfoil cool, the innovative cooling approaches used in the nozzle may impose high thermal gradients through the airfoil walls, making accurate knowledge of and optimization of such cooling critical. Internal convective heat transfer distributions will be supplied by two experimental models, one determining the impingement heat transfer characteristics within the several internal airfoil cavities, the other determining the specific impingement heat transfer enhancements due to the addition of various internal surface features such as miniature pin-fins. Both experimental models will utilize the thermochromic liquid crystal technique. This task is divided into three subtasks.

\section{TASK 8.7.9A - SURFACE ENHANCED INTERNAL HEAT TRANSFER}

\section{INTRODUCTION}

The first-stage nozzle end wall and airfoil cooling system is composed of several impingement modules connected in series and/or in parallel to cover the various regions of the end walls and the airfoil. The impingement hole patterns in each module are tailored to accommodate the hot gas side thermal loads and maintain wall temperatures at acceptable levels. Calculations performed for the existing hot gas side thermal load levels have shown that in specific regions with very high gas side heat transfer coefficients, some enhancement techniques are needed on the impingement surfaces to keep the wall temperatures within the required limits so that component requirements are fulfilled.

There is a vast literature on the impingement heat transfer of single jets impinging on surfaces. Since in the present work the interest was mainly with arrays of jets impinging on a surface, the vast literature related to single jets will not be reviewed. The impingement heat transfer coefficients for impinging jet arrays depend on the specific geometries of the jets (streamwise and spanwise spacing, distance to impingement surface), the jet Reynolds number, the cross flow at the impingement surface, and the geometrical configuration of the jet arrays whether they are placed in line or in a staggered fashion.

\section{OBJECTIVE}

An investigation and determination will be made of the heat transfer coefficient enhancements that could be generated under impingement jet cooling modules by adding surface roughness elements without increasing the total system pressure drop.

\section{TEST SECTION}

The test section used for the impingement heat transfer tests is presented in Figure 8.7.9A-1. The test set-up module is contained in a high-pressure enclosure that can be operated at 
pressures up to $10.2 \mathrm{~atm}$ ( $150 \mathrm{psia}$ ) by means of a back-pressure control valve. This operation under high pressures generates relatively high jet Reynolds numbers without high exit Mach numbers. The impingement air is fed to a supply chamber. The air supply pressure and temperature are measured by means of calibrated pressure transducers and thermocouples. The air flowrate is measured by calibrated venturi meters and pressure transducers. The test rig is equipped with square impingement jet plates $(5.08 \times 5.08 \mathrm{~cm})$ that can accommodate several jet hole configurations. The impingement test surface $(5.08 \times 5.08 \mathrm{~cm})$, which can be plain or an enhanced surface $(5.08 \times 5.08 \mathrm{~cm})$ is in intimate contact with a copper block that is heated by three cartridge heaters. The power dissipated by the heaters is measured by a wattmeter. The impingement test plates, positioned at a controlled distance from the impingement jet plates, are instrumented with four imbedded thermocouples that measure the test plate temperature on the side facing the heater block. The test rig is usually well insulated to minimize the heat losses to the surroundings. By varying the flowrate and the discharge pressure, tests can be conducted at various jet Reynolds numbers.

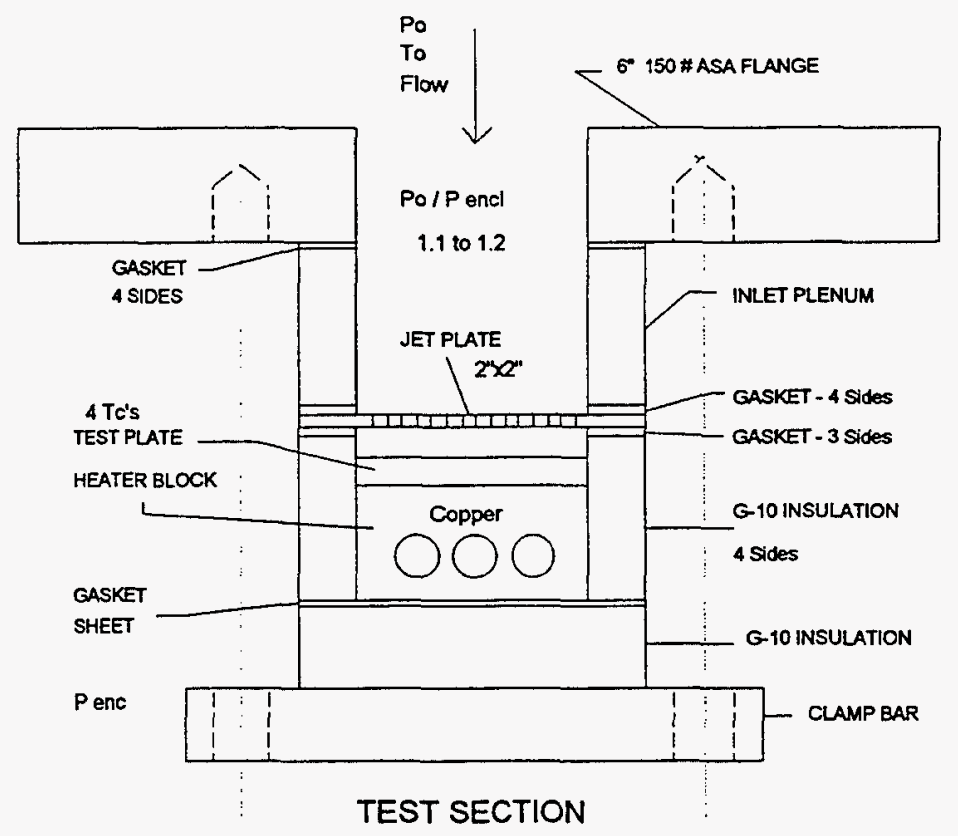

Figure 8.7.9A-1. Schematic of Test Set-Up

Heat transfer tests were conducted with several jet plates having different jet diameters.

Several bump geometries were investigated and, because of manufacturing considerations and thermal performance, the decision was made to concentrate the effort on one nominal bump geometry. To check the effect of the bump inclination with respect to the cross flow direction, test plates were also manufactured with the bumps axis tilted with respect to the normal to the surface. Two additional test plates were also manufactured and tested with a limited number of jet plates which had similar top and bottom diameters but were shorter and taller than the nominal one. 


\section{HEAT TRANSFER TESTS}

\section{TEST PROCEDURE}

The test procedure involved setting up the impingement jet flowrate and then increasing the power in the cartridge heaters, to raise the impingement wall temperature to any desired temperature (maximum of $93 \mathrm{C}$ [200F]). The air flowrate, the power, and the impingement plate temperatures were continuously monitored by a computer-controlled data acquisition system. Once for a given flowrate, a steady state is achieved, all the relevant parameters are recorded for analysis.

\section{HEAT TRANSFER RESULTS WITH A PLAIN SURFACE}

Impingement tests were first conducted with a plain surface test plate with ten specific jet plates. These experiments were performed to generate a baseline for the smooth plain surface conditions and verify the experimental technique by comparing the test data with the Florschuetz, Truman and Metzger correlation.

The overall results are quite satisfactory, showing that the data are consistently within \pm 10 percent of the correlation predictions and the test set-up and procedure are providing data that are reliable and accurate.

\section{HEAT TRANSFER RESULTS WITH THE NOMINAL ENHANCED SURFACE (PLATE 10)}

The impingement tests were then conducted with a test plate, which has the nominal bump geometry.

\section{FIN EFFICIENCY CALCULATIONS FOR NOMINAL BUMP GEOMETRY}

The data obtained with the enhanced bumpy surface were recorded at laboratory test conditions and were initially based on the bump base temperature. Because there is a temperature gradient along the bump, the heat transfer coefficients were corrected with a bump fin efficiency factor that was calculated based on ANSYS models with heat transfer.

The enhancement results presented above were corrected for the fin efficiencies at the laboratory conditions. The design calculations for enhanced surfaces using the bump geometries will use the same fin efficiency curve to scale the laboratory results to the machine conditions.

\section{SUMMARY AND CONCLUSIONS}

The pressure drop test results show that the impingement jet flowrates do not depend on the impinging surface geometry and they are all within the measurement accuracy for the smooth plain surface.

The heat transfer test results with eleven jet plate configurations and test plates covering a smooth plain surface and three test plates with increasing bump height show that: 
1. The plain smooth surface results agree with the Florschuetz, Truman, and Metzger correlation and all the data lie within \pm 10 percent of the correlation predictions.

2. The heat transfer depend on the jet plate geometry (spanwise and streamwise jet configuration) and the jet diameter.

3. The heat transfer with the enhanced bumpy surfaces also depends on the fin efficiency of the bumps. Fin efficiency calculations on conduction analysis were performed to account for the fin efficiency and provide the means to extend the laboratory test results to the design conditions.

4. All three enhanced surfaces showed similar thermal performances.

\section{TASK 8.7.9B - NOZZLE AIRFOIL IMPINGEMENT}

\section{OBJECTIVE}

The objective is to investigate and determine the pressure drop and heat transfer coefficient distributions for first-stage nozzle airfoil spanwise impingement passages and compare the results with the expected values from design methodology.

\section{TEST SECTION}

The test rig models cavities 4,5 , and 6 of the first-stage nozzle. Cavity 4 has an impingement insert with jet holes facing the suction and pressure sides of the airfoil cooling the cavity walls in contact with the hot gas path. The insert conforms to the cavity geometry, which is a trapezoid with the parallel walls facing the adjacent cooling channels. The suction and pressure sides were covered with two thin etched foil heaters and a liquid crystal sheet assembly to measure the local impingement heat transfer coefficients. The power dissipated by the heaters were measured by wattmeters. The impingement coolant air flow rate was measured by venturi flowmeters and calibrated pressure transducers. Static pressure taps were drilled along the spent coolant return wall to record the impingement discharge pressure levels.

\section{PRESSURE DISTRIBUTION TESTS}

\section{TEST PROCEDURE}

The test procedure involved setting up the impingement coolant flow rate and then measuring the static pressure distributions along the impingement insert on the supply side and also on the return side.

\section{TESTS WITH INSERT DISCHARGING TO ATMOSPHERE}

The first series of flow checks were conducted with the insert discharging to atmospheric pressure. During the test, the air flow to the insert was measured after setting the insert supply pressure. The static pressure distributions feeding each impingement jet were measured by plugging each jet with a plastic tube and using a calibrated pressure 
transducer. Three series of tests were performed to generate enough data to build flow circuit models. During the first test, the suction side impingement holes were plugged and the pressure side impingement jet supply pressure distributions were measured for each jet. Then the pressure-side holes were plugged, and the suction side impingement jet supply pressure distributions were measured.

Similar pressure distributions tests were also conducted with both the pressure and suction sides flowing. These static pressure ratios show that although the local pressure ratios change slightly, the overall picture is the same.

\section{TESTS WITH INSERT IN CAVITY 4}

Static pressure distribution tests were also conducted with the impingement insert in cavity 4 and the set-up assembled. The results were obtained with both the suction and pressure sides centered as described above. The pressure distributions were measured along the pressure and suction sides of the insert by means of a static pressure probe inserted in the insert and traversing from inlet to exit.

\section{HEAT TRANSFER TEST DATA}

Heat transfer tests were conducted with the impingement insert in cavity 4 . To run the heat transfer tests, the flowrate was set to a specified value, the static pressure distributions were measured, and the heat flux to the etched foil heaters was increased in specific increments. Once a steady state was reached and the temperature distributions of the liquid crystals were not changing with time, the color (temperature) field of the liquid crystal was recorded with the Liquid Crystal Video Thermography (LCVT) system developed at CRD. The digitized temperature distributions were then used to calculate the local heat transfer coefficients by using the liquid crystal color spectra versus temperature calibration data. Once again, tests were conducted with the pressure and suction sides centered as described above.

The tests showed regions in the design which had to be corrected to insure uniform flow through each impinging jet from inlet to exit thus generating a uniform impingement cooling pattern along the suction side.

\section{SUMMARY AND CONCLUSIONS}

The pressure drop test results presented showed that:

1. The impingement insert design did provide uniform pressure along the pressure side jet holes, but did not provide uniform static pressure distributions along the suction side jet holes.

2. The communication flow area between the pressure and suction side impingement feed chambers near the exit end of the insert should be enlarged to provide a uniform supply pressure for all the impingement jets from inlet to exit.

3. The spent air region showed a uniform pressure distribution. 
The heat transfer test results presented above show that:

1. The heat transfer coefficients reflect the pressure distribution results discussed above and they are not uniform along the suction side of the impingement insert. The heat transfer on the coolant side is lower near the end of the insert along the suction side. The heat transfer coefficient along the pressure side shows a low region near the apex of the passage where the included angle is less than $90^{\circ}$. A recirculation region seems to be formed and the cross flow does not effectively cool the region.

2. The heat transfer coefficient distributions along the suction and pressure sides did not depend strongly on whether the suction or pressure sides were centered at the exit of the impingement insert.

\section{TASK 8.7.9C - TRAILING EDGE FILM COOLING}

\section{OBJECTIVES}

The limited nozzle trailing edge air film cooling will be evaluated with warm rig testing to determine the most effective geometry for minimal coolant usage.

The two objectives for this film testing are:

1. Determine the most advantageous film cooling geometry for use on the turbine inlet nozzle trailing edge region, where air film cooling will be employed. The geometry is subject to certain constraints, such as castability for slots, limited axial space for the feature(s), and a common supply pressure for both pressure and suction side film.

2. Measure the adiabatic film effectiveness downstream of the film injection under conditions representative of the mainstream flow field, the coolant-to-gas density ratio, and the blowing ratio.

This task uses CRD's Warm Wind Tunnel Heat Transfer rig to evaluate film cooling performance in support of the ATS turbine inlet nozzle trailing edge region where a limited amount of external air film cooling provides protection for the component, Figure 8.7.9C-1. The rig is simply a large plenum supplying a straight channel of rectangular cross section. A suitable inlet piece transitions the flow smoothly from the plenum into the channel. The channel is large in cross section, $7.62 \mathrm{~cm}$ by $10.16 \mathrm{~cm}$ ( 3 inches by 4 inches), such that it acts as a wind tunnel with respect to the film cooling. The film cooling is introduced through removable test plates in one wall of the tunnel. Effectively, the rig represents a flat plate tunnel for film cooling evaluations. Downstream of the film injection location is an instrumented plate containing 87 imbedded thermocouples placed in an array to cover both streamwise and spanwise variations. Only the center streamwise line of thermocouples was used to report the present results, thereby avoiding any endwall or corner flow effects. The rig is operated with a mainstream air temperature between $288 \mathrm{C}$ to $315 \mathrm{C}(550 \mathrm{~F}$ to $600 \mathrm{~F})$, and coolant air injection temperatures of $10 \mathrm{C}$ to $52 \mathrm{C}(50 \mathrm{~F}$ to $125 \mathrm{~F})$, such that coolant-to-gas density ratios (DR) are in a range representative of the ATS turbine nozzle. Test conditions were varied such that a range of blowing ratios (M), coolant-to-gas mass velocities, were covered. The tunnel 
discharges to slightly sub-atmospheric pressure, so the total inlet pressure of the rig is only about $0.14 \mathrm{MPa}$ (20 psia). The Warm Wind Tunnel flat plate test section is shown in Figure 8.7.9C-2.

Initially, several candidate film geometries were fabricated in the form of individual test plates.

The following five film geometries were each tested at five blowing ratios:

a) Axial Round Holes

b) Radial Round Holes

c) Radial Round Holes-in-Slot, $S / D=3$

d) Radial Round Holes-in-Slot, Wide Slot with Deep Chamfer, $S / D=3$

e) Radial Round Holes-in-Slot, Narrow Slot with Broken Edge, $S / D=3$

All geometries had $\mathrm{P} / \mathrm{D}=4$ (distance between holes in diameters) as measured normal on the breakout surface, $30^{\circ}$ angles to the surface, hole diameter $\mathrm{D}=1.52 \mathrm{~mm}(.060 \mathrm{inch})$, and hole length $\mathrm{L} / \mathrm{D}=5$. For the slot cases, $\mathrm{S}$ is the slot depth. The slot width was $\mathrm{W} / \mathrm{D}=1.5$ for case (d), and W/D $=1.13$ for case (e). The chamfer of case (d) was $45^{\circ}$ and extended to half of the slot depth. Each film plate used 12 holes which were machined by drilling, not by EDM or laser. The character of the holes is similar to EDM.

One geometry represents the baseline case of radial round holes at a $30^{\circ}$ angle to the surface, exiting transverse to the mainstream flow direction. Another baseline case is that of axial round holes at a $30^{\circ}$ angle to the surface. The other geometries are variations on similar film rows, using other novel geometry alterations. Geometries with larger P/D (fewer holes) or greater angles, in addition to the other alterations, are considered desirable for manufacturing purposes, but may or may not provide improved film performance over that of the baseline case.

\section{PRESSURE SIDE FILM TESTS}

The test was set up in CRD's Warm Wind Tunnel. The wind tunnel was modified for the present pressure side tests by replacing the opposing wall to the film injection plate with a converging wall. The film injection location is at streamwise position 0 , where the mainstream Mach number is about 0.35 . The mainstream accelerates to Mach 0.8 over the length of the instrumented test plate. For these tests, a trip strip of about $1.59 \mathrm{~mm}(1 / 16$ inch) diameter was placed $10.16 \mathrm{~cm}$ (4 inches) upstream of the film injection to shorten the boundary layer development length. Downstream of the film injection location is an instrumented plate containing 87 imbedded thermocouples placed in an array to cover both streamwise and spanwise variations. Only the center streamwise line of thermocouples was used to report these results.

Tests were run under steady-state conditions for each blowing ratio. The mainstream air was typically about $294 \mathrm{C}(560 \mathrm{~F})$. The coolant was injected at temperatures ranging from $13 \mathrm{C}$ to $52 \mathrm{C}(55 \mathrm{~F}$ to $125 \mathrm{~F})$, depending upon the blowing rate. The coolant plenum increased in temperature as the coolant flow rate decreased, due to conduction of energy from the physical 
attachment region on the wind tunnel and also through the plate to the coolant; the former effect was minimized by the use of insulating gaskets. The freestream turbulence intensity was not measured in these tests, however, because the piping system is essentially the same as that of the ATS Turbine Inlet Nozzle Cascade rig where measurements werre made; it is expected that the present intensity level is about $4-5 \%$. These tests try to incorporate degrading effects on film cooling, including both elevated freestream turbulence and an accelerating flow field.

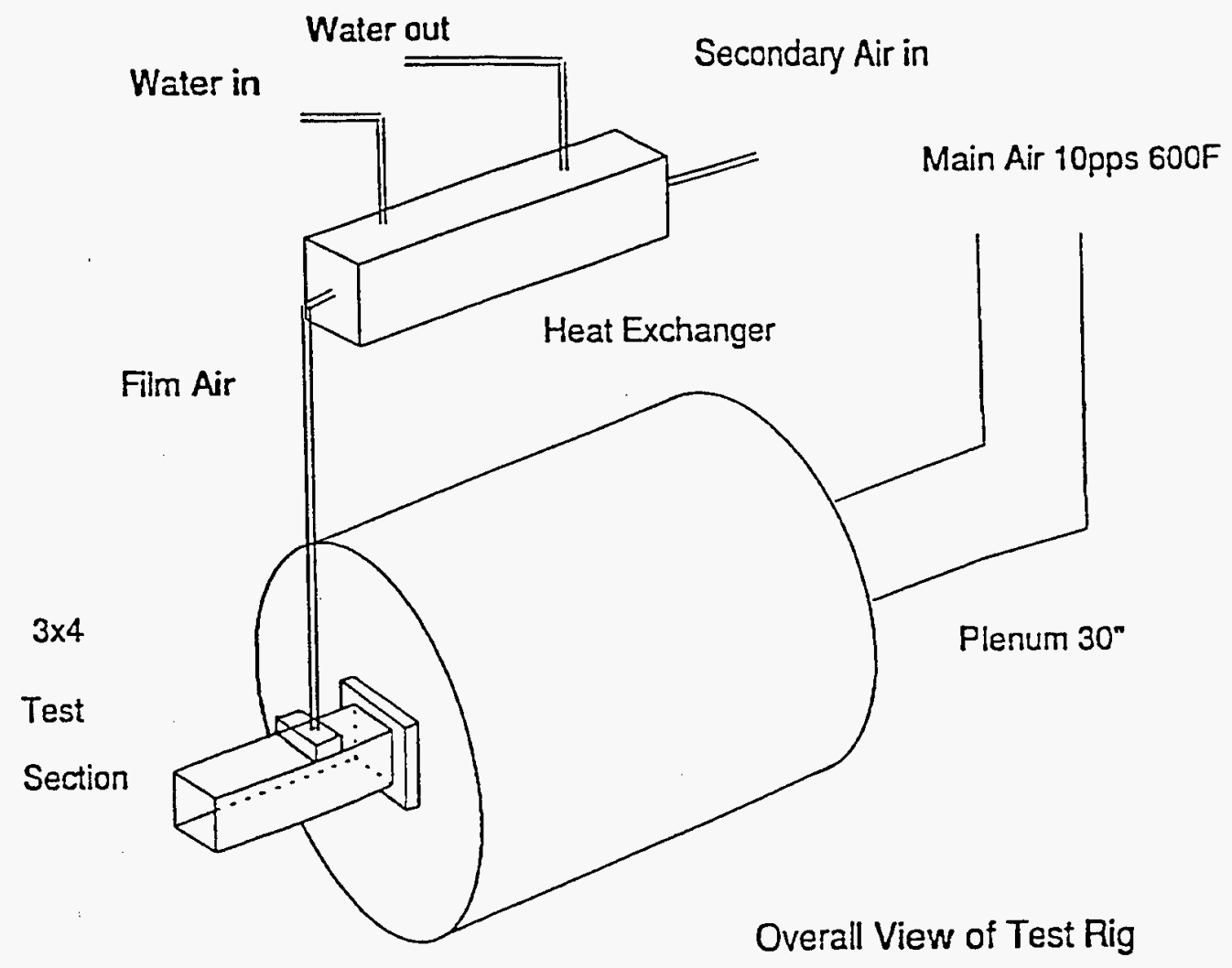

Figure 8.7.9C-1. Overall View of Warm Wind Tunnel Heat Transfer Rig. 


\section{DETAILS OF FLAT PLATE TEST SECTION}
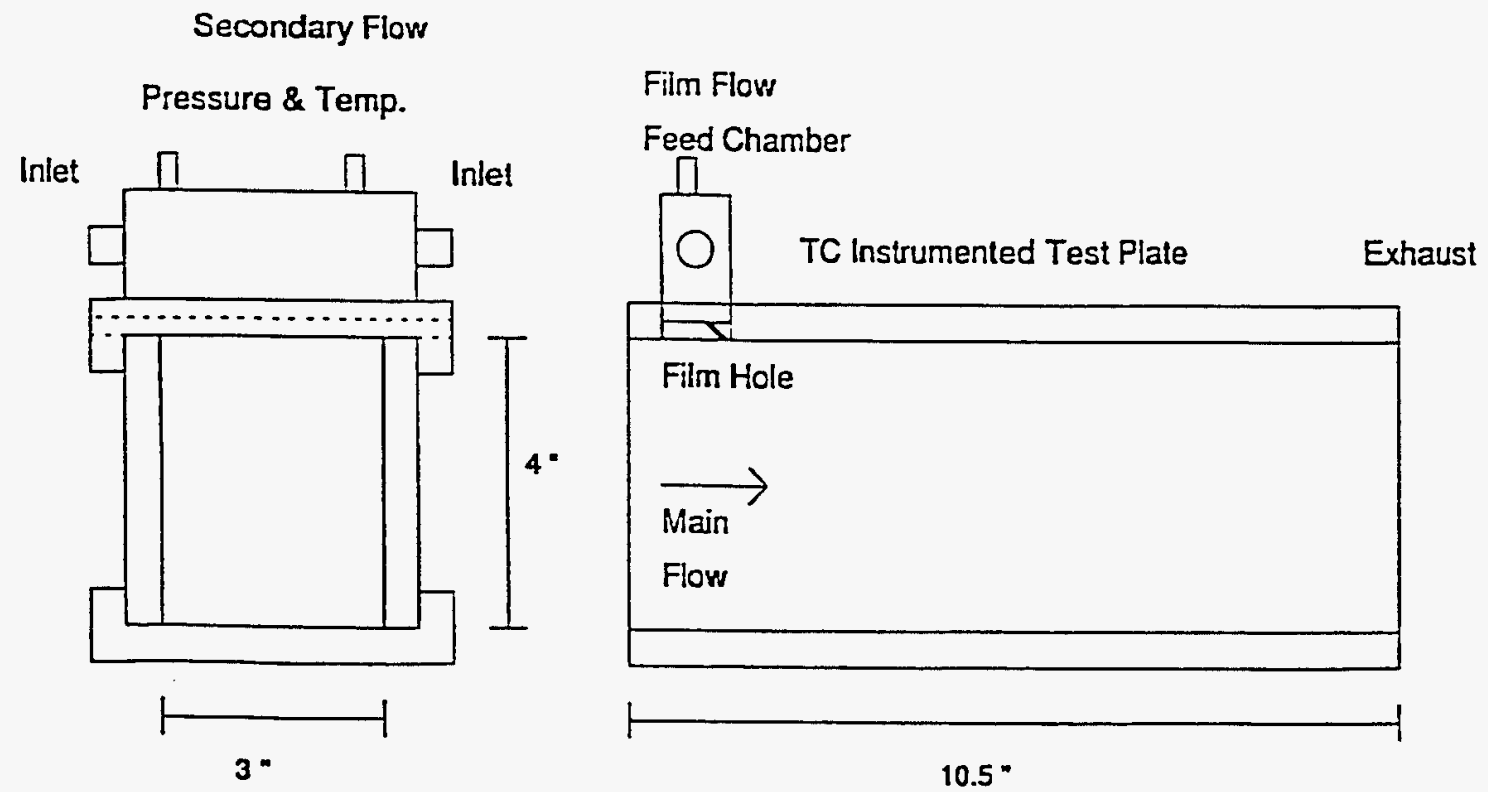

Figure 8.7.9C-2. Warm Wind Tunnel Flat Plate Test Section. 


\section{TECHNOLOGY APPLICATION}

Where use of conventional film cooling must be limited, it is necessary to provide the most effective film performance possible as well as the performance that meets the required conditions set by manufacturing and coolant supply constraints. The data obtained in this task will be used by design engineering to select the most appropriate film geometries to be used for the trailing edge region of the ATS turbine inlet nozzle. Knowledge of the film effectiveness under blowing ratios and density ratios that model the turbine conditions assures accurate design of the component.

\section{SUMMARY AND CONCLUSIONS}

Baseline and novel film cooling geometries have been tested for models of both the pressure and suction sides of the ATS turbine inlet nozzle trailing edge region. Results show the benefit of the novel geometries to be marginal to moderate, depending upon the particular blowing rates and mainstream Mach numbers. The narrow slot film configuration shows the best pressure side film effectiveness performance of all slotted or radial geometries over the blowing ratio range that the ATS turbine inlet nozzle trailing edge region should experience. This case is insensitive to blowing rate; it also provides constant performance. 


\section{TASK 8.7.10 - TRANSITION PIECE DESIGN TOOLS}

\section{INTRODUCTION}

Higher firing temperatures in the ATS gas turbine make the transition piece a crucial component. Flow separation in the transition piece must be avoided since it results in locally high heat transfer that could lead to liner burnout. Improved analytical prediction of flow separation in transition pieces will reduce the required amount of testing, and reduce design risk. Faster meshing capability will allow for increased use of computational fluid dynamic (CFD) analyses on complex transition piece geometries, reducing cycle time.

\section{OBJECTIVES}

One objective of this task was to further develop a 3D unstructured meshing system that is more automatic and robust for complex transition duct geometries. This is planned as a subcontract with MIT. The MIT subcontract consisted of four parts: (1) linking the unstructured mesher to a CAD system, (2) development of a graphical interface for mesh generation/geometry handling, (3) automatic specification of mesh size distribution, and (4) investigation of the possibility of converting unstructured tetrahedral meshes into meshes of prisms and hexahedra.

A second objective was to improve our ability to predict flow separation in transition pieces through the use of adaptive meshing and advanced turbulence models. The commercial CFD code, STAR-CD, was used to analyze transition pieces. This work had two goals: (I) modification of a script previously developed by GE Power Generation (GEPG) to mesh transition pieces so that no user input was needed after the script was started; and (2) improvement of the modeling of the transition piece within STAR-CD so that the transition piece model would predict flow separation more accurately. The effects of mesh density, differencing schemes, turbulence modeling and boundary condition prescription were investigated.

\section{RESULTS}

The new meshing system developed under this contract represents significant enhancements to the FELISA meshing system (developed under earlier NASA funding), and the development of a graphical interface to drive the geometry handling and the mesh generation process. Although the new meshing system shares many of the file formats of the original FELISA system, it is an entirely new piece of software, written entirely in C, in contrast to the original FELISA system which is written entirely in FORTRAN. Likewise, the new Geometry Viewer, while it shares the general appearance of the earlier Visual3 graphics program, is also an entirely new piece of software. The work on the MIT subcontract was performed by Professor Jaime Peraire and Mr. Robert Haimes of the Department of Aeronautics and Astronautics at MIT. The subcontract work was monitored by M. Braaten of CRD.

The work on automating the transition piece meshing script for STAR-CD was performed by $\mathrm{M}$. Lacey of $\mathrm{CRD}$, and the work on improving the ability of the transition piece model to predict flow separation was performed by M. Lacey and M. Braaten. 


\section{MESHING SYSTEM}

The work on developing an improved unstructured meshing system encompassed items 1 , 3 , and 4 of the MIT subcontract, i.e., (1) linking the unstructured mesher to a CAD system, (3) automatic specification of mesh size distribution, and (4) investigation of the possibility of converting unstructured tetrahedral meshes into meshes of prisms and hexahedra.

The CAD system used throughout GE, including GEPG, is UNIGRAPHICS/ PARASOLIDS. The output of the CAD definition of a transition piece is a PARASOLIDS solid model file. For that reason PARASOLIDS was selected as the solid modeler with which to link the new meshing system. The structure of the geometry modeler within the surface mesh generator was modified to make the task of reading PARASOLIDS models straightforward. The structure of the new code supports both PARASOLIDS and FELISA geometries as well as a combination of both. This capability satisfies the first contract objective of linking the mesher to a CAD system. The surface triangulation has been modified to allow for arbitrary stretching of the patches defining the geometry. The new mesh generator is also fully coupled with the newly developed Geometry Viewer, as described later.

Early in this project, it became clear that stretched elements along geometric edges with high curvature had to be created in order to allow grids to be created with adequate resolution of these features. Without this capability, the ability to automatically specify mesh spacing based on surface curvature is of little value because a grid with equilateral tetrahedra will require so many mesh points and tetrahedra for adequate resolution that it will be of little practical use. Once this requirement was recognized, the development of the directional pre-refinement capability was moved ahead of the development of an automated specification of the mesh spacing.

The successful implementation of a directional refinement module into the new surface and volume meshers, performed under this contract, represents a major advancement in the technology of unstructured meshing with tetrahedra. This module allows for the generation of grids that are stretched in one direction (e.g., for leading and trailing edges resolution) and two directions (e.g., for boundary layers). Unlike the stretching obtained using a linear transformation, as in the existing GE meshing system, the directional prerefinement algorithm produces elements with the largest angles being close to 90 degrees. This is important for stability and accuracy of the unstructured flow solver. An example of a mesh with the directional pre-refinement is shown in Figure 8.7.10-1. The initial grid has been pre-refined along the leading and trailing edges of a wing geometry.

A mesh for a typical GE transition piece geometry was successfully generated using the new meshing system, and is shown in Figure 8.7.10-2. The stretched elements created by the directional pre-refinement procedure, which are essential for resolving the flow in the boundary layers, are apparent in the figure. Using stretched elements rather than a mesh of refined equilateral tetrahedra allows for much more efficient use of the grid in the boundary layer. 


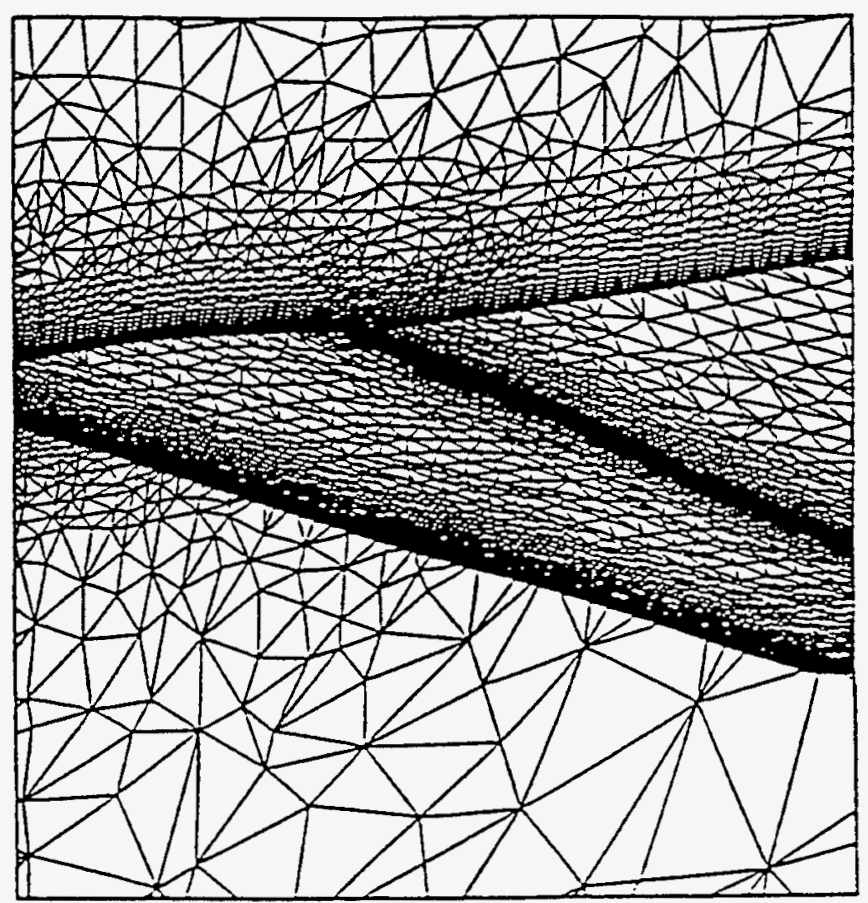

Figure 8.7.10-1. Directional Pre-refinement of Mesh at Leading and Trailing Edges of Wing Geometry

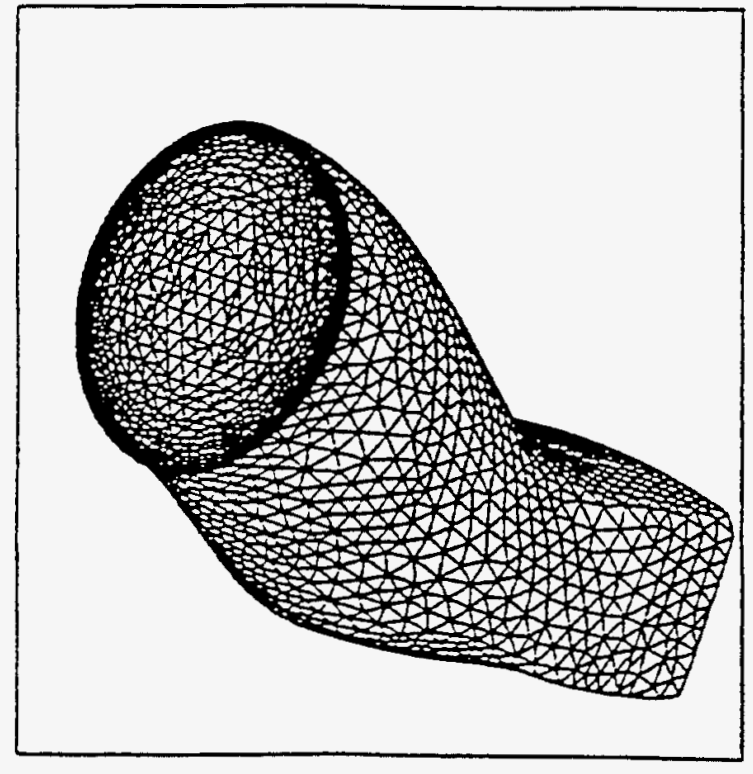

(a)

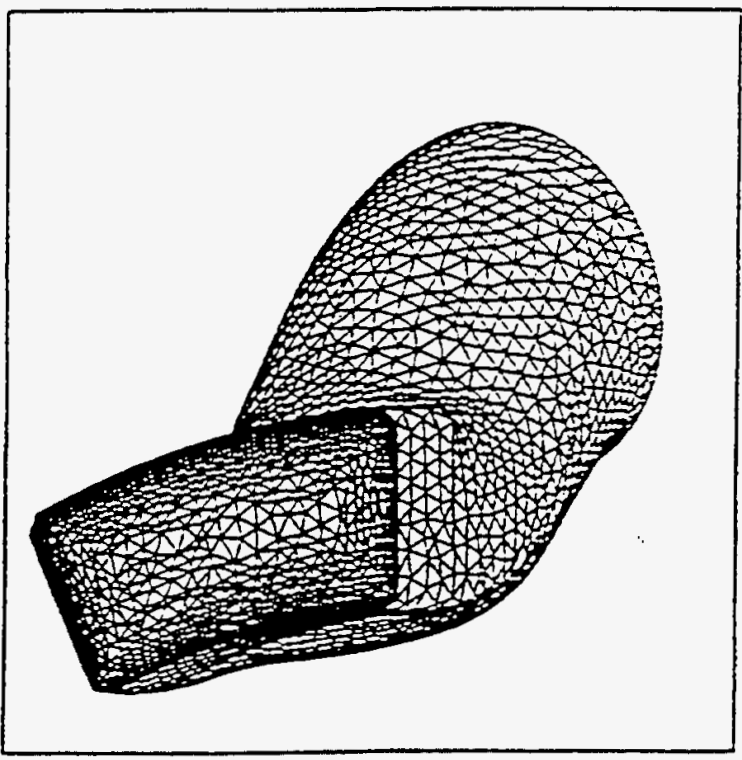

(b)

Figure 8.7.10-2. Unstructured Mesh for Typical GE Transition Piece, Generated with New MIT Meshing Software: (a) Forward Looking Aft, (b) Aft Looking Forward 
Progress has been made in using detection of surface curvature to automatically control the mesh spacing. The surface mesher has a new parameter that controls the minimum number of points per radian needed to resolve curved surfaces. If the prescribed background spacing is too coarse to resolve the curvature sufficiently, the spacing is modified according to this parameter to ensure adequate resolution. Another parameter prevents the spacing in the vicinity of a region of very high curvature from becoming too small relative to the background spacing.

An investigation into various means of combining tetrahedral meshes into prismatic and hexahedral elements was motivated by the fact that some commercial CFD codes (such as STAR-CD) favor the use of hexahedral or prismatic elements rather than tetrahedra. Unfortunately, this investigation was unsuccessful in coming up with any really practical means of obtaining suitable combined meshes. The proposed approach of splitting every tetrahedron into four hexahedra proved unsuitable because it leads to excessively distorted and excessively large hexahedral meshes. We have found that it is usually more difficult to create a coarse tetrahedral grid for a complicated geometry than it is to create a fine grid. We have encountered geometries for which the coarsest tetrahedral grid that can be produced has roughly 100,000 mesh points and over a half million tetrahedra. In general, for a tetrahedral grid, there are approximately six times as many tetrahedra as there are node points. If each of these tetrahedra is split into four hexahedra, there will be 24 times as many hexahedra as there were original mesh points. A cell-centered hexahedral flow solver such as STAR-CD would then have to solve for 24 times as many unknowns as were required by a vertex-based unstructured grid flow solver, solving on the original tetrahedral grid. It is not feasible to solve grids in excess of one million grid points on today's workstations. During the course of this project, a new version of STAR-CD was released which, it is claimed, has significantly improved capabilities for handling tetrahedral cells. This development makes the need to combine the tetrahedra into prisms and hexahedra less important.

GE provided MIT with some FELISA and PARASOLIDS models to use to test the new software. The prototype versions of the software were demonstrated to GE during a visit in early February; the final versions were delivered in early April. The meshing code has been ported to CRD HP workstations, and undergone initial testing. The link to PARASOLIDS appears good, and the surface mesher appears to work correctly. Some problems have been uncovered in the Delaunay volume mesher and are being corrected by MTT.

\section{GEOMETRY VIEWER}

The Geometry Viewer that was developed is an integral part of the unstructured meshing system. It allows for the visualization of the CAD geometry and the mesh as the mesh is being created, and allows the user to more effectively interact with the meshing procedure.

All low level 3D (and some 2D) drawing is done using the OpenGL standard. A freeware full emulation of OpenGL for X-Windows, MacOS, and Windows was located on the World Wide Web. The emulation package has been tested using Visual3 (which has simpler drawing requirements) on all major UNIX workstations with success using 8-bit color. 
Points, lines, and surfaces built of different primitives can be viewed in 3D. An object database has been constructed that allows interactive adjustment of some plotting attributes, including: points rendering (on/off), lines rendering (on/transparent/off), surfaces rendering (on/transparent/off), lighting (faceted/smooth), orientation (front vs. back, on/off), and mesh (on/off).

The graphical interface has the capability for picking and selecting geometrical entities, which makes the interactive creation of background meshes possible. In addition this capability allows for the interactive definition of surfaces such as wakes.

The Geometry Viewer software has been written to be modular and attachable to applications that deal with point, line, surface, and volume data. The Viewer has two execution modes: (1) normal, serial execution, where program control is passed to the graphics, the data are examined, and then, when the user is satisfied, execution resumes in the calling program, and (2) multi-threading, where the data are shared between two executing threads (application and graphics) and both can be concurrently active allowing viewing as the application runs. The Geometry Viewer was demonstrated to GE during a visit to MIT in February. The final code was delivered to GE in early April. Our evaluation of the software on our HP workstations is awaiting the upgrading of our machines to the HP 10.1 operating system, which is needed to support the multithreading required to run the Geometry Viewer concurrently with the new mesh generation software.

\section{AUTOMATION OF THE STAR-CD MESHING SCRIPT}

The CFD analysis of the transition piece has been automated to a large extent. The CFD analysis of the transition piece is done using STAR-CD, a general purpose CFD code written by Adaptco and Computational Dynamics, Ltd. GEPG had previously developed software to create a geometry file that could be read into STAR-CD and a script to automate the meshing and analysis of the transition piece in STAR-CD. Using the script developed by GEPG was faster than manually meshing the transition piece and setting the boundary conditions, fluid properties, etc.; however, the script required the user to interactively select the inlet, outlet, and symmetry plane of the geometry. The method by which STAR-CD allows the user to select these features is not well-suited for use in a script file. Once the script was running, the user could not stop the script to adjust the way the part was displayed, and that made selecting geometrical features difficult. If the features had not been selected properly, the script would have to be restarted and run again.

The GEPG script was rewritten so that no user input is required while running the script. Because the basic geometrical shape of all transition pieces is the same, the new script can use the information in the geometry file to locate the inlet and exit and then apply the proper boundary conditions at each location. The new script also locates the geometric symmetry plane and can either reflect the mesh across the symmetry plane, as is necessary to properly analyze flows with swirl, or it can set symmetric boundary conditions along this plane thus reducing the computational domain of the problem and significantly speeding up the analysis. A grid for a typical GE transition piece generated using the new meshing script is shown in Figure 8.7.10-3(a). 
The new script locates these geometric features in a very robust manner. It can locate the necessary geometric features regardless of the size and dimension of the transition piece. Additionally it can take into account differences that can occur in the geometry file (e.g., the geometry file can have a different starting node number).

Much of the old script contained numbers that were hard coded into the script. Those numbers described fluid properties, mesh spacing, node and cell numbers, etc. The script has been rewritten so that any number that must be defined or possibly changed by the user is assigned to a variable. The variable assignments are now located at the beginning of the script, and the variables are documented in a notes section adjacent to the assignment section. With this arrangement, the user can adjust the value of a variable in one convenient location, and it is no longer necessary to search through the script line by line to identify each occurrence of a hard coded parameter. Additionally, it is no longer necessary for the user to input variables that can be calculated from the information in the geometry file (i.e., inlet diameter and area).

\section{IMPROVED MESHES AND MODELING}

Experimental results from flow visualization tests performed at CRD have indicated that, on a particular transition piece design, there is a large zone of flow separation along the outer span, near the aft frame. This transition piece had been previously analyzed using STAR-CD and the script developed by GEPG. This CFD analysis had not shown this recirculation zone. Changes have been made to the GEPG script to improve the modeling and meshing of transition pieces. As a result, the CFD analysis is now able to predict flow separation in regions where it has been observed experimentally.

To improve the model's ability to predict separation, several changes were made to the script. The first change was to refine the mesh in the boundary layer. The old script only had one cell in the boundary layer; currently the script is set up so that there are at least five cells in the boundary layer. A close-up view of the grid in the vicinity of a suspected separation region is shown in Figure 8.7.10-3(b). The CFD results now show the velocity profile developing in the boundary layer.

The user can easily adjust the number of cells in the boundary layer. The script has been rewritten so that the mesh density in different regions of the model can easily be modified by adjusting the value of a few variables. To control the number of cells in the boundary layer, the user can specify the thickness of the outer blocks, the number of cells in these blocks, and the radial distribution of the cells within these blocks. The model is also divided into five sets of blocks in the axial direction. The number of cells in the axial direction and the start and end of each of these block sets can be changed by changing the corresponding variable. 


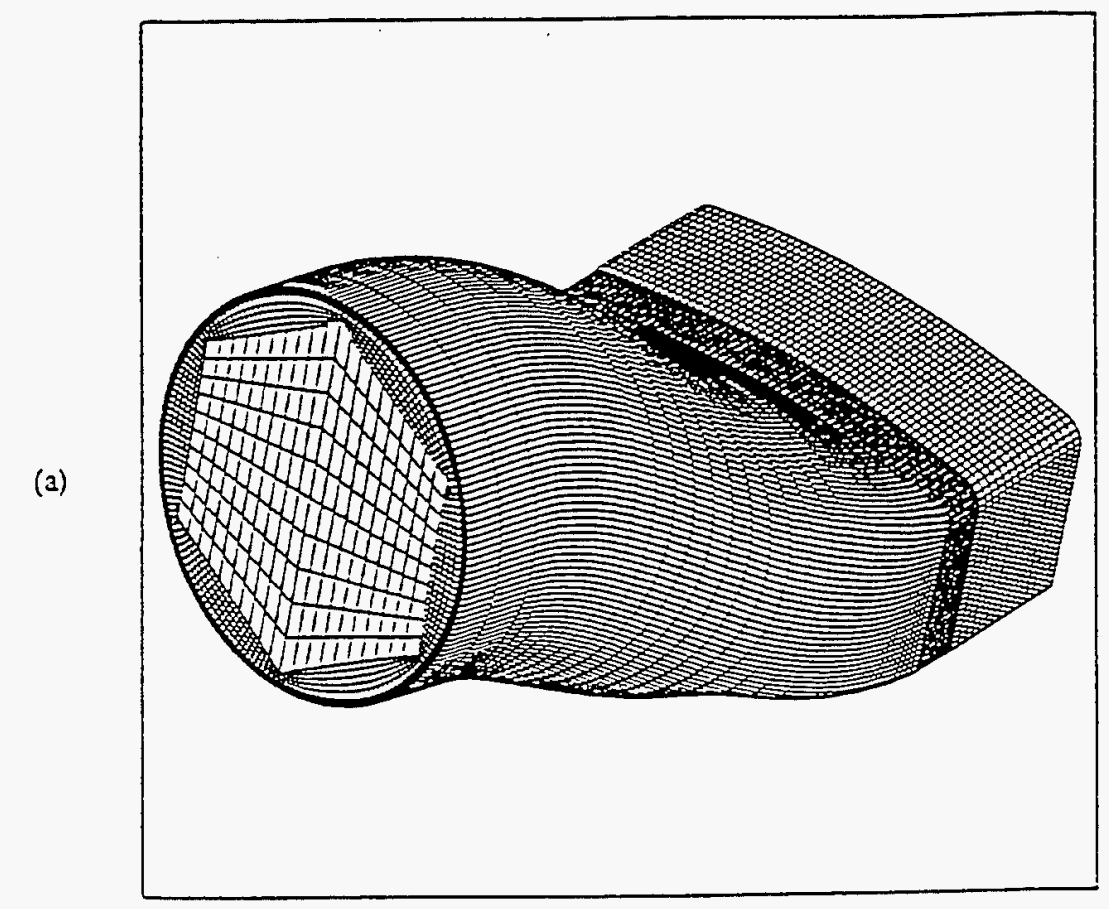

(b)

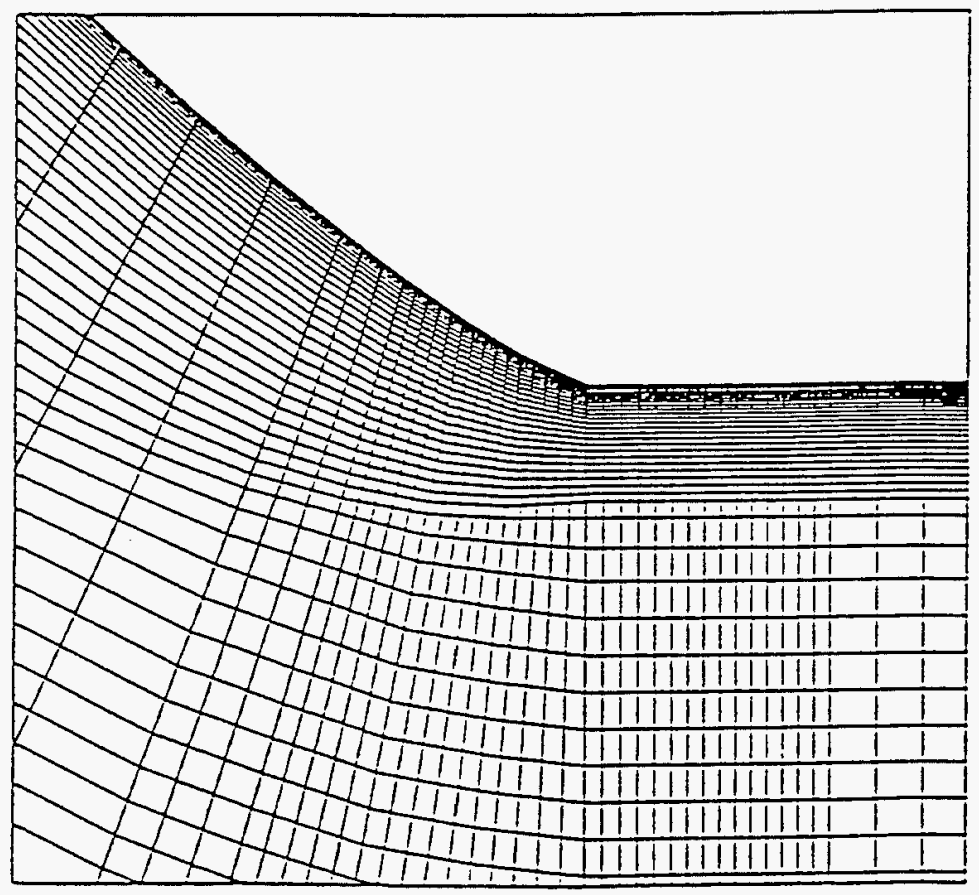

Figure 8.7.10-3. Mesh for Typical GE Transition Piece, Generated with New MTT Meshing Script: (a) Transition Piece Mesh, (b) Increased Mesh Density in Region of Flow Separations 
It was found that the choice of differencing schemes affected the model's ability to predict separation. The model now uses a blended differencing scheme; previously upwind differencing, which is the default differencing scheme in STAR-CD, had been used. Upwind differencing is a first order scheme which tends to be very diffusive. The numerical diffusion caused by this differencing scheme tends to suppress separation. To reduce the amount of numerical diffusion created by the differencing scheme, a higher order scheme was investigated. Central differencing is a second order scheme which produces less numerical diffusion than upwind differencing; however it can be dispersive and this can lead to convergence problems. When pure central differencing was used there were convergence problems, and the residuals did not decrease in a monotonic fashion as they did when pure upwind differencing was used. A blended differencing scheme (i.e., a linear combination of both of these schemes) offers the ability to work around some of the shortcomings of each scheme. Currently, the model is using a blended scheme that is mostly central differencing $(90 \%)$, with small amount of upwind differencing $(10 \%)$ blended in to avoid stability problems.

The turbulence modeling and the ability of the code to accurately predict the turbulent viscosity, had a major effect on the prediction of flow separation. Turbulence in the transition piece had been previously modeled using the standard $k-\varepsilon$ model. It is known that this turbulence model tends to overpredict the turbulent viscosity in regions of high shear. The region in which the flow separation occurs is a region of high shear and an overprediction of the turbulent viscosity in this region would tend to suppress the development of the recirculation zone. To reduce the overprediction of the turbulent viscosity, the turbulence model was changed from the standard $k-\varepsilon$ formulation to a modified $k-\varepsilon$ formulation based on Renormalization-Group (RNG) theory. Unfortunately, this model still overpredicts the turbulent viscosity in the region of interest. To further reduce the turbulent viscosity in the area of interest, an artificially low value of the turbulent viscosity is assumed at the inlet to the transition piece. The script developed by GEPG uses a turbulent viscosity that is 50 times the laminar viscosity; which is an artificially low value. Typically the turbulent viscosity at the inlet would be calculated using the following:

$$
\mu_{t}=\mathrm{c}_{\mu}^{\frac{1}{4}} \rho l k^{\frac{1}{2}}
$$

If it is assumed that the turbulent length scale (l) is $1 / 20$ th the inlet diameter, then at operating conditions, the turbulent viscosity is $\sim 2300$ times the laminar viscosity, which is significantly higher than the factor of 50 that has been used. The new model retains the approach of setting the turbulent viscosity to a lower value at the inlet so that the turbulent viscosity is not overpredicted in the regions of interest. The new script also gives the user the option of setting the turbulent viscosity to a constant throughout the model. This option can be selected by setting a variable flag before running the script. If this option is selected the program does not need to solve any of the turbulent transport equations, which significantly speeds up the analysis.

The modeling of the outlet boundary condition also had an effect on the ability of the code to predict flow separation in the region where it had been experimentally observed. The 
outlet boundary condition is modeled as a constant pressure boundary condition, and it is relatively close to the region of interest. To prevent the prescribed boundary condition from corrupting the solution in the region of interest, the GEPG script had moved the constant pressure boundary downstream, away from the region of interest, by artificially lengthening the transition piece. The results from the CFD analysis show that there is a region of high turbulent viscosity near the constant pressure boundary condition. This does not represent an actual region of high viscosity but rather is the result of imposing the constant pressure boundary condition there. To prevent this from affecting the solution in the region of interest, the constant pressure boundary condition has been moved downstream. Similarly, the inlet has been moved upstream so that the flow can develop properly at the inlet. Artificially lengthening the transition piece in this manner provides more realistic boundary conditions at the exit and inlet to the transition piece. The physical length that the script extrudes the inlet and exit, as well as the number of cells in these sections, is now defined by variables that can be changed by the user.

Figure 8.7.10-4 shows the results of a calculation made with the above modifications. The flow separation along the outer span, near the aft frame, is successfully predicted.

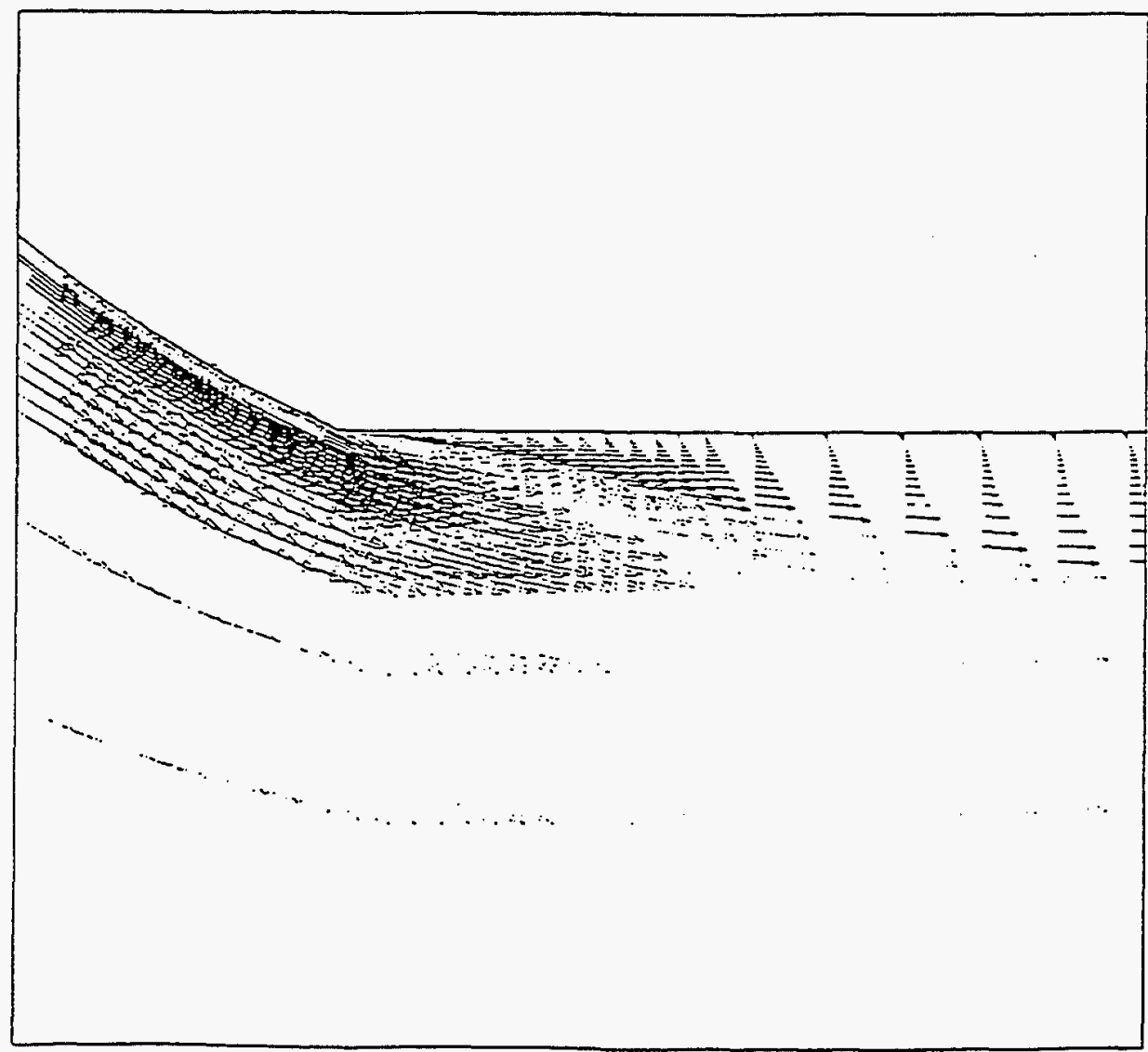

Figure 8.7.10-4. Recirculation Zone Calculated Using STAR-CD 


\section{TECHNOLOGY APPLICATION}

The unstructured mesh generation capability has greatly improved the transition piece flow modeling, improving the speed of solution and the ability to predict flow separation. The results of this task are being used to design the $7 \mathrm{H}$ and $9 \mathrm{H}$ transition piece geometry.

\section{PLANS FOR PHASE 3}

There is no work planned for Phase 3.

\section{DISCUSSION OF RESULTS}

The additional task of creating directionally stretched elements, while not envisioned initially, represents the major contribution of this task, and represents a significant advance in the technology of generating unstructured meshes, particularly for Navier-Stokes analyses. Earlier unstructured meshes like the original FELISA system generated primarily equilateral tetrahedra, which are adequate for Euler analyses but inefficient for viscous flow analyses. The new meshing system and the Geometry Viewer represent the framework for a powerful future production system for the automatic generation of transition piece meshes directly from their $\mathrm{CAD}$ definition very efficiently.

For the part of the task that involved improving the analysis of transition pieces using the commercial CFD code, STAR-CD, the objectives were met. The meshing script is now highly automated, and it is no longer necessary for a user to provide occasional input while this fairly long script is running. The conditions at which the analysis is to be performed and the mesh density can be altered by changing the appropriate variables before the script runs. It may be useful to further investigate the relationship between some of the meshing variables, and there may be opportunity to further reduce the number of variables that the user must define.

The modeling of the transition piece in STAR-CD has been improved to the point where it can identify flow separation along the outer span, near the aft frame. To predict the flow separation, several changes to the model were made and it was necessary to artificially reduce the turbulent viscosity at the inlet. It does not appear that changing the way that the transition piece is modeled within STAR-CD will improve the predictions any further; additional improvement in the accuracy of the predictions will have to come through an improvement of the code itself. 


\section{TASK 8.7.11 - EFFECTS OF HIGH MACH NUMBER DIFFUSER}

\section{INTRODUCTION}

The ATS gas turbine design calls for changes in the midframe geometry that will affect the aerodynamics and combustion system cooling performance. Figure 8.7.11-1 shows a schematic of a typical midframe area, its major components, and the air flow path through the midframe. Flow enters the midframe area from the compressor diffuser and exits through the combustor impingement sleeve and the combustor flow sleeve. One function of the midframe is to act as a settling chamber so that the flow can enter the combustion system in a uniform and steady fashion. The proposed ATS gas turbine design could compromise the effectiveness of the midframe as a settling chamber.

\section{OBJECTIVE}

Proposed compressor exit designs for the ATS gas turbine give much higher exit Mach numbers than have previously been experienced. Potential difficulties include high combustion dynamics, a need for higher combustor system pressure losses to cool hardware, and flow field imbalances that increase the difficulty of obtaining low emissions. Studies are required to quantify risk and evaluate alternate designs. At CRD, flow tests on existing multi-combustor models will be carried out for validation via flow visualization and pressure measurement of the impact of higher compressor exit velocities and split diffuser designs. CFD will also be utilized to model the flow field within the compressor diffuser/combustor wrapper volume to evaluate potential problems and evaluate likely solutions.

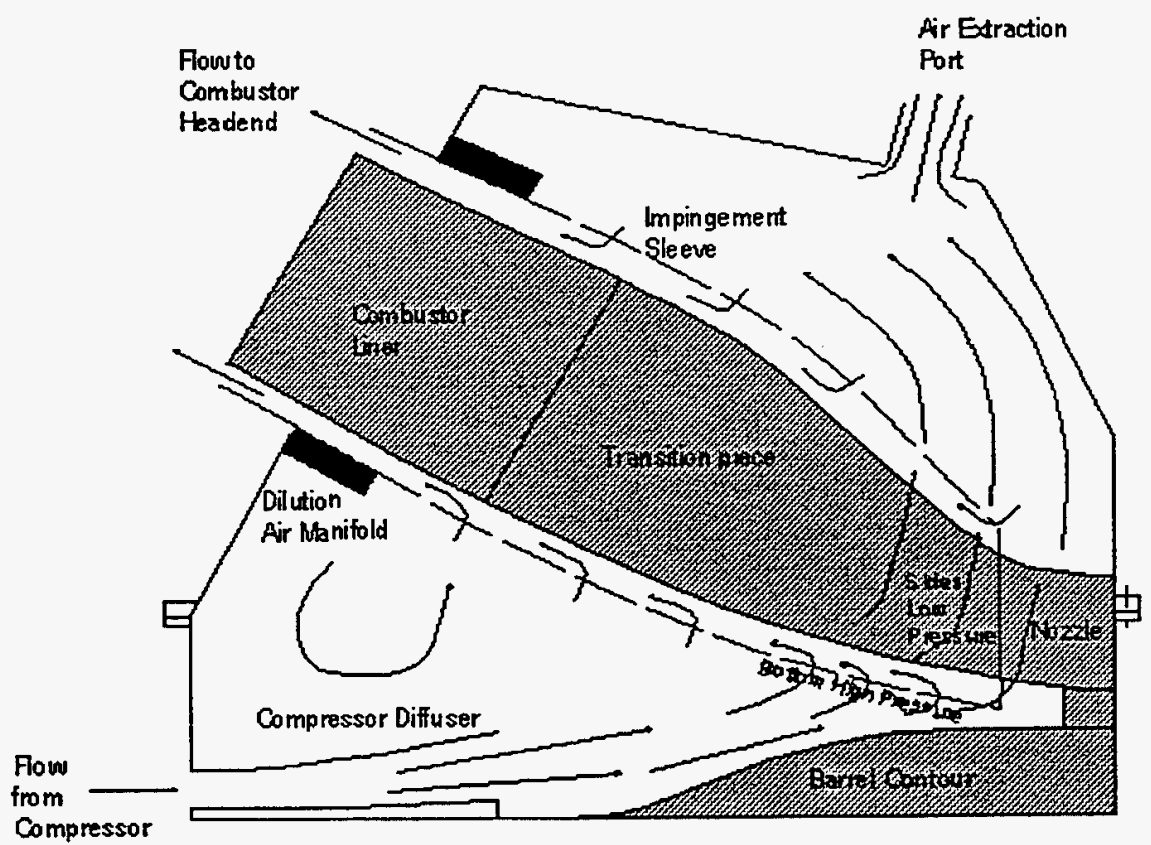

Figure 8.7.11-1. Typical Midframe Area Showing Flow Through a Single-Passage Flow Diffuser 


\section{PROBLEM DEFINITION}

The ATS gas turbine design will incorporate a high performance compressor that will increase the compressor exit Mach number and flow velocity significantly; it will also incorporate a 4stage turbine that will decrease the midframe axial length and volume. Both of these changes will affect the midframe aerodynamics. The effect that these changes will have on the combustor cooling and system pressure drop is of very great concern.

Combustor cooling includes the cooling of the combustion liner and the transition piece (TP) duct. The TP cooling is most sensitive to the changes in the midframe flow field. In Figure 8.7.11-1, it can be seen that the transition piece duct is cooled by directing jets of air at the backside of the hot TP duct. The life of the transition piece depends on backside cooling. It is likely that without TP backside impingement cooling, overheating would cause duct failure.

The device that forms the impinging jets is called the impingement sleeve. The impingement sleeve has the same general shape as the TP but is larger so as to form an air flow passage between itself and the TP. Flow enters the impingement sleeve through circular holes which form cooling jets. The jet momentum carries the flow across the passage so that the jet flow impinges on the TP surface. After the flow impinges, it turns and flows down the duct toward the combustor head end. Two parameters must be controlled to achieve the required jet impingement and cooling: (1) The jet must have the momentum required to cross the passage. The momentum is controlled by selecting the appropriate hole diameter and pressure drop across the hole. (2) The amount of cross flow in the passage must be controlled because the jet may not reach the TP surface if it encounters an unexpectedly strong cross flow. The cross flow is controlled by controlling the amount of air that enters the impingement holes. Important to controlling the flow through each impingement hole is an understanding of the flow/pressure field around the outside of the impingement sleeve. If the flow/pressure field around the outside of the impingement is not maintained as uniform as possible, an optimized TP cooling system cannot be designed. If the pressure distribution around the flow sleeve has low pressure areas, the pressure drop must be raised across the entire impingement sleeve until the desired flow is achieved in the low pressure area. Because increasing the pressure drop will decrease machine efficiency, it is of great importance to design a midframe with a flow and pressure field around the impingement sleeve that is very uniform.

\section{FACILITY AND MODEL DESCRIPTION}

Figure 8.7.11-1 is a cross section of the model, Figure 8.7.11-2 is a photograph of the facility, and Figure 8.7.11-3 is a schematic of the facility. The midframe model shown in Figure 8.7.11-2 includes: midframe casing, a standard single-passage axial compressor diffuser, and three combustors with liner, flow sleeve, and impingement sleeve. The midframe model design is typical of current GE " $F$ " gas turbine design. 


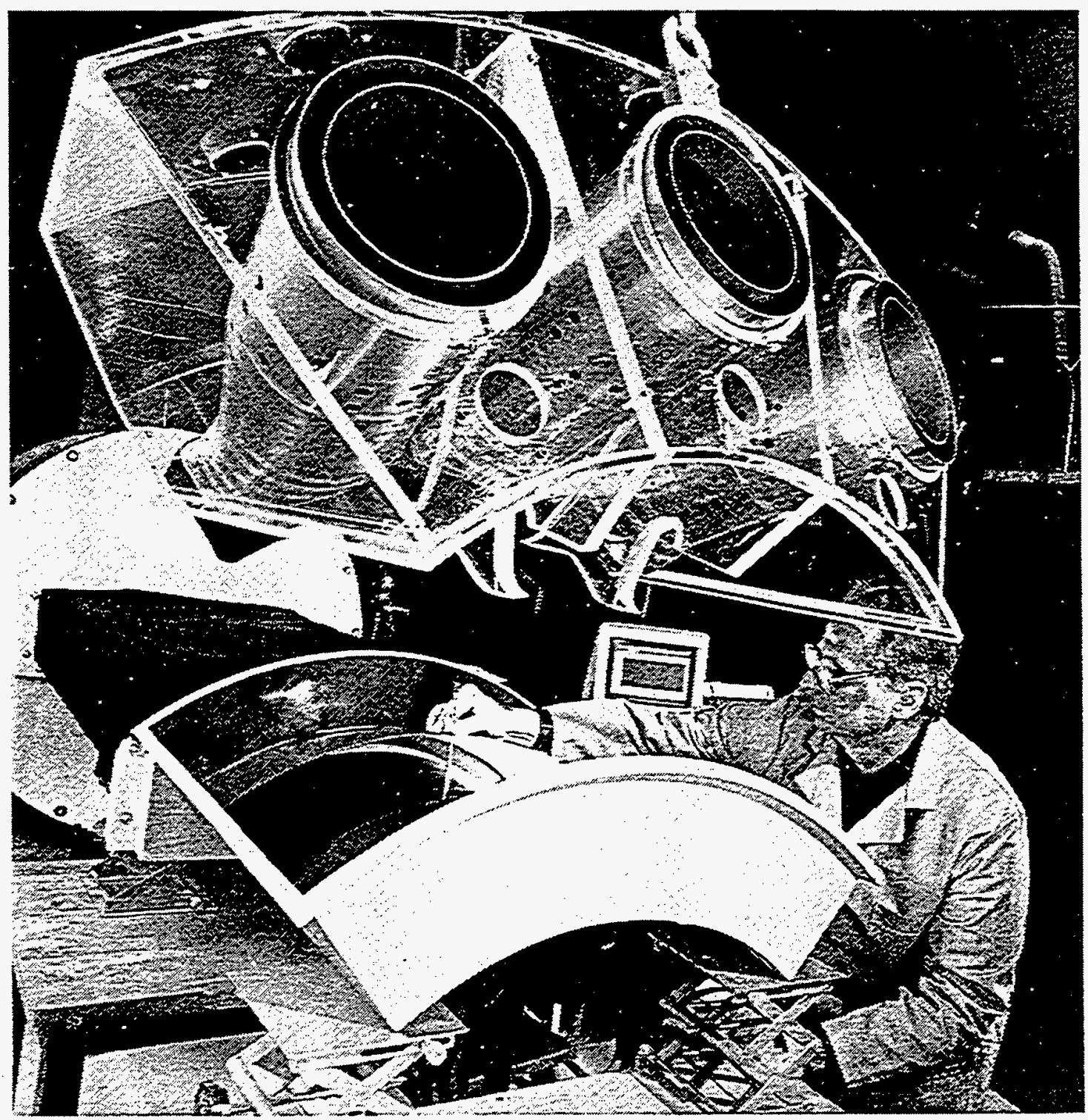

Figure 8.7.11-2. Photograph of CRD Midframe Test Facility

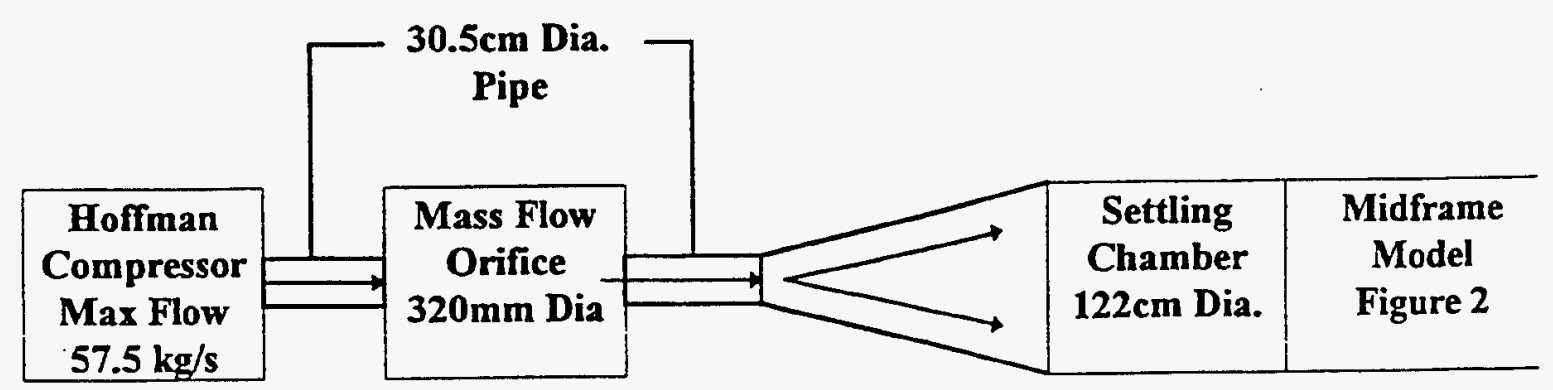

Figure 8.7.11-3. Flow Schematic of the Air Flow System for the Midframe Facility 
Before the flow enters the model, it goes through a 4-foot diameter settling chamber so that the inlet flow to the model is uniform. Total pressure and temperature are measured in the settling chamber to establish test inlet conditions. The total pressure is measured with a Kiel probe, and the temperature is measured with a standard thermocouple. Mass average velocity in the 4-foot chamber is $<305 \mathrm{~cm} / \mathrm{s}(10 \mathrm{ft} / \mathrm{sec})$ and is considered to have a negligible effect on total temperature reading. Flow exits the midframe model, as it would in an actual machine, through three of fourteen impingement and flow sleeves. The flow exits the model to atmospheric conditions at the point at which the flow would normally enter the combustor. No effort was made to model the combustor flow as it was felt that adding these flow features would have no effect on the flow in the midframe.

\section{MEASUREMENTS}

The primary reason for the test is to investigate the effect that increasing the compressor discharge velocity and decreasing the midframe axial length will have on the combustor transition piece duct cooling. Maintaining a uniform pressure distribution around the impingement sleeve is critical for the required cooling of the TP. When the pressure distribution around the impingement sleeve is uniform, the TP cooling can be optimized. To measure the pressure around the impingement sleeve, pressure taps were installed in the surface of the sleeve. The pressure taps are finished flush with the outside surface of the impingement sleeve. The taps are arranged in rings between the rings of impingement cooling holes. The surface pressure taps are not static taps; they indicate the pressure of the flow in the midframe housing. If the flow is being directed at the impingement sleeve, the pressure taps will indicate a value approaching the total pressure of the flow. If the flow passes by parallel to the impingement sleeve surface, the pressure taps will indicate a value approaching the static pressure of the flow. The flow distribution through the impingement sleeve is determined by $D P / D P$ ave , where $D P=P_{\text {surface }}-P_{\text {atm }} ; P_{\text {surface }}$ is the local surface pressure measurement; $\mathrm{P}_{\mathrm{atm}}$ is the pressure at the exit of the midframe casing or atmospheric pressure; and $\mathrm{DP}_{a v e}$ is the average pressure drop across the midframe as determined by pressure measurements in the casing and the exit atmospheric pressure.

\section{MACH NUMBER SENSITIVITY TESTS}

The baseline hardware is typical of a current " $F$ " technology gas turbine and is what was initially proposed for the ATS gas turbine. The midframe flow path has a single axial diffuser and a large-volume midframe casing. Tests at four different mass flows were run to determine the effect of increasing the compressor discharge Mach number.

The data clearly show that as the mass flow and Mach number are increased, the pressure distribution becomes less uniform. Rings 1-4 show a great deal of sensitivity to increased mass flow while Rings 5-7 show little or no sensitivity.

As the mass flow increases, the uniformity of the pressure distribution decreases. The data at $100 \%$ flow show the maximum pressure non-uniformity; the sides of the impingement sleeve have areas of low pressure while the bottom of the impingement sleeve sees high pressure. The high pressure means too much flow goes into the flow sleeve, and the low pressure means 
too little flow goes into the impingement sleeve. Both high and low flow conditions have detrimental effects on the TP cooling.

As the pressure and flow decrease, the impingement cooling of the transition piece decreases. As the pressure goes to lower and lower values, the flow through the impingement sleeve hole decreases and eventually reverses. From the flow visualization tests, flow reversal was seen at all areas where the pressure decreased below 0.6. Such flow reversal means that there is virtually no cooling of the transition piece duct in these areas, and this is obviously an unacceptable condition.

Not as obvious are cooling problems that can occur from high pressure areas. These areas should be overcooled because when the pressure is high the cooling flow in that area is increased. Cooling in other areas can be diminished by the higher flow, however. If more flow goes into the impingement holes at Ring 2, the flow that enters through the holes at Ring 3 encounters a stronger than anticipated passage velocity that the jet has to cross in order to cool the transition piece effectively. If the impingement jet fails to cross the passage, no impingement cooling of the TP takes place, and this is also unacceptable.

The non-uniform pressures are caused by the diffuser discharge jet velocity and the way the jet interacts with the impingement sleeve. With the single-passage axial diffuser, the jet from the diffuser impacts the impingement sleeve between Rings 1 and 4, at the turbine end of the impingement sleeve. The bottom surface of the impingement sleeve $\left(180^{\circ}\right)$ is almost normal to the jet flow, and slows the jet velocity to near zero and therefore sees the high total pressure, $P_{t}$ of the diffuser jet flow. The surfaces of the impingement sleeve sides (90 and 270 degrees) are parallel to the flow and squeeze the flow between adjacent impingement sleeves and therefore see the low static pressure, $P_{s}$, of the diffuser jet flow. As the mass flow increases the velocity and Mach number of the jet flow increase and the differences in these two pressures, $\mathrm{P}_{\mathrm{t}}$ and $\mathrm{P}_{\mathrm{S}}$, becomes larger and can be approximated by $\Delta \mathrm{P} \propto 1 / 2 \rho \mathrm{V}^{2}$, where $\Delta \mathrm{P}=\mathrm{P}_{\mathrm{t}}$ $-P_{S} ; P_{t}=$ Pressure at the bottom of the impingement sleeve for Ring $2 ; P_{S}=$ Pressure at the sides of the impingement sleeve for Ring 2 ; and $V=$ the jet velocity at the impingement sleeve.

\section{FLOW VISUALIZATION OF BASELINE}

Flow visualization work was done to determine whether cooling flow reversal occurs and, if so, at what pressure ratio. To see the flow reversal, it is necessary to see the flow as it enters each of the impingement sleeve cooling holes. There are approximately 200 holes. The fact that there were so many holes to look at and the flow was chaotic made visualization of flow direction very difficult. After trying several techniques, it was decided to fasten a small, thin flexible streamer over each impingement sleeve cooling. The streamers blocked approximately $50 \%$ of the hole area, were quite flexible, and were easily bent into or out of the hole depending on flow direction. The streamer technique worked quite well as it was a good way of indicating flow direction into or out of the hole and, to some extent, flow intensity (based on how severely the streamer was bent in or out).

The results of the flow visualization test showed that at the side regions of the impingement sleeve, the flow strength and direction were greatly affected by the system mass flow and compressor exit velocity. At $M=54 \%$, all streamers indicate strong flow into the impingement 
sleeve. At $M=77 \%$, the flow is still into the impingement sleeve but weaker. At $M=90 \%$, many of the streamers on the side of the impingement sleeve indicate that impingement flow had stagnated, not going into or out of the impingement sleeve. At $M=100 \%$, flow on the sides of the impingement sleeve clearly indicated reversed flow, that is, flow was exiting the impingement sleeve.

\section{PERFORATED PLATE TESTS}

The best way to improve and optimize the cooling to the transition piece duct is to provide a uniform pressure field around the impingement sleeve. Non-uniformity in the pressure field is caused by the interaction of the impingement sleeve with the high velocity single passage axial diffuser jet. The non-uniformity can be characterized by velocity of the flow as it intercepts the impingement sleeve. To minimize the non-uniformity in pressure, the diffuser exit velocity must be slowed and the flow must be distributed in such a way as to avoid accelerating the flow. When the flow is directed to the back of the midframe casing, it is forced into the sleeve around the impingement sleeve where there is minimal flow clearance, and consequently the flow is forced to higher velocity and lower pressure. To gain an understanding of how the flow should be redirected, it was decided to add layers of perforated plate at the exit of the diffuser to both slow the flow and direct the flow to areas in the casing where the flow would not be accelerated again by restricted flow passages. Perforated plate in itself is not a practical design to put into the ATS gas turbine, but it will give some quick and inexpensive guidance on how the flow should be directed.

For the first test, a single-thickness perforated plate was placed between the compressor discharge and the impingement sleeve. The effect of the single plate was to turn the flow and diffuse the flow to a lower exit velocity than the existing diffuser. For the second test, two duplicate layers of perforated plate were added to the first plate with the hole aligned so that there would be a negligible increase in flow resistance and virtually no change in exit velocity. The three layers of perforated plate turned the flow while keeping the flow velocity the same as in the single perforated plate test.

The pressure distribution for the single and triple perforated plate was better than the distribution for the axial diffuser shown in Figure 8.7.11-7. Clearly the pressure distribution around the impingement sleeve from the triple perforated plate is ideal for optimizing the transition piece duct cooling.

The perforated plate works because it both reduces velocity and tums the flow in a more radial direction, so the flow can circulate more freely. During both of these tests the flow visualization streamers showed no flow reversal.

\section{MULTIPLE-PASSAGE DIFFUSER TESTS}

On the basis of the results from the perforated plate tests, the decision was made to design and test two three-passage diffusers.

One diffuser would be similar to those used in aircraft engine designs and would turn the flow 5,10 , and 15 degrees. Because of the low flow turning, this diffuser was referred to as the 3passage axial diffuser. The low turning was of some concern, but because there was a large 
experience base with this type of design and because it would decrease the velocity, this design was pursued.

The other diffuser was of a more aggressive design. This diffuser was referred to as the 3passage diffuser or Design 1. Because the Design 1 diffuser was built using a fast prototype design and fabrication technique and efforts were made to keep the leading edge of the two splitters as thin as possible, the two splitter vanes cracked in the first test and a second model had to be built. The Design 2 diffuser was very similar to Design 1 but had thicker, stronger splitter vanes and was made from a stronger material.

A comparison of the results from the 3 passage diffuser to the results of the baseline diffuser shows a significant improvement in transition piece cooling. Also, the cooling flow from the diffuser test looked vary similar to the triple perforated plate test, and this pressure distribution was felt to be ideal for optimizing the TP cooling.

As a result of the diffuser cooling flow test this diffuser concept was selected for development.

\section{DESIGN 3 DIFFUSER}

Once the 3-passage diffuser was selected as the design concept for the ATS gas turbine it was decided that a third diffuser design should be built and tested. The Design 3 diffuser would be designed with inputs from designers at GEPG, GEAE, and CRD. The new design would undergo extensive aerodynamic performance testing that would measure the pressure recovery and stability of the design. Although the aerodynamic testing of the diffuser is necessary, it was well beyond the scope and time frame of the ATS Phase 2 program. A decision was therefore made to build the Design 3 diffuser under ATS Phase 2 and test it under the ATS Phase 3 program.

\section{DIFFUSER PERFORMANCE TESTING OF THE DESIGN 2 DIFFUSER}

To ensure that the diffuser will work under all compressor operating conditions, four diffuser inlet velocity profiles were chosen. To achieve these inlet velocity profiles the inlet to the test stand had to be modified. An annular sector inlet was constructed and attached to the front of the diffuser. A flow profiler was mounted to the inlet of the annular sector. The flow profiler consists of a perforated plate that covers the inlet; sheet metal profiler shapes are fastened to the perforated plate. The sheet metal plates block the flow in such a way as to achieve the required flow profile. There are different shapes of blockage for each profile. After much trial and error the four profiles were achieved.

Because the Design 3 diffuser would not be available, the Design 2 diffuser was used to make trial runs to check out inlet velocity profiles and make limited measurements of pressure recovery.

To adequately measure the aerodynamic pressure recovery of the Design 3 diffuser, it was necessary to install wall static pressure taps to all six surfaces In order to add static taps to the inner and outer flow splitters, the diffuser had to be cut into two parts along the center passage. To facilitate disassembly and reassembly while maintaining the diffuser geometry, 
aluminum alignment plates were imbedded into each of the endwalls. On the two diffuser endwalls, metal tubes connect the backside of each of the static taps which are then connected to pressure measurement instrumentation. On the splitters, metal tubes run the length of the splitters, and each tube has two static taps: one for the inside surface and one for the outside surface. The static taps on one side of the splitters will be plugged while measurements are taken on the other side; then the process will be reversed to get measurements from the other surfaces. Two axial lines of static pressures will be measured, one at $25 \%$ of the midspan and the other at $50 \%$.

\section{TECHNOLOGY APPLICATION}

The results of this task were incorporated into the $7 \mathrm{H}$ and $9 \mathrm{H}$ compressor diffuser designs. Results of the Design 3 tests will be used to fine-tune the final design

\section{PLANS FOR PHASE 3}

The Design 3 diffuser will be tested in Phase 3.

\section{SUMMARYICONCLUSIONS}

Using the current GE "F" single passage compressor diffuser and " $F$ " midframe flow path at the increased flow of the ATS gas turbine will provide inadequate transition piece duct cooling.

With the single-passage diffuser flowing at ATS gas turbine mass flow not only is the pressure around the impingement sleeve very non-uniform, but there are also areas of cooling flow reversal. Flow reversal means there will be some areas of the transition piece that receive no impingement cooling.

The only remedy for the flow reversals is to increase the pressure drop across the impingement sleeve, which will decrease thermal efficiency.

If the single-passage diffuser is used at the ATS gas turbine flowrate, the pressure drop across the impingement sleeve must be increased, and the increase will result in a thermal efficiency loss.

Optimized cooling can only be achieved when the pressure distribution around the impingement sleeve is made as uniform as possible.

The interaction of the impingement sleeve and the diffuser discharge jet velocity (V) is responsible for the non-uniform pressure. The amount of asymmetry in pressure distribution $(\Delta \mathrm{P})$ around the impingement sleeve can be approximated by the relationship $\Delta \mathrm{P} \propto 1 / 2 \rho V^{2}$.

The 3-passage diffuser produces a pressure profile that is nearly ideal for transition piece cooling in that the pressure distribution around the impingement sleeve is very uniform.

Pressure recovery tests of the Design 2 diffuser show evidence of flow separation on the inner passage splitter vane. As a consequence, a third design of the diffuser is recommended. 


\section{TASK 8.7.12 - NOZZLE CASCADE PRELIMINARY TEST AND FACILITY QUALIFICATION}

\section{BACKGROUND}

In support of GE Power Generation (GEPG) work on the $7 \mathrm{H}$ program, an existing test cell at GE Aircraft Engines was modified to allow installation of GEPG-provided test hardware consisting of: a full-sized combustor, transition piece, and either a first-stage segment or a nozzle box which simulates the nozzle area for combustion-only tests. The Phase 2 facility modification effort was preparatory to the testing scheduled for Phase 3.

A multi-step program is planned which will provide valuable information to the design process. Step 1 is a test of the combustion system, with the nozzle box installed. This test will characterize the combustor exit profiles in both diffusion and premix combustion modes.

In Step 2, nozzle cascade aerodynamic tests will be performed to define the mach number distribution on the airfoil surface. This parameter is important in establishing the nozzle heat load as well as verifying the aerodynamic quality of the test setup. The test setup is checked for periodicity using a full 3D CFD model.

In Step 3, the heat transfer phase of the test, several hundred metal temperature, steam temperature, and steam pressure measurements will be made to validate the Stage 1 nozzle internal heat transfer assumptions and calibrate steam flow calculations. Measurements will be performed with both unspalled and spalled Thermal Barrier Coating (TBC). The test will be conducted under operating conditions which closely match those of the actual production engine. Therefore, the viability of design concepts will be demonstrated in a controlled and quantified environment. The measurements will be used to calculate steam cooling effectiveness and will be compared to a detailed flow and 3D thermal analysis of the part.

Step 4 involves cyclic operation of the test facility to simulate daily startup and shutdown of the engine at a customer site. The rig will be transiently operated between two steady-state points (one at a low thermal stress state, the other at maximum thermal stress) up to several hundred times. Since Stage 1 nozzles are predicted to be life-limited by low cycle fatigue, this step of the test is a key element in overall program risk reduction. Test results will be correlated with detailed 3D stress models, thus allowing validation of low cycle fatigue life prediction techniques for Thermal Barrier Coated hardware under known conditions.

\section{OBJECTIVES}

- Characterize the combustor exit conditions in both diffusion and premix combustor modes by testing with a nozzle box installed in place of the test nozzle airfoils.

- Establish the Mach Number distribution within the test passages to allow interpretation of heat transfer data to be obtained in a subsequent test.

- Determine internal cooling circuitry conditions and airfoil metal temperature distributions by testing with extensive instrumentation with the airfoils in place. This work is in 
preparation for the Phase $3 \mathrm{LCF}$ testing to validate the life predictions of the steam-cooled airfoil design.

\section{FACILITY MODIFICATION AND QUALIFICATION}

Work on the facility and the initial buildup of the test stand was completed, and testing was initiated in June 1995. Work efforts completed in support of the Nozzle Cascade Preliminary Test and Facility Qualification are summarized below.

Under Task 1 - Initial Buildup/Checkout/Combustor Mapping, an amendment to the ATS Phase 2 NEPA report covering operation in this facility was provided. Forty hours of combustion testing was completed, up to present facility pressure and flow limits. Transfers from diffusion mode to premixed mode and back were accomplished with no indication of adverse dynamic activity. Combustor operation was excellent over the entire range of testing. Data acquired during this testing show good agreement with data previously obtained in the GEPG Engineering Lab; some minor differences in calculation techniques were identified and resolved during the course of this testing. Test facility and test hardware operation at the conditions to be utilized for the LCF test cycle were successfully demonstrated during this phase of testing. The balance of the Task 1 Checkout and Mapping will be completed after installation and checkout of the Nuovo Pignone compressors have been completed and will occur during Phase 3 of the program. Figure 8.7.12-1 shows the nozzle box in the rear hemispherical head, and Figure 8.7.12-2 shows the combustor and transition piece mounted in the forward hemispherical head.

Under Task 2 - Pressure Tap Testing, all necessary testing was completed. Pressure distribution data were obtained over a variety of power settings and showed excellent agreement with pre-test predictions. Figure 8.7.12-3 shows the pressure tap cascade, and Figure 8.7.12-4 shows the test stand configured for cascade testing.

The heat transfer cascade to be tested in Task 3 has been delayed, and activity in support of this effort has been limited to pre-test planning. This testing is expected to begin during the second quarter of 1996.

No activity related to Task 4 has been initiated to date. This testing will follow the heat transfer testing in Task 3.

Under Task 5 - Support Tooling and Equipment, the slave hardware required to support the steam cooling and slave water system for the cascade vehicle was designed and procured. This equipment has been functionally tested up to design conditions and has demonstrated satisfactory operation.

Under Task 6 - Program Management, support has consisted of periodic cost estimate updates to reflect the changing program schedule, integration with the various design, test, and other groups involved with the test program, and other administrative activities. 


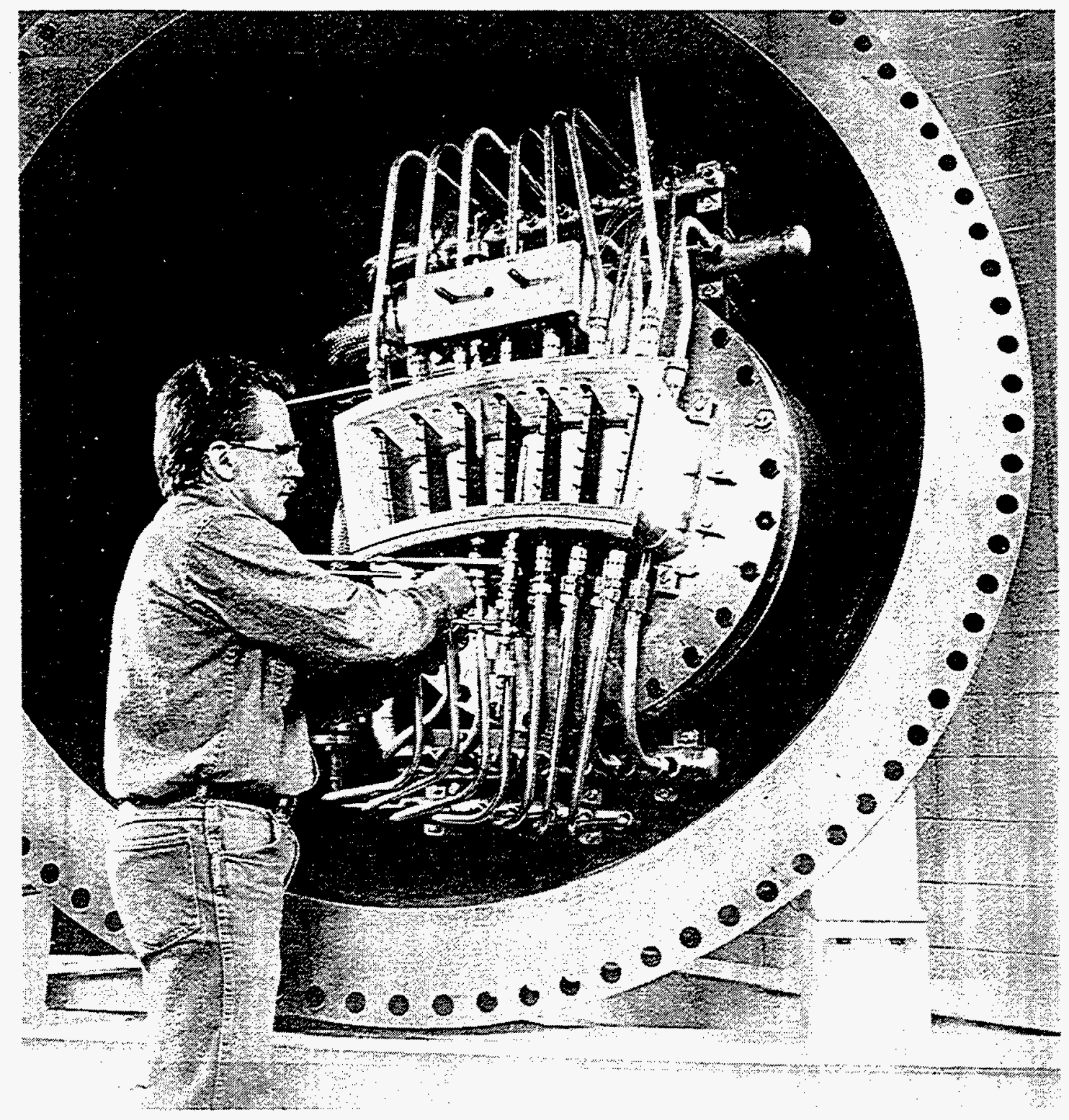

Figure 8.7.12-1. Nozzle Box in Rear Portion of Test Stand 


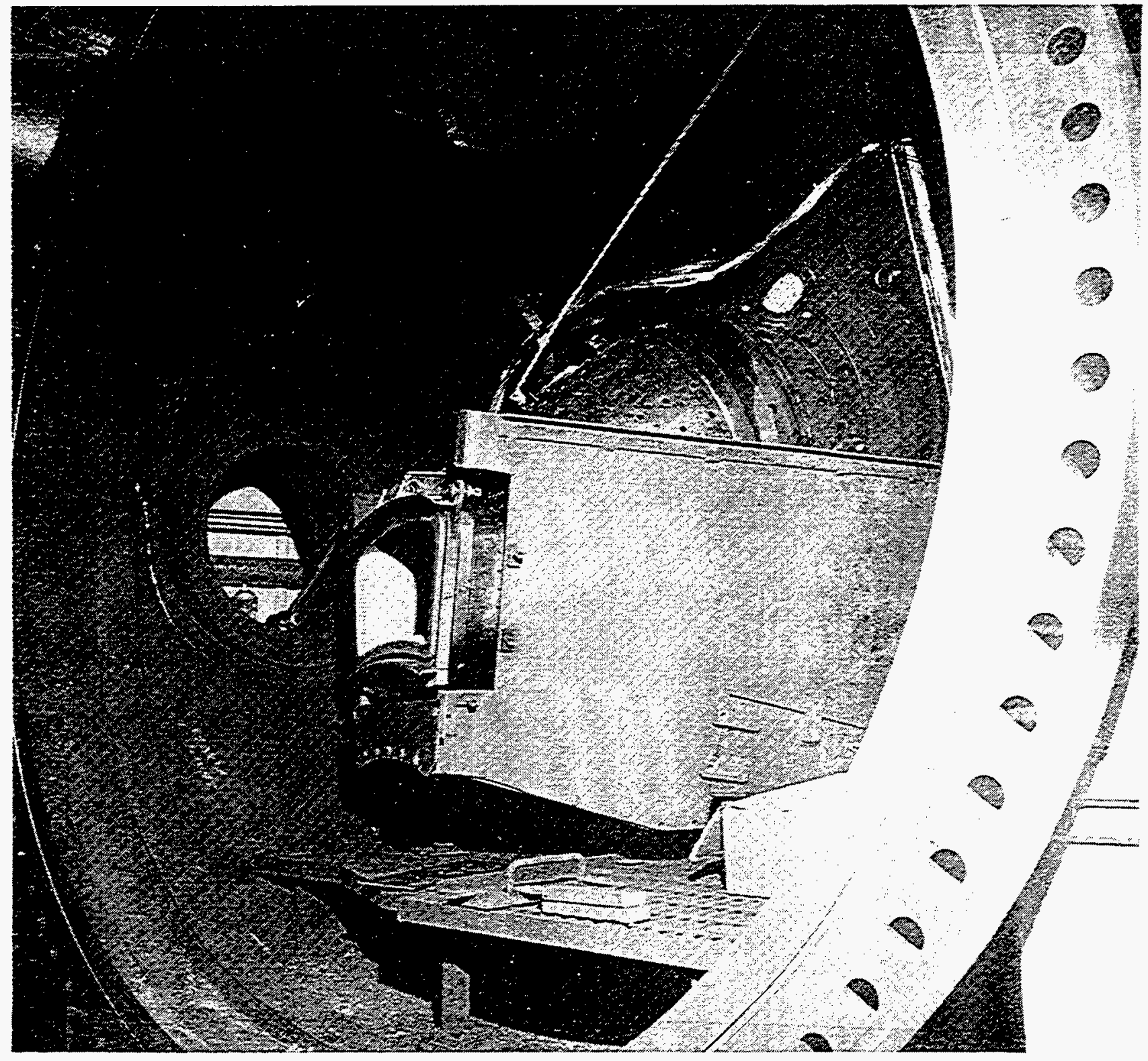

Figure 8.7.12-2. Combustor and Transition Piece in Forward Portion of Test Stand. 


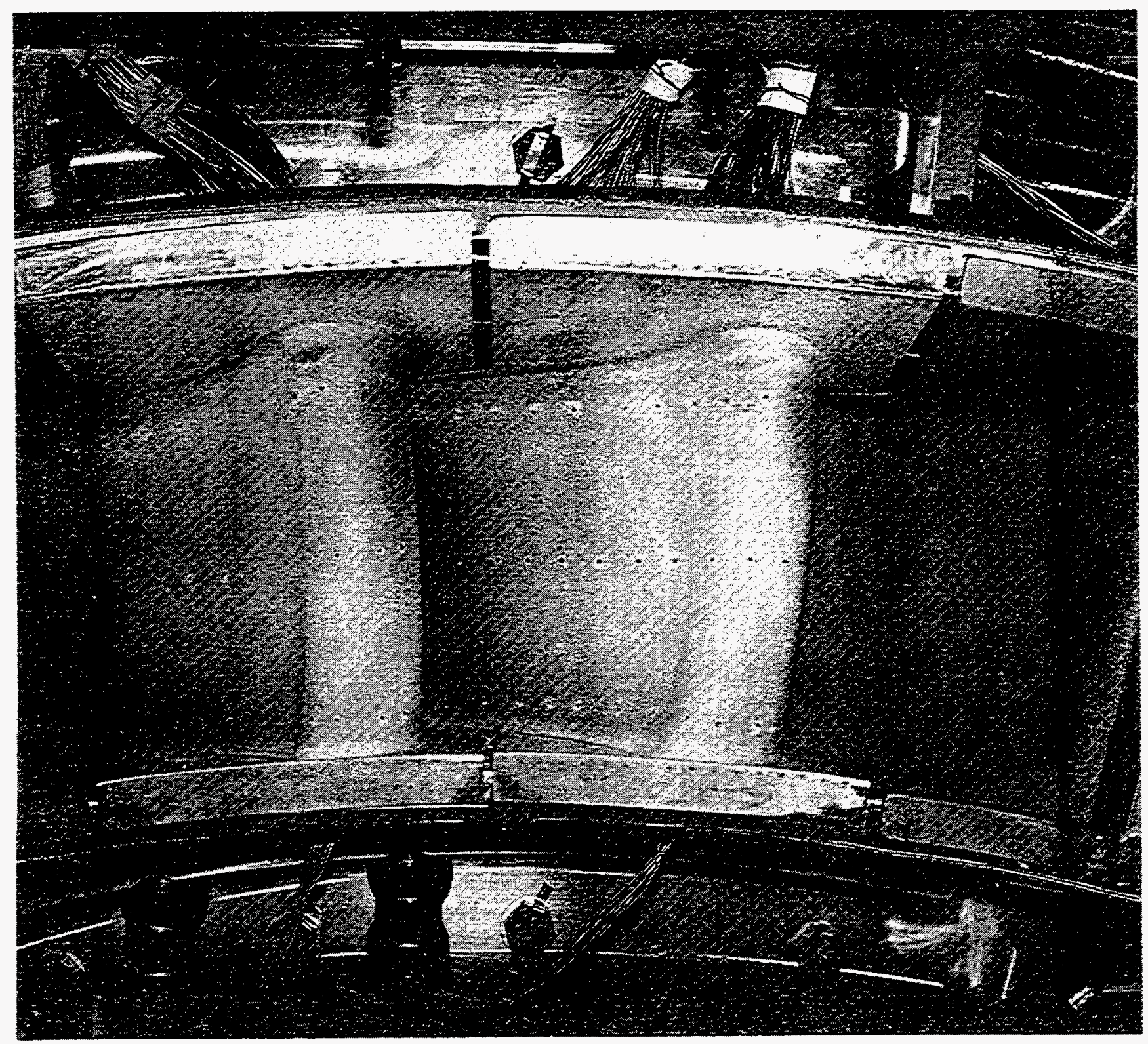

Figure 8.7.12-3. Pressure Instrumentation on Vanes. 


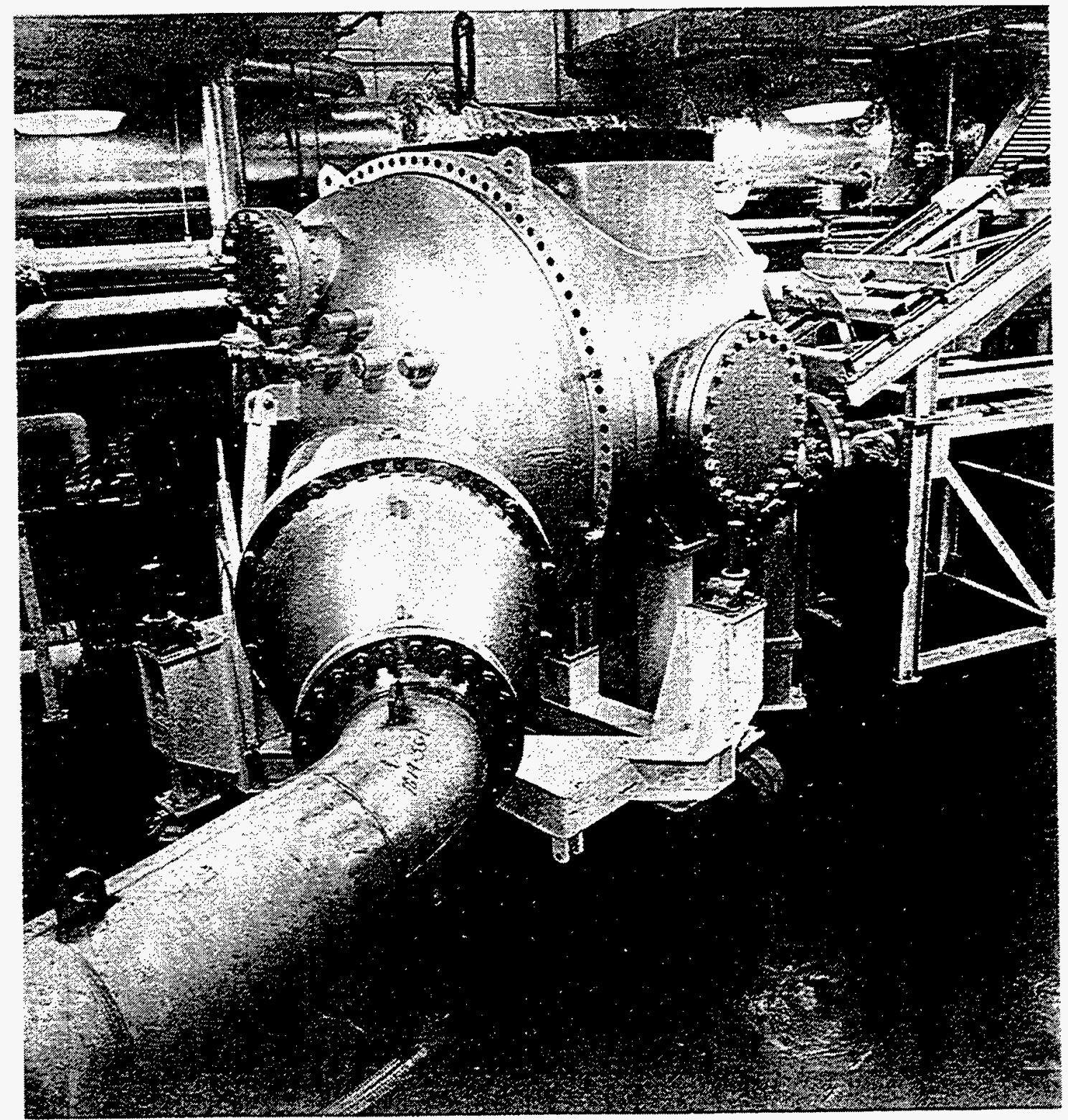

Figure 8.7.12-4. Exterior of Nozzle Cascade Test Facility. 


\section{SUMMARYICONCLUSION}

Test stand preparation and initial checkout and calibration testing were completed. Combustor operation, data acquisition, and all supporting activities were tested satisfactorily and met the objectives of this task.

\section{TECHNOLOGY APPLICATION}

This task will validate critical technologies for the ATS, including steam cooling effectiveness, TBC life, nozzle LCF, steam system calibration, and will verify nozzle temperature gradients and profiles.

\section{PLANS FOR PHASE 3}

The multi-step program described in the BACKGROUND section will be performed in Phase 3. 


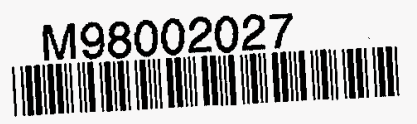

Report Number (14) DOE/MC/30244- -5822

Publ. Date (11) $\frac{1996 / 1}{20 E / F E, X F}$
Sponsor Code (18)
UC Category (19)
UC-10/,DOE/ER 